
BERKELEY

LIBRARY

UNIVERSITY OF

CALIFORNIA

EARTH

SCIEAICES 



\title{
GEOLOGICAL CLASSIFICATION
}

\author{
OF \\ ROCKS,
}

WITH DESCRIPTIVE SYNOPSES

oF

THE SPECIES AND VARIETIES,

COMPRISING

THE ELEMENTS

OF

\section{PRACTICAL GFOLOGY.}

By JOHN MACCULLOCH, M.D.

F.R.S. F.L.S. Vice Pres. Geol. Soc. \&c. \&c. \&c.

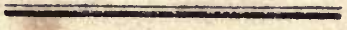

\section{Zlondon:}

PUBLISHED BY

LONGMAN, HURST, REES, ORME, AND BROWN, PATERNoster RoW.

1821. 


\section{EARTH}

SCIENCES

Printed by Joseph Mallett, 59, Wardour Street, Soho. 


\section{$M_{3}$ \\ EARTH \\ TO THE HONOURABLE SCIENCES \\ COURT OF DIRECTORS OF THE UNITED}

\section{East J্Jñía Company.}

NAMELY:

GEO. ABERCROMBIE ROBINSON, Esq. Chairman.

THOMAS REID, Esq.

JACOB BOSANQUET, Esq.

CHARLES GRAN'T, Esq.

JOSEPH COTTON, Esq.

GEORGE SMITH, Esq. M.P.

SWENY TOONF, Esq.

EDWARD PARRY, Esq.

WILLIAM ASTELI, Esq. M.P.

RICHARD CHICHEYEY PLOWDEN, Esq.

JOHN HUDLESTON, Esq.

CAMPBELL MARJORIBANKS, Esq.

WILLIAM WIGRAM, Esq. M.P.

Hon. HUGH LINDSAY, M.P.

JOHN MORRIS, Esq.

WILLIAM STANLEY CLARKE, Esq.

JOHN THORNHILL, Esq.

GEORGE RAIKES, Esq.

ROBERT CAMPBELL, Esq.

JOHN GOLDSBOROUGH RAVENSHAW, Esq. WILLIAM TAYLOR MONEY, Esq. M.P. CHARLES ELTON PRESCOT'T, Esq. JOSIAS DU PRE ALEXANDER, Esq. M.P. AND

NEIL BENJAMIN EDMONSTONE, Esq.

THIS WORK

IS DEDICATED,

BY THEIR MOST OBEDIENT HUMBLE SERVANT,

JOHN MACCULLOCH. 



\section{(C) (1) NTIRTS}

\section{CHAP. I.}

Introductory Remarks on the Methods of arranging Rocks which have been adopted by different Mineralogists............................

\section{CHAP. 11.}

On the meaning in which the term Rock is here used, and on the General Plan of the present Arrangement; with Remarks on the Nomenclature adopted.................................... .

\section{CHAP. III.}

On the Classification of Rocks adopted in the present arrangement.

\section{CHAP. IV.}

General Catalogue of the Families of Rocks contained in the present arrangement..................

\section{CHAP. V.}

Remarks on the general Catalogue of the Rocks. contained in this arrangement, and on the Order of their Succession in Nature. 


\section{CHAP. VI.}

View of the external and internal general Characters by which Rocks are distinguished.......

\section{CHAP. VII.}

On the external Configuration of Rocks............

\section{CHAP. VIII.}

On the internal Structure of Rocks.

\section{CHAP. IX.}

On the Texture, Fracture, and other remaining general Characters of Rocks.................. 146

\section{CHAP. X.}

Remarks on the Composition of Rocks, with a Catalogue of the simple Minerals of which they are composed. ............................. 162

\section{CHAP. XI.}

Enumeration of the several Rocks, arranged under the different Minerals which enter into their composition

\section{CHAP. XII.}

Remarks on the Associations and Transitions which occur in Nature between several different species, or families, of Rocks.......... 179 


\section{CHAP. XIII.}

Synoptical View of the general Characters of the Families of Rocks contained in the present arrangement.

193

Preliminary Remarks on the Nature and Characters of the Primary Class........................215

GrantTE.............................................. 225

SERPENTINE............................................. 243

GNEISS...................................................... 249

Micaceous Schist..................................... 267

Chlorite Schist.......................................... 282

TALCoSE SCHIST....................................... 293

HoRn BLENDE SCHIST.................................. 298

Actinolite Schist....................................... 314

QUARTZ Rock........................................ 317

Red (Primary) Sandstone............................. 331

Argillageous Schist . .............................. 344

Primary Limestone................................. 368

Compact Felspar........................................ 374

Preliminary Remarks on the Nature and Characters of the Secondary Chass......................... 379

LoWEST (RED) S.NuSTONE.............................. 390 
Superior Sandtiones............................ 413

Secondary Limestone.......................... 429

Shale.......................................... 455

Overlying Rocks................................ 464

Pitchistone....................................... 524

\section{Preliminary liemare on the Occa-} Sional Rocks................. 538 JaSper........................................... 544

Siliceous Schist................................. 557

Chert................................................. 564

GyPsum........................................... 571

Conglomerate Rocks......................... 574

Veinstones...................................... 587

\section{APPENDIX.}

Volcanic Rocks............................... 593

Clay, Marle, and Sand................... 606

Coal........................................ 612

Alluvia......................................... 619

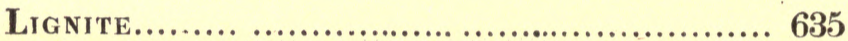

Peat................................................ 639

\section{ADDITIONS AND CORRECTIONS.}

Diallage Rock..................................... 644

Serpentine....................................... 652

Tabular View of the Classification.......... 655 


\section{PREFACE.}

In the "Description of the Western Islands of Scotland," and under the article which terminates the account of the Gneiss Isles, will be found the embryo of the following book. In examining many of the rocks which occurred in this group, it was found that, although in a geological sense, they belonged to the family of gneiss, they did not conform to the mineralogical definition of that rock commonly received among geologists ; this term having been allotted to a foliated mixture of quartz, felspar, and mica. Had these varieties been limited, or of trifling importance, the author might perhaps, like his predecessors, have been contented to pass over the whole with little notice, and to have infringed on the mineralogical definition of gneiss without acknowledgment. But such a practice appeared as pernicious as it is inconsistent with accuracy ; since 
it must have served to increase the confusion already prevailing in the characters of this rock, precisely in proportion to the number of new varieties that were observed.

No expedient could be adopted for naming. these varieties, without framing new terms; while they were too numerous and important to be passed over in silence. But such an attempt appeared no less difficult than inconvenient; and, to have made use of the general name of gneiss without explanation, would have been to produce the confusion which has invariably resulted from neglecting to define the sense in which such terms are used. Hence originated the Synopsis of Gneiss introduced into that work.

It was intended to have followed the same plan with respect to some other rocks described in those volumes, where their varying composition did not appear to have been thoroughly understood; but it was soon perceived, that the bulk of the work would have been inconveniently increased; and that an imperfect attempt toward 
a new classification of rocks would have been the result; as it was impossible to introduce all the requisite illustrations, and as some of the rocks found in nature do not exist in those islands. It seemed therefore preferable to reserve this matter for a separate essay ; a work which seemed to be imperiously called for by the want of any similar system to which a student could refer for information.

A more minute attention to the subject, and a recollection of the difficulties which the author himself had experienced in the commencement of his pursuits, when he had nothing to consult but the great book of Nature, led to many modifications, not only of the original design, but of the whole execution. If, in attempting to render, not only himself, but the subject which he has undertaken, thoroughly intelligible to those who have every thing to acquire, he has been led into a degree of minuteness which the accomplished geologist may disdain, he has been guided by a recollection of the gratitude which he would once have felt for information equally minute, and, to 
those who have nothing left to learn, equally redundant.

In considering the different plans on which a classification of rocks might be constructed, he was, without hesitation, led to adopt one founded on the geological relations and positions of rocks in nature. The reasons for this choice are stated at full length in an introductory chapter. It is, however, necessary here 10 remark, that the basis of the arrangement is virtually the same as that adopted by Werner. But, in the execution, it differs in many important particulars; either in consequence of the author's own observations, or of the views which have been more recently formed of the order of nature, by those geologists who, uneducated in the principles and doctrines of the German school, have undertaken to observe and think for themselves.

However numerous the varieties of rocks may appear to an inexperienced eye, and whatever confusion and uncertainty may at first seem to 
prevail among them, it will be found, on an attentive examination of their characters, that they admit of being placed in groups, distinguished by certain prevailing mineral characters, that these groups are not very numerous, and that the real differences of texture and composition are as limited as is the number of the minerals of which they are composed. It will further be seen that these different groups, thus united by some prevailing associations of mineral characters, are also in a great measure distinguished in nature by certain geological or general relations, more or less constant and perfect. Thus two natural methods of arrangement, the one founded on mineral characters; and the other on geological relations, have fortunately been found so far to coincide, that no very great or general breach of the relations of the one kind has been committed in adopting an order founded on those of the other. Wherever this has occurred, as in some remarkable instances has happened, the expediency of the adopted plan will be justified, even where it is most defective, or where it is incapable of embracing both views, by 
numerous considerations that will be found in their proper places in the body of the work.

There are two principal objects in view in the description of rocks ; namely, that of enabling a mineralogist to refer any given specimen to some general or particular title, according to its mineral characters, and that of assisting him in determining the place which it holds geologically in the order of nature. To accomplish the former object, it is evident that a description of all the most important and decided varieties was requisite. But even the latter could not have been attained without such a knowledge of every important variety as would enable the geologist to assign the general character in every case, however obscure. Although nature may be reasoned on in the aggregate, it must be studied in the details; nor can any useful and satisfactory knowledge of rocks, for the purposes of establishing general conclusions, be acquired, without an intimate acquaintance with all the parts which, by being reduced under a common or leading 
general character, are to form the basis of correct geological description and reasoning.

If even this general principle were not universally true, the experience of the student in this department would soon convince him of that which the author has deduced from his own; namely, that without a very accurate knowledge of all the variations to which rocks are subject, he can never feel confidence in determining the character and name of any. Hence arose those detailed enumerations of varieties which form the bulk of the catalogues in the following work; and the apology for them will be found in these considerations.

The number of the minerals essential to the composition of rocks is exceedingly limited. But they are also the repositories of nearly all the minerals in nature; 'which, in a certain sense, may therefore be considered as constituent parts of the masses which are treated of in this work. These unessential minerals are, however, the objects of systems of mineralogy ; in which they 
will be found described by the numerous authors who have written or compiled treatises on this subject. Here, it has been sufficient to enumerate them under the titles of the rocks in which they occur.

But, independently of these minerals, of chemical composition, numerous organized bodies, the remains of animals or vegetables, existing at remote periods during different states of the earth's surface, are found imbedded in rocks. These also, like chemical fossils, have distinct characters, dependent on their organization, which are of an interesting nature, but which, like those of minerals, form objects for a separate treatise, connected with the departments of botany and zoology.

One important difference however exists between chemical and organized minerals, as to the value which they severally possess in a geological view. From the former, little comparative information is derived respecting the different states of the earth's surface at different periods ; 
and they are chiefly therefore interesting as they are connected with the mineral history of rocks. But the different species of the latter, are, in many cases, intimately connected with the views that may be entertained respecting the different condition of the globe at distant periods. Thus they form an interesting part of the geological history of rocks; sometimes, indeed, offering the only proofs that can be obtained of similarity $\mathrm{or}^{\mathrm{r}}$ difference of character, in cases where the geological analogies or differences are of an important nature.

To have given therefore the names of these organic species in connection with the rocks which contain them, and of which the mineral characters alone are described in the following work, would have added materially to its value; more particularly as it is intended to facilitate the study of geological relations. This however was impossible. Our information on this subject is as yet so limited, that many species remain not only undescribed and unnamed, but scarcely any admit of being certainly referred to a constant 
order of geological position, or can be traced exclusively to particular strata. To have given that which is, or is thought to be, really known on this subject, would have been of little utility ; as the numerous exceptions, and the chances of error, must have produced a mixture of uncertainty and confusion that would have defeated the very objects for which this knowledge is principally valuable.

Even the mere history of the numerous fossil species, whether of plants or animals, must be the work of time; and can only be improved as the numbers of those geologists who have cultivated the study of botany, zoology, and comparative anatomy, shall increase. That history must also be completed before it can be effectually connected with the circumstances of their geological position and relations; nor will this connection be easily formed unless geological knowledge is united in the same individual to an accurate acquaintance with these organic substances. The rapidly increasing number of those who cultivate these departments of natural know- 
ledge, and the great additions recently made to the history of these species, give us reason to hope that the time is not far distant when a system of organic mineralogy (if this term is admissible,) will be formed. Whenever that shall happen, a new and independent work will be produced to comprise that department which could not here have been attempted with any prospect of advantage, and which has therefore been intentionally passed over.

The student whose pursuit is chiefly directed towards the mineral characters of rocks, or whose object it may be to form a collection of specimens, may be surprised to find that so many substances are comprised in the present arrangement under so small a number of names. But it has been the constant endeavour of the author, not only to shun technical phraseology where facts can be described in ordinary language, but to avoid introducing new terms wherever it was possible to proceed with those which have been long received or generally acknowledged. However exceptionable these may sometimes be, their in- 
conveniences are far exceeded by that which re. sults from frequent changes; while such a practice offers a bad example to those who, from a minute ambition, are always too ready to follow in the same path; or who, from incapacity or indolence, find it easier to remove a difficulty by the invention of a name, than by an attentive study of their specimens, and a comparison with the descriptions of preceding writers. To this it may be added, that whatever convenience may, on the other hand, result from reforming the present nomenclature of rocks, the state of the science is as yet so imperfect, that it could not at present be effectually done. To make changes therefore, that must in succession be amended by future reformations until the time for a complete and effectual one is arrived, would be to increase the confusion of this subject for a long period, and thus to generate a deeper obscurity than that which results from the present deficient state of the nomenclature.

The geological reader who is acquainted with some recent attempts on this sulject, will find 
strong examples of the truth of this reasoning. Leaving out of consideration the nature of the basis on which those reforms have been founded, and the geological confusion thence generated, it must be apparent that the descriptions of the authors who have thought proper to follow this plan, are unintelligible without a reference to a new catalogue; and that, were it even fixed in the memories of readers, they are still subject to the inconvenience of thinking in two languages ; while the want of a general reception of this new nomenclature, and the continued use of that of Werner, among many geologists, has produced authors of which the one half is unintelligible to the other.

The very extensive influence and reception of the terms adopted by Werner, would have been a sufficient reason for using them, had there been no other grounds for that selection. In what respect his views may have been incorrect or imperfect, it is not here necessary to enquire ; and the deviations from them which have been made 
in the following work, are, with their justification, stated whenever they occur.

It must also be remarked, that although there is a considerable deficiency of the terms which would be required to distinguish the rocks in the following catalogues, according to their mineral characters, the nature of the arrangement here adopted is such as to render this a trifling inconvenience. That arrangement is founded on geological principles; and, with a few modifications, the general terms already in use, have been found sufficient for the purposes in view. They will at least suffice in the present state of our knowledge. Should any serious imperfections still exist, or hereafter arise, it will be more prudent, as in some instances has here been done, to make the requisite changes or additions in a gradual manner; to repair the antient structure rather than to erect a new edifice. Authority of moderate influence will thus receive attention when good reasons are superadded to its weight; and time will thus perfect a system of terms which, 
if neither very elegant nor regular, will be useful and intelligible, and will not produce the great evil of throwing into absolute shade the observations of preceding writers. To submit to bare authority is not one of the characters of an enquiring age ; and the cultivators of the sciences under review, are far too numerous and too jealous to admit of a despotic and general reform, which, if it may sometimes proceed from a source so respected as that of Brongniart, is more often in danger of being found in hands ambitious of unmerited fame.

As the present arrangement of rocks is founded on geological principles, it is evident that the geological history of the rocks became an indispensible part of it. Without such descriptions, indeed, it would have been deficient in one of the circumstances most essential to clearness ; as it would have wanted an explanation of the sense in which the terms were used. These descriptions would, it is true, have been superfluous, if any system of geology had existed to which the author could with safety have referred. 
It is unnecessary, to geologists, to say that no such system does exist; as they must be fully aware of that defect; and to have referred the reader to that which has been proved incorrect and imperfect, would have been in some measure to defeat the objects of the present work; one of the designs of which has been, to bring into a system more consonant to the apparent order of Nature, those facts which the labours of the author, or the industry of others, have collected. Had he even been content to refer to other authors for that which he believes to be correct in their writings, he must still have followed the practice which he has adopted, in those cases where his own views differ from those of his predecessors. Thus the geological prefaces which precede each Synopsis became indispensible; as it was only by reducing the whole under one general plan, that he could either have preserved consistency or rendered his own statements intelligible.

In arranging these prefaces, it was found difficult to draw the line between that which might have been said on the subject and that which it 
was indispensible to say. It has been attempted however to limit those remarks rigidly to that which may be considered the natural history of the different rocks ; or to mere details of matters of fact respecting the general characters and relations of the larger masses which constitute the earth's surface. Thus far therefore the following work comprises the elements of geological science. But that science is not limited to a mere history of rocks; as, independently of the highly important branch of organic mineralogy, it involves the consideration of actions and events, and an enquiry after causes, for which no room could here have been found without adopting a plan entirely different; without combining, in one word, a general treatise on geology with a detailed catalogue of all the rocks in nature. It seemed expedient to keep these two works separate; that the manual of the student might be less encumbered with unnecessary matter; and that more ample room might be reserved for discussions which could not have been crowded, without great inconvenience, into a narrow space; that speculations and theories might, in short, be 
separated firom subjects of mere detail. The author hopes, in no long time, to present under a separate form, that which, after having been written, it became necessary to exclude from the present work.

In as far as the general views which are here entertained of the geological arrangements of nature, are not to be found in the writings of other observers, they have been drawn from the author's observations; and, as he imagines, confirmed by them when not strictly new. Thus far he is responsible. Where he has differed from such writers in these views, it was because their observations did not appear to him founded on an unbiassed and accurate investigation of nature, and because he could not reconcile them to the facts which came under his own notice. Where he differs only in details, or in points of minor importance, from those who have entertained the same general views, it is because he imagines their observations imperfect, and that, with the same store of facts, they would have arrived at the same conclusions. He can only 
add that he is, like every one else, willing to imagine himself an unbiassed observer, because, owing to the unexpected circumstances which forced this study on him, he was driven into the field of observation long before he knew what his predecessors in the same path had been doing. Nor, on a subsequent, and, as he trusts, an impartial review of those writings, has he found any reason to suppose that he had been misled by trusting only to that great book which is open to all who will bring to it a desire to learn.

For most of the local examples whence the conclusions have been drawn, he has been compelled to refer to his own observations; often very unwillingly; as he is sensible that they must appear to havebeen derived from too limited a source. Yet, on this subject, it may be said, that throughout the earth, a remarkable consistency, or at least a constant train of analogy and resemblance, is visible in the disposition and relations of rocks; and that in no spot of equally limited extent with Britain, is all the variety which the earth affords, presented in a more condensed and intelligible 
form. On comparing also these details with the observations of others, where the secould be divested of those theoretical opinions which sometimes obscure them, he has found no reason to doubt of their truth. If he has not referred to those authors, abundant reasons might be shewn for the omission, some of which must be obvious to every one acquainted with the subject, but into which he cannot here enter without endangering a lengthened detail and invidious discussions. He believes that the facts which are here stated are generally in harmony with those that are to be found in the works of his predecessors and cotemporaries who have seriously and practically investigated the same subject, with the wish to learn, and with that preliminary knowledge without which no one can see. As to those who have written, without observing, it is not in geological science only, that it is necessary to overlook the " questionable reporters of the questionable authority of others."

With respect to some of the geological prefaces, they may appear of an undue length. 
But the cause must here be sought in the previous obscurity of the subject, in the novelty of the views, and in the necessity thence arising for an ample elucidation. Hereafter, should these views be received as correct, and become an established part of geological belief, these details will admit of condensation. Where the facts have been such as are generally received, they are stated in the most brief form which was consistent with the objects in question. The same apology will apply to those repetitions of the same matter in different lights, which will occasionally be found throughout the work. From the same cause arose explanations and reasons, in defence of particular statements, and in justification of the adopted arrangements. To have rescinded that justificatory matter, which is in itself too often tedious and inconvenient, would have been to incur the greater blame of dogmatic assertion, and of an attempt to support by mere opinion, or from caprice, that which appeared really founded on a fair induction of evidence, or on some convenience in the plan of the work. It is bare justice to a reader to assign reasons for that novelty 
which, when once received, will require no further justification. Hereafter, much may be rescinded which could not now have been omitted. Those to whom these reasons are given will thus also be furnished with the means of making future corrections; since their attentions will be turned to those more questionable points for which the same justification is not offered: they will be led to examine that which the author has not sufficiently considered, and to improve a work, of the deficiencies of which he is far more sensible than his readers will at first be.

One remark yet remains to be offered on the plan of this work.

Although, from various geological writings, a more or less just notion, of the general features and dispesitions of rocks, and of the systems under which they have been arranged, may be derived, there is no one work in which these can conveniently be found, and none in which some of the views here entertained are to be learnt. The mere studeut, at least, would be at a loss to form 
for himself any accurate ideas on that which is known by experienced geologists, however differently it may be held in estimation by different persons ; since it is either traditional, or scattered through various miscellaneous writings. But even could this knowledge have been found elsewhere, it would not have been the less necessary here; although it might then have been stated in a more condensed manner. But it is the fate of all first attempts. to be superfluous, perhaps diffuse; since the eventual utility of that which is new cannot always be foreseen. Condensation is the result of time, and of that experience which rejects what is no longer essential. If, in studying to render his labours useful and intelligible to those for whose use it was designed, the author has produced a work far more bulky than he had at first contemplated, it must be recollected that it is easy to eradicate the feebler plants of the forest when the more vigorous trees have rooted themselves in the soil. 
The following Errata have been found in those Sheets which the Author's absence from the Press prevented him from superintending :

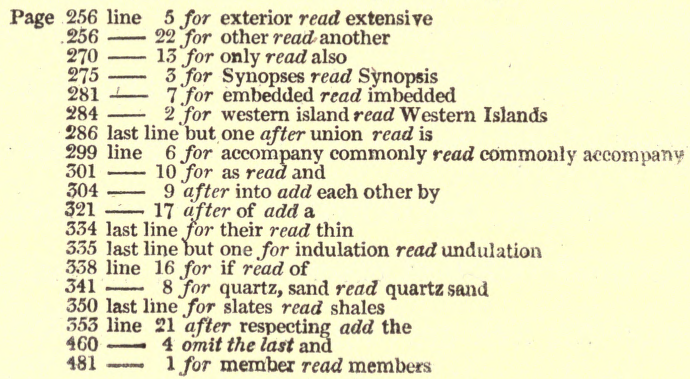


GEOLOGICAL CLASSIFICATION

or

\section{ROCKS,}

\&c. \&c.

\section{CHAP. I.}

INTRODUCTORY REMARKS ON THE METHODS OF ARRANGING ROCKS, WHICH HAVE BEEN ADOPTED BY DIFFERENT MINERALOGISTS.

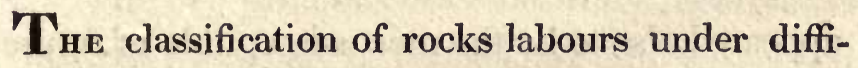
culties of such a nature, that no system has yet been proposed which can be considered unexceptionable; although the subject has occupied the attention of many geologists of the greatest experience. In the present state of our knowledge, they seem indeed to be insuperable; nor does it appear possible to suggest any arrange- 
ment which can even be said to approach to that which is considered a classification in the organic departments of Natural History. The difficulties which have been experienced, even by mineralogists, in their attempts to produce a perfect, or a commodious classification of minerals, have hitherto proved insuperable; but to the obscurity and doubt pervading that department, in which it necessarily shares, the classification of rocks adds others peculiar to itself. I do not pretend to accomplish that in which others have failed; but, in adopting the present as a temporary arrangement, have been guided by the principle of utility; chusing that method which, while it seemed most applicable to those researches for which the study of rocks is peculiarly desirable, appeared also to be the most susceptible of future improvement.

A critical examination of the different arrangements which have already been proposed, would doubtless be of utility to the reader, by displaying minutely the merits and faults of each, and by thus pointing out, in a practical manner, the 
difficulties under which the subject labours, and the objects yet to be accomplished. But the task might appear invidious, and would lead to a dissertation too extensive for an introduction of this nature. It will nevertheless be of use to examine the reasons which may be assigned in favour of each of the leading principles of arrangement which have divided geologists, and the objections which, on the other hand, may be made to both. Thus the reader of the following pages will obtain a clearer view of difficulties which he perhaps has never considered, and be enabled to appreciate the motives which have led to the selection of that classification which has here been adopted.

The two principal bases on which an arrangement of rocks may be formed, are a mineralogical and a geological one. Each of these is, in a certain sense, natural ; the former consulting, or professing to consult, the nature alone of the substances to be arranged, the latter being founded on the great relations which they bear to each other and to the general structure of the earth. Brongniart is the chief advocate in favour of the 
mineralogical method; different geologists of the Wernerian school maintain the superior expediency of the other.

The following are the advantages which are supposed to be derived from a mineralogical classification.

It is natural, inasmuch as it describes natural combinations of known substances, just as, in the organic departments of nature, these are distinguished by certain combinations of forms.

It separates the simple from the compound rocks; referring the former to that which is conceived their proper place in a system of mineralogy.

It describes the same compound but once; and hence avoids the repetition which, in a geological arrangement, results from considering a rock in two places because it occurs in two different positions in nature.

It limits the same term to the same compound, and, with a nomenclature sufficiently extensive, would provide a name for every rock.

It is easy of application, as it requires no geo- 
logical investigation, and only demands a previous knowledge of minerals.

It involves no hypothetical views.

To each of these advantages may be opposed corresponding disadvantages; independently of some general objections to the system. It will be convenient to consider these first ; adding to them such remarks as appear requisite for the more perfect illustration of the subject.

We must, in the first place, avoid being misled in favour of a mineralogical arrangement of rocks by the very obvious analogy of classifications of minerals. The study of minerals is distinct from that of the structure of the earth, however intimately allied these two subjects may be : and, in as far as that alone is concerned, they must be considered as independent natural productions, possessing-external characters more or less definite, and subject to certain laws, whether of chemical composition or geometrical arrangement, by which they are, or may be, arranged in some natural or artificial method. Their connection with 
rocks, or with the structure of the earth, is, doubtless, an important part of their history ; but as it does not enter into the principles on which they are to be arranged, so it offers no argument for thus extending that system under which they are classed, to the classification of these objects also.

It will here be readily admitted, that a mineralogical arrangement of rocks is the best adapted toillustrate the mineral history of the species which are to be ranked under it; and that, if we had no other view in studying rocks than to become acquainted with their mineral composition, it ought to be preferred. Such an arrangement, could it be perfected, would doubtless facilitate the description of a cabinet of specimens; but this is an object of very trivial importance.

The chief end in view in the study of rocks is to inquire respecting the structure of the earth. Hence it becomes our business to investigate their proportions, their gradations, their analogies to each other, their mutual dependence, their order of succession and disposition, and the general relations of all kinds which they bear to each 
other, as well as to that structure which forms the leading object of geology. On this subject a mineralogical arrangement can throw no light; as the same limited number of minerals is repeated; in different proportions or combinations, throughout every part of the whole series of rocks.

If a mineralogical arrangement of rocks is to be adopted, it should be combined with a classification of minerals ; of which the object is, to describe accurately, and to class in a manner the most convenient for investigation, all the subjects concerning which it treats. And, as in systems of mineralogy, the simple rocks are described among the simple minerals, so the compound ought to form a part of the catalogue of accidents in the history of each mineral, and should be enumerated ámong the circumstances of position under which that occurs.

If, in such an arrangement, some plan of this nature were not adopted, the rocks would be separated under two distinct heads: a plan produc- 
tive of great inconvenience, as they form so important a part of the history of the earth, and are, moreover, the natural repositories of the greater number of mineral substances. In this manner indeed they have already been separated by mineralogical writers; among whom it has been the practice to enumerate the simple rocks in their catalogues of minerals. In those works, no particular inconvenience follows this proceeding : the want of consistency which, in some instances, results, is not without its countervailing advantages.

But if this plan were extended to all rocks, as it must be, unless a better system of mineral classification is adopted, even the same rock must be sought for in two catalogues, perhaps in the works of two different authors; if, as frequently happens, it is simple in one part and compound in another. Compact felspar passing into porphyry, basalt passing into greenstone, limestone under many of its modifications, and many other rocks, offer examples illustrative of this inconvenience.

- Although a classification of minerals could be rendered perfect, this objection would of itself form an insuperable bar to the adoption of such 
a system for the classification of rocks. But even in this department, the involved, obscure, and often unintelligible nature of the affinities and qualities of the substances appertaining to it, have hitherto prevented, or rather defeated, all attempts at a natural classification ; and will probably long deprive us of an arrangement which shall be natural, and, at the same time, useful.

These apparently insuperable obstacles, which as yet imperle a classification of minerals, equally interfere with a classification of rocks. But even those are not the whole; since we must add to them the additional difficulties which arise from the innumerable and apparently capricious modes in which these minerals are intermixed and varied, and from the consequences in the composition and structure of rocks thence resulting.

If we first examine the effects which would arise from assuming the composition of rocks as the basis of an arrangement, we shall find, that, although nature presents us with many mineral species, a very limited number only of these enters into 
those compounds ; the most important characters of which are frequently independent of the minerals in their composition. Nor is it unusual for a rock to preserve all its most essential characters, even when it has lost one of the substances which, on such a classification, must be esteemed essential, or when it has acquired another which ought to transfer it to a different division. Such a basis of classification is, in fact, too narrow ; independently of the more essential fault of possessing no necessary relation to the other important characters of rocks.

If rocks are to be arranged according to some mineral, as, for example, mica, it is evident that substances so discordant and multifarious as granite, gneiss, micaceous schist, micaceous sandstone, micaceous shale, porphyry containing mica, and claystone with mica, will be found associated in one division.

If again, in thus arranging the compound rocks, the name of some one integrant mineral be made the leading characteristic, it will frequently happen that no sufficient reason can be assigned for selecting one in preference to another ; as, in many 
species, two, or even three minerals, may be present in nearly equal proportions. Moreover, in these compounds, as it is not unfrequent to find the component minerals alternately predominant, it must follow that different varieties of the same rock would be found in different divisions, and, of course, under different yames. We need not look far for examples of confusion under such a system : granite offers a very obvious one.

Such are the inconveniences that must follow from adopting the presence of any particular mineral as the principle of arrangement. But the same reasoning applies to any attempt to arrange rocks according to the degree of their composition, or the number of substances of which they are compounded.

If they are to be divided into binary or ternary compounds, it is easy to perceive that the same effect of separating those which are naturally conjoined, even in the same specimen, and of uniting those which are entirely distinct in every other essential character, will follow. Thus, for example, the granites of three ingredients would be 
separated from those which contain two, or four ; and thus also shale, and jasper, or claystone, and limestone, or micaceous schist, and sandstone containing mica or carbonate of lime, would be found in the same division.

It would be abundantly easy to illustrate these different remarks by innumerable examples ; but it is here unnecessary, as the geological reader can easily supply them, and, to the student, they could not be rendered intelligible without anticipating that which he cannot yet be supposed to understand.

Nor can any system be suggested, as far as can be perceived, formed on such a basis, that will not somewhere produce confusion and inconvenience similar to these: and it must indeed be obvious, that it possesses the deceptive rather than the real characters of a natural method. It is unnecessary to examine the several modes of arrangement on such a mineralogical principle, which have been, or might be suggested, as it would prolong these criticisms to little purpose.

If now, the structure, or rather, the texture, 
of a rock be made the basis of arrangement, it is equally plain, that under the granitic, the porphyritic, or the schistose, cognate substances will be widely separated, and those which are entirely different in other more essential circumstances, be associated.

As the very purpose of a mineralogical arrangement is to describe rocks considered as independent of their connexions in the great order of nature, or to produce accurate definitions of specimens, it necessarily renders of equal value those which are the most and those which are the least important in the history of the earth. Accidental or rare modifications thus claim as great a degree of attention as those which are the most steady and of the most general occurrence; while differences, extremely important in the geological history of rocks, but not of a nature to excite much attention in a specimen, or not presenting mineralogical differences of a conspicuous nature, pass with little notice.

Hence, although the affinities on which a 
mineralogical classification is founded, render that arrangement natural, in one sense, or according to the composition of its objects, it is, in a more important sense, unnatural; since it separates those wider and more interesting affinities by which rocks are connected with each other and related to the general structure of the earth. As a system, it is, in fact, an artificial one, with the imposing aspect of a natural association; since it is founded 'on a correspondence of one minute set of appearances, negligent of the larger features, and of the numerous other points of affinity or difference which prevail among the objects of its contemplation. It resembles the artificial arrangements of the antient botanists, as compared with the more philosophical views of the moderns in their attempts to found one on the characters of natural orders.

It is of little consequence, for example, whether a bed of hornblende schist alternating with gneiss, contains a few grains of felspar or not. Yet, in a mineralogical system, while the compound rock must be placed, as was formerly ob- 
served, in one class, the simple is placed in another ; or rather it is not at all to be found in the catalogue of rocks, being described in the mineralogical arrangement. Or, the occasional presence of calcareous carbonate in a specimen of micaceous schist, renders it necessary to erect a new species, when perhaps a whole continent may not produce a few yards in extent of such a variety. Thus also we may be led to confound in description, rocks so widely different in geological connexion as granite and the members of the overlying (or trap) family ; because their differences in mineral composition and structure are often such as not to be defined by words.

In concluding these general objections, it may therefore be remarked, that to attempt a perfect classification of rocks, in the present state of our knowledge, appears an useless as well as an injurious sacrifice to a logical order, to which, as far as we can yet perceive, nature refuses to conform. Mineralogists appear, in this instance, to have been misled by the example of 
Linnæus, and by the valuable consequences resulting from his system in the organized departments of natural history ; forgetful of the important and radical differences by which these departments are distinguished from that which is the object of their particular study.

Were it possible to make any analogous arrangement, however purely artificial, which should facilitate that study for which a knowledge of these objects is chiefly desirable, an important acquisition would be made to geology, as well as to the comparatively trifling pursuit of the collector of specimens. But if, in teaching us to arrange a cabinet, it helps to mislead us respecting the order of nature, such a classification tends only to introduce confusion under the seducing aspect of regularity.

Finally, as it has been stated among the advantages of a mineralogical method, that "it limits the same term to the same compound," and "would thus provide a name for every rock," it is necessary here to bestow a few words on the 
subject of a nomenclature although that question is more fully examined in its proper place at the end of this inquiry.

If it be admitted that such an arrangement could even be perfected, and that a complete series of rocks could be formed, classed according to their natural affinities of structure and composition, or classed under a convenient artificial system on such a basis, it is plain that it would require a numerous, as well as an appropriate set of terms, which, as far as it has been executed, it actually does.

As also there is no necessary or constant relation between one species of composition in rocks, and their affinities or positions in the order of nature, while many varieties of composition also occur in the same mass of rock, it would frequently happen that many terms would be required in describing one fact or one set of geological connexions, and that such connexions would often appear to be implied where they did not exist, in consequence of the similarity of the - names by which rocks corresponding in compo- 
sition must be designated. It is easy to comprehend that, in the first of these events, it would be impossible to describe the most common geological fact without a tedious repetition; and that, in the latter, there would be generated a degree of confusion in geological descriptions, which would be productive of the most injurious consequences.

The disadvantages therefore that may be individually opposed to the advantages already stated to arise from a mineralogical classification of rocks, are the following.

It is unnatural, as far as relates to the most important purpose for which the knowledge of rocks deserves our attention.

In separating the simple from the compound rocks, it disjoins, and with considerable inconvenience, that which nature has united; while, in many cases, it associates others which are essentially separated from each other in nature.

In describing a rock but once, and independently of its different connexions, it abandons one of the most important circumstances in the his 
tory of the substances of which it undertakes to treat.

In attempting an accurate limitation of terms, it must either accomplish that object imperfectly, and thus increase the confusion of the present nomenclature, or else introduce a cumbrous and unwieldy catalogue.

The facility of investigation professed to be acquired by such an arrangement, is limited to the mere knowledge of the specimen in the student's hand: it affords him no assistance in discriminating the accidental from the essential; nor in tracing the rock and its connections from a knowledge of the specimen.

If it involves no hypothesis, it also rejects all those known geological relations which have been rescued from this censure.

To which disadvantages it may also be added, that it makes all rocks of equal importance, however rare or however accidental they may be.

That it multiplies trifling and unimportant distinctions.

That it renders geological description, either 
impracticable or, at the best, circuitous and verbose; and therefore becomes, as far as this object is concerned, either useless or noxious.

And that, from the unavoidable influence which terms exert both over our reasonings and observations, it tends to mislead the student ; rendering those things affinities in the history of nature, which are little else than affinities in words.

IT is now necessary to examine in a more concentrated point of view the several defects and advantages which attend a geological method of classification. A few of these remarks have been unavoidably anticipated; as it was impossible to state the question of a mineralogical arrangement in a manner sufficiently clear, without occasionally adverting, for the purposes of: contrast or illustration, to the nature of a geological one.

In this statement no improper bias will be found towards that method in favour of which 


\section{1}

the author has decided, and on which the present work has been drawn up. It will, on the contrary, be seen that the defects are displayed in great detail, while the advantages are presented in a very condensed form. To palliate that which is faulty, or to conceal that which is defective, is to deprive ourselves of the chance of amendment.

The following emumeration comprises the principal advantages to be obtained by a geological classification.

It is founded on the most extensive and important affinities of the objects to be arranged, and thus resembles in its principles the classification of plants according to their natural orders.

While it teaches, as far as is admissible in such a work, the history of rocks as constituents of the earth, it combines with that, all that appears important of their history as mineral compounds: nor does it exclude the most minute subdivision of varieties, which it also separates 
from the former so as to give them their due value.

It affords, upon the whole, equal facility for reference as a mineralogical arrangement; adding, moreover, to the discriminating characters of rocks, the history of their order in nature. Thus it frequently may remove doubts respecting the nature of a rock, in those cases of frequent occurrence where words are insufficient to render intelligible the differences in aspect and composition that may exist between two compounds.

Although the mode of arranging a cabinet on this system is different, it is neither less easy nor less convenient than one derived from characters merely mineralogical.

The imperfections of such a system are however very considerable; and it is only by comparing these with the advantages, that we can be guided in our choice.

The following objections have been made against it by the authors who are advocates for a mineralogical arrangement; but most of these 
admit of a satisfactory reply. Some of them have indeed been already anticipated in the preceding observatious.

It is said that the simple and compound rocks are thus united in one class, and that, as the former have already been described in the systems of mineralogy, any further description is superfluous.

To this it may be answered, as it was already remarked, that this very association is convenient; since the general relations of the simple and compound rocks are the same, and since they pass into each other by imperceptible gradations. Nor can it be considered any inconvenience to describe a simple rock twice, if, indeed it were esteemed proper that it should be enumerated in a treatise on mineralogy: it is even necessary to describe these simple substances in every catalogue of rocks; since that study does not comprise all the circumstances which appertain to their geological history.

It is again objected, that, according to a geo- 
logical classification, the same rock, or mineral compound, must be described twice if it occurs under two distinct general divisions; which, in some instances, it is known to do. This inconvenience is trifling; even were it necessary to describe a second time that to which the student may as easily be referred in its first situation.

But this apparent inconvenience is, in fact, an advantage. It is an important part of the geological history of a rock, to note that it is repeated under a different association : it is most essential for the student to know, that many of the compounds which form granite, for example, are not necessarily inferior to the primary strata, but may occur even above the secondary.

It is objected further, that the system of a geological arrangement is hypothetical and difficult of application.

It may be retorted on this ground, to the rival system, that it is not hypothetical, only because it includes the much greater defect of entirely neglecting the natural affinities of rocks; and that it is not merely difficult of application, 
but absolutely inapplicable to the purposes of science. A geological system is, in truth, hypothetical, only in as far as it is incomplete: such a system points out its own defects; and every addition of knowledge, either demolishes an hypothesis, or converts it into a legitimate theory.

The last objection of any apparent weight which has been offered against a geological classification is, that different mineral compounds, or rocks, are enumerated under one name, and that the same rock is also sometimes described by two names.

This objection is merely a modification of the second; and it involves the very difficult question of a nomenclature; a difficulty from which the mineralogical method of arrangement is not exempt. That part of the subject will be examined at more length immediately : it is first necessary to state other objections which have been overlooked by the authors who have engaged in this discussion; as it is desirable that all the imperfections of each system should be stated with equal fairness. 
A true and correct geological arrangement is, in fact, at present unattainable; as we are not yet perfectly acquainted with the order and relations of rocks in nature. Whatever modification of it is adopted, must therefore be confessedly imperfect. But it is not less the foundation for a perfect one. It offers a basis always susceptible of correction, and gradually increasing in correctness; every investigation of the characters of a rock, necessarily adding something to the mass of knowledge on which it is founded. By its very imperfections it affords a stimulus to observers; not to rival each other in distinguishing the minute differences of specimens only, but in extending the bounds of geological science.

In addition to the imperfections above stated, it must also be admitted that it is logically imperfect, that it is not founded on one simple and consistent principle. This is a defect, if it be really considered as an important one, which is probably irremediable. The larger divisions are, according to the principle adopted, drawn from the order and general relations to the structure of the 
earth which rocks hold in nature. The smaller, are necessarily derived from mineralogical characters ; and as these are subject to the former in the system of arrangement, an obvious species of irregularity must follow; as the same compound may be found under more than one of the larger divisions. But this is a question that ought to be tried by the principle of utility.

In the other departments of nature, a rigid adherence to the logic of the adopted system is easy ; because the objects are definite, constant, and conuected by invariable and simple relations to each other: it is equally useful, as it facilitates that investigation which is the object of every arrangement. It is, or ought to be, adopted, not because it is consistent, but because it is useful ; and it is mistaking the means for the end, to transfer to the prisent class of objects, those rules to which, from their very nature, they are not ameuable. To sacrifice thus to the forms of an arrangement, is to be anxious about words and negligent of things ; it is to recur to that philosophy of the antient contemplatists which the labours of 
modern experimentalists have long sincè exploded.

A geological arrangement of rocks is in fact a history of their natural affinities : it is a branch of geological science; and, to this main object, all minor considerations ought to be rendered subservient, even at the risk of some trifling inconsistencies of order. That order which is the most useful ought first to be selected : if it were possible to add to utility, an unexceptionable regularity, such a system would be perfect: but a precision which serves no purpose, is a shadow deceiving with the appearance of a substance.

In examining the conditions requisite for a perfect geological arrangement, it will be more easy to judge of the value and amount of the present defects, and to conjecture what chance there is of future improvement.

The order of arrangement of every rock in nature ought to be known: to ensure facility, as well as perfection, it ought indeed to be constant:

Every rock ought to be definite and invaria- 
ble ; constant in its mineral characters, as in its position.

Every principal division, or species, should appropriate to itself a distinct set of subdivisions.

As yet, however, no prevailing general arrangement among rocks has been ascertained, although it has been imagined to exist : and it is indeed now certain, that no order can be assumed which is not subject to numerous exceptions. In the same way, it is demonstrated that the order of succession is inconstant in all the minor details, and moreover, subject to frequent variations.

So far also from being definite and invariable in their mineral characters, rocks are subject to frequent changes, both of structure and of composition; passing, in many cases, into each other by imperceptible transitions. This objection, however, operates equally against a mineralogical arrangement.

Lastly, rocks resembling each other in composition, are found under divisions often far remote in geological character and position.

These are, unquestionably, serious defects; . 
but although they detract from the regularity and perfection of a geological arrangement, they do not destroy its utility. With some sacrifice to order, and with some repetition, many of them may be so remedied as to leave the classification equally applicable to practice ; an advantage well purchased by such trivial inconveniences.

In discussing those objections to a mineralogical system of arrangement, which relate to the nomenclature of rocks, a few remarks on the nature of such a nomenclature became unavoidable. But it is necessary to examine this important branch of the subject in greater detail; as the defects of a geological arrangement will bé found to depend, in a very great degree, on the imperfections and deficiencies of the existing and very limited catalogue of terms by which rocks are designated.

If the only object of a nomenclature were to distinguish the individuals in a cabinet of specimens, it is true that they could scarcely become very inconvenient except from their numbers. Yet, unless an enormous number was adopted, it 
would be impossible to distinguish all those which, as specimens of mineralogical composition and structure, would require distinction. To be consistent, as formerly remarked, a nomenclature on a mineralogical principle must necessarily be large as well as appropriate.

The numerous combinations, and the endless varieties of aspect which rocks present, render it impossible to apply distinct names to all; nor is it easy to see, on this system, where the line is to be drawn. The inutility of such a nomenclature, even could it be rendered complete, is necessarily comprised in the inutility, already pointed out, of this nrode of classification.

If such names be thus contrived according to some principle either of structure or of composition, it is obvious that the greatest confusion of all the natural analogies of mixed rocks must ensue. In this case, as well as in the geclogical method, the same substances would recur more than once, whether the principle of the integrant minerals, or those of the structure, were made the basis of the nomenclature; as the same circumstances and 
the same minerals are found in many different rocks in many varieties of combination.

These remarks have already been sufficiently illustrated in the former part of this chapter, in treating of the several bases that may be assumed as the foundation of a mineralogical arrangement. The question of a nomenclature necessarily rests on the same grounds. Any attempt to combine these two circumstances, namely, the composition and the structure, is productive of still greater confusion; nor does it appear possible to adopt any natural system of nomenclature derived from mineralogical principles.

If an attempt be made, on the other hand, to avoid these difficulties by the adoption of unmeaning terms for all the varieties, (or rather species, as they would in this case be esteemed,) in the same manner as has been done with regard to many of the principal rocks, a nomenclature would, in becoming arbitrary, become useless for its professed purpose of displaying the mineralogical affinities of the rocks arranged under it. 


\section{3}

A burdensome and insufferable jargon would. also be the inevitable consequence; nor would the vexatious, and too often repulsive effects produced by such a nomenclature of technical terms, and such an inharmonious addition to ordinary language, be diminished, even by the most successful modifications of the classical tongues, adapted to some real or imaginary properties of the substances to be named. No one who has a regard for the purity and convenience of language, will wish to see extended, where it can be dispensed with, that system of nomenclature which has been, in most cases, inevitably, but, in too many, wantonly, introduced into systems of mineralogy:

But further, as the object of a nomenclature, like that of an arrangement, is to facilitate the study and description of the general relations of rocks, and of the structure of the earth, a comprehensive or minute system of nomenclature would be injurious; even were it free from that fault, which every nomenclature founded on mineralogical principles must possess, of disjoining substances geologically allied.

In geological descriptions there is an impe- 
rious necessity for general terms ; since, as numerous mineralogical varieties occur, often under every mode of gradation, yet under one general relation to the surrounding rocks, the want of these terms would render such descriptions unintelligible.

Further, as rocks are chiefly studied, so are they chiefly to be named for the purposes of geology; and the plan of a nomenclature should therefore, like that of a classification, be made conducive to those ends. The general terms should be founded on the geological relations, or should at least, be invariably associated with them ; as far as terms are wanted for varieties, it is indifferent from what source they are drawn, provided they do not interfere with the main object, nor excite improper associations respecting the true place of a rock in the order of nature.

It is the perfection of the study, as of the description of natural objects, to combine, with accuracy in the details, comprehensive general views. To be anxious only about the former, takes off the attention of the student from the latter; and, in attending to the minutiæe of an ar- 
rangement and a nomenclature, he is diverted from those general relations which are of a more important nature. The effect is even worse ; since he is tempted to imagine wide analogies where minute resemblance alone exist, and thus learns to regulate the structure of his globe by the affinities which he finds in his cabinet of specimens.

To render a geological system of arrangement complete, its advocátes should be allowed the privilege which has been claimed by those who follow the opposite method ; namely, that of framing and multiplying terms according to the wants of their system. There should, in fact, be no existing nomenclature, but a new one should be formed and adapted to this purpose.

The existing nomenclature does, in reality, produce many of the defects which appear, on a superficial view, to be the result of the arrangement. It has arisen gradually, in a period of ignorance, and during the increase of knowledge. Rocks have been named from their structure, - from their composition, and from their geological 
relations. They have also been denoted by local or antient terms which refer to nothing in their characters. It is impossible to adopt all these names and to preserve consistency : it is equally impossible to make a partial selection, or to introduce material alterations, without the greatest inconvenience and confusion ; and, in the present. imperfect state of the science, it would be unjustifiable to attempt an entire reform in the nomenclature, could we even hope to supersede the use of names so long popular, and so long associated with all our ideas. It is better to submit to some inconveniences, and to endure some repetition or circumlocution, than to hazard the confusion which is the invariable result of the frequent changes and the ambiguous use of terms. Even the attempts made by the advocates of the mineralogical classification, to introduce new names, have been ineffectual; nor, without changes equally numerous and important, would it be possible to render that system, any more than the other, perfect, or even intelligible.

The chief inconvenience in the present no- 


\section{7}

menclature of rocks, arises from the adoption of a double principle, namely that of the geological relations, and that of the mineralogical nature: and that inconvenience is increased in the works of many authors, even of the highest reputation, by capriciously admitting one of these principles in some instances, and rejecting it in other and similar cases. Thus the same rock is called slate clay in one position, and clay slate in another; while, in another case, the term greenstone is applied to two or more rocks, in the same manner identical in mineral composition, but differing in the important circumstances of being either stratified or unstratified, and of occurring either below the most antient, or above the most recent rocks. Whatever system be adopted, it is most necessary that consistency should be preserved. Else it is obvious, that this practice may be made to serve the purpose of any hypothesis; determining, or not, the position of a rock from its nature, just as it may suit the views of the geologist, and thus producing the grievous error of reasoning in a circle.

In the present state of things there is no re- 
medy for the evils arising out of this ambiguity, but to accompany the geological arrangement by geological explanations; and thus the natural history of a rock becomes an essential part of the system of classification.

For this reason it would have been desirable to have added to each family of rocks, a full history of its geological relations. Thus, indeed the present work was at first drawn up. It became however but too obvious, when completed, that it had assumed the appearance of a system of geo$\operatorname{logy}$, deficient in many important particulars which it was impossible to combine with the object first in view, and the presence of which could not be dispensed with in such a system. It seemed preferable therefore to abandon this plan, and to reserve for the contingent event of a future work, that which could not with propriety be introduced into the present. In truth, as the study of rocks is essential to that of geology, so is the latter study in a certain degree necessary to the former. Neither can well be understood without the other; and that an impossible object has not been at- 


\section{9}

tained, is a defect that will claim the indulgence which it need not solicit.

In a strict sense therefore, the present arrangement must rather be considered as an attempt to produce a brief and useful description, than an accurate and logical classification of rocks. Full of imperfections as it confessedly is in this sense, it must be tried by the test of utility; and it will meet with indulgence if, in its application to practice, it affords any counterpoise to the numerous defects already stated; of which, some are inseparably connected with the general ignorance of these matters that yet prevails, others with that of the author; but of which the far greater portion seems to be necessarily inherent in the subject itself. 
CHAP. II.

ON THE MEANING IN WHICI THE TERM ROCK IS HERE USED, AND ON THE GENERAL PLAN OF THE PRESENT ARRANGEMENT; WITH REMARKS ON THE NOMENCLATURE ADOP'TED.

THE compilers of systems have been divided respecting the substances to which the title of rock should be applied. By some, even metallic ores have been included in this term; by others, the simple rocks have been excluded, as belonging to a system of mineralogy. It is unnecessary to enter critically into an examination of these, or of other differences of opinion that have prevailed; nor is it easy to frame any definition of a rock which is not open to objection. As the object of the arrangement is utility, not logical refinement, it is equally unnecessary to attempt such a definition. There is an evident impropriety in ad- 
mitting the metallic ores to a place among rocks, as they appertain to a classification of minerals ; and there are still greater objections to excluding the simple rocks, on account of their perpetual transition into the compound, and the incurable confusion which their absence would produce in the arrangement.

The popular sense of the term rock is well understood, and it is here adopted in that sense ; comprising all the mineral earthy compounds, whether simple or mixed, that form conspicuous masses in nature, and enter into that which may be considered the structure of the earth. Rock salt has not been included; but there is added an appendix consisting of substances to which the term rock cannot be applied, but which have generally been described by writers on this subject. It is convenient to notice these, because they do not enter into a system of mineralogy, and are not sufficiently numerous to admit of a separate treatise; while they form an important part of the structure of the earth. 
As a geological system has been adopted in this arrangement of rocks, the principles are therefore similar to those of the followers of Werner. But neither the order of the arrangement, nor the number of the substances is the same as those which are to be found in the works of these authors. The experience of the writer has unavoidably led to modifications, often of a very important kind. Of the nature and truch of the facts on which those views are founded, the evidence is, for the most part, containerl at length, in his papers in the transactions of the Geological Society, and in his description of the W'estern Islands of Scotland. The extent and minuteness of this various matter, prevented its introduction here; but it is hoped that the facts in question will not be found at variance with the future observations of geologists in other countries, however they may differ in many respects from others, often of more antient date, which, from various causes, have commanded greater respect than they will probably be found to deserve.

Of the convenience or utility arising from 
these alterations, he must needs be a prejudiced and incompetent judge: they are necessarily left to the experience of others, who will not fail to improve that which is imperfect, and to reject that which is incorrect.

The reasons for the alterations that have been made, are staterl, wherever it appeared necessary, in the different remarks which accompany the work. Thus the student will be better enabled to judge of their propriety ; and to distinguish that which has received the writer's consideration, from changes founded merely on caprice or the love of novelty.

The classification is simple; all rocks being referred to a primary and a secondary class, and a smaller division being formed of those which are found in both. The substances which cannot be referred to the latter class, from their more recent origin, are considered separately in an appendix; and a similar expedient is adopted for the volcanic rocks. The reasons for this method of division are given at more length in an appro- 
priate place, where the principles of the classification are examined.

Each class is subdivided into certain geological divisions, or families of rocks, of greater or less magnitude; and these are, chiefly, such as have long been received among geologists. The alterations and additions that have been made, are such as appeared either convenient or necessary; but, whatever they may be, the reasons for which they were made are stated, and they are all conformable to the general principles which pervade the analogous systems that have already appeared in the writings of those who have proceeded on a similar plan.

The nature of these subdivisions is such that they can neither be considered as genera nor species; terms which, in reality, are much misapplied to the mineral departments of nature ; as, from their long application to objects admitting of accurate definition, they imply a degree of precision which cannot be found among these inorganic substances. Neither can the term family be always correctly applied to these subdivisions; 
as some of them contain no subordinate members, while others comprise an extensive range of substances, often very discordant, united by one distinct geological bond.

It is in these subdivisions, or families, if the term may be admitted, that the defects of the geological method of arrangement appear most striking. They may hereafter perhaps be diminished; but they cannot be wholly removed, as they belong to the very essence of the arrangement. Nature has, in one place, given us, perhaps, twenty rocks, united by a common bond of mutual transition, and bearing one general relation to the surrounding substances; in another place, we find only one rock, or perhaps two, independent of all the others, but still bearing to them, in a similar manner, one general and fixed relation.

It is obvious that, under such circumstances, no family, or no rock which contains more than one member, or variety, can admit of that which is properly called a definition. A notion more or less distinct may sometimes be conveyed, by a 
description of some of the characters; but an attempt at definition must be reserved for the varieties, and, even in these, it sometimes becomes a description rather than a definition.

Under each subdivision are placed those rocks which belong to it, or which, collectively taken, form the family ; the individuals all bearing the same geological relation to the general order, or to the structure of the earth. To facilitate the investigation of these, they are arranged, when numerous, according to certain obvious peculiarities of composition or structure; by means of which the family is subdivided into portions, each designated by one particular character. In this part of the arrangement also, the same want of logical precision occurs ; and, if the classification of the organized departments of nature is to be made the test of what is right, it must necessarily appear defective. In some cases, the characters of these rocks are of such a nature, that they might be considered as species ; in others, they present slight, and, sometimes, very transient variations. But distinctions of this nature are, in fact, inap- 
plicable. If they are made in some cases, where they really can be made with great ease and precision, that, in some other place, is found impossible; and nothing is gained by adopting an order in one part which cannot be extended to the whole. Whoever may make the attempt will soon be convinced that he has undertaken an impracticable task; and that he cannot even approach the accomplishment of his wishes, without sacrificing utility and convenience to an imaginary regularity.

Every rock which is described, is therefore considered a variety, no other term being equally unexceptionable; and as it must be considered a variety, in a geological sense only, it cannot well mislead a reader. The most important of these are generally placed first in that division in which they may occur; or, when necessary, additional remarks are subjoined, by which the student may judge of the comparative importance of the different varieties. That, perhaps, is of little moment. As the object of the arrangement is geological, he will not be long in discovering the relative value and constancy of the rocks which he 
may find : this forms almost an inevitable part of his acquisitions in procuring the specimen which he is afterwards to examine. To those whose only object is to form or arrange a cabinet, all varieties have the same value, if their mineral characters are sufficiently remarkable. Their geological importance is here no object.

The definition of each variety is, for the most part, a description of its composition; and, where necessary, of its structure also. Other details are occasionally added, for the purpose of preventing doubts, or facilitating the knowledge of the varieties under each family; utility and certainty being the objects in view.

The varieties which are here described, irclude all those which appear sufficiently constant to merit a description; and they are further noticed in those states where, by gradually losing their distinctive characters, they pass into some other rock. As, in many cases, similar' rocks occur under different families, they are, for the most part, noticed under each; an expedient which, however irregular, from the repetition 
which it implies, renders the investigation more easy to the student. It is also justified by the practice of botanists, in pointing out, under the genera to which they rigidly belong in one sense, those species which, from other characters, it is expedient to place under a different genus.

It is probable that many rocks are omitted, but the arrangement admits of perpetual correction. It was only in my power to describe accurately those to which I have had access; and they are chiefly therefore from Britain, as complete collections of rocks have not as yet been formed by geologists, and few foreign specimens are to be found in the cabinets of mineralogists in this country. It is probable, however, that the enumeration contains the far predominant number of rocks known; as the same substances have been found to occur all over the world. No imaginary varieties are given; a practice in which it would be very easy to indulge, as other authors have done. Such varieties may readily be conceived and multiplied; but to adopt them is to abandon the study of nature. 
It is presumed that every one who attempts to become acquainted with rocks, has acquired a competent knowledge of mineralogy: nor is it possible to make any real progress in this latter study, without learning the general characters at least, of the principal rocks, as well as minerals. The knowledge of rocks, however, whatever may be imagined, is seldom communicated by mere description, without the aid of some demonstration. Even mineralogists are perhaps not always aware how much of their own peculiar acquirements in mineralogy is traditional. It is probable therefore that the student will unavoidably open every work of this nature with a previous general knowledge of the subject; which will render less necessary that accurate definition of the families of rocks which the nature of the objects renders it impossible to give.

In terminating these introductory remarks on the arrangement, it is necessary to add some observations respecting the terms by which the rocks are designated.

The existing nomenclature of rocks is neither 
founded, as already remarked, on geological nor mineralogical principles, but is an unfortunate combination of both, which often leads to confusion. If a thorough reform were attempted, it would appear preferable to construct a nomenclature on geological principles; as the wide and general relations of rocks are the chief objects in view in their classification. But to render such a system perfect, an accurate knowledge of these relations is required; without which the parts could not be arranged; while, on the other hand, an accurate knowledge of the parts is requisite for the arrangement of the superstructure. Under this double difficulty the subject at present labours, nor is there any immediate prospect of removing it. It must not be concealed, at the same time, that there is an important evil which would result from the adoption of a nomenclature founded purely on geological relations. Throughout the whole system of nature the same substances are occasionally repeated in situations geologically far asunder ; a fact, of which limestone presents a conspicuous example. Such a nomenclature would thus dissociate two rocks which 
might present no differences of character ; and, perhaps, sometimes cause us to lose sight of an important circumstance of analogy in geological science.

In considering the numerous substances arranged in the following catalogues, it will be apparent that there is a considerable deficiency of terms by.which to distinguish them. In this respect, the history of rocks has not kept pace with that of the simple minerals; in which, new names have been adopted as fast as the discovery of a new species or variety rendered one necessary: much faster, it might indeed be added. This difference in the progress of the two catalogues has perhaps been unavoidable. The names of rocks having been rather of popular than scientific origin, no great attention was paid towards the discrimination of the substances which entered into their composition, the various modes in which these were combined, or the different circumstances of structure which might have afforded justifiable grounds for distinctions. In the mean time, the science of geology has been rapidly ad- 
vancing; but the groups into which rocks are associated, and the common relation which many of them bear to the arrangement of nature, have prevented the necessity of much refinement in distinguishing the several substances. General terms have thus continued to answer the purposes of geological arrangement and description, at least to a certain extent ; since it is still apparent to those acquainted with the subject, that occasional confusion, leading in many cases to important errors, has followed from too lax a use of these.

But no reform having been attempted until these defects had, in the progress of fresh information, accumulated to a considerable extent, it has become impossible to apply a complete remedy without an alteration so violent as to change all the habits already acquired. It is still however easy, as in the case of mineral species, to frame a new term on a mineralogical principle, whenever a rock essentially different from those formerly known, is discovered; an example of which is here afforded in the case of Hypersthene 
rock." Such terms easily unite to the general catalogue already in use, without inconvenience. To attempt more, in the present state of things, appears injudicious: were it even proper, it could not be carried:into effect without a general submission to some one acknowledged authority which does not at present exist.

It is undeniable however, that in describing geological facts, a renovated and universal catalogue, could it be formed, would prevent much circumlocution ; and that distinct terms, once definitely associated, each with its particular substance, would ultimately produce greater accuracy in the examination and description of rocks. But it may be doubted if the inconveniences now attending such a change, would be compensated by any corresponding advantages in the attainment of that great object for which the knowledge of rocks is chiefly valuable; namely, the study of geological affinities and analogies; while it would almost inevitably lead, as it has too often done in the other branches of Natural History, to the substitution of trifling details and catalogues 
of species and varieties, for those wider views and inquiries which constitute the true value of these studies.

It only remains to add, that, in conformity to these remarks, no change of nomenclature is made in the following pages. The common terms are used; although some of them have been more accurately limited, where it appeared necessary, to avoid confusion; and others have, in the same manner, been occasionally generalized ; but always conformably to received ana$\operatorname{logy}$, or to antient practices, and for purposes of obvious utility. Wherever this has been done, the reasons are submitted to the readers consideration. In the various prefatory remarks which accompany the synopsis, reasons will also be found for the very few changes or novelties of this nature which may be discovered. 
CHAP. III.

ON THE CLASSIFICATION OF ROCKS ADOP'ED IN THE PRESENT ARRANGEMEN'T.

IN the progress of geological science, two different plans have been adopted for the classification of rocks. In one of these, all rocks are divided into two classes, the primary and secondary : in the other, the division is into three, namely, the primitive, transition, and floetz; the last of these being the same as the second class of the first method. It is obvious therefore, that the establishment of a transition class is an attempt to subdivide the primitive class of some geologists. It is not here intended to explain or examine the hypothetical views on which this subdivision appears to have been founded; as it would lead to general disquisitions foreign to the subject of this work. But as it has not been adopted in the present arrangement, it is proper briefly to state 
the reasons for differing on this point from those geologists who have received it, and who, it must be supposed, have considered it, either a natural or a convenient division, or perhaps both.

The primary class is distinguished from the secondary by a number of circumstances, obvious, in a greater or less degree, to examination ; consisting, in a constant inferiority of position, a prevailing high angle of elevation in the strata, peculiar mineral qualities, and the rare occurrence of organic remains. It is also most frequently separated from that class by a definite boundary ; which is indicated by a reverse order, or a want of consecutive parallelism in the strata of the two classes at the place of contact, accompanied by a striking peculiarity in the rock which is found at that boundary, and which is the first and lowest of the secondary strata. The difficulties which, in a practical view, occasionally interfere with and obscure this arrangement, need not be examined at present, as they are discussed hereafter in the preliminary remarks on these 


\section{8}

classes. That division into two classes is therefore natural.

The characters of the transition class, as they have been laid down by those who have adopted it, are, the presence of organic remains, or the occurrence of fragments of previous rocks in the composition of its strata; implying an origin partly mechanical. It is further necessary, according to the hypothesis, that the rocks of this character should occur in a position intermediate between the secondary and primary rocks; thus forming, according to the view of its founder, a transition between the secondary strata, of which the origin and structure are supposed to be mechanical, and the primary, esteemed to be purely chemical. It is therefore obvious, from the nature and consequences of geological alternation, that wherever a stratum of the transition class is found, all those strata which lie between it and the secondary class, must also appertain to the former.

In examining the value of these characters, it 


\section{9}

must first be remarked, that many of the rocks of the transition class are purely chemical in their texture, as the limestones and greenstones, for example, and that many of them contain no organic remains. In the next place, rocks of chemical texture occur among the secondary strata ; and others, bearing marks of mechanical re-composition, are found among the primary. Micaceous schist containing fragments of granite, the primary sandstone, and the conglomerate schists that alternate with quartz rock, all afford examples of this latter occurrence. Innumerable secondary limestones present instances of the former.

The frequent absence of organic remains from the transition rocks, renders that character of no value in a practical view; nor can it be considered a natural character, if, in the predominant instances, it is absent. It has moreover been observed, that organic remains were found in limestone alternating with and succeeded by gneiss*; an event which would render it neces.

* Description of the Western Islands of Scotland. Article Garvh Island. 
sary, in this particular instance, to place gneiss in the transition class; while, in the predominant examples, it must necessarily belong to the primary division. No set of internal characters therefore can be assigned, which, either taken singly, or in combination, are capable of forming a distinction between the transition and the primary classes.

Neither can the former be distinguished by any definite boundaries. With regard to the secondary rocks, its boundary would be the same with that already laid down as the limit of the primary; should it be present, and should it be held to possess a boundary in this direction. That it has been held to be definite towards the secondary strata, must be presumed; because the rule of non-conformity, or the absence of the parallel consecutive position, and the existence of the rock known by the expressive term old red sandstone, are by the same geologists held to be generally characteristic of the commencement of the secondary strata. Towards the primary strata, it can have no boundary; if that must be removed as often as a stratum containing organic 
remains, or fragments of more antient rocks, is discovered in a position geologically deejer than that last assigned for the limits of the transition strata.

Lastly, it is admitted that the transition rocks are frequently absent; the primary and secondary coming into immediate contact. Although, from their nature, the secondary rocks may frequently be wanting, either from the effects of waste, or from their never having been deposited in some particular spot, it almost implies a contradiction in terms to suppose that absent which is esteemed to be a transition between two classes, when these are both present.

This class cannot therefore be considered a natural division, if it does not necessarily exist, if it does not form a transition between the primary and secondary classes, if it has no aggregate. of characters by which it can effectually be recognized and distinguished from those, and if it has no assignable boundary.

If the transition class were productive of any convenience in a practical view, it might never- 
theless with propriety be admitted as an artificial division; the lypothetical opinions on which it was originally founded, being such as, probably, to have now few advocates even among those who have adopted it.

In trying it by this test, it is plain that it cannot facilitate the classification and nomenclature of species; as the same substances which occur in the primary, must necessarily also occur in the transition class. They are indeed acknowledged thus to occur, and, for want of real distinctions, are generally denoted by the use of the hypothetical term, often applied in a manner purely arbitrary. Since.also it has been shewn that this division cannot be distinguished by any geological characters, it can evidently be of no use in geological investigation, or in classing the phenomena which may be observed. On the contrary, it is productive of confusion, and tends to mislead observers; as it is only by some presumed mineral distinction of the species, that a rock can be referred to this imaginary division. Hence, the nature of the species alone forms the ground of judgment; not only for the character 


\section{3}

of the particular stratum, but for that of all those which may lie above it in succession, as far as the boundary of the secondary strata.

It is obvious that the consequences of this proceeding, as far as it relates to the determination of the class of any series of rocks from this principle, is to reason in a circle ; an assumed class first giving the name to a certain number of species, and those again being used to prove the existence of that very class. Whatever resemblance to this process may ocaasionally occur in describing the primary and seeondary classes, it is evident that, in these, we can always have recourse to the infallible test of geological position ; if not actually in the spot under consideration, yet deduced from ample experience in other situations. To this test the transition class is seldom or never properly amenable.

The arrangement here to be adopted is therefore the first, or the division into two classes, with certain modifications. For the form primitive, there is also substituted the word primary, which is merely of a relative nature, 
and can lead to no improper associations of ideas respecting the formation of the earth. The primary class is thus considered simply as anterior in date to the secondary; and all rocks therefore become divided into two leading classes, the Primary and the Secondary.

Each of the two classes is subdivided into two divisions, the stratified and the unstratified, distinguished, respectively, by that difference of disposition, which is indicated by these terms. As these subdivions have not yet been introduced into any of the arrangements of rocks, they will each require some explanation.

In the first class, all the modifications of granite are considered as entering into the unstratified division; together with serpentine. The reasons for not including porphyry in it, will appear in considering the second class.

Granite is disposed in large irregular masses, from which, veins are often found to proceed and to penetrate the stratified rocks in its vicinity; nor has it yet been observed in any instance to be de- 
cidedly stratified. A more minute examination of this subject will be found hereafter in the article which treats of that rock. It is, at the same time, entirely and properly limited to the primary class : having hitherto been found merely in contact with the secondary strata and in some rare instances only, however near it may approach to them: nor do the veins of granite ever pass beyond the primary into the secondary strata. It is not however thus limited with respect to the secondary unstratified rocks. For reasons that will immediately appear, it will occasionally be found in contact with that subdivision; but, even in this case, the granite veins do not pass into those rocks ; while, on the contrary, the veins of those substances pass into the granite, by which the relative dates of the two are ascertained.

In treating of the two divisions of the primary class, granite is considered first. That plan is adopted from the fact of its position being always inferior to that of the stratified rocks of the same class. The veins penetrate these, but the masses never alternate with or lie above them. It does 
not here enter into the consideration, whether, in point of origin, it is prior or posterior to these; that question appertains purely to that part of its geological history, of which this work does not pretend to treat.

The position of Serpentine, on the contrary, which is the only other rock contained in this division, is not necessarily inferior to that of the stratified rocks of the primary class. It occurs in every part of the series, from granite upwards, even to the confines of the secondary strata. As an unstratified rock, however, it is necessarily placed in this division; and it will soon be seen that, in the uncertainty of its position with respect to the stratified substances, it is by no means a solitary instance of irregularity.

The stratified division requires here no explanation beyond that which its name will suggest; and its several characters are fully examined in that chapter which is appropriated to the structure of rocks, and in the preliminary remarks to the primary class. 
In the secondary class, the stratified division is placed before the unstratified, for the same reasons that the reverse arrangement is adopted in the primary.

The rocks of this latter division, with certain: exceptions that do not affect this arrangement, are placed above even the latest of the secondary strata ; one doubtful case alone, of a partial deposit of stratified rocks, namely, that of the recently ascertained fresh water formations, remaining for future decision. They are consequently posterior in point of time; although the marks of that posteriority are sometimes obscure, and, occasionally, wanting. But they are also found in contact with the primary strata, and, as before remarked, even with granite. As these circumstances might be supposed to offer an objection to this arrangement, it is necessary to introduce a few words on that which belongs properly to the general history of these rocks.

The actual superficies of the earth offers examples of every rock, from granite to the last of 
the secondary strata; those now under review being purposely unnoticed at present. Whether or not they were left in that manner at their formation, does not affect the question now under consideration; but it is ascertained that the surface bears marks of waste, in consequence of which, portions of the superficial rocks have been removed. More particularly, it is known, that the secondary rocks, as being the uppermost, have been in the greatest degree subjected to these changes.

It is evident now, that if an universal deposit of rock were to occur on such a surface, it must be in contact with every member of the two classes. It is equally evident, that if it were one of the characters of such a rock to penetrate into vacuities among those to which it succeeded, it would be found intermixed with them in the shape of veins, or in that of masses of other forms, according to previous, or concomitant circumstances. Thus the unstratified rocks posterior to the secondary strata, would not necessarily and exclusively be connected with these. Even their predominant connections would be regulated by 
the state of the surface as to the relative proportions of primary and secondary rocks at the time they were deposited. Although, therefore, strictly appertaining to the secondary class, their dates, or connexions, might not be discovered by their position, merely in one part. But if the same continuous mass is found to cover, interfere with, or ramify into a primary and a secondary rock also, there is to be obtained, even when in the former connexion, a proof of its appertaining to the secondary class.

It has been just remarked, that the surface of the earth bears marks of waste, and that this waste is necessarily most sensible in the uppermost rocks, other circumstances being equal. As the secondary unstratified rocks under review, are the uppermost, they consequently exhibit the most extensive and remarkable losses of substance. It thus happens in nature, that masses of the unstratified rocks are found insulated on the surface of the stratified, or, in other ways, occupying distinct and detached positions. It must therefore, also occasionally happen that they will be found connected with the primary rocks only, in the 
manner of superposition, or interference, or both. And there is in fact, ample evidence that, in many cases, the unstratified secondary rocks are thus connected with the primary strata: the proof of their true nature being founded on community of mineral structure between these masses and others of more extensive connexions, on proxinity of position, and on other concurring circumstances.

In other cases, however, there is not the same evidence; and there is then less facility in determining whether such unstratified rocks are of a secondary origin, or whether they may not have been formed previously to the deposition of the secondary strata. The classification therefore here fails to possess all the requisite evidence of a natural arrangement: it is to be seen whether it does not probably still remain natural, and whether it is not practically convenient.

In the first class, there is one decided division of unstratified substances, namely, granite, of a peculiar mineral character, and always inferior to the stratified rocks; its nature, and the proof of its position being unequivocal. The characters of 
the secondary unstratified substances are equally: remarkable; and the chief of these is a frequent or predominant superiority. There is thus a common geological feature by which this arrangement is distinguished. There is further a common set of general mineral characters in all the unstratified rocks which are not granite, wherever they may be found; serpentine being here excluded : these characters being so strong as to render it often impossible to distinguish between those now exclusively connected with the primary, and those connected in the same manner with the secondary strata.

This arrangement, which thus appears natural, as well as convenient, will even become necessary, if it is impossible to discover a criterion. by which these two can be certainly recognized. and distinguished. The nature of the remaining doubts respecting these rocks, are too intimately connected with their geological history to admit of being here stated more fully: but they are not such as apparently to supersede the convenience. which will be found to result from the method of 
division here adopted. In the further progress of this science, when some absolute characteristics shall be discovered, it will be easy to restore to the first class, and to a place in the first subdivision of that class, the porphyries that are now peculiarly connected with the primary strata; should it be proved that they are of an origin prior to the secondary.

As it is scarcely possible to explain these views without a glance, at least, at the origin of rocks, it must here be remarked, that the preceding sketch of the supposed originally universal extent of the secondary unstratified rocks, is an assumption for the sake of elucidating the present arrangement. There is no doubt that these rocks are rather partial than general; but that fact does not alter the principal views here held out. Partial depositions at a recent period, would admit of the same train of reasoning to a great extent. The only doubt which arises is, whether such partial depositions may not have taken place at very distinct periods. If they have occurred at any time, before the formation of the secondary 
strata, they must be considered strictly primary ; and this may be true, as already suggested, respecting the porphyries now connected with the primary strata: or with some at least of these; since it is very certain that the double connection just pointed out does actually exist in many of them.

It has been seen that the unstratified division of the primary class comprises only one rock, namely granite. But under the same head, in the secondary, is included a great variety of sub. stances, differing in their characters, and constituting many distinct rocks. As all these, however, pass into each other by imperceptible gradations, and are connected by one common geological bond, it has been judged convenient to adopt one common term for the whole. This term is that of the overlying rocks. It must be considered as generic and geological. No single term derived from any individual of the whole family, could have been applied to them; as is conveniently done in the case of granite, where the same word suffices to express both the geolo- 
gical and the mineral characters. This term will thus comprise, in the subsequent catalogue, a division much more comprehensive than any other ; under which many rocks strikingly distinct in character, will appear rather in the light of varieties than in that of distinct species. If such a blemish could have been avoided it would have been desirable; but as all these rocks are united by a common geological position, as the natural history of the whole is the same, and as they are connected by indeterminate transitions, there appeared to be no choice.

In chusing the term overlying, a word in many respects objectionable, regard has been had to established habits, to the difficulty which exists in framing new terms, and to the objections against this practice; but it will afterwards be seen that these rocks are also occasionally inferior to the strata which they accompany, and that they are further connected with these in a variety of modes.

No remarks are here necessary on the division of the stratified rocks in the secondary class ; 
as they will, like the former, be necessarily examined in the chapter on the structure of rocks.

The two classes of primary and secondary, are followed by a division termed Occasional rocks. This indispensible irregularity in the present arrangement, has been adopted for the purpose of comprising some rocks which occur indiscriminately in both classes, together with the substances of a stony nature which are found in veins, and are therefore of posterior origin to the strata, whether primary or secondary ; in both of which they occur.

To the whole are subjoined two appendices. The first contains the volcanic rocks, which, if they are not in every instance decidedly distinguishable in character from the rocks of the trap family, are sufficiently distinct in their origin to deserve a separate consideration.

The substances contained in the second appendix might perhaps have been omitted in an arrangement professing to treat of rocks; but as 


\section{6}

they have usually been described by geologists, their omission would form a sensible blank. They are moreover interesting, as in many cases, tending to illustrate the origin and nature of the more recent strata; while their enumeration serves to complete that department in the elements of geological science, which forms part of the plan of this work. 


\section{7}

CHAP. IV.

GeNeral CATALOGUE OF THE FAMILIES OF ROCKS CONTAINED IN THE PRESENT ARRANGEMENT.

Is the following catalogue, the several families of rocks are arranged according to the divisions which have been discussed in the preceding chapters. The reasons for these divisions have already been examined : those on which the nearly arbitrary succession of the families has been founded, will be treated of in the subsequent chapter. Their very unequal importance and extent is very striking in the case of talcose and of actinolite schist, compared with gneiss or with the overlying rocks. But the increase of such families, or genera, is so much more desirable than their diminution, that it seems expedient to adopt any reasonable excuse for multiplying them, wherever that can be borne out by' their mineral characters and their geological con- 


\section{8}

nections. The probable, consequence of an increased acquaintance with the history of rocks, will be to add more of these divisions to the now circumscribed and irregular list.

\section{PRIMARY CLASS.}

UNSTRATIFIED.

Granite.

Serpentine.

STRATIFIED.

Gneiss.

Micaceous schist

Chlorite schist.

Talcose schist.

Hornblende schist.

Actinolite schist.
Quartz rock. Red sandstone. Argillaceous schist. Primary limestone. Compact felspar.

\section{SECONDARY CLASS.}

\section{STRATIFIED.}

Lowest(red) sandstone. Limestone. Superior sandstones. Shale.

UNSTRATIFIED.

Overlying (and venous) Pitchstone. rocks.

\section{OCCASIONAL ROCKS.}

Jasper.

Siliceous schist.

Chert.
Gypsum.

Conglomerate rocks. Veinstones. 


\section{APPENDIX FIRST.}

VOLCANIC ROCKS.

\section{APPENDIX SECOND.}

Clay, marle, and sand. Alluvia.

Coal.

Lignite and Peat.

In introducing the last articles into this list, it may perhaps appear necessary to apologize for the presence of coal, which has no claims to the character of a rock; as well as for that of peat. But the former is intimately connected with the strata in which it lies; and as it must also be treated of in any geological history of these substances, of which the arrangement and description alone is here attempted, it could not have been omitted without inconvenience. The latter illustrates, in so many important points, the history of that valuable mineral, that, as it must also be described in any geological system which shall hereafter attempt to complete this subject, its adoption in the arrangement became equally a matter of necessity. 
In a geological classification of rocks, it might appear proper to have made a separate division of those which are found in the several freshwater partial formations that have recently been described. But our knowledge of these deposits is as yet in its infancy; nor are the rocks which they comprise so different in character as to require a separate division. For the present, they fall without inconvenience into the secondary class. The principal interest attending these strata is of a geological nature: and, indeed, depends chiefly on that of the organic substances which they contain. If future acquisitions of knowledge respecting them should render it necessary, there will hereafter be no difficulty in modifying the present arrangement so as to give them an appropriate place. 
CHAP. V.

REMARKS ON THE GENERAL CATALOGUE OF THF ROCKS CONTAINED IN THIS ARRANGEMENT, AND ON THE ORDER OF THEIR SUCCESSION IN NATURE.

IN the preceding general catalogue are comprised all the rocks which seem to have been decidedly ascertained by geologists to constitute distinct massses in nature. Our knowledge is not however as yet sufficiently accurate or extensive to enable us to determine whether all the inferior varieties, here ranked under the general heads, are accurately referred; or whether some of them may not have claims to distinct places in the system. The chief of these doubts relate to certain rocks not found in Britain, the geological connections of which have not been satisfactorily investigated or described. I may quote, as an example, the topaz rock, which is here placed under gneiss; from its general character. Future exa- 
minations will rectify these and many similar blemishes; under the present uncertainty, the most probable places for the doubtful rocks have been chosen ; since no proofs of geological distinctness have been brought forward so as to claim for them decided places in an arrangement which is intended to be geological.

Another practice has here also been adopted, which it is requisite to explain in this place. The number of the minerals which constitute the great masses of mixed rocks, appears to be very limited, as will be shown in an appended list. But many other minerals are occasionally found, as is there mentioned, intermixed in rocks, so as to constitute remarkable varieties. In most cases, these varieties seem to be of limited occurrence; the rocks in which they are found, however distinct in specimens, forming portions only, more or less extensive, of the larger and more ordinary masses.

It is also well known that these accidental minerals often occur, occasionally, or dispersedly, in rocks, in proportions so small as not to modify 
their general characters. No limit could therefore be drawn in an arrangement of this nature, between those specimens, or rocks, in which such minerals abound, and those in which they occur, as it were, by chance. For these reasons, such compounds, even where rendered very remarkable by the predominance or abundance of some particular accidental or superfluous mineral, have not been enumerated in the synopses, even among the lowest divisions of varieties. Micaceous schist is an example in point. In this rock, a single garnet only is sometimes contained in a large fragment; while, at others, these crystals are so numerous as to form a large part of the bulk of the rock. The practice has here been, not to consider this as a distinct variety, but as an ordinary specimen containing imbedded minerals.

The same rule has further been extended to all the cases where minerals occur in a state of mixture, however considerable; provided these are not found in that list which is generally received by geologists as containing all the minerals essential to rocks. It may perhaps be hereafter found necessary to extend that catalogue; in. 
which case some of the rejected varieties will naturally fall into the synopses among those which now exclusively occupy that place. At present, the several minerals which occur in a state of mixture, whether more or less extensive, with the ordinary ingredients of any rock, are added at the end of each enumeration ; and, by examining that list, collectors will be enabled to verify any specimen of which the character might, from the prevalence of some adventitious mineral, appear otherwise doubtful.

It may lastly be remarked on this subject, that the geological connections of some of these mixtures of essential and unessential minerals, have as yet been so imperfectly described, that, as in the case of the doubtful rocks just mentioned, it is by no means certain that they have been always truly chosen in this arrangement : but the correction of these and many other faults, must be trusted to time, and to an increased attention to a subject nearly in its infancy.

In the present catalogue there will also be found some rocks which have scarcely obtained 
places in a geological arrangement, and of which two, at least, have been hitherto enumerated only among minerals : These are, siliceous schist, jasper, and chert. As far as can be ascertained, from the circumstances attending their geological positions, they are all of a local nature, and appear to be modifications occurring at the common boundary of the stratified and the unstratified rocks ; being apparently produced, in most cases, by the local influence of the latter. As they belong equally to both the primary and secondary classes, they have been placed, as already remarked, under a distinct title. This expedient appeared preferable to that of enumerating them merely among the varieties; where however they are also noticed when necessary. Siliceous schist indeed has long been considered, like argillaceous schist, a peculiar and distinct formation, and its absence might therefore have excited surprise. Moreover, on the view of its geological history here adopted, it became absolutely necessary, in giving it a place, to allot one also to each of those substances which bear so striking an analogy to it in their origin and connexions. 


\section{6}

Under these several views the preceding catalogue was drawn up. But some preliminary observations respecting the adopted succession of the families, or general titles, are necessary, to prevent it from being imagined that this is the order in which the several rocks actually occur in nature. The minuter details requisite to illustrate this and many previous statements, must be sought in systems of geology, if indeed they are there to be found; the most general sketch alone must here be sufficient.

With respect to the order of succession in the primary class, the claim of granite to the first or lowest place is unquestioned; and has already been discussed ; as has the unsteady and variable position of serpentine; but after the former, no further certainty can be obtained as to the next rock, or the first of the strata; since they are all occasionally found in contact with it. That place has here been given to gneiss, chiefly because it has been the custom so to do.

The relative order among the stratified rocks themselves is also inconstant; but it is not impro- 


\section{7}

bable that a distinction may exist in this case between the larger tracts and the more limited collections of strata. It is however undoubted, that, in many instances, there is no such distinction; but that even the largest masses or tracts occur in: an uncertain order. Thus, although the great tracts of argillaceous schist are most commonly: found on the confines of the series of primary: strata, they sometimes also exist below quartz rock and micaceous schist; of which Scotland furnishes examples.

It must now also be remarked, that it is, in general, only in the smaller tracts, or collections of strata, that the fact of alternation, or the nature of the relative position, can clearly be ascertained. In the larger masses, the connections are often in visible or unassignable; either from their dimensions, and the great spaces which they, cover, or from the impossibility of ascertaining truly what bed is uppermost where the inclinations of the strata undergo a reversal, as they are found to do among the primary rocks. To assign an order in such cases, is beyond the reach of our powers.

The occasional deficiency of certain classes of 


\section{8}

rock produces similar uncertainty; or rather, perhaps, this ought to be considered as an unquestionable proof of the irregularity in the succession of the primary rocks. It is, plainly, but the same fact expressed in different language.

Where, however, alternations are clearly visible, as in those cases where strata of limited extent follow each other with a conformable inclination and in contact, no constant order can be found; or rather, the greatest irregularity seems to prevail. I shall, to illustrate this statement, here subjoin a catalogue of some of the most remarkable alternations among the primary strata as they occur in Scotland. Some of these are limited to one succession ; in others, the alternations are repeated ; but it is unnecessary for the present purpose to distinguish them.

The order adopted in the catalogue is therefore arbitrary in the primary class; and has only been selected, as being the most conformable to established habits ; but it comprises certain alterations that became requisite in consequence of the adoption of a different division, and of a new member. 
In the secondary class, no order is to be assigned, from the limited number of substances contained in it, and from the frequent alternations in which these are found.

The following list contains, in confirmation of the preceding views, a few examples of the different orders of succession which occur among rocks. The examples are all selected from this country, partly for the purpose of increasing the authority of the statements, by permitting them to be easily verified, and partly for that of facilitating the access of the student to a set of facts which are at variance with some of the received geological systems. The localities have been added for the former reason; and they might easily have been multiplied had it appeared necessary. Geologists have recently ascertained that similar uncertainties of arrangement exist in other countries, and the student may consult their writings. The examples are not quoted: as, throughout this work, it has been deemed expedient to rely as far as possible, only on those facts respecting which the author imagines he has received that conviction which is founded on obervation. 


\section{SUCCESSIONS AMONG THE PRIMARY ROCKS.}

Granite.

Gneiss.

Limestone,

Quartz rock.

In Glen Tilt.

Granite.

Limestone.

Quartz rock.

Micaceous schist.

Gneiss.

In Glen Tilt. Hornblende schist also occurs in any part of this series.

\section{Granite.}

Argillaceous schist :

(clay slate, and fine graywacke).

Gneiss.

In Iona: in Bamffshire.

Granite.

Micaceous schist.

Quartz rock, or else the quartz rock next to the granite.

In Mull, and in Glen Tilt. In Morven and in Mull.
Granite.

Primary sandstone.

Secondary strata, with coal.

In Sutherland.

Granite.

Gneiss.

Primary sandstone.

In Sutherland.

Granite. Micaceous schist. Secondary strata. In Arran.

Granite. Argillaceous schist. Secondary strata. In Arran, and in Aberdeenshire.

Granite.

Gneiss.

Calcareous sandstone, including shale and coal. 
Granite.

Lowest (red) secondary sandstone.

In Aberdeenshire: at Kildrummy.

Granite.

Argillaceous schist :

(clay slate or graywacke).

In Cornwall.

Granite. Argillaceous schist : (clay slate and graywacke).

Lowest red sandstone.

In the Isle of Man.
Gneiss.

Primary sandstone.

Conchiferous limestone: above the lowest (red). sandstone: lias.

In Sky.
- Gneiss.

Secondary sandstone, (red, lowest).

Superior sandstone and limestone (lias).

In Inch Kenneth.
Gneiss.

Primary sandstone.

Quartz rock.

Gneiss.

In Sutherland.

Granite.

Argillaceous schist.

Gneiss.

Conchiferous limestone:

(above the red sandstone); lias?

In the Isle of Man.

Argillaceous schist.

Gneiss.

Quartz rock.

Limestone, bituminous, or containing organic remains.

Quartz rock.

Gneiss.

In Sutherland.

Argillaceous schist.

In Isla, and in Rosshire and Sutherland. 
These are among the most simple successions which it appears necessary to point out.

In the following examples the different rocks in each group occur in every possible mode of relation and succession, and in repeated alternations.

Micaceous schist.

Fine argillaceous schist: (clay slate).

Micaceo-argillaceous schist: (graywacke).

Arenaceo-argillaceous schist: (graywacke).

Fine conglomerate schist: (graywacke).

Quartz rock.

In Jura and Scarba.

Fine argillaceous schist: (clay slate).

Coarse, of various characters : (graywackes).

Chlorite schist.

Micaceous schist.

Gneiss.

To which is sometimes superadded

Limestone.

In the southern Highland border, and in Bute.

Hornblende schist.

Actinolite schist.

Quartz rock.

Micaceous schist.

Chlorite schist. 
To which are sometimes superadded

\section{Limestone.}

Argillaceous schist.

Gneiss.

Knapdale, Nether Lorn.

Respecting the secondary rocks, it is only necessary to offer some general remarks ; since from their very limited number, as far as essential characters are concerned, they do not admit of the same method of enumeration.

It has already appeared, that the lowest (red) sandstone does not necessarily succeed to the primary strata.

Any member of the three leading species of which they consist, namely, sandstone, limestone, and shale, may succeed another in any mode of repetition or alternation.

It is not however believed that local varieties, such as the oolite among the limestones, or the red marle of England among the sandstones, can have their order inverted, so as to appear above, and also below, any other local rock. But any of the members may be absent; and thus one rock may, in some places, follow another in im- 
mediate succession, when, in others, the two are separated by different intervening strata. It is however doubtful whether observations have as yet been sufficiently extended to justify the adoption of any invariable laws on this subject.

With respect to the trap rocks, it is now unnecessary to observe, that they are found in contact with every substance in the catalogue. 
VIEW OF THE EXTERNAL AND INTERNAL GENERAL CHARACTERS BY WHICH ROCKS ARE DISTINGUISHED.

Rocks, like the simple minerals of which they are formed, are, independently of their composition, possessed of various characters more or less obvious, by which they are capable of being discriminated with a greater or less degree of certainty. Neither technical nor common language however, are always sufficiently copious or precise to serve the purpose of conveying ideas of some of the minuter differences, which are still suffciently palpable to the eye. This defect is probably irremediable; but it will nevertheless be of use to enumerate the different circumstances to which mineralogists have applied discriminating terms; as, in a great numberr of instances at least, 
it will facilitate the progress of the student in investigating the names of rocks; and as many of them can be rendered sufficiently intelligible.

Independently of those varieties of character of a minuter kind which are in some measure common to rocks and minerals, the former are also, in many cases, distinguished by certain external modes of configuration or disposition, as the latter are by their geometric forms. As these constitute an essential part of the natural history of rocks, and are frequently referred to in the following pages, an enumeration of them is equally required. That enumeration is indeed rendered peculiarly necessary by the geological principle of arrangement which has been adopted. It may perhaps be conceived to belong more properly to a system of geology. Assuredly, it would require to be detailed in every such system ; but the reader who shall imagine it rescinded from the present work, will soon become sensible of the inconveniences that would arise from its absence.

The following are the circumstances which it has been judged proper to select as the general 
charàcters which seem principally applicable to the discrimination of rocks :

The external configuration of the masses; or their geological forms and disposition.

The internal structure; or the concretionary forms which are peculiar to certain rocks and independent of the preceding.

The texture; a distinction analogous to that circumstance in the simple minerals.

The fracture; a distinction often intimately allied to, or identical with the preceding; but, frequently also, independent of it.

The hardness; or the degree in which they resist the action of hard and pointed bodies of different kinds.

The frangibility ; a circumstance distinct from the former, and consisting in the greater or less facility with which they are broken.

The lustre; or the degree in which they reflect light.

The degree in which they transmit light; or the transparency.

The effect of acids in extricating air.

The specific gravity. 


\section{8}

The distinctions derived from the touch, or the feel, in rocks, are so limited, that it is unnecessary to consider them in this place.

Those derived from odour, are nearly of equal inutility ; although the argillaceous smell has been often enumerated as a distinction. It belongs to so many different rocks as to form no criterion in itself; and is so generally accompanied by other characters of greater distinctness, as to be rendered unnecessary even when present.

The property of absorbing water with rapidity, appears, in the same way, to be a character of little or no practical use, and no further notice is therefore taken of it. 


\section{CHAP. VII.}

ON THE EXTERNAL CONFIGURATION OF ROCKS.

Rocks are found under the following different forms :

\section{IRREGULAR MASSES.}

These may be of any size, even of mountainous bulk. Examples of them are afforded by granite, and by the overlying rocks, or the traps and porphyries.

Pseudo-strata : Beds of some geologists.

These forms belong to the same rocks, distinguished in the arrangement by the term unstratified. They are often combined with the preceding, and pass imperceptibly into them. The mode of distinguishing them from real strata will be pointed out hereafter.

This form is sometimes the apparent result of a peculiar concretionary structure, as in granite; 
and might, in this case, have been classed with the lamellar, into which (on the large scale) it occasionally passes.

The beds are sometimes straight, at others curved, and they are often placed in many different directions within a small space; varying in position from the horizontal to the vertical.

They are also frequently jointed, or divided at right, or oblique angles, into cuboidal or prismatic forms. In these cases they might equally be referred to the large concretionary structure.

The form of a bed, or pseudo-stratum, is often assumed by the trap rocks, or the rocks of the overlying division, in consequence of their being deposited on a real stratum.

That form also results from the intrusion of veins between parallel strata, and the distinctions are considered in treating of veins. It assumes the appearance of true stratification in a very accurate manner, when, by the wearing away of the upper of the including strata, it occupies the surface.

Strata. Sometimes also called beds by many geologists. 


\section{1}

These are masses far more extensive in two dimensions than in the third, and commonly occupying large spaces. In its simplest form, the stratum may be considered as a horizontal bed, the superior and inferior planes of which are parallel, or nearly so, and straight, or lying in one mathematical plane. It is held to arise from the deposition of earthy matters from water. That form is however rare, and the stratum is subject to many modifications.

The planes may be straight, and inclined to each other; so that the stratum, if prolonged, would terminate in an edge:

By the gradual approximation of the planes and their successive divergence, they may vary in thickness in different parts ; and, in such cases, it is obvious that the planes will no longer be mathematically straight, but variously curved.

In these cases, strata sometimes vanish entirely in the planes of their courses, and are renewed at some distance, with the same or with other connections.

Whether parallel, or not, they vary extremely in thickness ; in some cases being even less than 
an inch, in others assuming a dimension of many yards. It is obvious that very thin strata cannot be very persistent. Many different dimensions are sometimes found associated in the same series of successive strata.

An apparently continuous general stratification will sometimes extend for even many miles ; but the surface of the earth is seldom in such a state as to allow the same individual stratum to be traced for a few hundred yards.

A stratum is sometimes simply bent; or undulated, and in curves of greater or less magnitude. That undulation, or curvature, may be limited to one direction, or another, or it may extend to two. In such cases it produces effects in varying the apparent position of strata, which will be considered in treating of their dip.

The curvatures of a stratum are sometimes such as to cause it to assume the form of a spheroidal crust. They are also occasionally of such a nature as to amount to contortions. In other cases, when considerable, they are sometimes attended by fractures more or less numerous.

Strata are also frequently fractured, without 


\section{3}

contortion; and, in such cases, the fractured ends sometimes remain in contact; at others, they are shifted so as no longer to be in the same plane; and, at others again, are separated by veins of intervening materials.

In one rock only, it has been observed that a stratum will in one part lose its character and become a shapeless mass. This happens where secondary limestone is in contact with the primary rocks ; and also where it is in the vicinity of trap. The Isle of Man, and Sky, furnish examples of both these facts.

The positions of strata vary from the horizontal to the vertical, through every intermediate angle.

The horizontal position requires no further remarks; but the inclination of the others to the horizon is called the dip; in which term is further implied its tendency towards some point of the compass, where it is not vertical; while the quantity of that inclination is expressed in the number of degrees by which it deviates from the horizontal position.

If a vertical stratum be assumed, of which the 


\section{4}

edge is parallel to the horizontal plane, it is obvious that such an erge will have a linear direction on some line of the compass, which is at right angles to the inclination, or dip, and indicates the position of the plane towards the meridian. In similar strata, although the edge is not thus parallel to the horizon, the position of the plane with respect to the meridian may be ascertained by a spectator placed in the same line, but the edge will no longer be at right angles to the vertical.

This position of the plane of a stratum with respect to the meridian, is therefore called the direction of a stratum. This term is equally applied to strata at all the angles which deviate from the vertical; but as the tendency of the plane can be truly discovered from the edge, only when that is parallel to the horizon, the direction is determined by an imaginary line at right angles to the inclination, or parallel to the horizontal plane.

In many cases of inclined strata therefore, as the direction of the strata cannot be determined by their elevated edges, but must be deduced from their dips, the knowledge of the one is evidently implied in that of the other. 
When strata become horizontal, it is plain that the term direction is no longer applicable. It is also proportionably difficult to determine as the angles of inclination are small; , and becomes therefore a far less useful circumstance in tracing the connections of distant strata.

The inclination of any stratum is subject to change along the imaginary line of its direction, in consequence of undulations or flexures ; and hence the same stratum frequently presents different angles of dip in different parts.

The direction of a stratum is also subject to apparent, or: local variations, in consequence of flexures or undulations in an order the reverse of the former; and hence the same stratum occasionally presents, in different places, different tendencies of the elevated edges. A mean direction may be deduced in such cases ; but, strictly speaking, the term is no longer applicable.

It is lastly evident, that, in cases of complicated curvature, nothing satisfactory can be determined with regard either to the dip or direction of strata. 


\section{6}

Practically, there are few cases in which general conclusions with regard to these circumstances can be safely drawn from the measurement - of one part of a stratum.

The positions of strata with regard to each other, or to the neighbouring rocks, are various.

When in contact with granite, or other irregular rocks, they are rarely, if ever, parallel to its surface, for any considerable space, or adapted to the external form of the mass.

More commonly, such an irregular rock is found in contact with many successive associated strata, or meets them at some angle to the planes of their stratification. In such cases they are frequently contorted, or fractured, and penetrated by veins which are connected with the irregular rock and formed of the same materials. In some rare instances they are also broken into fragments of different dimensions, which are found insulated in the irregular rock.

When strata follow each other, they are very often parallel for a considerable space ; or as nearly parallel as the inequality of their thickness permits. 


\section{7}

In other cases, one series of strata meets another at some angle; and this occurrence happens most frequently where the primary are followed by the secondary strata, but is by no means confined to these. In such a contact, the planes of the superior strata may lie on the edges of the inferior; a position known by the terms unconformable and overlying. Otherwise, the edges of the superior may abut against the planes of the inferior. There are cases moreover, in which one stratum, or series of strata, may be both parallel and unconformable to the series immediately below it; being in contact with the edges in one place and with the planes in another.

In a succession of strata, the angle of inclination is sometimes found gradually to increase, or to diminish, according to the mode in which they are examined. In this way, strata pass gradually in some cases, even from the horizontal to the vertical position.

Some cases occur in which this disposition takes place in a corresponding manner on both sides of a vertical stratum, or set of vertical strata. In such instances, the strata have been said to ra- 
diate. This radiation is sometimes so disposed that the strata diverge from the upper visible edge of the vertical stratum; while, at others, they con-. verge towarc's it.

In some instances of the latter disposition it can only be known that two strata meet in an angle like the roof of a house; the intermediate rock being inaccessible.

Such reversals of the dip are sometimes repeated several times in the horizontal space occupied by one set of strata.

One set of strata is sometimes found occupying a limited space, and lying on another stratum, or set of strata, in such a manner as to present a considerable depth in the central parts and to diminish gradually towards the edge. Such a collection has been called a basin; and, under favourable circumstances, each stratum of it will in some place be found in contact with the inferior rock on which the whole reposes.

The thickness, or depth, if in a position approaching to the horizontal, of any series of strata, is extremely various, even from a few yards up- 
wards; but its limits are unknown. Scotland presents one example, in which an uninterrupted series of one rock, in a position approaching to the horizontal, is nearly 4000 feet in depth. This is the mountain Kea cloch in Rosshire, composed of red sandstone.

When the inclination is considerable, access is obtained in a horizontal direction to a much greater extent of a series; and, in such cases, the thickness of a collection of strata has been found to amount to many miles. In Argyllshire the lateral thickness of that which I have elsewhere called the chlorite series, is nearly twenty:

Strata are separated from each other by mathe matical planes, sometimes, (technically, called seams. They are also at times further divided at some angle to their planes by other planes called joints. In some instances, such joints are observed to be parallel to each other:

Asseries of strata sometimes consists of one substance, or rock, only; at others, one prevailing rock is divided by much thinner strata of another; as sandstone is by shale. 
In other cases, two or more distinct rocks unite to form one series; being repeated in an order which may be either regular or otherwise. Thus gneiss is associated with hornblende schist.

Sometimes, a small proportion of one rock occurs in a series principally consisting of another. The term subordinate has been applied to such a rock; occasionally with no small inconvenience. Shale alternating with sandstone, is an example of this disposition.

It is a prevailing rule in nature for a given stiatum to consist of one rock. It also most commonly consists of one modification of that rock ; but this rule is far from universal. Thus, the upper part of a stratum may consist of a fine sandstone, and the lower of a conglomerate; or the reverse. This change may also take place according to the plane of the stratum, or laterally.

Strata frequently contain foreign organic bodies imbedded; sometimes confusedly, at others, with more or less of conformity to the plane of the stratification.

There are cases in which it may be difficult to 


\section{1}

distinguish strata from the pseudo-strata, or beds, already mentioned. In these, recourse must be had to those characters on which the distinction was originally founded, which are the following.

In some places the pseudo-strata pass into the irregular masses which they generally accompany ; or else they become irregular in some part. This occurrence does not take place among real strata, except in the solitary instance of limestone, elsewhere mentioned, where the presence of organic remains is a sufficient criterion of the stratified nature of the rock.

Pseudo-strata do not maintain an invariable parallelism to the real strata which they accompany. When above, they meet them obliquely ; or the base of the pseudo-stratum is in contact with different strata of the inferior series. When intermixed, they either present similar irregularities, or, being parallel in one place, they intersect in another.

Veins are found to proceed from pseudo-strata as they do from irregular masses, and to penetrate the adjoining strata. No veins proceed from real 
strata the appearances which might be mistaken for these, are noticed under the head of veins.

Pseudo-strata are limited to the rocks of the overlying division, or to the traps, syenites, and porphyries, and to granite. This distinction is practically the most easy; and it is the only one necessary for the student, if, as is presumed, the observations on which it is founded are correct. If otherwise, it may still remain a rule, until it is proved to be unfounded by a more extensive knowledge of this subject.

Nodules. Or imbedded irregular masses.

This term is adopted, for want of one more appropriate, to include rocks which are not stratified, nor disposed in pseudo-strata, and which do not resemble in their connections the large irregular masses.

The form of nodules is very various. They are sometimes extremely irregular, at others, bounded by smooth or even surfaces, and possessing an average general dimension alike in évery part. Not unfrequently, they have a much greater dimension in two directions than a third; and, in 


\section{3}

such cases, they pass into the form of non-persistent and extenuated strata.

Nodules are frequently imbedded in stratified rocks; but they are also found in granite. Serpentine presents an example of this last case.

The size of these masses varies from a foot to a mile or more.

As yet, limestone, serpentine, and compact felspar, alone, have been found in this form, which must be considered rare.

\section{VEINS.}

Veins are distinguished by their laminar, or filamentary forms, and by intersecting all the other forms in which rocks are disposed. They also intersect each other.

The course of a vein is sometimes straight; or in one plane; at others it is curved, or even bent at angle; but the latter occurrence is rare.

The flexures of a vein are sometimes such as to amount to undulation ; rarely to contorsion, except in the case of quartz and carbonat of lime, which are scarcely to be enumerated with pro-: priety among rock véins. 
Veins are sometimes, like strata, fractured, and the fractured parts either remain in contact, or are separated (shifted) so as no longer to be in the same plane. Such fractures are sometimes occupied by other veins; or one vein is intersected by another of the same, or of a different substance.

In some cases, veins are simple. In others, they divide into two or more, or they give off smaller branches, or, lastly, ramify into successive subdivisions. Such ramifying veins are almost necessarily filaments, at least in their ultimate branches. In such cases, which occur principally in granite, the character of the rock often varies in the progress of subdivision.

The size of veins is extremely various. Those of granite sometimes descend to that of a thread; those of the trap family reach to a breadth of an hundred yards and upwards. To the extent of laminar veins, according to the direction of their planes, there are no limits to be assigned.

The breadth of laminar veins is sometimes the same for a considerable space, or the sides are parallel : in other cases, they are inclined, so that the vein becomes gradually extenuated till it dis- 
appears; or they are alternately extenuated and expanded, so as to present a sort of undulating appearance.

The positions of veins with respect to the horizon, vary through every possible angle. The direction and the dip are estimated in the same manner as they are in strata.

When veins traverse stratified rocks, their positions with respect to the general plane of stratification is equally various. They frequently intersect it at some angle, so as to pass through many successive strata. Occasionally, they are parallel, for a greater or less space, to the plane of stratification, and thus lie between any two strata in a parallel manner. Sometimes the same vein possesses both characters; intersecting in one place those strata to which it is parallel in another.

In súch cases, it becomes sometimes difficult to distinguish between a vein and a stratum ; and, as the distinction is important, it is necessary to state the circumstances by which it may be made. They resemble those by which pseudo-strata are distinguished from real strata.

$V$ eins, although in any one place parallel to 
the stratification which they accompany, rarely maintain that position for any considerable space. In some part of their course they will be found to become oblique, so as to touch more than one stratum of a series ; or to intersect it at a considerable angle, or to detach ramifying veins through it. These are the cases in which the accompanying strata are so frequently bent, contorted, and fractured; often to such a degree as to be mixed in a confused manner with the veins. Fracture and confusion of the neighbouring strata, thus also become criteria by which a vein may be distinguished fròm a stratum.

$\therefore$ In cases of this nature, veins of a simple rock sometimes contain imbedded fragments of the strata which they traverse." Such fragments are sometimes unaltered; at others, they are much changed in aspect, and graduate into the matter of the vein.

Veins, like pseudo-strata, are limited to the rocks of the overlying family, or to the traps, syenites, and porphyries, and to granite; and, as in that case, it is here presumed, on grounds of which the reasons cannot be stated here, that all 


\section{7}

the apparent strata formed of these substances are, in fact, veins. If this rule be true, the nature of the rock is the easiest criterion, and will always be sufficient for the purposes of distinction.

It must be recollected, that veins of quartz and of calcareous spar, are excepted from the general rules that apply to rock veins. They form however a distinct class of mineral veins, highly interesting to the geologist from their frequency.

They are seldom of very large size, although quartz veins occasionally attain a considerable dimension. They are seldom tabular, or continuously laminar for a long space; but are more generally ramose, and more or less largely filamentous. They intersect each other frequently, and are often, at the same time, shifted.

There are some rare instances in which strata, and that most frequently when they are in contact with the overlying rocks, are minutely divided, extenuated, and contorted, so as to put on the appearance of veins, on a superficial observation. Such false veins even present occasional appearances of ramification. They are most frequent in the argillaceous schists ; but they also occur in mica- 


\section{8}

ceous schist, and in sandstone. They are distinguished from the rock veins above described, by their nature, by their connections, and by the limited extent of their connections.

Rock veins can often be traced to some irregular mass. In other cases, it is impossible to discover these connections, from the difficult or incumbered nature of the surface. It is presumed nevertheless, that they are in every instance thus connected; as no unquestionable example of an independent and insulated rock vein has yet been discovered.

The veins which have been called contemporaneous, are enumerated among the varieties of internal structure.

Conglomerate veins appertain more nearly to the class of mineral veins, and do not find a place in this division of the subject. One or two exceptions, it is true, have occurred, of conglomerate veins not appertaining to that class; but they are considered in another part of this arrangement. 


\section{CHAP. VIII.}

ON TIE INTERNAL STRUCTURE OF ROCKS.

Tre following modifications include the different varieties of structure that are found in rocks.

Laminar: Including the foliated and the schistose.

This term requires no further explanation; except to remark that, although it may in some cases coincide with the stratified disposition, it possesses no necessary connection with that. It occurs under three modifications, which may be conveniently distinguished into the lamellar, the foliated, and the schistose.

In the lamellar modification of this structure, a rock is found to divide with more or less faci- lity, either by the application of force, or from the 
action of the weather, into plates, which are rarely continuous, as in the schistose structure, and still more rarely admit-of subsequent division.

The lamellæ are either straight, or curved in one or more directions, or contorted.

They vary in dimensions, from the thickness of many yards down to an inch, and even to that of paper. There are thus a large and a small lamellar structure ; and the former may be identical with the bedded or pseudo-stratified disposition, as already remarked.

They are sometimes persistent for a considerable space ; and, at others, are very limited; being divided at short intervals by joints. In such cases, they assume prismatic, and even cuboidal forms, so as to become confounded with those of the prismatic structure.

The lamellar is thus sometimes united to the prismatic structure, by the latter being an accident of the former. In other cases, they are combined in another manner, in consequence of a laminar structure of the prisms ; as is pointed out under another title.

It is also occasionally united to the spheroidal 


\section{1}

structure, both on the small and large scale ; as in granite, trap, pitchstone, and certain limestones; but these are more particularly mentioned in other places.

The lamellar structure is sometimes detected by modifications of colour, even when the lamellæ cannot be separated. It is also discovered . in some cases by the action of the weather, even when that does not produce the effect of separating the plates ; the edge of one lamella yielding more readily to its impression than another. This -occurs in the sandstone of Strathaird in Sky.

- A lamellar structure may however be indicated by the action of the weather, when it has in fact no existence. This happens in granite, where masses of this rock of artificial forms, are found to exfoliate in solid crusts.

Examples of the lamellar structure on the large - scale, are found in granite; on a small, in the rocks of the trap family. In this case it has been called, with some inconvenience, schistose.

The small lamellar structure occurs in pitch-stone; and the contorted, both in that rock and in basalts. 
This structure is not limited to masses, but occurs also in veins.

The foliated structure is the result of a peculiar disposition of parts, and occurs in mixed rocks only; while the former is equally found in the simple. It consists, rather in a tendency to split into parallel laminæ, or in an appearance of parallelism in the disposition of the integrant minerals, than in the property of actually splitting. But, as it passes into the schistose structure, no positive limit between these two forms can be assigned. The distinction is nevertheless convenient in practice ; and is visible in gneiss, to which the foliated structure is nearly limited.

In the foliated structure, the splitting, when it takes place, seldom produces a continuous or even lamina. When it does, the structure must generally be considered schistose.

The lamina is more frequently uneven and irregular than smooth, is deficient in parallelism, and is, not unfrequently, curved.

The foliated is often combined with a very uneven granular structure. 
Whether the foliated rock admits of being di. vided or not, it often exhibits marks of curvature, on a great and on a small scale; sometimes amounting to contortions.

The schistose structure is distinguished by the facility with which the rock splits into laminæ by mechanical force. A schistose rock rarely, if ever, exfoliates by the mere action of the weather.

In some cases, the schistose structure is found in a simple rock, as in fine argillaceous schist, (clay slate). In these, it appears at times to be the result of mechanical deposition ; being parallel to the stratification : at others, being oblique to that, it seems to arise from a concretionary arrangement of the particles, analogous to that by which the spheroidal forms are produced.

In other cases, the schistose structure exists in aggregate rocks, even of a very coarse texture, or containing large nodules; and, in those, it appears to be dependent on the simple rock which forms the basis of such mixed masses. Coarse graywackes and conglomerates, present examples of this occurrence. 
Lastly, the schistose structure sometimes results from the laminar alternation of two distinct substances, one of which is more yielding than the other. This is found in sorne limestones, but it may also be considered as a variety of the lamellar modification.

The thickness of the laminæ produced by the schistose structure is various; it seldom, however, exceeds one, and rarely descends to the twentieth of an inch.

The laminar continuity is equally various. It may extend to twenty feet, and is often limited to a few inches, or even less.

In these cases, the schists sometimes terminate by extenuation; at others, in consequence of transverse joints. These joints are frequently so placed, and so straight, as to divide the laminae into prismatic masses of different forms. They are much more fiequently oblique than vertical to the laminar plane, and are often mutually parallel.

The laminæ, or schists, are sometimes even; at others uneven, rough, or tubercular.

They are generally straight, occasionally 
undulated on a small scale, or curved on a large.

The schistose and the fibrous structures are sometimes united.

The schistose structure exists only in strata. Organic remains are often united to it ; or they are imbedded in the schistose rocks.

\section{Fibrous.}

This structure is not common, and occurs only in argillaceous schist and in limestone. In the latter case, it might perhaps rather be considered as the result of crystallization, and as claiming a place with the varieties of texture.

It is sometimes simply parallel; being more or less distinct and straight, or curved.

The fibres sometimes assume a sort of ramified appearance.

\section{SPHEROIDAĹ.}

Under this general term, are comprised alt the varieties of concretionary structure, which are neither fibrous, prismatic, nor laminar. The forms of such concretions are therefore 
various. They are sometimes nearly or absolutely spherical; in which case they touch by points only, and the intervals are filled by the same, or by another substance. Examples of this are to be found in some siliceous schists and in some limestones.

In other cases, by compressing each other, they become oblate, or indented, or assume various irregular shapes: and they thus sometimes form a mass which presents an aspect as much granular as it is concretionary. Some of the shales which are found in contact with trap rocks, present examples of this peculiar structure, and they are found, very conspicuously, in the Shiant isles.

Such coneretions further possess at times a distinct lamellar, or a radiated structure; and, in one rock (pearlstone), they sometimes contain a central particle of another substance.

Rocks of this structure often acquire a botryoidal surface after exposure to the weather; and, in some instances, this concretionary arrangement is so concealed in the apparently uniform fracture of the rock, that it is only distin- 
guishable under these circumstances. Arran, and many other places in the Western isles, present examples of this occurrence, in the siliceous schists.

In the cases to which the preceding remarks apply, the general structure of the rock is concretionary throughout. The concretions are also of limited size, varying from that of poppy seed to the diameter of an inch.

In other instances, the concretionary structure is confined to particular parts of a rock ; or insulated concretions are imbedded in an uniform mass.

Such concretions are commonly of large size; and generally in the farm of obate spheroids. In some rare instances, they are attached in pairs by a cylindrical stem ; as in the limestone and sandstone of Rasay and Sky.

In others, they are cracked on the surface into polygnnal forms, which are, consequently, frusta of pyramids. Of this, the sandstone of Egg presents examples.

Where the spheroidal form results from the desquamation of a prism, it is noticed under the following head. 


\section{Prismatic.}

In this division are included the common prismatic, and the more remarkable columnar structures.

The common prismatic structure is exemplified in granite, and is rarely found except on the large scale. It appears to be a modification of the large lamellar structure ; a lamella being subdivided by joints, which, in this case, are at right angles to it. Hence the forms are sometimes nearly cubical ; in other cases, they are quadrilateral prisms ; rarely presenting a greater or a less number of sides.

The prisms are frequently rounded at the angles, so as to appear the consequences of a spheroidal concretionary structure; but this seems almost always to be the effect of wear, or of partial decomposition.

In some cases, this wear proceeds gradually. from the circumference; in others, the prisms desquamate in crusts ; thus giving indications of a lamellar structure united to the prismatic. For the reasoms already, stated in treating of the lamel-: lar structure, it must remain doubtful whether 
that desquamation is any proof of its existence in this instance more than in that one.

Either in the case of simple rounding, or of desquamation, the cuboidal, or prismatic form, becomes ultimately spheroidal; for mechanical reasons sufficiently obvious. But as instances also occur where a simple prism exhibits more than one desquamating centre, it is undoubted that, in some cases at least, there is a lamellar concretionary structure united to the prismatic.

In the columnar structure, as the term implies, the prisms generally possess a considerable length in proportion to their breadth, and they are not limited to the quadrilateral form. In a few instances, from the extreme shortness of the prisms, the columnar passes to a tabular, or a lamellar and jointed structure; but the two are united under this head, in consequence of their general resemblance, and of the undefinable line by which they are separated. Where the columnar structure is on a very large scale, it might be supposed to belong to that division which is included under the term of external 


\section{0}

configuration; but, in reality, it is properly placed here.

The columnar structure is invariably aggregated. No instance, that I know of, has yet occurred, of a single column, as there are of single spheroids, included in an amorphous mass. Pitchstone scarcely offers an exception; as the small columns which it sometimes exhibits, are portions of lamellæ.

As the prisms are often accumulated in a parallel manner, of the same length, and for a considerable space, they unite to form a bed, or pseudo-stratum; or else such a bed appears to be split into prisms, and that division generally takes place nearly at right angles to the leading planes. But as such planes are not necessarily parallel, so, in a mass of prisms, the lengths of these concretions will be found to vary in different parts.

Not unfrequently, the most regular columnar structure vanishes in the same continuous mass, and in a gradual manner. This takes place, either laterally, or in the direction of the axes.

In a columnar mass, the axes may be vertical, or inclined to the horizon at any angle, or hori- 
zontal; and, in these cases, it is implied that the prisms are straight, as well as parallel to each other.

The parallel position is not lowever necessary. In a collection of prisms, they are sometimes found to radiate from some imaginary centre, or from more than one. In other cases, they are placed in various irregular ways and entangled together. In some instances, such irregular prisms are found more or less accumulated, or dispersed, and intermixed with the same rock in an ainorphous state.

When a collection of prisms is parallel and erect, with straight axes, and on a large scale, the well known effect of architectural regularity is produced.

The prisms are not necessarily straight. At times they are slightly, at others, very conspicuously curved. Sometimes the same curvature affects a considerable associated number; or the prisms are then bent in a manner more or less parallel. In such examples, the general effect of regularity is not destroyed. In other instances, 
the curvatures are variously opposed; or the bent are intermingled with straight prisms.

A columnar mass is sometimes formed of a collection of short prisms, placed in a manner more or less parallel, but so that the extremities of some are in contact with the middle parts of others. In such cases they impress each other; and the effect of regularity in the structure of the mass, nearly disappears. A remarkable example of this occurs in the Scuir of Egg.

As the prismatic is united to the bedded, or pseudo-stratified form, so it occurs together with the spheroidal concretionary ; but, in the only instances yet known, the prisms are short and united with the amorphous mass. This circumstance was noticed in treating of the spheroidal structure, and is found in the sandstone of Egg. It also occurs in Rum, in trap; the spheroid being of an enormous magnitude.

The preceding remarks on aggregated prisms, like many of the following, apply chiefly to the rocks of the overlying family, trap, syenite, and porphyry. They might have been mentioned 
exclusively under that head; but, to have omitted them in the present chapter, would have left this account of the forms and structures of rocks imperfect.

On the small scale, as in columnar ironstone, which is but a modification of shale, a collection of prisms is not only curved but sometimes minutely undulated.

The prismatic structure is not limited to beds, or masses, but occurs also in veins. In this case the prisms are most commonly at right angles to the plane of the vein. But they have been also found to occur in a direction parallel to it, and either horizontally or vertically placed.

The columnar structure is sometimes combined with the lamellar; and the lamellæ may either be parallel, or at right angles, to the axis of the prism.

It is almost unnecessary to remark, that the prismatic does not exclude the minute kinds of structure, namely, the amygdaloidal and the porphyritic.

In an aggregate of prisms, they are always found in contact, except in the case of an union 
with the spheroidal structure already noticed; when they are separated by empty intervals, or by intervals filled with another substance.

The contact is sometimes such as to admit of the ready separation of the prisms; at other times, there is a partial or more complete coalescence.

The sizes of prisms are various.

In diameter, or thickness, I have not found examples exceeding 9 feet; and, from that, they vary to one foot, or less; in columnar ironstone, (which, as a modification of shale, is here ranked with rocks) they are sometimes even less than the tenth of an inch, so that the mass becomes nearly fibrous.

In length, they vary from one, even to 300 feet, or much more; but when the length becomes so considerable, it is difficult, for want of access, to determine truly whether the single prisms of a mass are continuous throughout.

The forms are equally various, from three sided, upwards, even to twelve; but figures of four, five, and six sides, are the most common. Such figures are by no means regular, unless in 
a few accidental cases; and every modification of form may be found aggregated in the same mass. - Nor are the sides of the prisms necessarily straight; being sometimes convex, or concave.

Prisms are sometimes continuous for a considerable length. At others, they are divided by oblique or irregular joints. In many instances, the joints are at right angles to the axes, and occur at different intervals, from an inch to many yards. When such joints possess an average general distance varying from one to three feet, a considerable appearance of artificial regularity follows; and it must be remarked, that the most perfect and numerous joints occur in the most regularly formed columns. They are in some cases, as already noticed, so frequent as to produce tabular prisms, not reaching to, or exceeding, an inch.

In the joints, the surfaces in contact are sometimes uneven, at others flat, at others again, alternately concave and convex; and either of these forms may be found in the lower portion. 


\section{6}

In some remarkable examples of a lower concave surface, the angles of the inferior portion protrude in a point which covers a corresponding deficiency in the upper. In others, equally remarkable, the surface of a joint is marked by a channel parallel to its boundary and near the edge of the prism. The first of these is exemplified in the columnar traps, or basalts, the last in columnar ferriferous shale, or ironstone.

In the smaller columnar structure, the prisms are sometimes longitudinally striated; and, in some instances, further distinguished by protuberant rings, or inseparable joints. Examples of this may be found in limestone, in jasper, and in argillaceous ironstone.

In the act of decomposition, the portions of jointed prisms sometimes give indications of a lamellar structure, which, in the progress of desquamation, leaves a spheroidal nucleus ; each successive lamina becoming gradually more regularly curved. This case is analogous to that which occurs in the common prismatic structure, already noticed, and admits of the same doubts as to its real nature. 


\section{7}

VEINED.

This peculiar disposition seems properly to appertain to the circumstance of internal structure in rocks. It comprises, not merely those appearances which are only to be discovered by the action of the weather, but many of those visible veins which do not pass out of one rock into another, and which consist of the same substances as the including mass, under some variety of aggregation. It thus includes some of the contemporaneous veins of geologists ; a term applied in so many ways as to be a source of considerable inconvenience.

In some examples of this structure, a single vein is sometimes found traversing a mass; or there are two, or more, either separated, or interfering in some way. It is not unfrequent, in this case, to find the same peculiarity of aspect which distinguishes the vein, disposed, in some other place, in irregular patches, and, consequently, in a kind of concretionary form. This occurrence is common in granite.

The sizes of such veins vary from the breadth of a foot or more, to one of less than 
an inch; and, in length, they are equally uncertain.

They are sometimes distinguishable in the fresh rock, by difference of aggregation, or by differences in the proportions or sizes of the parts, occasionally accompanied by variations of colour. In other examples, their existence is only discovered after the decomposition of the including rock; when they remain traversing the mass of clay or other materials which have resulted from this cause. Indications of their existence are also given, even where a rock has not been disintegrated or decomposed; their superior hardness causing them to protrude above the general surface.

They often, in this case, present a reticulated appearance; indicating that the interior of the rock contains laminæ crossing each other. Examples of this structure are common, both in granite, and in the sandstones.

When such laminæ are numerous, the intervals form depressions or cavities; and the venous then passes into a cancellated structure which may be included with the following. 


\section{Cavernous.}

The cancellated structure, arising from the intersections of numerous laminæ, passes into a decided disposition of a cavernous nature; the intervals by which the cells are separated, no longer bearing the appearance of veins. The small cavernous is distinct from this particular structure, and generally accompanies the amygdaloidal.

The large cavernous, or cancellated structure, like the veined, is scarcely to be discovered but after the weathering of a rock, and it then becomes apparent on the surface. The cells vary much in size, in form, and in aggregation; and hence a variety of appearances, examples of which are afforded in sandstones and limestones; as the merely veined is chiefly prevalent in the traps and in granite.

The small cavernous structure actually exists in the rock so as to be always visible; and it is more or less perfect; as the cells are sometimes partly filled with some foreign substance. They vary in number within a given space; being sometimes sparingly dispersed, at others crowded, 
so as to produce a scoriform appearance. Such cells are of various sizes; but they do not often exceed half an inch in dimensions, and they are also of various forms, spheroidal or elongated.

\section{Amygdalordal.}

The amygdaloidal structure may be understood from the preceding remarks; the caverns being filled with a variety of foreign mineral substances, which thus appear like imbedded nodules. These nodules vary in size, from a diameter of some inches down to that of poppy seed. The cavernous and amygdaloidal structures are often united in the same mass; and both of these are limited to the rocks of the trap, or overlying, family, and to those of volcanic origin.

\section{Aggregate.}

In this structure, fragments of various sizes are united into one mass, or the aggregate is composed of previous rocks broken and reunited. It concludes all the conglomerates and breccias of geologists; and must also be 
conceived to comprise the sandstones, as the limits between these and the former are undefinable. In this latter case however, the appearances may equally be ranked under varieties of texture.

In the aggregate structure, the parts may consist of one, or of more rocks, or of these intermixed with quartz, or of quartz alone.

These different substances are sometimes united without any apparent general intermedium; at others, a common base appears to pervade and cement the whole.

The sizes of the fragments vary, from the finest sand to a diameter of many feet; but they are generally limited to very moderate dimensions.

In the finer aggregate structures, an average general size commonly pervades all the parts; in the larger, or coarser, fragments of all sizes are united in the same mass.

In some examples, the parts are rounded, as if by previous attrition; often, also, bearing other marks of the action of air or water. In others, the fragments possess more or less of that 
acuteness which would result from a recent fracture. Geologists have sometimes distinguished these varieties by the distinct terms, conglomerate and breccia ; the former also sometimes by that of puddingstone; but these terms not having been always used in the same constant sense, no advantage has arisen from them.

In many examples of the aggregate structure, sharp and rounded fragments are united in the same mass.

In certain cases, a rock is fractured, or divided, into parts so minute, by the intersection of veins of quartz, or of carbonat of lime, or of basalt, as to emulate the aggregate structure.

The two following modifications hold a sort of intermediate place between the accidents arranged under Structure and those included under the term Texture; and they may with equal propriety, therefore, be considered in this division.

\section{Granular.}

The finer varieties of the aggregate structure 
may also rank under this title, but it includes other appearances distinct from aggregation.

In the granular structure, one, or more minerals may be engaged; and the latter variety includes the compound rocks, in which the several minerals are distinguishable, and which are not noticed under other titles.

The granular structure may, from its minuteness, be united with many of the preceding without destroying their characters; and hence a rock may be granular, and at the same time foliated, or columnar, or spheroidal.

In the strictly granular structure, grains of the same, or of different minerals, are closely aggregated, as if by a simultaneous and confused crystallization; and hence they influence or destroy each others regular forms. The magnitude of the parts is various, but generally limited ; ranging most commonly from the twentieth to the half of an inch.

It is often difficult, in practice, to distinguish between an aggregate and a granular structure; and, in these cases, the nature of the structure is presumed from that of the rock ; the true charac- 
ter of a single example being determined by ex perience respecting the predominant examples in that rock.

As the crystals in the granular structure may sometimes possess a greater dimension in one direction than in another, a fibrous structure more or less perfect may result; but this modification being rare, and less decided than the ordinary kind, is, apparently, with more propriety ranked under the head of texture.

In the solitary case of graphic granite, the granular structure becomes imperfectly prismatic; but where nature has made no decided limits, it is impossible to preserve an artificial classification, like this, pure.

The granular structure is also known by the name of the crystalline; a convenient term, had it always been strictly limited.

\section{Porphyritic.}

In the rigid porphyritic structure, crystals of one mineral are imbedded in a continuous mass of another. But the term is also extended to cases in which crystals of two or more minerals 
are so imbedded, or where crystals of one, or more, are imbedded in a granular, or a compound base.

The crystals are commonly minute, not exceeding the tenth of an inch in dimensions; occasionally, they attain to the size of an inch or more.

The porphyritic.structure varies in the number of the imbedded crystals; and becomes evanescent by the loss of their forms, or in consequence of being obscured by the granular nature of the base, or, lastly, by their entire disappearance.

Like the granular, it may be united to any of the larger modifications of structure, or to the amygdaloidal. 
ON THE TEXTURE, FRACTURE, AND OTHER REMANING GENERAL CHARACTERS OF ROCKS.

\section{TEXTURE.}

$\mathbf{I}_{\mathrm{T}}$ has been attempted to distinguish between the structure and the texture of a rock, by arranging under the former term those modifications in which the component parts are either more or less distinctly separated, or are thus separable under peculiar circumstances. In the modifications arranged under the head of texture, it must, on the contrary, be conceived, that the mass is continuous, but that it is so constituted as to presentanalogous appearances to the former ; these being generally, however, on a smaller scale, and consisting of parts that cannot be separated. The texture is thus an indication of an imperfected and minute structure. As it is scarcely dis. 
cernible, except on a fracture, the accidents arranged under it pass thus, on the one side, into those comprised under the term fracture, as they do, on the other hand, into those included under that of structure. The indefinite boundaries of the forms of nature do not easily permit greater accuracy of language and arrangement; and there are cases, moreover, in which the term texture is so convenient, as to make us unwilling to part with it ; independently of the claim which it has acquired from its use among Mineralogists.

\section{Granular.}

The term here repeated under the head of texture, as well as that of structure, is sufficiently explicit; and it is easy to understand how a substance may be arranged in a granular manner, without being absolutely formed of distinct parts, or admitting of being separated into grains.

The granular texture admits of being modified in various ways.

It may be arenaceous and, thus, distinct; or else, flat and evanescent. It may be united to a crystalline, or to an earthy appearance. It may 
also vary in size. The most compact varieties of quartz rock, and some varieties of argillaceous schist, present examples of these textures.

It may pass into an elongated crystalline, and distinct, or into a fibrous, or a scaly texture. It may also be intermixed with distinct examples of these.

\section{Blaned.}

This, or the flat prismatic texture, arises from the interlacement of prisms; and as it passes from the granular texture on the one hand, so it passes into the fibrous on the other. The modifications which it may present, are so analogous to those of the following division, that they do not stand in need of enumeration. It occurs in some hornblende and actinolite schists.

\section{Fibrous.}

This texture results from the condensed aggregation of minute irregular prisms.

It may be more or less distinct, or it may consist of parts of various magnitude.

The fibres are sometimes continuous for a 


\section{9}

certain small space; and, as they may be parallel, straight, or curved, or interlaced, or radiated in a manner more or less complete, many subordinate distinctions are the consequence. These have been denoted by certain technical terms; which seem scarcely wanted, as the modifications are never such as to render it inconvenient to designate them by ordinary language.

The appearance of a fibrous texture is sometimes produced by the parallel position of minutely granular or scaly particles, of which the length is greater than the breadth, when no continuous fibres exist. This texture is sometimes combined with the scaly, or passes into it.

\section{Scaly.}

In the scaly texture, the scales may be considerably continuous, when it is easily confounded with a minutely lamellar structure. But, in the predominant instances, the continuity of any scale is soon interrupted, and, in general, they are minute.

In respect to position, they may be parallel, or confusedly intermixed. 
They may also be more or less easily separated; and, when very distinct, the scaly texture might with equal propriety be called a scaly structure.

The most imperfect scaly texture passes into the flat granular; and, it need scarcely be added, that several textures may be intermixed.

\section{Сompact.}

In the compact texture, no appearance of obscure integrant parts is to be seen; or it may be considered to imply the absence of all the preceding modifications. The varieties of aspect which accompany the compact texture, appertain to the following division.

\section{FRACTURE.}

By the fracture of a rock is understood the appearance of a fresh surface after forcible separation. As this depends in a great measure on the texture, it is now easy to perceive how, in 


\section{1}

certain cases, these terms are mutually convertible. It is not the less necessary to retain this distinction; as there are some modifications of fracture where no proper differences of texture are perceptible.

There are two distinct classes of fracture, the large and the small; and it is the latter which is more especially connected with the texture of a rock.

\section{Even.}

In the even fracture, the surface is a plane of greater or less extent; without, or with, a very slight degree of curvature.

\section{UNEVEN.}

When one plane surface is very limited, and succeeded by other planes variously inclined, the fracture becomes uneven, and the angles formed by the meetings of these planes, produce elevations and depressions. It is obvious, that a fracture minutely uneven, with considerable elevations and depressions, becomes granular, and may thus be ranked under the head of Texture. 


\section{Conchoidal.}

In the conchoidal fracture, one of the separated surfaces is concave and the other convex. It is also not unusual for them to be marked by curved undulations more or less parallel, or, at least, respecting, with greater or less accuracy, one centre.

The conchoidal fracture varies in the degree of curvature, or in the depth of the concavity. It also varies in extent, or in lateral dimensions. Under these several variations, it presents a great diversity of aspect.

Occasionally, two distinct concavities occur ; the one of a smaller size and within the other.

A succession of minute conchoidal fractures produces an undulating surface; sometimes further becoming splintery.

The three preceding fractures may be united, or they may pass into each other in various ways. They may also be united with one, or with more than one, of the smaller varieties that follow. The peculiar aspects sometimes found on the surfaces of these larger fractures, are mentioned under the subsequent heads. 
Splintery.

This fracture is constituted by minute wedgeformed scales, either straight or curved, and adhering by their thick ends to the mass. As the thin edge alone is visible, and as it is often translucent, the appearance is sometimes similar to that produced by mere scales.

In the larger splintery fracture, the scales are flat, or curved, and of considerable breadth in proportion to their thickness. This fracture occurs, especially, in union with the conchoidal.

The smaller, when the splinters are very narrow, may be attended by a somewhat fibrous aspect; when they are thick and short, it passes to the granular; and all these variations may be easily expressed by compounding the terms.

\section{HackLy.}

This variety of fracture is rare in rocks, and is characterized by the extreme asperity and sharpness of the protruding parts. The transverse fracture of loosely aggregated fibres or scales, produces a hackly fracture. It occurs in some of the schistose rocks. 
It is unnecessary to do more than name the granular, fibrous, and scaly, fractures ; as they must be already understood from the description of the several textures to which they belong, and with which they are almost synonymous.

The remaining circumstances by which rocks are characterized are of a miscellaneous nature, and do not contain any material subordinate varieties.

\section{HARDNESS.}

The range of hardness in rocks extends from that of quartz to that of chalk. To describe the various intermediate degrees accurately, is impossible, nor is it necessary. A sufficient notion of most of them may be conveyed, partly by comparison with those two extremes, which must be well known to every one, and, partly, by stating the comparative facility with which such rocks yield to the point of a knife, or of other familiar objects. To give fire with steel, is an inaccurate 
test of hardness ; as it depends in a great mea. sure on the form of the fragments, and, oftem also, occurs in rocks otherwise of very inferior hardness ; arising, in this case, from the intermixture of quartz.

\section{FRANGIBILITY.}

The degree in which different rocks resist the effect of a blow, is infinitely various, and is independent of their hardness. Thus, lydian stone cannot endure the slightest blow without breaking; whereas potstone is difficultly broken by any force. Fortunately no technical phraseology has been invented to express these variations, and they may be rendered intelligible by comparison with known objects, and by the use of common language.

It must be recollected, in making such trials, that the power of a hammer in splitting a rock, or in detaching a fragment, depends more on its impulse than its weight.

It must also be recollected, that the frangibility of rocks varies in proportion to the water 
they may contain; and that, when fresh from the interior of a mass, they are often exceedingly brittle, but become tough after a few days of exposure to the air.

\section{LUSTRE.}

Under this term is necessarily comprised even the absence of all lustre.

The highest degree of lustre found in rocks, is the plumbaginous; which occurs in some argillaceous schists: it is a term easily understood, from the familiar nature of the object of comparison. Where there is an absence of all lustre, as in chalk, the appearance is called dull, or earthy. The intermediate degrees, as far as it is necessary to discriminate them, are not very numerous; although, from passing into each other, they are not very definite. As the technical terms commonly used for this purpose are unintelligible without the examples, it seems more convenient to use the examples themselves in the place of terms, or to use adjective denominations derived from these. The degrees of lustre 
which may be defined in this way, and which seem sufficient for use, are, the plumbaginous, the silky, the resinous, the vitreous, the flinty and the waxy. The four first have been already used by mineralogists, and are easily understood from the very definite character of the well known objects from which they are derived. The lustre of common flint is inferior to that of glass, and is a convenient point of comparison for some rocks. The lustre of wax that has been melted, is still inferior, and occurs in many substances. When broken, it offers another convenient object of comparison. Intermediate, or complicated kinds of lustre, are easily described by the joint use of some of these terms.

It must be recollected, in estimating the lustre of rocks, that it is frequently complicated, or modified by the minute surfaces of the smaller varieties of fracture.

\section{TRANSPARENCY.}

In the strict sense of the word, this property is not found in rocks, although it occurs in some 
minerals. The thin edge of a splinter sometimes transmits light in a slight degree; in which case it is called translucent.

\section{ACTION OF ACIDS.}

The extrication of carbonic acid from rocks, by the action of dilute nitrous or muriatic acid, and the greater or less facility with which it is extricated, sometimes offer convenient methods of discriminating certain varieties of limestone.

\section{SPECIFIC GRAVITY.}

The specific gravity of rocks must be ascertained in the usual manner, and ought to be stated in describing a rock, where the weight is to be mentioned; as vague comparative terms convey no ideas on this subject. This character is, however, of little use in the discrimination of rocks.

\section{COLOUR.}

In concluding this catalogue of the obvious 
characters by which rocks may be distinguished, it is necessary to bestow a few words on that of colour, since it has often been made a ground of distinction. It is, however, generally ah empirical, and, frequently, a fallacious criterion of the nature of a rock. In the case of mixed rocks, it sometimes facilitates the investigation of the different substances which enter into the composition ; but, being subject to vary, it frequently deceives, by its changes or its absence, those who have been accustomed to rely on it. In some instances, it appears to have misled many observers respecting the true nature of a rock, so as to have produced much confusion ; its obvious nature encouraging a careless mode of examination, and taking off the attention from the more obscure, but more essential circumstances, in which the distinction consists. The different substances ranged under the term basalt, and the occasional confounding of the primary and secondary sandstones, in consequence of the red colour of both, will illustrate this latter remark. Gneiss, will illustrate the former; being often confounded with micaceous 


\section{0}

schist, when the felspar is white so as to be mistaken for quartz.

Circumstances which have neither constancy nor precision, can have no value as distinctive characters. The colours of rocks, therefore, must only be considered as adventitious and variable features. But, as constituting a portion of the natural history of these substances, and being often very conspicuous and ornamental, they deserve attention. This is more particularly the case where, as in marble, rocks are used for the purposes of ornament, and where the very species (in an œconomical sense) are constituted by modifications of colour.

Hence, in the following catalogue of rocks, the colours are enumerated among those inferior distinctions which do not aspire even to the rank of varieties. But as language has no terms by which to convey ideas of the innumerable tints by which the pure colours are modified, this enumeration has been made in the most general manner; and, it may be added, with very little anxiety to render it complete. It is 


\section{1}

no small addition to the evils of a cumbrous technology of colouring, that its inefficacy is equal to its deformity.

Except in a few instances, as in the jaspers, the limestones, and serpentine, the colours of rocks are rarely pure, or decided. The effect of brilliancy, where it exists, is more commonly the result of gradation or contrast. Broken tints prevail ; and, among them, the endless modifications of grey are the most abundant.

It is almost unnecessary to remark, that different colours are frequently intermixed in rocks ; that appearance sornetimes occurring in a homogeneous substance; at others, depending on the different tints of several substances variously united into one mass.

In the greater number of rocks, the colours, under all their variations, have been found to result from the presence of iron in different conditions. 


\section{CHAP. X.}

REMARKS ON THE COMPOSITION OF ROCKE, WITH A CATALOGUE OF THE SIMPLE MINERALS OF WHICH THEY ARE COMPOSED.

IT has already been remarked, that the knowledge of minerals in their simple state, is an indispensible requisite in the investigation of rocks. It is also necessary that this knowledge should not be limited to mere experience respecting the aspect of such minerals in their most simple and perfect forms. The student must be able to recognize them by their essential characters, even when under their most irregular modifications ; often, when very minute, or when intermixed and confounded with others, or when obscured by unexperienced variations of colour.

It is trae that the number of minerals entering into the composition of rocks, is so small, that a very limited acquaintance with the cata- 


\section{3}

logue would answer his purposes ; were it possible for him to acquire that accurate knowledge of a few, without a familiarity with those general principles of distinction. which would equally. enable him to master the whole of his subject. To prove the necessity of this knowledge, it is sufficient to point out Augit rock and Hypersthene rock; hitherto confounded with Greenstones, for want of attention to those characters by which the minerals whence they derive their names are distinguished from Hornblende. Even now, when the existence of these rocks has been ascertained, the student has no means of recognizing them except by the distinctive characters of the two minerals in question. In every case of mixed rocks, indeed, he must have recourse to his mineralogical knowledge; as it is only by an enumeration of the ingredients that it is possible to describe them.

Mineralogists have sometimes divided rocks into two great classes; the simple and the compound. According to the geological principles on which the present arrangement is founded, such a distinction is seldom applicable, as already shown, to any purpose but that of denoting 
varieties. Even there, its use is very limited; as, in a very short space, or in a mass of very in considerable extent, the structure may be both simple and compound. It thus becomes incapable of being applied even to the specimens in a cabinet; much less is it fitted to form the basis of an arrangement.

There are however a few rocks, such as limestone, characterized by an absolute simplicity of composition, or consisting of one acknowledged mineral species. Others, like clay slate, present a comparative degree of simplicity; possessing an uniform composition, and having been ranked, although not very properly, among mineral species. The frequent deviations of these from the simple standard, serves to prove that the integrant earths are rather in a state of mixture than in that combination which is probably essential to a mineral species. If Mineralogists have frequently enumerated such rocks in their catalogues of minerals, the practice, though inaccurate, is attended with some convenience; as, in such a case, it is preferable to err by excess than by defect. That enumeration has, however, in some instances, been unwarrant- 
ably extended to rocks obviously compounded, such as bituminous limestone, shale, and chlorite schist. In here enumerating, for the purpose of the following catalogue, the minerals which enter, singly or jointly, into the composition of rocks, these most obviously compounded substances have been omitted; but the list is extended to those which present, at least, the appearance of simplicity.

In the catalogue of varieties which accompanies each principal rock in the Synopses, it has been attempted, as already indicated, to separate those of which the characters are most constant, from those which seem the most purely accidental, and which derive their peculiarities from containing imbedded minerals that are foreign to the prevailing composition of the species. If this distinction cannot be rendered very precise or certain, it is nevertheless convenient ; and, in the far greater number of instances, well founded. In the catalogue of the component minerals which here follows, the different substances are, in the same way, separated into two divisions; the one containing those that 


\section{6}

seem properly to belong to the composition of rocks, and the other comprising those which appear to be merely incidental. Such mineral substances must, in these cases, be considered as being accidentally accumulated in particular places in those rocks which are their natural repositories.

Catalogue of the Minerals which enter into the Composition of Rocks.

\section{INDURATED CLAY.}

This is a substance of great importance in the composition of rocks ; forming the whole of some, and a principal portion of many others. The chief variations which it presents are in the degree of induration, and in the massive or schistose nature of its structure. It is here understood to comprise the softest substances found in the rocks of the trap family, and the hardest, which constitutes jasper and siliceous schist.

\section{CLINKSTONE.}

This substance forms simple rocks, and is 
also an ingredient in some of the compounds of the family of overlying rocks, to which it appears to be limited.

\section{COMPACT FELSPAR.}

This mineral, not always very strongly distinguished from the former, is found in a similar manner ; either simple, or entering into a great number of very important and extensive compound rocks. It probably possesses some variety of composition which has not yet been ascertained. It is further certain that it differs from crystallized, or common felspar, in its chemical nature; the specimens hitherto examined having been found to contain soda together with potash, when common felspar contains potash alone. It is a subject yet deserving the attention of chemists, to enquire whether, instead of these alkalies, lithion may not enter into the composition of some of the minerals in question. Whenever the true nature of compact felspar shall be decidedly ascertained, it would conduce - to perspicuity if it were distinguished by some other title. 
This well known mineral is by far the most important in the composition of rocks ; entering into a greater number than any other, and forming a considerable proportion of most of those in which it is an ingredient.

FELSPAR.

Two varieties of felspar, the common and the glassy, are found in many of the compound rocks; but the former in much greater abundance than the latter. An opaque kind, which sometimes also occurs, appears to have been thus changed by an incipient decomposition.

\section{CARBONAT OF LIME.}

This substance, sometimes pure, but more commonly in a state of intimate mixture with other earths, is so well known as the basis of limestone that it requires no particular notice. It is very rarely found entering, as an ingredient, into mixed rocks.

MICA

Forms an important and conspicuous ingre- 


\section{9}

dient in a large class of compound rocks, chiefly belonging to the primary division.

$$
\text { CHLORITE, (FOLIATED). }
$$

This is less common, and is found under similar circumstances.

\section{TA LC}

Must be considered as a rare ingredient, and is limited to a very few rocks.

\section{HORNBLENDE.}

Hornblende, either simple, or in a state of mixture with other minerals, is among the most conspicuous ingredients of rocks.

\section{ACTINOLITE:}

This mineral, so nearly allied to the preceding, is found in some of the same situations, but must be considered as a rare ingredient.

AUGIT. HYPERSTHENE. DIALLAGE. TOURMALIN.

These minerals are limited to some peculiar rocks, and the three latter, in particular, must be. considered rare. 
SERPENTINE:

Mineralogical writers have enumerated this in their catalogues of minerals, but it is only known as forming simple masses of rock. It does not enter into mixed rocks unless with limestone: supposing the conglomerates to be excluded from this term.

\section{STEATITE}

Is not a common ingredient, and is nearly limited to serpentine and limestone. In granite it rather seems accidental than essential.

\section{NOBLE SERPENTINE}

Occurs in similar situations with the former; to which it is very nearly allied.

\section{GYPSUM.}

This is found only in Gypsum, which has been here enumerated among the rocks.

\section{IRON,}

This metal deserves to be enumerated among the constituents of rocks, on account of the quantity in which it sometimes enters into their com- 
position, and the effects which it produces in modifying their characters. It appears to exist in at least four distinct assignable states, that of the peroxide, the protoxide, the carbonat, and that combination of the carbonat with water which forms rust.

\section{BITUMEN.}

This must also be considered as a constituent of some rocks, from the remarkable character which it communicates where it is found.

\section{PITChStone}

Is only found in the rocks of the same name.

\section{CHERT.}

This also occurs only in the rock which is here designated by the same term. The Hornstone of many authors is compact felspar. 
Catalogue of the minerals which are occasionally imbedded in rocks, so as sometimes to modify the characters of the mixtures in which they are found.

Garnet.

Olivin.

Cyanite.

-- Pinite.

Spodumene.

Chiastolite.

- Staurotide.

Epidote.

Mesotype.

Zircon.

Topaz.

- Beryl.
Chrysoberyl.

Fluor spar.

Corundum.

Oxydulous iron.

Pyrites.

Chromat of Iron.

Prehnite.

Andalusite.

Apatite.

Sphene.

Oxyde of Tin.

Molybdena.

In this list, and in each division, the minerals placed towards the end, become gradually so rare, that they can scarcely be said to modify the aspect of the rocks, as those do which are found at the beginning. Besides these, many other minerals also, are found in rocks ; generally very sparingly dispersed, and sometimes occupying short veins rather than imbedded in the general composition. It appeared preferable to enumerate these under 
the titles of the several rocks which are their natural repositories ; as this catalogue might otherwise have been so extended as to comprise the greater number of mineral substances. Those also which form amygdaloidal nodules, will be found more conveniently enumerated in their appropriate places. 
ENUMERATION OF THE SEVERAL ROCKS, AKRANGED UNDER THE DIFFERENT MINERALS WHICH ENTER INTO THEIR COMPOSITION.

IN this chapter, the several minerals enumerated in the preceding, as essential to the composition of rocks, are introduced, for the purpose of arranging under them all the rocks in which such minerals are severally found.

This enumeration will assist the student in discovering the place of any rock of which the name is unknown to him. It being already presumed that he is able to distinguish the component minerals, his researches among the families of rocks will thus be limited within certain bounds; as, the presence of any one simple substance in a specimen, will direct him to those in which alone it exists. 


\section{INDURATED CLAY.}

In Claystones : not schistose. Some Porphyry and Amygdaloid.

Basalt (of some): when dark and hard.
Argillaceous schists. Shales.

Limestones : in both classes.

\section{CLINKSTONE.}

As a simple rock: also porphyritic and amygdaloidal.

\section{COMPACT FELSPAR.}

Simple, both in the primary and secondary classes.

In Gneiss.

Porphyries.

Amygdaloids.

Syenites.
In Greenstones. Augit rock. Hypersthene rock. Granite: rarely.

\section{QUARTZ.}

In Quartz rock.

Granite.

Gneiss.

Micaceous schist.

Chlorite schist.

Talcose schist.
In Argillaceous schist. Sandstones, in both classes.

Porphyries. Syenites and Greenstones : rarely.

FELSPAR.

In Granite.

Gneiss.

Chlorite schist.
In Hornblende schist. Actinolite schist. Quartz rock. 
In Primary sandstone. In Syenites.

Lowest (red) sandstone: Porphyries. rarely.

Greenstones.

\section{CARBONAT OF LIME.}

In Limestones: in both In Sandstones: in both classes.

Micaceous schist and gneiss : rarely. classes. Amygdaloids : imbedded.

\section{MICA.}

In Granite.

Gneiss.

Micaceous schist.

Quartz rock.

Sandstones :

occasionally.
In Limestone, primary ; rarely.

Claystones and Greenstones : rarely. Syenite : rarely. Porphyries.

Shale: occasionally.

\section{CHLORITE (FOLIATED.)}

In the Chlorite schists.

Gneiss; some anomalous varieties.

Granite: in the same circumstances.
In some actinolite schists.

In some argillaceous schists.

\section{TALC.}

In Talcose schist.

Primary limestone : rarely.
In Serpentine.

Granite: rarely. 
HORNBLENDE.

In Granite.

Gneiss.

Hornblende schist.

Micaceous schist; rarely. .

Argillaceous schist; rarely.

Primary Limestone ; rarely.
In Serpentine; rarely.

Syenite.

Greenstone.

Basalt.

Porphyries.

Chlorite and actinolite schists; some varieties.

\section{ACTINOLITE.}

In Actinolite schist. In Gneiss and granite : rarely.-

\section{AUGIT.}

In Augit rock.

Some varieties of Syenite.

HYPERSTHENE.

In Hypersthene rock.

DIALLAGE.

In Serpentine. In Diallage rock and Smaragdite rock-

TOURMALIN : AND SCHORL.

In Schorl rock (Granite?) In Micaceous schist and Gneiss : rarely.

SERPENTINE: COMMON AND NOBLE.

In Serpentine.

In some limestones. 
STEATITE.

In Serpentine.

In Limestone.

Granite : rarely.

\section{BITUMEN.}

In Shale.

Limestone: primary and secondary.

In Marle slate.

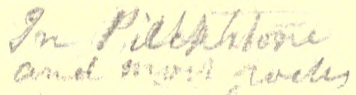

PITCHSTONE.

In Pitchstone; pearlstone; porphyritic pitchstone. CHERT.

In Chert : only.

It is obvious, that as the conglomerates partake of the different natures of the rocks of which they are formed, their constituent parts must be separately investigated. 


\section{CHAP. XIl.}

REMARKS ON THE, ASSOCIATIONS AND TRANSITIONS WHICH OCCUR IN NATURE BETWEEN SEVERAL DIFFERENT SPECIES, OR FAMILIES, OF ROCKS.

BEFone proceeding to describe the general characters of the families of rocks, which is the subject of the ensuing chapter, it is necessary to call the reader's attention to a circumstance which is a frequent source of uncertainty in attempting to assign the names to the individuals, or varieties, ranked under them. It has equally been a source of difficulty in arranging these in the several synopses, and has led to the inevitable repetition of many of them under different titles.

The circumstance in question, is the transition, which, in the mixed or compound rocks, in particular, so often occurs, not only between the several varieties of each family, but even between the families themselves; in consequence 
of the gradual variation of character, or else of the ultimate loss of one, or more, of the ingredients which constitute the distinction. The instance of gneiss, which, in losing its felspar, becomes micaceous schist, and of shale, which, by an increase of its hardness, becomes siliceous schist, will explain the nature of these transitions among the families of rocks.

Where the transition is thus completed, as in these two instances, there is no longer any difficulty; as the specimen can be referred to its proper place. But, in the gradual change of character which precedes the perfect transition, it becomes often impossible to determine where such a rock should be placed; unless when decided geological evidence can be obtained, to confirm that which remained doubtful from its mineral characters.

This difficulty, however, is a part of the very nature of the subject; since no arrangement can pretend to define and separate those objects which the hand of nature has neither defined nor separated. 
As these transitions thus constitute an important part of the natural history of rocks, and, more especially, of that branch of geologicalscience to which the remarks in this work are limited, it will be useful to place in a brief and comprehensive statement, the several rocks among which they are most frequent, although these circumstances are necessarily noticed in the preliminary remarks to each family. The learner will thus the more readily know where he may expect to find these uncertainties, and cease to suspect his own want of accuracy and discernment, where neither care nor acuteness can avail him.

It will also be found, that this gradation of character among the families of rocks, occurs, especially, in those cases where a prevailing association, either of sequence or of alternation, exists among certain kinds, whether of stratified or unstratified substances.

For this reason, it is also proper to give a general view of these prevailing associations : a view otherwise necessary, as these affinities also, constitute an interesting part of the natural his- 
tory of rocks. That sketch must, however, be brief; as an attempt to make it full, would encroach on that which is the more especial province of a system of geology, and is partly rendered unnecessary by the remarks which precede the Synopsis of each family.

Granite, as remarked in another place, is found in contact with all the primary strata; and, in some of these cases, a gradation of character is to be seen at the place of junction.

In the instance of gneiss, so accurately resembling that rock in composition, this gradation is perfect; and thus, the strata of gneiss are often, when in contact with granite, not to be distinguished from it.

Where granite is in contact with micaceous schist, this substance also often loses its character for a short space, by the acquisition of felspar : but as the resulting compound is gneiss, the transition, in this case, takes place through the medium of that rock. In this instance; Geologists have often imagined the whole series to consist of 


\section{3}

gneiss, when a more accurate examination would have discovered its true nature.

In the contact of granite with quartz rock, the latter sometimes assumes a highly crystalline aspect; and where the quartz rock contains felspar, it thus becomes impossible to distinguish the two, or a perfect gradation of character is found.

When granite is immediately followed by hornblende schist, it happens, in the same manner, that the character of the latter becomes more decidedly granitic: it may more properly, indeed, be said to become gneiss; and, as the granite, in these cases, always contains hornblende, the same transition takes place here as in the contact of granite with other varieties of gneiss.

The differences in the characters of granite and argillaceous schist are so great, that no real transition can exist between them. Yet, where they have been found in contact, it has been observed that the schist was intermingled both with quartz and with felspar, so as to lose its peculiar character and pass into a variety of gneiss enumerated in the synopsis of that rock. 


\section{4}

It is unnecessary to describe the transitions of granite into the porphyries, greenstones, and basalts of the secondary unstratified rocks; as these are the consequences of affinity, not of contact, and are fully detailed elsewhere.

Among the stratified rocks, one of the most prevailing associations is that of gneiss with hornblende schist. Between these two substances, the gradation is so frequent, and often so perfect, that numerous examples are perpetually occurring, which may, with equal propriety, be re. ferred to either.

The association of gneiss with micaceous schist is also very common; and in this case, when the felspar, or the hornblende, of the former, becomes very scanty, the rock, although, in a rigid sense, still appertaining to gneiss, cannot, without great care, be distinguished from micaceous schist.

In Scotland, at least, the association of gneiss and quartz rock is more common than the preceding; and the gradation here, is not only fre- 


\section{5}

quent and perfect, but is effected with great facility by the loss, either of the mica, or of the felspar, or of both.

Of a gradation between gneiss and primary sandstone, the island of Sky affords a very perfect example: and it is a highly interesting instance, as the latter is, in a great degree, a rock of a decidedly mechanical structure. The process by which the change is effected, is the gradual substitution, first of chlorite schist, and ultimately of mica, for the argillaceous schist which alternates with the layers of sandstone; which, at the same time, become gradually thinner, more indefinite, and more perfectly cystalline, The two rocks are, in other places, often associated in frequent alternation.

The gradation above-mentioned, includes that of gneiss into chlorite schist; which also occurs in other situations, producing intermediate varieties that are enumerated in their proper places.

A gradation between gneiss and argillaceous schist, is not uncommon in Scotland; and, as might be expected, this change takes place where 
the two rocks are found, as is not uncommon, in alternation. The variety of gneiss thus produced, is described in its proper place.

Independently of the association which micaceous schist forms with gneiss, it is intermixed with, and passes, by similarly easy gradations, into the following rocks.

With quartz rock it is so frequently associated, and in beds so thin, that the two cannot be distinguished in the general descriptions of a tract of country. As the ingredients of one of the leading varieties of quartz rock, are the same as those which constitute the essential character of micaceous schist, it requires only a change of proportion to convert the former into the latter, or the reverse; and that change is of such frequent occurrence, as to produce endless examples where neither term is more applicable than the other.

Where talcose schist occurs in union with micaceous schist, as it sometimes does, there is frequently an indefinite transition between the two; the mica, either superseding the talc in the 
compound, or else the one mineral passing into the other.

The passage from micaceous schist to chlorite schist is effected with equal facility; as the constituent minerals of both are so nearly allied : and that passage is no less common than is the association between these two rocks.

It is more rare to observe transitions between micaceous and argillaceous schists. Yet they occur in several parts of Scotland, both between the fine and the coarse varieties, respectively, of each rock. But the association in position between the two, is much more frequent than the transition; as it is most usual for them to be separated by a definite bourdary.

Instances of a decided transition between micaceous schist and hornblende sehist, are rare, when compared to those that have been described above. They occur in those cases where micaceous schist is found to contain hornblende; and the two rocks are not unfrequently united in alternation, without any absolute transition. 
Besides the common association of quartz rock above mentioned, it is frequently found alternating with the primary sandstone. The facility with which two rocks, so nearly allied, may pass into each other, is such as to render it almost superfluous to say that the transition is of frequent occurrence.

Although quartz rock is, in many of the Scottish isles, found alternating with argillaceous schist, the differences of character are so great, that a transition could scarcely be expected. Yet it takes place with great facility through the intervention of the coarser varieties of both rocks. The former first acquires fragments of schist, or else the quartz becomes intermixed with schistose clay, which, gradually predominating, that mineral is at length excluded. A minutely laminar intermixture of the two is also occasionally found. of such a nature as to constitute an imperfect transition. 
Hornblende schist, independently of its transitions formerly noticed, is also found, in some situations, to pass into clay slate, or fine argillaceous schist; although I have not observed any instance of a decided alternation or association of distinct beds of those two rocks. In this case, the change from the hornblende into the schistose clay of slate, seems to be effected very gradually, and with great facility. An example of this nature occurs in Rossshire. As a converse to this case, it may also be stated, that argillaceous schist. sometimes becomes partially, but gradually also, converted into hornblende schist when in the vicinity of granite or of the trap rocks.

In some of the Western Isles of Scotland, there is an alternation between chlorite schist and hornblende schist, of a very remarkable nature, and accompanied, also, by other strata, such as quartz rock and micaceous schist. In some parts of this series, there is an imperfect gradation between the two former rocks ; produced by an intermixture of hornblende in the chlorite schist, at length predominating so far as to exclude it. 


\section{0}

With respect to the argillaceous schists, it is only necessary to mention two more of the associations and transitions which they display. The finer kinds sometimes pass into chlorite sehist where they occur in company with that rock. The coarser often alternate with the primary sandstone; and they pass into it by a gradual increase of the quartz, and a loss of the clay, in their composition.

The last transitions in the primary class that remain to be noticed, are those of serpentine. This rock is occasionally associated with hornblende schist, in which case it sometimes passes into that rock by an imperceptible gradation. It seems also, in some rare instances, to pass into the basalt or greenstone of the overlying family ; a transition which, perhaps, would have been more properly described in the secondary class.

The very limited number of the rocks that belong to the secondary class, leaves but little to say on the subject of the transitions which occur among them. 
In the stratified rocks; as the sandstones, both red, and white, are found alternating with the shales, so they pass into them by gradations similar to those which occur between the primary sandstone and the argillaceous schist which so often accompanies that rock.

In the same way, the beds of secondary limestone that are interstratified with shales, sometimes become so overcharged with argillaceous and siliceous earths, as to produce impure eompounds scarcely differing from the accompanying shales that are in a similar manner intermixed with calcareous matter.

The transitions which are to be observed among the multifarious unstratified rocks of this class, do not require notice here: they must be considered as variations of structure and composition in a single family, throughout which a complete system of gradation exists in every part.

These associations and transitions which are often very remarkable among some of the most important and extensive varieties of the secondary strata, are not subjects for notice in this place. They belong to geological systems, or to 


\section{2}

topographic geology, and not to the proper history of mere rocks, which is alone the subject of the present enquiry.

There is not much to remark respecting the occasional rocks. As the jaspers appear to be derived from claystones, or from common clay, or from argillaceous sandstones, the siliceous schists from argillaceous schist and shale, and the cherts from limestone and from calcareous sandstones, it is easy to comprehend how, from the peculiar circumstances of their origin, they must necessarily graduate into the various rocks to which they owe their origin. 


\section{CHAP. XIII.}

SYNOPTICAL VIEW OF THE GENERAL CHARACTERS OF THE FAMILIES OF ROCKS CONTAINED IN THE PRESENT ARRANGEMENT.

IT has already been remarked, that, according to the geological arrangement here adopted, where many distinct mineral compounds must sometimes be arranged under one general title, nó condensed descriptions or definitions of the families can be given. Such descriptions can only be expected in the catalogue of varieties; the characters of the family being, in fact, contained in the preliminary remarks by which each of these is preceded.

But as, in some cases, a certain general mineralogical character will be found to pervade the whole family, it has been judged expedient to bring these into one condensed view, as far as was practicable, adding to them an abstract of such 
other circumstances as were admissible in a view so brief. As the object of this sketch is to facilitate the researches of the student respecting the name or place of a specimen, I have been little scrupulous about the nature of the characters selected, provided they conduced to the main end, utility. Mineral and geological characters, negative distinctions, and empirical marks, are therefore indiscriminately used; that, in consulting this abstract, the reader may be enabled, in some degree, to limit his search through the several Synopses among which his specimen will somewhere be found more accurately described. Towards accomplishing this object, additional assistance is afforded by the arrangement in the eleventh chapter. No expedient ought to be despised if it serves to diminish the labour and remove the doubts by which a beginner is so often disgusted in the commencement of his career. If it has been sometimes found necessary to repeat these general characters in the preliminary remarks to the different synopses, the present collective view of them was not the less requisite. 


\section{5.}

\section{PRIMARY CLASS.}

\section{GRANITE.}

Turs rock necessarily contains two or more of the following minerals, quartz, felspar, mica, and hormblende, but does not exclude others. These are aggregated by a confused crystallization; and, by the marks of mutual interference thence resulting, this rock is to be distinguished from coarse sandstones, or conglomerates, composed of similar ingredients ; some indications of previous attrition and mechanical agglutination being visible in these.

Some varieties of granite may be confounded with other substances in the secondary family of overlying rocks; and, in such a case, the geological position must be resorted to ; the rocks appertaining to granite being inferior to every rock which they accompany, (when in the mass,) and the others being superior, if not precisely at the point examined, yet in some part of their position

\section{SERPENTINE.}

It is seldom difficult to recognize this rock. 


\section{6}

The variety of lively or peculiar colours which it presents, generally affords a good empirical character. It is commonly simple; with an uniform fracture, imperfectly conchoidal and splintery; but some varieties have an indistinct granular fracture, and others are even formed of small lamellar concretions. The broken surface is almost always dull and earthy; but it frequently contains natural irregular joints, with polished surfaces having an unctuous aspect and feel. The hardness is so various as to afford no distinction; as it sometimes resists the knife, when, at others, it can be scratched with great ease. The frequent presence of steatite, asbestos, and talc, forms an empirical mark which may also be of use to beginners. Moreover, it is not stratified.

\section{GNEISS.}

Is composed principally of the same ingredients as granite, under the same license; but there are some varieties in which clay slate, and chlorite slate form constituent parts. It is distinguished from granite by a parallel position which pervades the mica, most generally; or the 
hornblende, where that is not present; or in any case, by a foliated appearance which is often attended by a greater or less degree of fissility. It may pass into granite, or into other rocks, as formerly remarked, and thus becomes undefinable.

\section{MICACEOUS SCHIST.}

In this rock, mica and quartz form the essential ingredients, but the presence of garnets or other occasional minerals is not excluded. The mica is invariably parallel, at least to the plane of the bed, as in gneiss ; whether that be straight or curved, or else to the planes of the contorsions, where these exist; and the rock is similarly foliated, and occasionally schistose. The varieties of gneiss which might be confounded with it, may be distinguished by the presence of felspar, which is essential to that rock; and when this mineral is difficult to distinguish in the fracture, it may be recognized by the white powdery appearance of the weathered surfaces. According to this description, micaceous schist might also be confounded with some varieties of schistose sandstone, of the secondary class; but the loose 


\section{8}

arenaceous texture of the quartzose lamina in this, generally presents a perfect distinction, independentiy of the geological position. As micaceous schist often passes into quartz rock, it is particularly indefinite with regard to that substance. The other cases in which it may lose its distinct characters will be found in the twelfth chapter.

\section{CHLORITE SCHIST.}

The presence of chlorite, or, to a beginner, the green colour of that which would otherwise pass for mica, is sufficient to distinguish this rock, which, however, passes by an apparently indefinite transition, into micaceous schist, and into other rocks, as already noticed.

TALCOSE SCHIST.

This, rare rock, is also distinguishable by the known properties of the mineral whence it derives its name. Like the former, its analogy to micaceous schist in the other general characters, is perfect. 
HORNBLENDE SCHIST.

In this very common rock, hornblende alone, or hornblende and felspar, form the necessary ingredients. The structure is not always, or necessarily, schistose; and it cannot be confounded with any other substance, excepting as it presents the transitions into gneiss, formerly described.

\section{ACTINOLITE SCHIST}

Is in every respect similar to the former in structure; but it is rare, and is readily distinguished from that ; as far, at least, as the essential mineral is distinguishable from hornblende.

\section{QUARTZ ROCK.}

This consists, either of pure quartz, compact, or imperfectly granular; or it is a compact granular compound of quartz and felspar, or of quartz and mica, subject to other accidents which must be sought in the table of varieties. The obviously re-united structure even of the most compact kinds, together with the marks of stratification, prevent the compounds of quartz and 
felspar from being confounded with granite, except, perhaps, at the points of junction with that rock. From certain varieties of micaceous schist, it can only be distinguished by the predominance of the quartz; the limits of the two, as already remarked, being evanescent. If, when loose in texture, it is in danger of being confounded with secondary sandstone, recourse must be had to the geological connections.

$$
\text { PRIMARY (RED) SANDSTONE. }
$$

All the varieties of this rock are not red, although that is a prevailing character. It is most generally a granular aggregate of quartz, or of quartz and red clay, or of quartz and felspar : it may also contain fragments of quartz, or of certain rocks. Its chief distinction from the red sandstone of the secondary class, consists in its superior compactness, and in the prevailing intermixture of a continuous crystalline with the reunited, or arenaceous, structure. It will, however, always be necessary for the student to have recourse to the geological position. It cannot be confounded with granite, if as in the case of 
quartz rock, attention be paid to the structure. Into this latter rock it passes not unfrequently, as already remarked; into gneiss, very rarely; and thus its characters may become doubtful.

ARGILLACEOUS SCHIST.

All the varieties of this rock, however dissimilar they may appear in a general view, agree in containing stony, or indurated clay, either alone, or as the cement of sand, or of fragments of various kinds. Most of the varieties are more or less perfectly schistose in the structure. If, according to this description, it is ever in danger of being confounded with the claystones of the overlying family, and there is no schistose structure present by which to distinguish it, recourse must be had, either to the stratified disposition, or to the geological connections.

It may, in some cases, be confounded with the harder shales of the secondary class; and, against this, there is no remedy but an examination of the geological position. 
LIMESTONE (PRIMARY).

A general, and, commonly, an active effervescence on the application of dilute nitrous or muriatic acids, is the well known test of limestone; but the student must recollect, that the very compact, or impure, varieties, do not always effervesce freely unless they are powdered or bruised. It may often be necessary to have recourse to the geological position to distinguish the primary from the secondary limestones; but those varieties which contain mica, hornblende, or other minerals intermixed, may with safety be referred to the primary class.

\section{COMPACT FELSPAR.}

This rock is simple, and of various colours, green, brown red, pale grey, white, dark grey, purple brown, black. The fracture is compact, uniting the small splintery with the flat, or imperfectly conchoidal. It is less hard than quartz, but resists ordinary steel. It generally possesses a peculiar aspect on the surface, resembling that of wax, which is highly characteristic; and, it 
may assist a beginner to say, that, except in hardness and in refusing to effervesce with acids, it very strongly resembles in external characters many of the compact and smooth varieties of limestone.

\section{SECONDARY CLASS.}

\section{LOWEST (RED) SANDSTONE.}

THIs is generally, but not necessarily, red of various hues; being often grey, seldom white. It consists, when most simple, of sand and red or grey, clay, seldom very firmly united, and except in a very few rare cases, never possessing that general crystalline compactness which is often so remarkable in the primary rock of the same name. In addition to those two, almost essential, ingredients, it may contain the sand of felspar, or mica, or carbonat of lime, or the whole of these; as also, fragments of any rock of the primary class, and of any size; when it becomes a conglomerate. As it is so important, in a geological view, to distinguish it from the primary sand- 


\section{4}

stone, the position must be consulted where the internal characters are not satisfactory.

Some of the red varieties may be confounded with some varieties of the superior sandstones, such as the red marle of England; and, in the same manner, the white varieties may be mistaken for others belonging to the upper sandstones. As important geological considerations may often depend on the solution of such doubts, it becomes necessary to examine the geological relations, whenever they may arise.

SUPERIOR SANDSTONES.

These consist of quartz sand alone, or of that sand with carbonat of lime, or with clay of various colours; more rarely, with mica. The far predominant varieties are white, or, at least, pale. The circumstances under which they may appear doubtful, have been already noticed.

\section{LIMESTONE.}

Effervescence, as in the case of the primary limestones, distinguishes these from other rocks ; but it must be recollected that the magnesian 
and argillaceous varieties effervesce with difficulty. Almost all those which contain organic remains, may safely be classed with the secondary rocks ; as may the highly argillaceous; but as some interesting cases occur in which those of the primary and secondary class cannot be distinguished by their mineral characters, it is necessary to have recourse to their geological positions. In how far some of those which contain organic remains, and which have been called transition limestones, may belong to the primary class, is not yet determined.

SHALE.

The shales consist of schistose indurated clay, commonly grey, or blackish ; occasionally, of other and brighter colours. In general, they may be distinguished from the argillaceous schists, by their comparative fragility and want of the continuous schistose structure. But, as formerly remarked, cases also occur, where the characters of the two so nearly resemble each other, that these cannot be satisfactorily determined without consulting their geological positions. 
OVERLYING ROCKS:

So many substancés, of external characters and compositions so different, are included in this family, that it is necessary to separate them into divisions before attempting to enumerate the general characters by which a student may be induced to search for his specimen among them. They may, for this purpose, be conveniently divided into the simple, the granitic, the porphyritic, and the amygdaloidal.

The simple rocks of this family, consist either of compact felspar, clinkstone, or indurated clay.

The characters of compact felspar have already been described, and as this substance occurs both in the primary and secondary class, although under slight differences of aspect, it is evident that these can only be distinguished by their respective geological positions.

The characters of clinkstone are the following. It is a simple rock, massive, but occasion- 
ally exfoliating, on the exposed surfaces, in irregular laminæ. The fracture is even, or imperfectly conchoidal, and splintery also. When long exposed to the weather, it assumes a granular appearance. It has not the waxy aspect of compact felspar; which however it much resembles, and into which it appears to pass by an undefinable transition. On the other hand, it becomes more earthy, and passes into claystone. Under these different circumstances, it yields with more or less difficulty to the knife. It is not necessarily or exclusively sonorous, as its name would imply. That property is possessed by many other rocks in a much higher degree, and very often depends more on the form than the material. The colours are very various.

The indurated clays are of different degrees of hardness, and vary in colour, from nearly white to black. They might, according to the name, be confounded with some of the argillaceous schists ; but they are almost always distinguishable by breaking with the same facility, 
and in the same manner, in all directions. In certain cases, it is true, they are actually schistose; or rather, laminar; but the laminæ are, in this case, produced by the progress of disintegration, and that structure does not, as in the argillaceous schists, pervade the whole stone. However difficult to describe the peculiar aspect by which they may be recognized, so as to satisfy the student who has never seen them; when once known, they can never be confounded again with any other rock.

The same remarks may be made on basalt, some of the varieties of which may also be known by consisting, or appearing to consist, of hornblende in a much more minutely granular and compact state than it ever occurs in hornblende schist.

The granitic division offers peculiar difficulties ; as it is in this, that the frequent resemblances to some of the varieties of granite occur.

In the first place, all those which contain either augit or hypersthene, may be safely referred to this family. So may those which con- 


\section{9}

tain compact felspar as a conspicuous or leading ingredient; and this substance seldom occurs, except in very minute proportions, and as an occasional constituent, in the granites. A large proportion of the more equal mixtures of hornblende with felspar, both common and compact, belongs to this division; but as similar mixtures are also found among the granites, they are not necessarily and exclusively members of this family. Even the finer compounds, forming one of the varieties of basalt, are found accompanying granite. The student, in these cases of doubt, must unavoidably have recourse to the geological position; and this last example, in particular, offers one of the strongest which geology affords, of the hazard of determining the geological characters of these rocks from their mineral structure or composition.

The porphyritic and the amygdaloidal rocks are recognized by the peculiar structures already described in the chapter on that subject; and may always safely be referred to this family, as they occur in no other department of nature. 


\section{PITCHSTONE.}

This rock is either simple, or porphyritic, or spheroidal concretionary, (as in pearlstone); but, in every case, it may be recognized by its smooth glossy fracture when simple, or by that of the base when it is compounded. The lustre is more properly like that of broken pitch than glass, and it could only be confounded with obsidian; a mineral strictly volcanic, and otherwise distinguishable by its almost absolute identity with the glasses formed in metallurgic operations, and by other characters to be found in systems of mineralogy.

\section{OCCASIONAL ROCKS.}

\section{JASPER.}

The brilliant or varied colours of this rock, either mixed or simple, form its most ostensible and convenient distinction. These are, however, chiefly reds, of various hues, and yellows. The lustre is sometimes equal to that of pitch ; in 
which case it has been confounded with pitchstones ; at others; it is dull and earthy. It is commonly very brittle, and scarcely less hard than quartz. The fracture is generally flat, or conchoidal, where the lustre is considerable: more or less granular, or splintery, when dull. It is a simple rock.

\section{SILICEOUS SCHIST.}

This rock varies materially in aspect and in hardness, as might be expected from its origin. When least hard, it is scarcely distinguishable by the eye from the schists whence it is derived; even in this case, however, the power of resisting the knife is a sufficient test. The structure is simple and uniform, the fracture more or less perfectly conchoidal, and also splintery. The lustre sometimes approaches to that of pitch; but, at the other extreme, the aspect is earthy. The colours vary considerably; as it is found of a reddish brown, dark purple, yellowish brown, and greenish, but the tints of grey, and black, are the most frequent. It is often striped with different colours. 
CHERT.

The cherts of this arrangement must be expected to differ materially in aspect, when their nature is considered; as the rocks to which they owe their origin, not only vary in composition, but, may have undergone various degrees of induration. In general, however, all the varieties agree in being simple, in breaking difficultly, yet suddenly, with a fracture more or less conchoidal, and, according to circumstances, either granular or splintery, in forming acute cutting fragments, in resisting steel, and refusing to effervesce with acids. By this latter character they differ from the limestones which they so often resemble, and from which they are derived. The colours are grey of various hues.

\section{GYPSUM.}

As a rock, this substance could only be confounded, by the student, with granular or primary limestones; and it is readily distinguished from these by not effervescing with acids, by its comparative softness, and by the facility with which it loses its water on exposure to heat. 


\section{3}

CONGLOMERATE ROCKS.

The name of these renders any description of their characters unnecessary; and, for the distinction of the varieties, the reader must have recourse to the Synopsis.

\section{VEIN STONES.}

These also require no observations; since, being attached in some way to the rocks in which they lie, or depending for their essential distinctions on their geological position, they are necessarily recognized. Like the conglomerate rocks, they are formed of distinct portions of different substances.

\section{APPENDIX 1st and 2d.}

\section{VOLCANIC ROCKS.}

The resemblance of many of these to the overlying rocks, renders it also necessary to be acquainted with their geological situations. These, in fact, are always known, from the circumstances 


\section{4}

under which the specimens are collected. To describe their general mineral characters would be little else than to repeat the remarks on the overlying rocks, which have preceded.

\section{CLAY, SAND, MARLE.}

Marle is recognized by its effervescence; sometimes by containing fragments of shells. It would be trifling to describe the characters of substances so familiar as clay and sand.

The same remarks may be made on coal, alluvia, and peat; substances, of which the characters are as familiar as the names. 
PRELIMINARY REMARKS ON THE NATURE AND CHARACTERS OF THE PRIMARY CLASS.

In the name of this class, is implied the essential character on which it is founded. The rocks that are included in it, are so arranged, from an opinion that they were formed previously to the deposition of those which are ranked in the secondary class. That opinion is founded on the fact, that wherever the rocks of the latter division occur in company with the former, they are always superior in geological position; and that, in no case, a member of the primary class is found intruding among those of the secondary.

If, in all instances where rocks occur in nature, both classes were to be found together, or a regular sequence could be inferred by the comparison of positions, there would exist no difficulty in distinguishing the two, in every case, by their geological situations; it being here pre- sumed that their common line of separation is 
known. But, in many places, large tracts of one, or of the other class, are found separately; in others, detached portions of the secondary are found connected with extensive tracts of the primary, or insulated masses of the latter are found among the former; the relative positions of the two being further, in each case, such, as either to afford no evidence respecting the superiority of the one or the inferiority of the other, or, sometimes, even indicating a relation which is discovered, by an extensive set of analogies or comparisons, to be false. It is, moreover, often necessary to decide on the class to which a single specimen should be referred, when detached from its native connexions. The single character of relative inferiority, is not therefore sufficient to form a practical distinction for the primary class ; although it is the essential one, and that on which the class itself is founded.

There is another character, however, by which it has been supposed that the primary was distinguishable from the secondary class of rocks ; and on which, indeed, too much stress has frequently been laid, as if it formed an essential dis- 
tinction. This is, the comparatively erect position of the strata. But, in many instances, the primary strata occupy very low angles, and even assume the horizontal position; while the secondary, are frequently found elevated to angles of considerable inclination. Even were this distinction much more complete, it would not be of universal application ; since, in each class, there is a large division of rocks that are not disposed in strata.

The next circumstance in which the rocks of the primary class differ from those of the secondary, is their nature, or mineral character.

Many rocks, readily distinguishable by their peculiarity of aspect, occur in the primary class, but are not found in the secondary; although the rocks of both classes are often composed of the same mineral substances. Others are so distinct, even in their mineral composition, as to have no resemblances in the secondary class. Such rocks, even in detached specimens, indicate, without the necessity of geological investigation, that division in nature to which they belong. Without considerable experience, however, it is rarely safe 
to draw such conclusions respecting the first of these; as the peculiarities by which they are characterized, although distinguishable by a practised eye, can scarcely be described in words with sufficient accuracy to convey a definite idea of their differences.

There are, further, some rocks in the primary class, so nearly resembling others in the secondary, that, in some specimens, no difference whatever can be detected; while, in the remainder, the distinctions are so slight as scarcely to be perceived, except by long and habitual intercourse with all their modifications. In these cases, the mineral character serves no purpose in ascertaining the class to which a rock belongs; and recourse must then be had to the other characters, which ccmprise its geological connections. Where these are obscure, or difficult of access, a rock may thus, for a long time, remain doubtful, as far as relates to its relative antiquity ; or erroneous conclusions may be drawn, to be rectified only by careful subsequent investigations, or by a fortuitous concurrence of circumstances.

Lastly, the absence of organic remains has 
been sometimes made a ground of distinction for the primary class. In a practical view, this character would be of no use in discriminating individual rocks, were it even constant in that class ; as, among the secondary strata, such remains are but of partial occurrence. But it entirely ceases to be a distinction, unless that expedient of a transition class, which has here been rejected, is adopted. As the reasons for rejecting this class have been given elsewhere, no further remarks on this character, as distinguishing the primary from the secondary rocks, are required.

It must therefore be concluded, that there is no single character by which the primary class can in all cases be distinguished. The proofs of that essential circumstance, inferiority, on which it is founded, being sometimes inaccessible, recourse must then be had to one or more of the remaining characters; and, although there are cases where the distinction may call for all the industry and acuteness of a geologist, his endeavours will rarely be disappointed. It is only by such exertions that he can hope to improve an 
imperfect science, and to extend the boundaries of our knowledge.

It therefore follows from the preceding remarks, that in every distribution of rocks founded on the present, or on any geological arrangement, the same mineral compound will occasionally be repeated in both divisions. Whatever confusion or inconvenience may be supposed to flow from this, it is evident that the circumstance is in itself highly interesting, as forming part of the natural history of rocks, and that it is an important fact in geology. It is one of those occurrences which prove that, in a practical view, much greater inconvenience would follow from an arrangement founded on mineral characters alone; as it would confound together substances which it is most important to distinguish. In consequence of this occasional resemblance, or identity, between certain members of the primary, and others of the secondary class, it will assist the student to enumerate those rocks appertaining to the former which have no resemblances in the latter; and to point out those 


\section{1}

which are more or less difficult to distinguish without referring to their order in geological position.

Among the unstratified rocks of the primary class, granite, when composed of quartz, mica, and felspar, is always to be distinguished, as no corresponding rock has yet been found in the unstratified members of the secondary division. But where granite contains hornblende, there is sometimes ground for doubt; as similar compounds occur with the syenite of the overlying family.

In a similar manner, rocks compounded of hornblende and felspar, which prevail among the members of the latter division, are sometimes found associated with granite, and therefore necessarily to be ranked in the primary class; however differing in their mineral characters from the prevailing rocks known by this general term. These cases are however rare, and will seldom produce much practical inconvenience; as they will chiefly excite the attention of those geologists whose experience will enable them to assign their true geological situations, and whose 


\section{2}

object it is to investigate those circumstances, rather than to collect specimens for a cabinet. As in all the other instances of this species of uncertainty, these rocks are noticed in the catalogues, under the several heads where they occur.

Gneiss, micaceous schist, chlorite schist, talcose schist, hornblende schist, actinolite schist, and serpentine, have no copies or counterparts in the secondary class, and therefore require no observations. The case of serpentine connected with trap veins, is too rare, and, at the same time, too obvious, where it does occur, to require any caution.

Between some varieties of quartz rock and the secondary sandstones, there is an occasional resemblance ; as the former may present a loose texture, and the latter an indurated one : in such cases, as in that of granite, recourse must be had to the geological connections of the rocks in doubt.

The same remark, even in a greater degree, applies to the primary and secondary red sandstones, which often bear a very exact resemblance, both in compositior and general aspect. It is true, that the primary rock is characterized 
by a predominant degree of compactness not often found in the secondary ; but that is rarely sufficient to form a distinction, except in the hands of a geologist long versant in the minute characters of rocks. This instance affords a striking example of the necessity of attending to geological characters in the classification and nomenclature of rocks, and of the utility of an arrangement founded on geological principles; since it had always been confounded with the secondary sandstone, till it was first pointed out in that work on the Western Isles of Scotland, which is here referred to, on several occasions, as the authority for many of the present statements.

The distinctions between the argillaceous schists of the primary class and the shales of the secondary, are, in many instances, sufficiently marked. But cases also occur in which they are undistinguishable when separated from their connections; a circumstance which, in this instance also, renders the examination of those connections necessary.

In the limestones, the same difficulties sometimes occur. It has been asserted that the primary calcareous rocks are always to be distin- 


\section{4}

guished, by their crystalline texture, from the secondary, which are, on the contrary, said to be characterized by a compact texture and earthy aspect. But this observation is perfectly erroneous ; as limestones of an earthy, and of a compact aspect, occur among the primary; and, although perhaps more rarely, the most perfect . crystalline limestone is sometimes found among the secondary strata.

The difficulty between the compact felspar associated with gneiss, and therefore primary, and that which is found with the overlying rocks, is of little moment ; as the former is rare, and is generally so intimately connected with its associates as to be necessarily referred to its proper place.

With respect to jasper, chert, and siliceous schist, which the geologist will often find among the primary rocks, it will hereafter be seen that they occur in both classes; for which reason they have been separated and placed in a distinct division, so as to render any remarks on them unnecessary in this place.

The difficulties that regard porphyry and its associates, are stated at length in the preliminary remarks on the overlying rocks. 
GRANITE.

\section{GRANITE.}

Is conformity to the general practice of geologists, I have placed granite as the lowest, or first in order, of the primary rocks. For the same reason, confirmed by my own limited experience, I have also considered it as unstratified. Further than this 1 cannot enter on its geological relations; as they would be incompatible with the design of the present work. It is only necessary to remark, that every member of the primary strata has been found in contact with it; and that, in some rare instances, the lowest red sandstone has been observed in the same situation.

By the term granite is here understood every compound rock which is found in irregular masses beneath the lowest strata; including; further, those veins which proceed from them so as to traverse the adjoining rocks, together with those similar veins which, though of the same 
mineral composition, cannot be traced in the same manner to a leading mass.

Granite masses are sometimes continuous for a great space; so that they possess no definite form ; or, if any such form be present, it cannot be discovered. At other times, they are disposed in large definite bodies, not unaptly compared to feather beds, "separated by fissures or joints. When these masses possess a large dimension in two directions only, they often resemble the beds of stratified rocks, and have sometimes been mistaken for true strata. Occasionally, these dimensions are so proportioned, that they resemble irregular spheroids: but these forms appear to have resulted from the wearing of the angles of masses originally prismatic.

The extended beds above mentioned, are frequently subdivided by fissures into smaller prismatic and cuboidal masses; and as this subdivision generally takes place in two opposite directions, or are vertical and parallel to the great mass or bed, these prisms are found piled on each other in a manner resembling huge 
masonry. The angles of the prisms being further subject to wear, as are the contiguous surfaces in a less degree, the result is an aggregate of irregular spheroids often piled on each other in a very fantastical manner. This consequence, it is evident, can only take place when the fissures are nearly horizontal and vertical. In all others, the detached parts must fall away. A few rare instances occur in nature where the dimensions of the prisms are so considerable in one direction, that, when grouped in erect positions, they present an irregular columnar ap. pearance.

Lastly, the great laminæ, or beds of granite are often vertical, as well as horizontal or in. clined; and it thus presents continuous smooth precipices laterally, while, above, it terminates in sharp peaks.

A minute, but irregular prismatic structure, independent of the former, is sometimes to be seen in granite. It is also occasionally $\mathrm{mi-}$ nutely laminar, or exfoliates in crusts. These crusts are sometimes concentric, respecting one, or more, centres; at others they are flat. In 
some cases they appear to be the consequence of an original concretionary structure in the rock: in others, it is equally certain that they are produced by the action of the atmosphere; as they occur equally in masses of artificial forms ; in the shafts of columns, for example, and in blocks squared by the tool.

With these comprehensive geological features, are united the following mineralogical characters.

The texture is, with one exception, always crystalline and confused; the several minerals of which it is composed, interfering with each other's forms. With the single exception of the graphic variety, it is also granular ; but varying much in the fineness of the texture, or in the magnitude of the parts.

As the mineral composition of granite resembles that of gneiss, and as, in many instances, these rocks approximate, even in texture, it will be convenient to state here, the characters by which these substances may be distinguished. In granite, the crystals of mica, or of hornblende if present, are placed irregularly in all directions ; but, in gneiss, they preserve a general parallelism, 
so as to give a foliated appearance to the rock, and, very frequently, communicating to it a tendency to split in one direction.

In certain cases, however, the distinction between granite and gneiss is evanescent, and the two become mineralogically identical. The cautious geologist will therefore beware of drawing any general conclusions of a geological nature, from the mere examination of specimens; but will examine the connections of the rocks themselves, and their general relations to the surrounding strata.

The minute structure of granite sometimes approximates to that of porphyry; or distinct crystals of the felspar which belongs to its composition, are imbedded in the general granular base. This variety has been termed porphyritic; and it is also proper here to remark, that the porphyries sometimes lose their characteristic structure in particular places, and assume that of granite so nearly, as to be scarcely distinguishable when in hand specimens. In this case, as in many others, such specimens can only be truly referred to their place in this system, by examining their geological connections. 
The magnitude of the parts in granite is extremely various ; each constituent mineral sometimes exceeding an inch in dimensions, and, at others, being almost invisibly minute. Various textures are also often united in a very limited space, or the rock passes imperceptibly from fine to coarse-grained. Occasionally also, irregular patches, or veins, of a fine texture, are seen imbedded in a coarser variety. In one rare instance the parts affect a spheroidal arrangement.

Mica, felspar, and quartz, have, by some mineralogists, been enumerated as the sole minerals essential to granite. This distinction is too limited for practical purposes; and, in a geological sense in particular, it is inadmissible. Within a very narrow space, either the quartz or the mica may disappear: in graphic granite, the latter is always wanting. Moreover, hornblende is very often present in one part of the same continuous mass which, in another, contains only the three ingredients above named: and it is also very frequently the substitute for mica ; the rock being then a ternary compound of quartz, felspar, and hornblende. The term 
syenite has been applied to this compound: but with great inconvenience; as it has also been used to denote a member of the latest unstratified rocks incumbent on the secondary strata. To prevent additional confusion in the geological description of two families of rock, often sufficiently difficult to distinguish with every attention, it seems absolutely necessary to appropriate this term exclusively to the granitic compound which is posterior to the secondary strata. In a geological arrangement, like the present, it is, at any rate, indispensible.

Granite therefore, consists fundamentally of quartz, felspar, mica, and hornblende, variously combined. But other minerals vccasionally enter into the composition, so as to form integrant parts of a common mixture. They are, it is true, comparatively rare, but they cannot conveniently be excluded from the definition.

These minerals are, actinolite, chlorite, talc, compact felspar, and steatite. This list might perhaps be extended; but the descriptions of rocks hitherto published, are so unsatisfactory; and the collections which have been formed, 
either so imperfect or so inaccessible, that it appears preferable to leave this question open for future correction. Those minerals therefore which are found entering into granite so as to modify its character, are enumerated in an appended list; in which are also contained all those which enter into it in smaller proportions, or of which granite is the natural repository.

Finally, there are certain compounds of minerals, of a granitic character, the claims of which are not yet determined in a satisfactory manner. It seemed desirable to place them in an appendix for future correction, rather than to run the risk of misleading the student by a premature decision.

The colours of granite are infinitely varied. That of the hornblende, where it exists, being invariably black, or an extremely dark green, it only contributes to modify that of the rock, by the proportion which it maý bear to the other ingredients. When in great excess, it forms compounds nearly black. In other cases it produces various tints of grey. Grey and black tints also arise from the presence of black mica. But this 
mineral is also either white, or brown; and is thus productive of corresponding differences in the colours of the granite into which it enters.

The felspar is subject to a greater variety of hue than either of the other ingredients; and, as it is commonly the most abundant, it often regulates the colour of the rock. Dark red, and white, are the most common extremes of colour, and it is also found of various intermediate tints of red. Occasionally it is ochre yellow, pale grey, blackish grey, or nearly black, and, in one rare instance, green. It does not seem well ascertained, whether those varieties which, like that of Labrador, disperse coloured light, belong to granite: in some instances, at least, it appears certain that the compounds which contain them, appertain to the overlying or trap family.

The quartz of granite is most commonly white, or watery ; and, being generally the next ingredient in proportion to the felspar, it also assists in many cases to determine the colours of the compound. Occasionally, it is also grey, and smoke coloured : sometimes nearly black. It may be remarked, in concluding this part of the 
subject, that each of the three preceding minerals may exist of different colours in the same compound.

\section{SYNOPSIS OF GRANITE.}

\section{FIRST DIVISION.}

Of two ingredients.

A. Felspar, and mica.

This variety does not seem to constitute extensive masses.

B. Quartz, and felspar.

a. An uniform mixture of these ingredients.

b. The quartz, or felspar, or both, imperfectly crystallized and influencing each other's forms. Graphic granite.

This remarkable variety seems to occur exclusively in veins, particularly in those which traverse gneiss. The quartz and felspar which compose it, are aggregated in lengthened parallel prisms. The prismatic structure therefore is seen in one direction; while, in the reverse, the peculiar appearance whence the term is derived, becomes visible. That appearance is produced 
by the cross section of the quartz prisms. These are frequently triangular, occasionally hexagonal and flattened; and in a few rare instances, the two minerals form alternating laminæ, The felspar is generally predominant; often in a great degree. The sizes of the prisms vary materially, and hence a great variety of aspect. In some rare instances, where cavities exist in the veins, the quartz is found with pyramidal summits. Throughout a whole vein of this rock, however large, it will generally be found that a common polarity pervades the felspar; or, practically, that the corresponding laminæe reflect light at the same angle over a wide extent of irregular surface.

C. Quartz, and hornblende.

This appears to be merely an incidental variety.

\section{Felspar, and hornblende.}

a. Large grained, or the hornblende crystallized.

b. An uniform granular mixture; the respective ingredients varying materially in their sizes and proportions, so as to produce a great variety of aspect.

c. Intimately mixed, so as to be nearly undistinguishable.

Var. b. often resembles the greenstones of 
the trap family ; and is, in fact, only distinguished by it geological connection with granite. Var. c. is often similarly undistinguishable from basalt; occasionally from the non-fissile hornblende schists; but, like var. b., it is connected with, and passes into granite of the most common characters.

These varieties occur in Aberdeenshire; where they are connected with the most ordinary granite, subjacent to gneiss, both by transition and alternation, in a manner so distinct as to leave no doubt respecting their true place in a geological classification, like the present.

\section{SECOND DIVISION.}

Of three ingredients.

A. Quartz, felspar, and mica.

a. An uniform mixture of the different ingredients.

b. Distinct additional crystals of felspar imbedded in the general mixture: porphyritic granite.

Cornwall presents very remarkable examples of this variety.

c. With two kinds of felspar, the common and the glassy. 
d. The quartz, or the felspar, or the mica, or all of them crystallized.

This variety is never perfect, as it contains the same minerals also without form. It often contilins minute cavities, and it is in these that the crystals are most distinct. Bennachie in Aberdeenshire produces very perfect examples of this variety. The varieties of aspect in $\mathbf{A}$ are in- numerable; depending on the relative proportions of the different ingredients, on their varying magnitude, or their colours, and on the different modes of intermixture.

B. Quartz, felspar, and hornblende.

a. Large grained.

The syenite of some mineralogists ; a term here limited to similar rocks in the overlying family. In Scotland, at least, this variety appears as common in many situations, as var. $\mathrm{A}$.

b. Small grained, and, like F. b. Div. Ist. often resembling the greenstones of the trap family, by which name some mineralogists have also distinguished it.

C. Quartz, felspar, and actinolite.

D. Quartz, felspar, and chlorite.

E. Quartz, felspar, and talc. 
These three latter varieties are rare, but they occur in different parts of Scotland.

F. Felspar, hornblende, and mica.

This variety occurs in the same manner as $D$. Div. 1st. but is rare.

\section{THIRD DIVISION.}

Of four ingredients.

A. Quartz, felspar, mica, hornblende.

This, like var. B. Div. 2d. is the syenite of some writers, and is often not easily distinguished from that variety, particularly when the mica is black and not abundant. It is equally, or more, common. Both these varieties, like all the others enumerated under this head, pass into the var. A. Div. 2d. or into common granite.

B. Quartz, felspar, mica, compact felspar.

This might perhaps be arranged with equal propriety under var. A. Div. 2d. the latter substance being considered accidental: the compact felspar is often of a bright green. Occurs in Guernsey and in Scotland.

C. Quartz, felspar, mica, actinolite. Rare, and analogous to var. A of this division. Occurs in Perthshire. 
D. Quartz, felspar, hornblende, chlorite.

E. Quartz, felspar, hornblende, steatite.

F. Quartz, felspar, mica, porcelain clay.

It is doubtful whether the apparent steatite of $\mathrm{E}$ is not decomposed talc or chlorite. The porcelain clay of $F$ appears also to be the result of the decomposition of one variety of the felspar in its structure. When the mixture is ternary alone, or of quartz, mica, and clay, it is evidently a decomposed rock and has lost its compactness. This rock occurs in Cornwall.

The remarks respecting variations of aspect, made on var. A. Div. 2 d. are applicable to all the other modifications of granite. In some rare instances, it offers other varieties of a very peculiar character, in consequence of a spheroidal concretionary structure, of which the orbicular granite of Corsica is a well known example. Many varieties of granite contain other minerals imbedded, as already noticed; and the following catalogue contains those of most usual occurrence.

Garnet.

Zircon.

Cyanite.

Fluor spar. 
Spodumene.

Corundum.

Beryl.

Topaz.

Chrysoberyl.

Epidote.

Apatite.

Pinite.

Idocrase.

Anthophyllite.

Andalusite.

Stilbite.

Iade.

Fettstein.
Tourmalin.

Schorl.

Tremolite.

Actinolite.

Emerald.

Gabbronite.

Wernerite.

Pyrophysalite.

Pyrites.

Oxydulous iron.

Sphene.

Oxyde of Tin.

Lapis lazuli.

Graphite.

A few of these only, are occasionally so abundant as to modify the aspect of the granite in which they occur: the greater number are sparingly dispersed. The authority for such inbedded minerals, here and in the following synopses, rests, sometimes, on the recorded observations of various authors; at others, on my own. The remarks on these subjects have been every where omitted ; partly because they belong more properly to systems of mineralogy, and partly because they would materially have prolonged these pages. 
I am under the necessity, as already mentioned, of introducing into this synopsis, in the manner of an appendix, four substances, of some of which, at least, the places have not been thoroughly described. They appear, as far as can be judged, to have a greater analogy to granite than to any other family. Hereafter, when their geological connections and characters are better known, and when it is determined whether they are really entitled to places among rocks, they may be removed, should it prove necessary, to some other part of the system.?

A. Mica and compact felspar, sometimes contâining garnets.-Weiss stein-Whitestone.

It is possible, that this substance rather appertains to gneiss; if the structure is schistose, as is said, it is the more likely ; but the only specimens which have come under my notice, were not characterized by that structure.

B. Felspar, quartz, smaragdite-sometimes containing cyanite and garnets - of Styria and Corsica.

C. Smaragdite and compact felspar.

D. Splendent Diallage (Schiller spar) and compact felspar.-Of Corsica, \&c.

This rock is found accompanying serpentine, 
at Mussinet, near Turin; so that its geological position is doubtful. There are reasons for suspecting that it may belong to the trap family.

D. Schorl and quartz, sometimes with felspar.Schorl rock of Cornwall; and with the same geological relations as granite.

This might, perhaps, like the compounds C, D, E, Div. 2d. have been enumerated in the same place. 


\section{SERPENTINE.}

THERE is so little accurate information to be obtained, from authors, respecting the geological history of this rock, and the opportunities of studying it in this country are so few, that I cannot pretend to give much satisfactory information respecting it.

As far as has yet been ascertained, it occurs almost exclusively among the primary rocks, and is therefore properly placed in the present division. It does not appear to be ever decidedly stratified, or to alteinate in such a manner with the primary strata in which it lies as to give ground for supposing that it is a stratified substance. It presents, at the same time, one striking difference from the unstratified rocks, which, of whatever date they may be, are connected. with veins that branch from them into the surrounding strata. No veins have yet been de- 
tected ramifying from masses of serpentine. As far as is yet known, it seems to form irregular masses included among the primary strata, and resembling those which are sometimes found in the primary limestones. Rarely, it is included immediately in granite, occurring in that situation in Aberdeenshire.

These masses vary in size, sometimes extending for miles, and, at others, not exceeding a few feet in dimensions. In the latter case, they frequently put on a parallel figure, determined by that of the strata in which they lie, but not persistent, inasmuch as they are extenuated at the edges till they disappear.

The strata among which masses of serpentine occur in this country are chiefly gneiss, argillaceous schist, hornblende rock, and limestone; it is also found rarely and sparingly in micaceous schist. In the case of their contact with argillaceous or micaceous schist, a change of the including rock takes place near the junction, by the intervention of the talc which is so often associated with this substance. In the same way, the neighbouring masses of gneiss assume a pe- 
culiar character, which is noticed in the synopsis of that rock. When they occur in contact with limestone, the two substances are frequently much intermixed; veins of the carbonat of lime penetrating the serpentine, or fragments of both being confusedly blended together. When the contact is that of hornblende rock with serpentine, a perfect gradation between the two can sometimes be traced:

There is one interesting situation, in the secondary class, in which serpentine occurs, although two examples only of it have fallen under my notice, and it has not been observed by other geologists. In both these cases, veins of trap pass through strata of secondary limestone, and where the vein is in contact with the limestone, it changes its character and becomes a serpentine, while it also contains, in those parts, the minerals usually found in that rock, namely, asbestos and steatite. The limestone, at the planes of contact, also contains steatite ; and thus a species of irregular gradation becomes established between the trap and the limestone. The gradation from the serpentine to the trap, within 
the vein, is perfect and insensible. This fact may perhaps assist, at some future period, in illustrating the real nature of a rock of which we are now ignorant.

Although the varieties in the aspect of serpentine, are innumerable, and more ostensibly striking than in most other rocks, the real differences in the essential characters are very limited. It is always easily distinguished by the circumstances already mentioned in the thirteenth chapter, and by the details of the subjoined catalogue.

\section{SYNOPSIS OF SERPENTINE,}

\section{First Division.-Opake.}

A. Common serpentine.

a. With an earthy uniform fracture.

b. With a splintery fracture, passing to the conchoidal. nülar.

c. With a splintery fracture passing to the gra-

d. With a granular fracture. 
B. Softer, and becoming gradually sectile: the potstone of some mineralogists.

C. Passing to indurated talc: the potstone of others, and enumerated under the head of talcose sehist.

Common serpentine is noted for the variety of its colours, which are either simple, or variously intermingled, in clouds, spots, or veins. The prevailing colours are, green of various hues, black, brown, dark red, and purplish brown : yellow, pink, lilac, and pale grey, are more rare. The variations which result from the admixtures of these in different modes are infinite. It varies further in aspect, from being intersected by veins of noble serpentine, steatite, asbestos, or calcareous spar, or from containing the imbedded minerals to be enumerated at the end of this article.

\section{Second Division.-Translucent.}

A. Noble serpentine of some mineralogists.

a. Foliated and splintery.

b. Conchoidal, or splintery conchoidal.

The colours of this variety are more limited, and are generally the following modifications of 
green: dark olive, pale olive, dark, or bright yellow, green, and pale greyish green. It also occurs of a pale fawn colour, and white; and there is an esteemed variety consisting of bright and very dark green intermixed. 'Translucent serpentine passes into common steatite, and into hard steatite, or figure stone; nor does it appear to have a much greater claim than these minerals to a place in the catalogue of rocks.

The minerals which chiefly occur imbedded in serpentine are the following, and some of them, besides diallage, in such abundance as materially to modify the character of the rock.

$\begin{array}{ll}\text { Diallage. } & \text { Pyrope. } \\ \text { Asbestos. } & \text { Calcareous spar. } \\ \text { Amianthus. } & \text { Schiefar spar. } \\ \text { Steatite. } & \text { Oxydulous iron. } \\ \text { Hornblende. } & \text { Chromat of iron. } \\ \text { Actinolite. } & \text { Hydrophane opal. } \\ \text { Tremolite. } & \text { Chrysolite, } \\ \text { Talc. } & \text { Idocrase. } \\ \text { Jade. } & \end{array}$

Rocks, composed of serpentine and carbonat of lime, are found of considerable extent, of which the verde antico is a striking variety, 


\section{GNEISS.}

THE space occupied by gneiss is often very considerable; and, in many countries, it is found to be the most abundant of the primary stratified rocks, constituting extensive districts, and rising into mountains of great elevation. In such cases, it sometimes forms masses of enormous thickness, without any intervening strata of another nature.

In such situations it is often found immediately following granite, and succeeded by the other primary strata. But, as already noticed, it is also frequently observed to succeed one or other of these, or to alternate in large tracts with tracts equally extensive of many of them.

Besides these more extensive alternations, a large body or series of strata, consisting principally of gneiss, often contains a number of alternating strata of other rocks in much inferior proportion. The most common of these, 
as already noticed, is hornblende schist; but quartz rock and micaceous schist are also not uncommon; and, though much less frequent, argillaceous schist is known to occur in a similar manner. Such beds have been called subordinate; a distinction, the propriety of which, however questionable it may be, is not a subject for discussion in this place; although, in geological descriptions, it is often, not only convenient, but necessary, to consider a series of this nature as gneiss, and to omit all notice of these inferior strata.

The dimensions of the strata of gneiss are extremely various. They are generally very considerable where they do not alternate with the other strata already mentioned; but where hornblende schist, in particular, abounds, they are often very thin. Where they are not separated by the intervention of these and similar strata, the distinctions between the different beds are generally formed by some change in the proportions of the ingredients, and principally by variations in those of the hornblende or the mica. 
Although gneiss is a stratified rock, the several varieties of which it consists, present that disposition in very different degrees. When the texture is coarsely granular, and resembling that of granite, the strata are generally least defined; and, in some such cases, particularly, when it abounds in granite veins, it is difficult for an inexperienced eye to distinguish it from an irregular granitic mass.

The same difficulty sometimes occurs where it is very irregular in position; either from a discordant inclination of the approximate portions, or from flexures and contortions. The difficulty is in this case increased by the circumstance that such irregularities prevail most where granite veins are most abundant; and such is the confusion hence generated, that it often requires an eye of no small experience to distinguish between the vein and the including mass; or to determine what is granite and what is gneiss.

Further, the granite veins are not necessarily transverse to the strata or laminæ, but often lie in a parallel manner, so as, for short spaces, to resemble portions of the stratified structure of 
the gneiss itself. Such parallel veins are sometimes mistaken for beds of stratified granite, when of considerable dimensions, or when care has not been taken to trace their real nature and connections.

The stratification of those masses of gneiss which contain few granite veins, is commonly very regular and discernible; and this regularity of stratification will be found chiefly to prevail in the two varieties distinguished here by the terms schistose, and laminar.

The contortions of gneiss are often extremely remarkable, and they occur on a very large, as well as on a small scale. Where hornblende schist alternates with the strata, they are rendered very conspicuous by the contrast of colour between the two rocks. In some rare instances, a sudden change occurs in the position of the laminæe, as if the rock had been fractured, and the parts reunited at an angle to each other. It must be remarked, however, that the contortions of gneiss are seldom so minute as to be comprised, like those of micaceous schist, within the limits of a specimen. 
The varieties comprehended under the term gneiss are so considerable, that no general description of the structure of the stone can be given : it is necessary to describe separately that of each variety. The three marked varieties of structure may be comprised under the granitic, the schistose, and the laminar.

The granitic variety is distinguishable by its general resemblance to granite, which it also emulates in the infinite variety, intermixture, magnitude, and proportions of the several ingredients. As already remarked, it frequently passes into granite by an undefinable transition : and, both this transition, and the resemblance to the granitic character, occur chiefly in those cases where the beds of gneiss are in the vicinity of granite. At the point of junction, the two rocks are sometimes undistinguishable : and a similar gradation often exists in those parts which are traversed by granite veins. The distinction, as already mentioned in treating of granite, consists in the general parallelism of the mica, or of the hormblende; or else of some other ingredients; from which cause the rock 
is either actually fissile, or else displays indications of a foliated structure. As that structure becomes more perfect, it recedes further from granite.

In the schistose variety, the texture is commonly minute, while the position of the several minerals above mentioned, is more accurately parallel. Hence the rock is almost always very readily fissile; and, in some instances indeed, possesses this quality in such perfection as to be applicable to the same purposes as argillaceous schist. This variety passes into quartz rock, by the loss of its mica, or hornblende, or, sometimes, of its felspar also; and, in this case, its structure is commonly more granular than when it passes into micaceous schist. When it graduates into the latter rock, by the loss of its felspar, it is generally very distinctly laminar or schistose.

The two preceding varieties are the most abundant. The laminar is rare, but it occurs in several parts of Scotland, as, for example, in Sky and in Ardgowar. In this variety, each constituent mineral is disposed separately; in laminae 
nearly continuous; and, as the quartz and the felspar are the predominant substances, it is marked by considerable peculiarity of aspect ; particularly when, as is not unfrequent, the former is white and the latter red, or when their colours are in any other manner strongly contrasted. When perfect, the laminar variety presents no trace of a granular structure; but it passes into both of the preceding, and thus loses its definite character. Although so decidedly laminar in composition, it is far less fissile than the preceding variety.

In composition, gneiss fundamentally resembles granite; or, the prevailing minerals which enter into it are quartz, felspar, mica, and hornblende. To describe the mode in which these are combined, would be merely to repeat that which has already been said under the head of granite.

But there is one important variety in which compact felspar forms an essential and conspicuous ingredient, and to which granite affords no parallel. That rock has been without scruple ranked in this division, because it accompanies 
the ordinary varieties of gneiss, and also graduates into them. It does not appear to have been described by foreign geologists ; but it cannot be considered as an accidental rock, as it forms exterior tracts of country on the northwest coast of Scotland.

It must also here be observed, that there have been introduced into the synopsis, several compounds formed of other ingredients than those now enumerated as the constituents of gneiss. The reasons for this are, that these compounds alternate with and pass into the more ordinary varieties of that rock, and that no other place exists in which they can be arranged. As yet, they have either been overlooked by geologists, or classed with those other rocks to which they are also allied. In the present very imperfect state of our knowledge, it seems impossible to adopt a better arrangement; but, to accommodate the student, such varieties, both here and elsewhere, wherever they trespass on the characters of some other rock, or occur as parts of other series, will be found enumerated in two places. Such a superfluity appeared preferable to the 
limitation of a given rock to one place, when it exists in two.

As in granite, many minerals are found imbedded in gneiss, in greater or less abundance: and these, as in the former case, are enumerated in an appended list.

The colours of gneiss vary from the same causes which influence those of granite; and to repeat these would be superfluous. It may only be added, that the peculiar structure of this rock, by frequently causing the several colours to be disposed in stripes, produces a much greater diversity of aspect in a series of specimens, than can be found in a collection of granites.

\section{SYNOPSIS OF GNEISS.}

\section{FIRST DIVISION.}

Of regular composition, containing at least three of the four minerals, quartz, felspar, mica, and hornblende. 


\section{FIRST SUBDIVISION.-Granitic.}

Resembling granite, i. e. large grained and often losing the foliated structure.

A. Quartz, felspar, inica.

B. Quartz, felspar, hornblende.

C. Quartz, felspar, mica, hornblende.

These varieties abound in Lewis, Harris, and the associated islands. They sometimes contain superadded crystals of felspar, thus forming the porphyritic gneiss of some authors.

\section{SECOND SUBDIVISION.-Schistose.}

The structure foliated, like that of micaceous schist, or granular with a slight laminar tendency, like that of quartz rock :-fine grained.

A. White felspar and quartz in minute grains intimately mixed, with rare scales of mica. The position of the mica determines the foliated structure, which is however often so very indistinct that the specimens can scarcely be distinguished from quartz rock.

B. The mixture of felspar and quartz finely granular as in the former, but the mica so abundant as to cause it to resemble certain varieties of a micaceous schist.

C. The mica so abundant as to form distinct continuous laminæ; and as in these cases it is often very 
difficult to distinguish the felspar from the quartz, the specimens are easily confounded with common micaceous schist.

D. A schist of foliated mica, with interspersed and large irregular crystals of felspar; the quartz being scarcely discernible.

E. An undulated coarse schist, consisting of large grains of felspar and of quartz closely packed and connected by the smallest possible quantity of mica. Occurs in the argillaceous series of the Highland southern border in company with micaceous schist of the same structure and appearance.

It may be added that the whole of this subdivision presents transitions from gneiss into quartz rock and into micaceous schist. Where the felspar is red they are easily distinguished: when white, it is much more difficult to recognize them. I may also add that hornblende is, as in the first subdivision, an occasional ingredient, and that this subdivision also, is occasionally porphyritic.

This variety occurs abundantly on the west coast of Scotland, in Rannoch, and in the middle Highland districts of Atholl and Badenoch. 


\section{THIRD SUBDIVISION.-Laminar.}

Each substance occupying a distinct lamina, the quartz and the felspar being separated; sometimes remaining in contact, at others being divided by intervening laminæ of mica or of horublende: the quartz frequently puts on the muddy aspect of chalcedony.

A. Quartz and felspar in alternating laminæ : belonging, with $\mathrm{D}$, strictly, to the third division.

B. Quartz, felspar and mica, similarly alteruating.

C. Quartz, felspar and hornblende, disposed in the same manner.

D. Felspar and hornblende in alternating laminæ.

E. Quartz, mica and hornblende; the two latter generally in one lamina.

The varieties A, B, are abundant in Glen Ely, Rona and Ardgower; the third occurs occasionally in various situations. The quartz is also found alternating with mica only, or with hornblende only, in the same situations; but it is scarcely necessary to specify these varieties, as they appear to be very limited in extent.

In varieties $\mathbf{C}, \mathbf{D}$, the felspar often assumes a very peculiar aspect; consisting of crystalline 
grains compacted together into a dense and somewhat granular aggregate, and having often a glassy lustre. The rocks of this character are more easily recognized than described; and they abound on the west coast of Sutherland and Rossshire.

With respect to the first division I may add, that the several varieties enumerated under it are occasionally found passing into each other, in all situations where gneiss occurs; notwithstanding the leading prevalence of one or other of the subdivisions.

\section{SECOND DIVISION.}

Of irregular composition, containing compact felspar, and consisting of that substance united to some or all of the ordinary ingredients of gneiss. In structure it sometimes resembles common gneiss, but more frequently its fracture is like that of the non-fissile schists ; presenting no indication of laminæe.

A. Compact felspar with hornblende. This also occurs as a variety of hornblende schist. 
B. Compact felspar with quartz; in various proportions.

C. Compact felspar and chlorite : with gneiss, in North Uist. Occurs also as a member of the chlorite series of Argyllshire.

D. Compact felspar, with quartz, and mica.

E. Compact felspar, with quartz and hornblende, or with mica superadded.

F. Compact felspar superadded, in various ways, to any of the preceding varieties of gneiss which contain common felspar also.

The substances ranked in this division are frequently traversed by veins of compact felspar, often reticulating in an intricate manner, and so numerous as to form a large proportion of the rock. The predominant colours in the compact felspar are various shades of grey, but green is also very common. They occur abundantly, sometimes in connexion with the varieties of the first subdivision, in Sutherland and Rossshire; and are also found in North Uist and West Rona, where they are connected with and pass into argillaceous schist; forming a compound included in the next division. 


\section{THIRD DIVISION.}

Of irregular composition, being either deficient in the number of ingredients required to meet the definition of gneiss, or containing some substance not included in that definition.

A. Quartz and felspar; simply laminar and at the same time granular. The foliated disposition here results from the crystalline position of the felspar.

B. Hornblende and felspar, foliated and sometimes imperfectly schistose. Analogy and geological connexions claim a place here for this rock; it is however the primitive greenstone of some, and the hornblende schist of other authors. It is also described under the head of hornblende schist.

C. Felspar and mica.-Lewis, \&c.

D. Felspar and clay slate.-Isla, Lewis.

E. Felspar and chlorite schist._Gigha, Sky.

F. Felspar, quartz and chlorite schist.-Sky.

G. Felspar, quartz and clay slate.-North Uist.

H. Felspar, quartz and talc.-Scalpa, (West.)

I. A granular mixture of felspar and quartz in one Jamina and clay slate in another.

- K. The same with chlorite schist instead of clay slate.-Sky.

L. The same with grey wacke schist, ditto.

M. Compact quartz with imbedded grains of felspar, in one lamina, and the same schists in the other.Sky. 
N. Schistose felspar containing crystals of hornblende interspersed.-Glen Tilt.

O. Actinolite occupying the place of hornblende. -Sutherland.

P. Compact felspar, argillaceous schist, and any one or more of the other ingredients of gneiss.-Lewis. Loch Carron.

Of all these I may remark, that the geological position and general features are the same as those of the most ordinary gneiss, and that they often pass into the regular varieties. It is perhaps superfluous to remark, that although I have thus distinguished the varieties of gneiss by fixed divisions, there are, as in all cases of compound rocks, intermediate gradations which cannot be decidedly referred to either. But I may observe that many other combinations probably exist, and that an ideal catalogue of much greater extent might easily have been formed. The present enumeration has been rigidly limited to the varieties actually observed.

No division is here made of those varieties which contain occasional minerals, however abundant, or in whatever manner disposed. 
The following are those of most usual occurrence:-

Epidote.

Garnet.

Actinolite.

Quartz.

Felspar.

Hornblende.

Fluor spar.
Carbonat of lime.

Zircon.

Tourmalin.

Melanite.

Idocrase.

Oxydulous iron.

Molybdena.

Garnet and Epidote are sometimes so abundant as to modify the character of the rock. The quartz and felspar present various colours and characters; more so than in any other rock in which they occur.

Many other minerals have been occasionally described as found in gneiss, but the true repositories of these appear to be the granite veins: or, at least, sufficient care has not been taken so to distinguish between the two cases, as to admit of their being here enumerated. The preceding list includes those which have been observed in the gneiss itself.

It does not appear, that the geological rela. tions of the Topaz rock of Werner have been 
satisfactorily ascertained; but I am induced to give it a place here, in an appendix, from its foliated structure and general characters. To whatever family it may belong, it appears, at any rate, to have no claim to a separate place as a distinet geological formation.

It is a compound of quartz, schorl, mica, and lithomarga, or of quartz, schorl, and lithomarga, containing topazes imbedded. 


\section{MICACEOUS SCHIST.}

ThE uncertain position of micaceous schist with respect to the other primary rocks, has already been stated as far as is necessary for the objects of this work. Like gneiss, it generally forms extensive tracts of country and ranges of high mountains, but is sometimes also found occupying very small spaces, in alternation with other primary strata, The consecutive beds therefore, constitute, in some cases, masses of great thickness; while, in others, they may be found not exceeding a few feet in dimensions, and forming a very unimportant part of some series composed principally of other substances. In gneiss, as already shewn, it sometimes occurs in beds of very inferior dimensions; and, in the same manner, it is found accompanying quartz rock, with which it is often very extensively associated, as will be more particularly detailed hereafter. 
The individual strata in a series, are equally variable in dimensions, but are most commonly very thick where that series contains no intervening substance. They are often indeed of a thickness so great, and are, at the same time so imperfectly defined or separated, that the stratified nature of the rock is only to be deduced from a knowledge of its general characters, and not from any appearances visible in the spot under examination. The difficulty of determining this point is greatest, as in gneiss, where the disposition of the beds is least regular, or where they are much bent or contorted.

When the beds of micaceous schist are not separated by any intervening rock, they are distinguished, like those of gneiss, by some change in the proportions of the constituent parts, and the actual separation takes place where the mica is most abundant.

The flexures above-mentioned as occurring in this rock, are often so great as to amount to contortions. But in many cases of contortion, where the intricacy and minuteness of this structure is very considerable, this feature appears to 
be independent of the bed, and to involve the laminæ of which the stratum is formed, without affecting the stratum itself. Many interesting geological considerations, not admitting of examination in this place, are connected with this subject.

In all cases, whether straight or contorted, the structure of micaceous schist, like that of gneiss, is foliated, or laminar; and, as in that rock, the laminæ are more or less easily separated, or the rock is more or less easily fissile, according to the proportion and mode of disposition in which the mica enters into the compound. In some instances, it may be separated into slates adapted to oconomical uses; in others, the laminar fracture is very irregular and imperfect. Such laminæ are sometimes straight, like the general structure of the bed; but, without exhibiting actual contortion or flexure, they are often minutely undulated. These undulations, like the contortions, are always most sensible on the transverse fracture; but that fracture can scarcely ever be neatly effected but by the action of gunpowder; as a less degree of 
force, only separates the laminæ, or produces as very irregular transverse surface.

It is yet unsettled whether, in all cases, the laminar structure of micaceous schist is parallel to the plane of stratification, or whether it may not, as in argillaceous schist, be sometimes at angles to that. But if the minute undulations be excepted, no observations as yet prove the latter; and, from the analogy of gneiss, where they appear to be always coincident, it is probable that the former is true.

Micaceous schist, as it differs from gneiss in composition, differs only from that rock in not containing granite veins as a frequent feature. Wherever these are found, they occur only, as in other rucks, where it is in contact with granite; and the veins are then limited to a small distance from the mass of that substance; being ramifications from some larger intruding vein, or from the principal rock, and, commonly, easy to trace. But it is subject to be much penetrated by quartz veins, either transverse or parallel to the laminæ ; and, where these are contorted, the veins follow those contortions. 
The texture of micaceous schist is various; being coarse, or fine, according to the magnitude and disposition of the parts of which it is formed. The aspect of the fracture is equally various; depending, moreover, not only on this cause, but on the direction which it bears towards the laminæ of the stone. Thus, in a parallel fracture, a smooth surface of mica alone will often appear; while, in the reverse direction, quartz only, is sometimes visible.

Whether the texture of micaceous schist is to. be considered as crystalline and granular, or laminar, depends on the particular variety under examination. In many cases, where the mica is: not only abundant but continuous, it is strictly laminar. Where that is abundant, but less continuous, it is either minutely and imperfectly. laminar, or scaly; and where the quartz, on the contrary, predominates, or is irregularly intermixed with the mica, it is scaly and granular together, or almost purely granular and crystalline, or continuously crystalline. In all these varieties of texture, it corresponds very nearly with gneiss; 
which, in most other particulars, it so strongly resembles.

It is a theoretical question whether this texture is the result of chemical action or of mechanical disposition, and therefore not adapted to the present work. But it may briefly be remarked, that the parallel position of the mica may be accounted for on either supposition; while, with respect to the quartz, it certainly, in every case, even where most granular, is united by the intervention of a crystalline cement of the same substance.

Nevertheless, certain varieties of micaceous schist occur, which possess the unquestionable characters of a compound, at least partly mechanical. In these, fragments of granite, of quartz rock, and of limestoue, are imbedded in the general mass; resembling, thus, the conglomerates which accompany the sandstones.

Moreover, in certain places in Scotland, where small beds of micaceous schist alternate with clay slate and graywacke, or with coarse and fine argillaceous schists, some remarkable 
varieties occur which resemble exactly in their texture those varieties of graywacke of which the texture seems almost purely mechanical. In these, the grains of quartz appear to be merely agglutinated without the intervention of a proper siliceous cement, while they also bear marks of previous attrition. In such specimens also it is very remarkable, that, as in the analogous graywackes, the grains in any one bed preserve an average general size, whether coarse or fine; and that the two are scarcely ever intermixed in the same. In these also, the quartz is principally united by the smallest possible quantity of intervening mica, which follows the minute undulations produced by the packing of the irregular gravel, producing an undulated and peculiar appearance on the transverse fracture which is highly characteristic.

It is scarcely now necessary to say that the minerals of which this rock is formed are, essentially, quartz and mica. To the varying proportions and disposition of these, are owing all the leading varieties which are found in this rock. As it differs from gneiss, chiefly in ex- 
cluding felspar, so it easily passes into that rock by the admission of this mineral. With greater facility, it passes into quartz rock; as the same ingredients form one of the chief varieties of that substance; nor indeed is it often possible to determine to which of these two, any specimen, or even stratum, ought to be referred.

As the limits between chlorite and mica are evanescent, or, at least, as no effectual distinction between the two has yet been discovered, micaceous schist easily passes into chlorite schist; and, although more rarely, it seems also to pass into talcose schist, producing indefinite varieties which are noticed in the subsequent catalogue. In some rare instances also, it presents transitions, but less perfect, into the finest varieties of argillaceous schist.

Besides the essential minerals above mentioned, hornblende, chlorite, and talc, sometimes occur in micaceous schist, in such abundance as materially to modify its character; occasionally producing transitions into the rocks characterized by these ingredients, which it appeared convenient to enumerate in a particular division. 
Carbonat of lime occurs in a similar manner, but rarely.

Many minerals, hereafter noticed in the Synopses, are occasionally found imbedded in this rock. Among these, garnet is eminently conspicuous; as it sometimes abounds to such a degree as almost to equal in quantity the including rock, and thus materially to affect its character. Whatever singularity or beauty such varieties may present, from containing one or more of these extraneous minerals, they require no further notice than that which is given of them in the list appended to the catalogue of varieties.

The colours of micaceous schist offer very little variety. With the exception of those which contain a conspicuous quantity of imbedded extraneous minerals, or pass into clilorite schist, they present tints of grey alone; the mica varying from white to black, and the quartz being atmost invariably colourless. The degree of colour, in these cases, depends chiefly on the proportion of mica in the compound. 


\title{
SYNOPSIS OF MICACEOUS SCHIST.
}

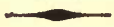

\section{FIRST DIVISION.} \\ Consisting of mica and quartz.
}

FIRST SUBDIVISION.- Simply laminar, or foliated.

A. Formed of mica, continuously laminar, with scarcely a discernible proportion of laminar quartz.

A variety of considerable beauty arises from the mica occasionally presenting two distinct colours, as white and black, or greenish and grey. Many of these specimens appear to consist of mica only, but I believe that quartz is never entirely absent.

B. Formed in the same manner, but the proportions of the ingredients reversed.

In this case, the cross fracture presents the aspect of quartz rock, while the mica alone is visible in the laminar fracture.

C. The continuity of the mica becoming interrupted, and the quartz becoming granular. 
The varieties of this are endless, and it passes both into quartz rock and into gneiss.

D. The mica greenish, and more tender; thus approximating to chlorite schist, yet forming large tracts of country without passing decidedly into that rock.

In point of disposition, this variety comprises all the modifications above named.

E. The mica grey, but tender ; and thus approximating to talcose schist, a rock which appears to be frequently subordinate to the present, and to occupy very limited spaces among its beds.

F. Modifications similar to the preceding two; but the passage being, in this case, into clay slate.

The chief instances of contortion are found in this subdivision.

SECOND SUBdIVISION.-Granularly laminar.

A. Granular quartz uniformly mixed with scales of mica in a parallel position, by which the laminar fracture of the rock is determined.

B. Granular quartz, occupying distinct laminæ, which are separable, in consequence of the interposition of scales of mica congregated into distinct spots.

C. Granular quartz divisible into laminæ, between which distinct, and often distant, scales of mica are interspersed. 
These two, like the former, pass into quart\% rock, and into gneiss...

D. A rock of similar construction, with this difference, that the mica is further disposed in a longitudinal manner, so as to give the stone a fibrous appearance on splitting.

Many of this and of the preceding variety admit of being polished, like the analogous specimens of quartz rock, into which they pass. Those which are most compact and sparkling; form the mineral known by the name of avanturine; the most esteemed variety of which is of a reddish yellow, or brown, colour.

E. The mica imperfectly parallel and scaly, being bent round the grains of quartz, which are often of large size; that flexure, in the latter case, giving a very peculiar character to the rock, particularly in the transverse fracture. Thus, in some instances, it has the general aspect of gneiss; in others, that of the graywacke schist which accompanies the clay slate of the Highland border.

It occurs in that situation; in Bute, and elsewhere. 


\section{SECOND DIVISION.}

Compounded of three or more ingredients.

A. Micaceous schist of many of the preceding varieties, containing hornblende in minute crystals, or in larger crystals or concretions.

This is not uncommon in Perthshire.

B. The same, containing felspar, and thus passing into gneiss; already alluded to under a preceding head.

C. Containing chlorite or talc superadded, and thus passing into chlorite schist, or talcaceous schist.

D. Irregularly compounded with more than one of the above-named ingredients, so as to pass out of the arrangement.

E. Micaceous schist, containing carbonat of lime in addition to the ordinary ingredients; that substance so much resembling felspar, that the rock is easily mistaken for gneiss.

This variety seems limited and rare. Observed in Perthshire only.

\section{THIRD DIVISION.}

- Conglomerated.

Containing superadded fragments of granite, quartz rock, limestone or other substances. 
This rock is found in Isla, in the Garvelock Islands, in Rannoch, and elsewhere, alternating with the general series, and it must therefore be considered as a regular bed. In other cases, possibly, it may be analogous to the local conglomerates that are found at the meeting of two rocks of different kinds.

I must add to this enumeration a variety which is, in a certain degree, distinct from any of the former, although it can only be considered as an accidental modification. Any one of the preceding may put on this aspect, which occurs in the vicinity of granite. The ingredients are, in this case, so strongly cemented as to be inseparable, and, sometimes, almost undistinguishable. It is not enumerated with the siliceous schists, because it has not been the practice so to do ; but it bears a strong analogy to the primary varieties of these.

Under the preceding heads, as far as I have observed, every variety of micaceous schist may be arranged; although the diversity of aspect is so great as to convey an idea of the existence of an infinitely greater number. These diversities 
will be found to consist in the varying proportion, colours, compactnèss, undulation, and distribution of the parts. In Rannoch and Schihallien a variety occurs, in which large crystals of mica are superadded to the general composition of the rock.

The following minerals occur embedded in micaceous schist. The garnets are sometimes perfectly crystallized, at others very obscure. In this latter case, their mineral composition is often so imperfect, that they are scarcely discernible, except by their superior hardness and persistence after the rock has weathered.

$\begin{array}{ll}\text { Garnet. } & \text { Andalusite. } \\ \text { Actinolite. } & \text { Pycnite. } \\ \text { Epidote. } & \text { Prehnite. } \\ \text { Tourmalin. } & \text { Apatite. } \\ \text { Beryl. } & \text { Oxydulous Iron. } \\ \text { Corundum. } & \text { Pyrites. } \\ \text { Staurotide. } & \end{array}$




\section{2}

\section{‘ CHLORITE SCHIST.}

Alrhough chlorite schist does not, like the preceding rocks, form any extensive tracts in nature, as far as the observations of geologists have yet extended, and although its characters are not in all cases very definite, it is sufficiently distinct from micaceous schist in many points, and sufficiently remarkable with respect to some of its connexions, to require a separate place in a classification like the present.

As it has not hitherto obtained such a place in the only geological arrangements of rocks which have been published, and as it also appears to have received but a small degree of attention from geological writers, the observations which relate to it are drawn solely from the appearances which it presents in Scotland.

Its predominant association is with micaceous schist, into which it passes, in so gradual a manner, that different observers rarely coincide in 
opinion respecting the name. It is in these cases, however, that it forms the most continuous and extensive masses, however imperfectly defined its characters may often be. Under these circumstances also, it so exactly resembles micaceous schist, in the disposition, the thickness, and the other general characters of its stratification; that it is superfluous to state these circumstances more particularly.

But it also occurs in association with gneiss ; alternating with its beds, and even entering, as already noticed, into the composition of some of the varieties, so as to pass, by a transition, more or less complete, into the ordinary and perfect kinds of that rock.

Not unfrequently also, it is found accompanying the argillaceous schists, into which it sometimes further passes ; by transitions, however, of no very perfect nature. In one extensive tract in Scotland, it is thus seen alternating and intermixed in a very irregular manner, not only with that rock, but with micaceous schist, and with some varieties of gneiss, as well as of primary limestone; forming a series of great interest in a 
geological view, which is fully described in that work on the western island to which the reader is here so often referred for the authority of many of the present statements.

In the same work, a full account, inadmissible in this place, will also be found of its association, in a very peculiar series, with hornblende schist, quartz rock, micaceous schist, and other strata; in which series it presents the greater number of the very peculiar varieties which are enumerated in the subjoined catalogue. In that list are also enumerated those transitions and modifications, as yet undescribed, which it is unnecessary to dwell on in these prefatory remarks.

Although, when associated with micaceous schist, it often forms beds of considerable dimensions, the strata are commonly thin in the cases last enumerated, and often indeed of such tenuity as not to exceed a few inches. In such instances, it is, commonly, very accurately fissile, and not unfrequently so continuously laminar as to be applicable to architectural purposes, as a substitute for common slate. More frequently, however, the constitution of chlorite schist is too tender, 
and the laminar structure too little continuous, to admit of this application to use.

Where the beds are thicker, and approximate more in character to micaceous schist, it is also frequently, like that rock, very imperfectly, or at least irregularly fissile; and, in the same manner, it presents similar contortions and undulations. Even in the most perfectly laminar varieties of this rock, minute undulations are very frequent ; and as the lustre of the parallel fracture is often so considerable as to approach to the metallic, such specimens are exceedingly beautiful and often highly splendent, even in larger bodies.

In the minuter circumstances of texture, chlorite schist partakes, not only of the characters of micaceous schist already described, but, under its other modifications, of those of gneiss also; and, although more rarely, even of those of argillaceous schist. It is unnecessary to detail these circumstances where they resemble those which occur in micaceous schist, as it would be merely to repeat what has already been said on that subject. It need only be observed, that the same double character of a chemical and a mechanical 
deposit is visible; except, that in no instance as yet, within my observation, it has been found to contain fragments of other rocks. Where the texture assimilates to that of gneiss, it presents similar undulation, or roughness, in the parallel fracture; is more or less coarsely granular in the transverse, and is often undistinguishable from it without a careful examination.

The textures of those varieties which approximate in character to the coarse and fine argillaceous schists, or to graywacke and clay slate, are in every respect the same as those which occur in these rocks. In the first, the grains of quartz seem to form a mechanical rather than a chemical assemblage; varying much in the magnitude of the parts, often bearing the apparent marks of previous attrition, and being also separated in laminæ more or less distinct, by the intervening chlorite. As in those varieties of micaceous schist which present a similar character, this sand or gravel of quartz, not unusually possesses an average general size, whether large or small, in one bed; and the union produced by the smallest admissible quantity of chlorite. Thus the trans- 
verse fracture often presents quartz only, while, on the parallel, the other constituent is visible. In those varieties which resemble fine clay slate, the rock consists almost entirely of an imperfect, or argillaceous, foliated chlorite, finely laminar, with an earthy aspect on the cross fracture, and a shining smooth one on the parallel surfaces.

The minerals peculiarly essential to the composition of chlorite schist are quartz, and foliated chlorite. Whatever difficulty mineralogists may find in assigning a determinate character to the latter substance, it mast not be confounded with scaly chlorite; yet the frequent occurrence of this more definite mineral in chlorite schist, and the varying degrees in which foliated chlorite approaches to it, prove that there is an affinity between the two. The green hue of foliated chlorite is the most convenient empirical character by which it can be distinguished from mica, and by which, consequently, chlorite schist can be distinguished from micaceous; but it must be added, that the former mineral is more tender and more flexible than the latter, and possesses more of that saponaceous feel which characterizes talc. 
Among the less essential minerals which sometimes enter into the composition of chlorite schist, felspar, hornblende, mica, actinolite, and compact felspar, sometimes abound so as to modify its characters. Where the former is present it passes into gneiss; and the varieties which contain the three latter are also enumerated in the synopsis, as they form extensive rocks, of very peculiar aspects, which seemed to merit that distinction.

The best characterized specimens of chlorite schist are of a greyish green hue; and from that colour, they vary, by an imperceptible transition, to the more common pale grey of micaceous schist. It may also be observed, that the greenest specimens commonly present the greatest degree of lustre. 


\section{SYNOPSIS OF CHLORITE SCHIST.}

\section{FIRST DIVISION.}

Simple : of chlorite only.

A. Foliated chlorite; plain, or undulated; with minute, or with large undulations.

The lustre is sometimes considerable; being silky, or even pseudo-metallic. The colour varies from dark to very pale sea-green.

\section{SECOND DIVISION.}

Compound : of two ingredients.

FIRST SUBDivision.-Foliated or simple laminar and alternating.

A. Foliated chlorite with laminar quartz.

B. Foliated chlorite with granular quartz.

C. Foliated chlorite with laminar felspar.

D. Foliated chlorite with grains or imperfect crystals of felspar disposed in a laminar manner. 
SECOND SUBDIVISION.-Granularly laminar;

mixed.

1

A. Scaly, o inperfectly foliated chlorite with quartz sand.

a. Large grained, with a rough granular fracture.

b. Small grained, with a homogeneous aspect, and, often, scarcely fissile.

c. The preceding varieties passing into graywacke schist and into clay slate.

B. Scaly chlorite with large grains of quartz. Analogous in structure and appearance to the var. of micaceous schist E. first div. second subdiv.

C. Scaly chlorite with large imperfect crystals of felspar; similar to the former in structure, and resernbling granitic gneiss.

D. Scaly chlorite, highly compacted, with minute grains of felspar interspersed: difficultly fissile.

a. Scaly and somewhat granular.

b. Scaly and somewhat fibrous.

E. Scaly chlorite intermixed with hornblende, or with distinct particles of hornblende imbedded, and passing into hornblende schist.

F. Scaly chlorite intermixed with actinolite : very compact, difficultly fissile, and sometimes presenting an imperfectly fibrous texture.

G. Scaly chlorite with mica : passing into micaceous schist. 


\section{THIRD DIVISION.}

Compound : with three or more ingredients.

FIRST SUEDIVISION.-Laminar, aiternating.

A. Foliated chlorite, felspar, and quartz.

This is enumerated among the varieties of gneiss, but is also introduced here, as it occurs in both series, and is equally entitled to a place in each.

SECOND SUEDIVISION.-Granularly laminar;

mixed.

A. Scaly chlorite, quartz, and felspar.

B. Scaly chlorite, felspar, and mica.

C. Scaly chlorite, hornblende, and mica.

D. Scaly chlorite, hornblende, quartz, and green compact felspar.

The preceding enumeration will, I believe, contain all the varieties that can be included under this head ; and, as in other instances, they present transitions into different rocks; a circumstance of universal occurrence among the mineral compounds, and which must always render any arrangement, to a certain degree, arbitrary.

The only minerals hitherto observed in chlo- 
rite schist, besides the constituents of the rock, are the following:

Common and crystallized chlorite. Brown spar. Quartz, coloured green by chlorite. Tourmalin. Scaly, and octoedral oxydulous iron. Pyrites. 


\section{TALCOSE SCHIST.}

This rock is now for the first time introduced into a geological arrangement, though it is often mentioned by writers, and frequently found in the cabinets of collectors.

Although it is not common, and, where it is found, is also very limited in extent when compared with the other primary strata, it seemed impossible to avoid giving it a place here; as it occurs in the form of a rocky stratum in alternation with other substances, and cannot be considered as a variety of chlorite or of micaceous schist, when the three minerals which give the character to these compounds, are considered distinct.

As the space which it occupies is commonly very small, the strata are neither very thick nor persistent: and, in some cases indeed, it occurs in such minute quantities, that, were there no examples of its existence in larger masses, it might without inconvenience have been omitted 
in a classification of rocks, and enumerated as a modification of the simple mineral, talc, whence it derives its name and character.

It is sometimes found to form thin beds in a series of gneiss, in which case it is often associated with the hornblende schist or actinolite schist, which so often occur in the same situation ; and it, commonly also, in these cases, is conspicuous on account of the imbedded extraneous minerals, such as actinolite and cyanite, which it contains.

In a series of micaceous schist, it may also sometimes be observed that a gradual change of character takes place in some of the beds, and that they ultimately pass into this rock; which is thus found occupying a certain limited space in the series, very often presenting the form of an imbedded and stratified mass; since such collections of strata of talcose schist, are generally thick in the middle, and gradually evanescent at the edges. Sometimes the transition takes place by the intervention of chlorite schist; and talcose schist is also, in a similar manner, sometimes found imbedded in a series of this rock. 
In a few rare instances; it has been found imbedded in argillaceous schist; but, as far as I have observed, it is, in this case, generally small in quantity, and often so very limited as scarcely to deserve notice as a separate rock.

In all these cases, and more particularly in the two former, it is generally associated with some of those minerals, such as steatite and asbestos, which possess a kind of mineral affinity to talc; and is also not unfrequently accompanied by small bodies of serpentine.

The last association to be pointed out, is that with the more extensive masses of serpentine, which is scarcely however sufficiently distinguished from the former; since these masses must also be considered as included in the primary strata in which it is found. The boundary between the serpentine and the including rock, in these cases, is not unfrequently observed to consist of talcose schist ; and it moreover sometimes happens, that there is a transition between the two rocks, formed by massive scaly talc passing into potstone:

Talcose schist presents no particular varieties 
of structure requiring notice; and, as far as I have observed, it does not occur in a contorted state, like micaceous schisi ; although it is sometimes minutely undulated.

Its mineral composition resembles that of the two preceding rocks, as it may consist either of talc alone, or of talc and quartz, together with some less essential minerals. It is always sufficiently distinguishable from those rocks by the peculiar characters of the talc, and its colours are generally limited to white, lead grey, and dark obscure green.

\section{SYNOPSIS OF TALCOSE SCHIST.}

\section{FIRST DIVISION.}

Simple : of one ingredient,

A. Schistose talc.

a. Scaly and foliated.

b. Scaly and semigranular.

c. Minutely scaly-granular and indurated : the potstone of some mineralogists. 
This variety passes into serpentine, and is enumerated under that head.

\section{SECOND DIVISION.}

Compound : of two ingredients.

A. Talc, and quartz: foliated; the quartz variously disposed, and the rock bearing a general analogy to micaceous schist, into which it passes.

B. Talc, and foliated, or scaly, chlorite : passing into chlorite schist.

C. Talc, and felspar.

D. Talc and argillaceous schist : passing into common clay slate, and enumerated also under that head.

E. Talc, and serpentine; passing into serpentine.

\section{THIRD DIVISION.}

Compound: of three ingredients.

A. Talc, quartz, and felspar.

B. Talc, quartz, and mica.

The following minerals occur in talcose schist.

Asbestos.

Actinolite.

Cyanite.

Diallage.
Automalite.

Chromat of iron.

Pyrites.

Staurotide. 


\section{HORNBLENDE SCHIST.}

I HAve thought it necessary, in the present arrangement, to rank under this general title a variety of rocks, which, however agreeing in their general characters and geological relations, have been disting'uished by different names by other geologists.

'Those names, as they are used in this country, are the following : hornblende rock, hornblende schist, primitive greenstone, and greenstone slate; it is unnecessary to enumerate the terms sometimes employed for the same purpose by foreign geologists, as they only increase the obscurity of the subject, and have already generated much confusion. The reasons why three of those names are rejected, are the following.

It will, I believe, be found, that wherever hornblende rock occurs, it is only a portion of those beds of which the greater parts present the 
same characters as hornblende schist ; and, that if it is ever deficient in the schistose structure, the limits are evanescent. Further, the nonschistose varieties of this rock, are always interstratified with the other schistose rocks which they accompany, commonly in their beds; while, where numerous alternations occur, as is generally the case, some of the beds will be found deficient in the schistose structure, while others possess it in different degrees. Lastly, the same bed will, in one part of its progress, present a laminar or schistose, in another an uniformly massive structure.

The term primitive greenstone is applied to this rock whenever it consists of an intermixture of felspar and hornblende, and is not schistose ; not very correctly, since, in almost every case, the felspar is either red or white, and the hornblende black. But the chief objection to its use is the following. The greenstone of the trap family is often found in the form of veins intruding into the primary as into the secondary strata; and, in a few instances, these veins are so far parallel as to admit of being confounded with real 
beds. Such masses of greenstone can often be proved to be, not only of later date than the primary rocks into which they intrude, but even to be connected in some other part with the uppermost of the secondary strata, or to be posterior to these. But, by the same geologists, their affinity being understood to be regulated by their position, these substances have also been called primitive greenstone. Thus two rocks are confounded together which, in their origin and connexions, are amongst the most remote; and it has consequently happened in geological descriptions, drawn up by those who judge rather from the nature of a rock than its connexions, that serious errors have been committed. By limiting the term greenstone to the trap family, such errors are easily avoided or prevented.

The objections to the term of greenstone slate are not perhaps so strong, as the additional word slate has not so often been used in discriminating any of the greenstones of the trap family. But on account of the exact analogy subsisting among these several rocks, in each of these distinct families, and the total distinctness of the fa- 
milies themselves, it seemed prudent to avoid the use of a term, which, while it is unnecessary, might also be a source of confusion. One of the principal objects in view in this arrangement, has been to facilitate geological descriptions and to diminish the ambiguity arising from a misapplication of terms. In describing rocks for any other purposes, it is still in the power of those who prefer the use of the terms which have been rejected, to have recourse to them; as they are, with this view, most commonly mentioned in the catalogues of varieties.

Hornblende schist rarely occurs independently, or in such a manner as to form extensive tracts without the interference or alternation of some other primary rock. The only large mass of this nature known to me, forms the mountain of Ben Lair in Ross-shire.

It is most commonly associated with gneiss, and generally in strata of very moderate dimensions, often of great tenuity. This association is so intimate, and, in many instances, the hornblende schist is in so small a proportion to the gneiss, that it has been considered a subordinate 
rock. In other cases, however, the former equals, or even exceeds the gneiss in quantity, so that the term subordinate is in no rational sense applicable to it. Whatever theoretical views may be implied in this term, they are not matters for inquiry in this place.

Where it occurs in this association, it commonly follows all the contortions of the gneiss, and is traversed by the same granite veins: a fact which only proves that these veins are posterior to the whole series. In other cases, hornblende schist may follow gneiss without exhibiting that appearance; which equally proves that, in these, it is posterior in origin to the time at which the granite veins penetrated the inferior strata. It is also found, but less conspicuously, in Scotland at least, interstratified with those varieties of gneiss, formerly described, which are more evenly disposed and contain no granite veins. In all these instances it passes into the gneiss by alterations in the proportion of the leading ingredient, hornblende, and by the acquisition of the quartz which is nearly essential to the composition of that rock. 
Hornblende schist is far less commonly associated with micaceous schist, but is also found in that situation, forming occasional beds of very various dimensions. In these instances also, it sometimes passes into the micaceous schist by means of those varieties of the latter rock already mentioned under that head. Such intermediate substances are, as in most other cases, noted in the synopsis under each title, that the student may be at no loss in referring to them.

In almost all cases where hornblende schist occurs in the situation last mentioned, it is accompanied by chlorite schist, and by many anomalous compounds, which will be found enumerated in the synopsis, under the general title of those rocks to which they seem most nearly allied. But, besides this, it is found, in Scotland, forming a member of a very extensive and singular association of strata, already noticed under the head of chlorite schist, and consisting principally, or essentially, of quartz rock, micaceous schist, chlorite schist, and hornblende schist.

This rock is not often found associated with argillaceous schist; but where this occurrence 
takes place, it is sometimes observed to pass into it by an insensible gradation. An example of this association is visible in the mountain Ben Lair already quoted.

It must lastly be remarked, respecting its geological associations, that it accompanies that rock, so little distinguished from it, which has been placed in a separate chapter by the name of actinolite schist, and that the two pass into insensible gradations.

The forms of the strata of hornblende schist require no further detail than that already incidentally given in speaking of its associations; nor does it, in the greater number of these, present any varieties of structure requiring particular description.

But in those varieties which occur in association with chlorite schist, in that which is here called the chlorite series, the beds often present a prismatic structure which may be a source of great difficulty to geologists. That difficulty is materially increased by the texture and composition of the rock, which are, in these instances, not distinguishable from those of many green- 
stones belonging to the trap family. The prisms, in these examples, are of similar general forms and climensions to those that occur in many members of that extensive family; and, when the beds are horizontal and uppermost with respect to the surface, as they are always at right-angles to these, such rocks are not distinguishable from overlying masses of trap, without a careful investigation of their geological character and connexions,

With respect to minuter varieties of structure, or texture, it is only necessary to say, that, independently of the larger flexures and contortions to which the laminar varieties are subject; in common with the gneiss with which they are so often associated, they frequently present a minutely undulated disposition similar to that of micaceous and chlorite schists.

Both the magnitude and disposition of the separate minerals which constitute hornblende schist, are subject to great variation; and hence arise numerous varieties of texture, of which the minuter details must be referred to the synoptic catalogue. The leading distinctions of tex- 
ture, however, depend on the laminar and on the granular crystalline dispositions of the parts. In the former case, the rock is always, and necessarily, either laminar or schistose; but, in the latter, it is not necessarily the reverse; a similar fissile disposition being prorluced by the manner in which the crystalline particles are arranged. In those cases where, to a granular texture, there is superadded a massive or non-fissile disposition, it forms that which has been already mentioned as constituting the hornblende rock of many geologists.

Whatever appearance of a mechanical disposition, may arise from the occasional laminar alternation of the ingredients of this rock, it is unnecessary to make any remarks on it, as they would only be a repetition of the doubts already stated under the head of micaceous schist. It is barely necessary to observe, that the texture appears to be truly crystalline, or chemical, in all the varieties; and that it has not hitherto presented. any, containing, like micaceous schist, decided fragments of other rocks.

The minerals essential to hornblende schist, 
are felspar, either compact or common, and hornblende; but the latter often occurs alone. In this respect it differs from micaceous and chlorite schists, in which the characteristic minerals seldom exist without some quartz. The less essential minerals which sometimes occur in this rock to such an extent as to modify its general characters, are mica and chlorite; but the latter is rare, nor is the former very common.

As an imbedded mineral, garnet sometimes abounds in this rock, as it does in micaceous schist, but much -more rarely; and the general character and aspect of the hornblende schist present corresponding variations. The other, and more rare imbedded minerals, will be noticed in a more appropriate place.

As the colour of hornblende is almost invariably either black, or a green so dark as scarcely to be distinguished from it, the only varieties of tint in the rock depend on the proportion and colours of the felspar. A large proportion of that mineral produces a grey hue, which varies in intensity according to that proportion, and, in tone, as it approximates to white, green or red. 


\section{SYNOPSIS OF HORNBLENDE SCHIST.}

\section{FIRST DIVISION.}

Simple: of hornblende alone.

A. Very compact, with a smooth and dull fracture; the particles being almost invisibly minute.

B. Granular, from small irregular aggregated crystals : varies in the degree of fineness.

C. Scaly, from an aggregation of flat crystals.

D. Flat continuously laminar.

a. Large laminar.

b. Minutely laminar.

E. Fibrous.

a. Simply fibrous and with short fibres.

b. Fibrous, radiated.

c. Very fine fibrous and silky.

F. The texture so fine that it loses its character and passes into argillaceous schist.

These varieties are sometimes imperfectly, or not at all fissile, and thus form what is called hornblende rock. Occasionally many different textures are intermixed in the same mass, or specimen ; thus producing additional diversities of aspect. Sometimes large distinct crystals of 
HORNBLENDÉ SCHIST.

hornblende are imbedded in the crystalline aggregate.

\section{SECOND DIVISION.}

Compound : of two ingredients.

A. A laminar alternation of hornblende and felspar,

a. Continuous platy and schistose, easily splitting.

b. Continuous platy, but scarcely or not at all fissile.

c. Granularly laminar, and imperfectly schistose.

B. The hornblende scaly or fibrous, and the felspar arenaceous : not occupying distinct laminæ.

C. A granular uniform mixture of the same ingredients.

a. Scaly, splitting into rough schists or imperfectly fissile.

b. Uniformly arenaceous and mixed ; fissile.

c. Mottled, from the particles of hornblende being condensed in spots and patches.

d. Dull, both substances minutely intermixed and compacted.

e. A very compact distinct intermixture of the two ingredients : not schistose, and undistinguishable from the greenstone of the overlying rocks.

Many aspects result from the varying sizes of the 
grains of both substances, and from their relative proportions: the felspar being sometimes in equal proportion, at others scarcely discernible. These modifications also vary in colour ; the felspar being white, greenish, or red. The hornblende also may be black or dark green. The laminar mixtures are also sometimes straight, at others large or minutely undulated, It is to these varieties that the term primitive greenstone seems to be applied.

D. The felspar in excess, and the mixture granular.

This rock is placed here on account of its geological connexions, occurring with common hornblende schist and chlorite schist, in the chlorite series of Argyllshire. Its aspect is however entirely different from that of any, other hornblende schist. The felspar being of a greenish colour, that of the rock is a greenish grey.

E. A minute admixture of hornblende with dark compact felspar; the two minerals not distinguishable without much attention. The felspar is dark green or lead blue. 
The aspect of these varieties is so different from those of any of the preceding, as to justify a distinct enumeration.

F. Common hornblende schist with interspersed particles and filamentous veins of bright green compact felspar.

This, like the former, has a very remarkable appearance. It occurs in Iona, as the former do on the west coast of Ross-shire.

G. Hornblende with mica; the former is in excess and the rock fissile.

Mixtures of micaceous schist and hornblende may be confounded with this when the hornblende predominates; but they differ in containing quartz, and are enumerated under the head of micaceous schist.

H. Hornblende and chlorite intermixed.

This is also enumerated under the head of chlorite schist.

\section{Hornblende and actinolite.}

This passes into actinolite schist. The distinction between these two minerals is not 
great; but, in this case, the hornblende is black, and scaly or granular; the actinolite green and fibrous.

K. Hornblende and indurated talc.

This variety appears to pass into serpentine, and is enumerated under that head.

\section{THIRD DIVISION.}

Compound : of three or more ingredients.

A. Hornblende, mica, and felspar.

B. Hornblende, felspar, and quartz.

C. Hornblende, actinolite, and mica.

D. Hornblende, chlorite, and felspar.

E, Different quaternary mixtures of these ingredients, which do not require to be particularly specified.

These varieties are placed here for facility of reference; but some of them appertain to gneiss, under which head they are also enumerated, while others will be found under other titles.

The varieties of aspect in all the rocks of this division are endless, and arise from the varying colours, magnitude, proportion, and intermixture of the several ingredients. 
The only minerals hitherto found embedded in hornblende schist are iolite, pyrites, and garnet. The latter sometimes occurs in such quantity as materially to modify the appearance of the rock. It is sometimes imperfectly crystallized; or more perfectly, as it is in micaceous schist: in some rare cases, it is disposed in laminæ among those of the hornblende. 


\section{ACTINOLITE SCHIST.}

It may perhaps appear superfluous to distinguish this rock from hornblende schist; but as it has been mentioned by Saussure, as it occurs in gneiss under a distinct character, and also very conspicuously in the chlorite series elsewhere described, it will facilitate the student's pursuits to find it in a separate place. Its analogy in position, and in other characters, to hornblende schist is in every particular so perfect, that these will require no additional notice. Its most striking difference will be found to consist in its frequent and intimate association with chlorite schist ; the mineral, which is characteristic of the latter substance, being frequently intermixed with that which characterizes the former, in such a manner that the two rocks pass into each other by an insensible gradation.

Substituting actinolite for hornblende, the de- 
finition of both rocks is the same. It may also be remarked, that it is often the repository of the several varieties of the mineral of which it is principally composed, and that it is generally easily recognised by its green colour, as well as by the peculiar properties of the characteristic mineral. If mineralogists should finally think fit to consider actinolite as a variety only, of hornblende, actinolite schist must also be replaced among the varieties of hornblende schist; but as long as these minerals continue to be distinguished as species, it will be convenient to pursue the same plan with respect to the rocks in question.

\section{SYNOPSIS OF ACTINOLITE SCHIST.}

\section{FIRST DIVISION.}

Simple: of one ingredient.

A. Antiinolite under various appearances.

a. Formed of distinct interlaced crystals varying in size. 
b. Formed of a confused aggregate of small crystals: sometimes acicular.

c. Passing from the preceding variety into a granular texture.

d. Flat foliated.

e. Fibrous: the fibres straight or undulated.

It varies in colour through different shades and tints of green; from dark bottle green to sea green, and even to white.

\section{SECOND DIVISION,}

Compound : of two ingredients.

A. Actinolite and felspar.

B. Actinolite and hornblende.

C. Actinolite and mica.

D. Actinolite and talc.

E. Actinolite and cllorite.

This last compound is also enumerated under the head of chlorite schist.

\section{THIRD DIVISION.}

Compound: of three or more ingredients.

A. Actinolite, hornblende, and mica.

B. Actinolite, hornblende, mica, and felspar.

It is not unlikely that other compounds exist which would fall into this division, but they have not yet occurred in my researches. 


\section{QUARTZ ROCK.}

ThIs important member of the primary strata has been long known to geologists, but had never been thoroughly understood until it was described in a succession of papers published in the Transactions of the Geological Society. An abstract of these was afterwards introdaced in the "Description of the Western Islands," to which work the reader may be referred for a fuller account of its geological characters.

Quartz rock, like the primary rocks with which it is usually associated, is stratified; the distinction of the beds being however much more strongly marked than they are, either in gneiss: or micaceous schist, and very commonly as well defined as in the secondary sandstones. They vary exceedingly in dimensions, even from an inch to many yards in thickness; and as they often possess natural joints, they break, like many of the schistose rocks, into rhomboidal or rectan- 
gular fragments. The strata are occasionally, but rarely, bent, and they never present those contortions which are so common in micaceous schist.

With regard to the precise place which quartz rock occupies among the primary strata, nothing positive can be laid down; since it is found alterrating with all those which follow granite.

Under the head of gneiss it was already mentioned that this rock was frequently found alternating with it, and that the limits of the two were; often undefinable. The variety which occurs in this case, is generally that which contains felspar as an ingredient, and the change is produced by the loss of the other ingredients by which gneiss is characterized. In this association, the beds of quartz rock are often inferior in quantity to the gneiss, or subordinate; but alternations also occur among strata of dimensions so extensive âs not to permit the use of this term.

In many places it will be found to alternate in thin strata with micaceous schist; and it was already showr that many of the rocks ranked with this substance; contain but a rery sparing quan- 
tity of mica, while their predominant ingredient is quartz in various states of mixture. Such varieties holding an intermediate state between two rocks, have an equal claim to be ranked under either; but as it is a fruitless attempt to define that to which nature has not set bounds, and as no advantages are gained by multiplying terms to express such gradations; it is most proper to class the doubtful specimen in that division which is the predominant one, geologically considered. Thus the occașional presence of mica will no more exclude a specimen or a bed from the series of quartz, rock, than the predominance of quartz will remove an occasional bed from the mass of micaceous schist in which it is situated:

But the alternations between micaceons schist and quartz rock, are often more decided and on a larger scale; a sudden and complete change taking place where they meet. Scarba and Jura afford abundant examples of this nature, and it is also to be found in many other parts of Scotland. The space occupied by the quartz rock in these cases is so great, that it constitutes the chief part of the series, and cannot therefore be considered 
as subordinate to the micaceous schist. In many places indeed this latter substance is altogether wanting; large tracts of country, exhibiting strata of some thousand feet in thickness consisting solely of quartz rock; giving it thus a decided claim to be ranked as a principal nember of the primary class.

As micaceous schist and clay slate have been shown to alternate, thus quartz rock also alternates with this latter substance. The mode of this alternation, like that of the former, is various; the laminæ being of greater or less thickness. On a small scale, these alternations are not unfrequent; between large beds they are rare. In some of these cases the same gradation occurs between those two substances, as in the alternations of micaceous schist with quartz rock; but in others, they are separated foy a precise line. Of this latter variety, Jürand Scarba offer striking examples; the quartz rock possessing a wellmarked and independent character, and forming. a principal member of the whole; while the clay slate and micaceous schist alternate with it.

A more interesting alternation is that of quartz 
rock with graywacke schist, and in this instance its analogy with the secondary sandstones which so often follow that substance, is particularly apparent. Jura, Scarba, and Lunga, afford conspicuous examples of this association.

It is also found associated by alternation with primary sandstone, which it so much resembles in many important particulars; but, in this case, the alternations appear always to be on a large scale, or, at least, none have occurred within my observation where it can be considered as subordinate in quantity.

Peculiarities of structure in quartz rock are very rare; but, where they occur, they are interesting from their resemblance to those which are found in the secondary sandstone. Thus it often contains the indications of spheroidal, and of a cylindrical, or minutely columnar, imbedded structure, exactly resembling that, hereafter described at more length in the account of those rocks, but far less distinet, and less frequently exposed by the action of the weather. In a few very rare instances also, of which an example is found in Glen Tilt, it contains prolonged and 
flattened cylindrical bodies of considerable size, very much resembling those found in the secondary sandstones; but without the scaly surface, and easily detached, even without the assistance of the weather, from the surrounding mass.

The varieties in the mineral character of quartz rock are numerous; but I shall limit this enumeration to the most important and the best marked, as a more full account of them will be found in the Synopsis.

It is occasionally, but rarely, found in a compact state, and crystalline throughout ; little differing from quartz as it occurs in veins; but even in these cases showing a constant tendency to divide in parallel beds. More generally, when pure, it has an aspect obscurely granular, which. by degrees becomes somewhat lax and arenaceous; the grains varying in size and in the intimacy of their union. In some of these examples, it appears to be a granular crystallized mass ; in others, it possesses a mixed mechanical and chemical texture; while, in a third, the rounded aspect of the grains, and the small number of the 
points of contact, appear to indicate an origin chiefly mechanical, and resulting from the agglutination of sand. These are its varieties when in the purest state; and I may add, that cavities are sometimes found in the specimens, containing regular, although minute, crystals.

The next, and perhaps the prevailing variety of this rock, consists of a mixture of quartz and felspar; and, from the latter, it generally derives a reddish hue. Its texture is various, the grains of felspar being at times imbedded in a crystalline quartz, while, more frequently, the whole rock is a mass of agglutinated grains of the two substances, in various proportions and of various sizes. In every instance it has a foliated disposition; and, sometimes, even the texture is the same, since it splits into lamina of extreme thin. ness.

The next remarkable variety is that in which quartz is intermixed with mica; but I have already said all that is necessary on this subject when treating of its alternation and affinity with micaceous schist. I may only add, that, in these cases, it often admits of being split in the direc- 
tion of the micaceous laminæ into large flags applicable to the purposes of architecture.

Tracing the progress of the granular kind, we find them at length consisting of grains so large as to appear mere agglutinations of gravel, with occasional vacuities among the grains; nor is it uncommon to find specimens containing rounded pebbles of large size. In these varieties the marks of mechanical formation are obvious ; and they are rendered still more so by the occasional intrusion of dissimilar fragments, such as jasper, clay slate, and micaceous schist, examples of which occur so as to form considerable beds both in Scarba and in Jura. From these, the passage into common graywacke is easy, and, in these islands, abundantly obvious.

Quartz rock never appears to contain any unessential minerals capable of modifying its general characters; and it is equally remarkable that it is very rarely the repository of any independent mineral, except garnet and pyrites.

The colours are extremely limited. In the purer varieties, white is the predominant hue; but they are occasionally to be found tinged with 
ochre yellow, or with reddish, and even dark purple tints. Where mica is present, the colour is often grey; and the presence of felspar, in the same manner, often confers a pink or flesh coloured hue on the compound rock.

\section{SYNOPSIS OF QUARTZ-ROCK.}

\section{tancitan}

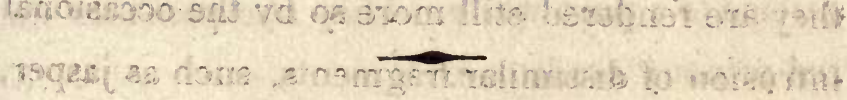

\section{0 astgnase FIRST DIVISION.}

Simple: of quartz alone.

A. Pure quartz, resembling that which occurs in veins.

a. Hyaline.

b. Opake.

B. Pure quartz, compact, laminar; often very finely fissile or almost scaly : sometimes laminar and striated.

C. Granular splintery; occasionally passing into the uniformly compact.

D. Granular: with large grains or concretions. a. Crystalline compacted, and either transparent or opake.

b. Gravelly, with distinct condensed grains. 
E. Arenaceous, or finely granular.

a. Condensed saccharine, passing into var. C.

b. Loose, arenaceous, resembling the secondary sandstones.

These varieties are occasionally blueish grey, or ochre yellow, or brown or dark red, or deeply stained on the surface with a reddish yellow from the decomposition of pyrites. They are sometimes yellow internally, and bleached on the surface to a pure white. They also pass into the red primary sandstone.

\section{SECOND DIVISION.}

Compound : of two ingredients.

Hirst suBdivision.-Of quartz and felspar.

A. The quartz compact, opake or hyaline, with imbedded particles of felspar irregularly disposed.

B. Similar varieties of quartz with interspersed felspar, but with a laminar tendency; the felspar also predominating in one lamina rather than in another.

This variety often presents a resemblance to gneiss, which it frequently accompanies. 
C. An uniform rock, more or less laminar, with a fracture intermediate between the granular and splintery.

This rock is apparently homogeneous, but is proved to contain felspar by the white siliceoargillaceous crust which it assumes on weathering. A similar rock occurs with the primary sandstone, where it is also enumerated.

D. The quartz and felspar both in distinet grains and intermixed in various proportions.

a. Highly compacted, and cemented by silica, or quartz.

b. Gravelly, or sandy, sometimes loose.

There are many different aspects of these varieties, arising from the varying proportion of the two ingredients. In some cases, the felspar bears a very small one to the quartz; in others, but more rarely, it is the reverse. In some specimens, the felspar being white, it can scarcely be detected but on weathering. Varieties of a large grain are occasionally found, in which the particles are large and have suffered little attrition before their consolidation, and these have been - sometimes mistaken for granite. 
SECOND SUBDIVISION.-Of quartz and mica. mica.

A. Compact quartz with interspersed scales of

a. The quartz opake.

b. The quartz hyaline.

This latter sometimes forms the substance well known by the name of avanturine, and already noticed under micaceous schist; the colours varying according to those of the mica or the quartz.

B. Laminar ; the lamination of the quartz being chiefly determined by the position of the mica.

a. The mica in distinct scales, dispersed, but parallel.

b. The mica accumulated in distinct lamine.

This variety passes into micaceous schist, and is enumerated under that head. It forms the bond of union between these two rocks. The colours of these varieties differ; according to those of the mica which they contain. 
THIRD SUBDIVISION. - Of quartz and blue

$$
\text { schistose clay. }
$$

A. A laminar alternation of pure quartz and clay slate.

B. Quartz, arenaceous and minutely interlaminated with black or blueish clay; resembling some of the sandstones that accompany coal. clay.

C. Quartz sand intimately mixed with blueish

This passes into the fine graywacke schist which alternates with some examples of quartz rock.

\section{THIRD DIVISION.}

Containing more than two ingredients; or of a conglomerated structure.

A. Quartz sand alone, or sand and gravel of quartz and felspar, with imbedded pebbles or fragments of quartz.

B. The same, with fragments of argillaceous schist.

C. The same, with fragments of micaceous schist, or with both.

These latter varieties pass into coarse graywacke schist, and graywacke conglomerate, as the 
former do into fine. They present great varieties of compactness, and are either distinctly schistose or not. They may be equally ranked with the graywackes under the head of argillaceous schist.

Quartz rock, when in the vicinity of granite, is sometimes broken and re-united, forming peculiar local conglomerates; and, in these cases, the cavities which sometimes occur, contain quartz crystals.

I have observed no minerals imbedded in quartz rock, except garnet, hornblende, oxydulous iron, and titanite; and even these are rare. 


\section{1}

\section{RED PRIMARY SANDSTONE.}

Tuis is now for the first time introduced into a catalogue of rocks. An abstract of the reasons for this innovation may be deduced from the sketch of its geological connections which follows. A more full account of the history of this interesting member of the primary strata, is inadmissible in this work; but it will be found in the authors' volumes already quoted, where an ample detail is given of the evidence which justifies the arrangement here adopted.

If the specimens are sometimes not very distinguishable from those which are found in the lowest sandstone of the secondary class, the geological nature of this classification did not the less demand the present proceeding; which is, moreover, strictly analogous to that, long since admitted in the case of limestone; in which rock, a distinction between the examples found in the 
primary, and those occurring in the secondary classes, is often equally difficult.

The alternations of red sandstone on the large scale, are with gneiss and with quartz rock; and as it has hitherto been examined only on the north-west coast of Scotland, the history of its geological position is limited to the phenomena there visible. Under this system of alternation; it-occupies very extensive tracts, forming also some of the highest mountains which Scotland possesses.

Although, in some places, its regular alternation with the gneiss is distinctly perceptible, in others it follows the strata of that rock in a reverse or unconforming position; being sometimes nearly horizontal where these are much elevated. In these instances, the sandstone appears to be connected with the gneiss by the intervention of a conglomerate formed of fragments of the latter, which, generally however, seems tó occupy a very limited space.

Where it alternates in a parallel manner with the gneiss, it is often found to pass into that rock ly an undefinable transition ; and this is effected 
in two modes. In Sky, the gradation is produced by the gradual attenuation of the beds of argillaceous schist which so frequently alternate with this sandstone. These gradually become the laminæe of a variety of gneiss which is described in the account of that rock; and, finally changing their character into chlorite schist, they produce another variety which, in a manner equally imperceptible, passes into the best characterized beds of that substance. In other places, thie beds of the argillaceous schist form the bond of union ; alternating in such a manner with the strata of the sandstone, and with those of the gneiss also, that it is impossible to fix on a point where the transition can with certainty be said to take place:

The transition from the red sandstone to quartz rock, is, on account of the affinity of the two, so easy, that it requires no particular notice: particularly as it is mentioned in treating of that substance.

Besides these extensive alternations of the great tracts of red sandstone, the strata alternate with many varieties of argillaceous schist as was noticed in the last paragraph; but most fre- 
quently with those of a coarse texture, which contain either mica, or sand, or both, and which are commonly known by the name of graywacke. In most cases, the schist is far inferior in quantity to the sandstone; and, in many, it is entirely? absent for a very considerable space. Some few instances may however be observed, where it considerably exceeds that rock, and where, if the term subordinate were admissible, the sandstone should be considered the subordinate substance: Respecting these alternating schists, it may yet be remarked, that some of them contain fragments of older rocks, and that a few are highly indurated, so as almost to lose their ordinary characters. If ever the sandstone appears to pass into the schists, the transition is almost always too imperfect to deserve notice as an instance of that occurrence. In most cases, the two rocks are separated in a very decided manner.

The thickness of the strata is extremely variable; amounting sometimes to many yards; and in those cases where schist is present, they are frequently of extreme tenuity. In some places, the beds are even separated into their laminse 
without the intervention of schist-sometimes it would appear, from the action of the weather, and, at others, in consequence of a slender micaceous lamina; in which cases they often resemble the laminar, or schistose sandstones of the : secondary class.

These strata, like those of gneiss, are in many places subject to flexure and contortion; and where these flexures are sudden' and considerable, it is not unusual for the stratified disposition to vanish entirely, and in such a manner as to permit a gradation to be traced from the most shapeless and fractured mass to the most regular stratification. In such cases, the shapeless mass is broken or divided into very irregular angular portions ; but the more regular strata are commonly split into prismatic and cuboidal masses like granite, and, when the angles have been rounded by exposure, scarcely to be distinguished from them at a distance. The only other circumstance of internal structure deserving notice in this rock, is an indulation on the surfaces of the beds; which is also known to occur in the 
secondary sandstones, and which so much resembles the marks left by the retiring sea on a shore of sand.

The texture of this rock is various. It is sometimes fine and granular, resembling the more ordinary varieties of the red sandstone of the secondary class. But it is much more common to find the granular intermixed with a continuous crystalline texture; or the grains, which occasionally adhere by mere agglutination, are. united into a continuous mass by a cement of crystalline quartz. 'That compactness is sometimes so perfect, that the marks of a granular imbedded structure, nearly, or entirely, disappear ; and the sandstone then resembles those varieties of quartz rock which are scarcely distinguishable from common venous quartz. Under such circumstances also, and under particular modes of composition, it sometimes presents a minute splintery fracture. It is in this circumstance of frequent and crystalline compuctness, that this sandstone is principally distinguishable, in hand specimens, from those of the secondary 
class. When doubts arise on that subject, the geological position is necessarily, as in all analo-" gous cases, the only guide.

The texture, from beng finely granular, or arenaceous, becomes gravelly or coarse, and, at length, passes to an ordinary conglomerated structure. That mode of disposition, however, often differs sufficiently from that which occurs in the secondary sandstones, to eirable a mineralogist who is acquainted with both rocks, to recognize the differeuce, even in hand speciments. Where the fragments are numerous and nearly equal in size, they are often united in such a manner by a crystalline agglutination, as to deceive an unpractised eye so as to pass for granite. Where they are rounded, however, as is most frequently the case, that mistake cannot happen. Moreover, even in the coarsest conglomerates, the fragments are often united by, or imbedded in a crystalline basis like that which forms the finer varieties. It must lastly be remarked on the subject of texture, that single, or widely detached fragments, are very commonly found imbedded in the finer varieties, even throughout a 
whole series of strata; a circumstance of very rare occurrence in the secondary sandstones.

The mineral composition of this rock is in general far simpler than that of the corresponding secondary sandstone; a circumstance not difficult of explanation when its more antient origin is considered. The prevailing strata consist either of quartz alone, or of quartz mixed with felspar; and the latter mineral is much more commonly crystalline than reduced to the state of clay. Argillaceous varieties are therefore comparatively rare, and mica is also very seldom found in this sandstone. In the conglomerate varieties, the prevailing fragments consist of quartz and felspar. Red jasper is also not unfrequent; and, if the compound rocks, of which the characters are still to be traced, I have rarely observed any except gneiss and argillaceous schist. Where this latter rock abounds in the fragments, it often also forms a sort of joint cement for the whole mass, and the specimens of this character thus pass into a graywacke or coarse argillaceous schist. All these fragments may be either angular or rounded; but the latter form is prevalent; 
and the jasper, in particular, seems to be invariably worn by attrition.

The prevailing tints are varieties of red, but they are more particularly detailed in the synopsis.

\section{SYNOPSIS OF PRIMARY SANDSTONE.}

\section{FIRST DIVISION.}

Simple : apparently of quartz only.

A. Granular.

a. Coarse grained.

b. Fine grained, passing to compact.

B. Compact, the fracture rough, but the grains scarcely distinguishable: passes into quartz.

C. Splintery in the fracture; passing into the granular, and also into the compact: some of the varieties have an aspect much resembling that of compact felspar.

The colours are various, but modifications of red are predominant. These are, pink, bright brick red, brown red, purple red: it also occurs of a pale grey, of a lead blue, of an ochre yellow, 
of a dark brown approaching to black, of black and red intermixed, of red and white intermixed in stains, or in stripes and laminæ, and of a pure white. The colour is disposed in the mottled varieties exactly as it is in the secondary variegated sandstone, but these varieties are rare. The white, is ordinary quartz rock, into which this rock passes and with which it is sometimes connected.

\section{SECOND DIVISION.}

Compound : of two ingredients.

A. Of quartz and felspar.

a. Distinctly granular, and each substance easily distinguishable.

The colours, and consequently the aspects of this kind, are various; as both the ingredients may be red, or white, or either may be of a different colour from the other. It also differs materially in the size of the grains, varying from gravelly to fine arenaceous.

b. A mixture of quartz and felspar so intimate that the latter substance is only discovered by the weathering of the 
stone, when it assumes a white siliceoargillaceous crust. The fracture is commonly splintery with a translucent edge.

This variety appears, at times, almost to pass into compact felspar. The colours are generally shades of grey; leaden, pale, or greenish ; more rarely, red.

B. Of quartz, sand and clay.

a. The clay red, and appearing to be the result of decomposed felspar.

b. With grey clay, apparently produced from decomposed schist, and of various shades of grey, often nearly black.

This variety passes into common fine graywacke, and into fine argillaceous schist, (clay slate,) with which many varieties of the primary sandstone alternate, as before mentioned.

\section{THIRD DIVISION.}

Compound : of three or more ingredients.

A. Quartz and felspar, with mica.

This variety is more or less distinctly laminar; the laminæ being determined by the mica. It passes into a flaggy or schistose sandstone. 
B. Quartz and felspar, with blue schistose clay and mica, or quartz alone, with the two latter ingredients.

This variety is more or less laminar, and passes into the micaceous graywacke which also alternates with the primary sandstone.

\section{FOURTH DIVISION.}

With a coarse structure: sandstone conglomerate.

A. Fragments of quartz and felspar firmly united by crystalline quartz.

B. Quartz, felspar, and hornblende, similarly compacted.

C. Quartz, and felspar, with fragments of jasper.

D. The same, with fragments of schist, or with both.

E. Distinct fragments of gneiss, and of granite, firmly cemented by solid quartz.

F. The same substances in greater or less number, with so large a proportion of schist as to pass into a conglomerated graywacke, under which it may also be equally ranked.

These different compounds present a great diversity of aspect, and are enumerated here as well as under the head of conglomerates, for the 
purpose of rendering more complete the history of this hitherto neglected rock.

The only mineral which I have yet observed in this sandstone is garnet. It occurs either in indistinct crystals, or diffused ; and is only found in the very compact varieties, which are charac terized by an uncommon degree of hardness wherever it is present. The presence of this mineral, which is unknown in the secondary red sandstone, may be regarded as an additional and important characteristic mark of difference between the two; and, from analogy, as indicating a much more antient origin, since it belongs exclusively to the primary rocks. 


\section{ARGILLACEOUS SCHIST.}

UNDER this head are included all the schistose argillaceous rocks of the primary class, however differing in texture, and it thus comprises the clay slate and the graywacke of some geologists. The reasons for adopting this innovation are the following.

In all cases, the coarser and finer varieties of this rock occur as parts of one series, however the one or the other variety may predominate in particular instances. If ever fine beds, or strata of clay slate, are found unaccompanied by coarser, or if the coarser are occasionally seen excluding the finer, these instances are insufficient to justify a separation of the two, any more than the separation of gneiss or of micaceous schist of coarse and fine textures would be justified by similar circumstances. Moreover, even the same bed will sometimes present both textures; the 
variation taking place, either laterally, according to the extent of the strata, or transversely, according to their stratification.

Lastly, this arrangement is justified by the corresponding practice in the case of sandstone which this rock resembles in its prevailing mechanical texture and composition. In that rock, no geological distinction is made between the varieties of fine and those of coarse texture; although the differences between the conglomerates and the fine sandstones, are far greater than any that occur in the series of argillaceous schist. It will indeed be seen on the slightest review of the former system of division, that it has arisen from defective observations, combined with, or biassed by, hypothetical notions respecting a supposed necessity for placing the coarse argillaceous schists, or graywackes in a transition class. That such mechanically recomposed strata should occur among the primary rocks, is no more cause of surprise or difficulty, than that conglomerate varieties of micaceous schist, or of quartz rock, or of red saudstone, should be found in the same situation.

Argillaceous schist, like micaceous schist, 
occurs in two modes; in the one, forming very extensive tracts of country; in the other, alternating in small proportion with many other rocks, and often in a very intricate manner.

In this country, where it is found occupying great spaces, it is generally the uppermost rock of the primary strata, being immediately followed by the secondary class. The same remark has been made in other countries; but, in many instances, there is reason to suspect that these observations have been biassed by theoretical notions respecting the place which it is conceived necessarily to hold in the order of nature. In other cases, it alternates with one or more of all the primary strata ; often also lying in the immediate vicinity of granite, as it does in Cornwall. In Scotland however these alternations chiefly occur where it occupies a small space in comparison with the other rocks among which it lies.

In this manner it is found accompanying gneiss, micaceous schist, quartz rock, and red sandstone; and, in the latter case, it sometimes appears to form a necessary part of the series, as already noticed under that head. 
In Jura and the connected isles, it forms a triple series with quartz rock and micaceous schist, occurring in very thin beds and in frequent alternations; and, on the adjoining main land, in many places, chlorite schist and limestone are superadded to this series.

In the line which forms the Highland boundary to the southward, it occurs in a similar way in a very irregular manner; the different varieties being intermixed with chlorite and micaceous schists; as also with limestone and minute beds of gneiss. The island of Bute presents this series in great perfection.

The stratification of argillaceous schist admits of no question, however difficult it may often be to trace the beds. They are sometimes extremely irregular in their forms and disposition, and they vary very much in dimension. Where they atternate with other rocks in the manner last described, they are often very thin; but where they occur in extensive tracts and unmixed, they attain to such a thickness that it is frequently impossible to discover the places where they are separated. In this respect they present the same dif- 
ficulty as micaceous schist ; in which, as already remarked, it is often impossible to trace the divisions of the strata. These separations between the heds, are sometimes caused by intervening rocks of some other character; but, more frequently, they result from a change of texture in the approximate parts of the general mass.

The strata of argillaceous schist are subject to flexures similar to those which occur in micaceous schist and gneiss; but the rock itself is rarely contorted in the very minute manner in which those sometimes are.

It presents also some varieties of internal structure, one of which constitutes its chief value for the purpose of architecture. This is the schistose disposition, in consequence of which it is capable of being split into slates, of considerable tenuity in many cases; while, in others, it rather presents imperfect indications of a fissile tendency, than the property of dividing into continuous plates. This quality occurs both in the finer and coarser varieties; but the former possess it in the most perfect manner, although many 
of the latter, or the graywacke schists, are sufficiently divisible for œconomical purposes.

In most cases, these laminæ are indefinitely; although imperfectly, divisible; so that the entire structure of the stone is schistose, or nearly scaly; but, in others, it appears limited to some definite dimension, so as to afford examples of that which, in the 8th chapter, is distinguished from the schistose structure by the term laminar.

In general, the schists are flat, being sometimes also smooth ; but, in others, they are minutely undulated. In some rare instances, however, an example of which may be seen in the island of Luing, the laminæ are bent while the strata themselves are straight. This occurrence indicates that the laminar disposition is not invariably the consequence of the mode in which the rock was deposited; a fact which is further proved by the following circumstances.

Although the fissile tendency is often parallel to the plane of stratification, it will sometimes be observed to lie in an oblique direction to that; proving, as in the former case, that it is the result of a concretionary structure. A more cer- 
tain proof of this is, in some instances, afforded by the persistence of the fissile tendency, or the lines of splitting, through beds which, in different places, present an alternating fine and coarse texture indicating the true position of the stratum, or that in which the deposition of the materials took place.

As the seams, or divisions of the strata of argillaceous schist, are often invisible, either in consequence of their great distance from each other, or from the nature of the ground, or from other causes, the fissile direction may often be mistaken for the plane of the stratification. The alternation of the fine and coarse kinds, here serves to mark the true disposition of the bed, eveli where the different textures are not actually divided; but where neither of these indications are present, there seems to be no criterion by which the one can be distinguished from the other.

This doubt is necessarily confirmed by the fact, that, in many instances, the fissile tendency is actually parallel to the plane of stratification, as it invariably appears to be in the secondary argillaceous schists or slates. In these cases it 
must ever remain a doubt whether this structure is the result of a concretionary arrangement or a mechanical deposition. From the other instances occurring in the same rock, we should be inclined to determine on the former; while, from the analogy of the shales, of which the mechanical structure is proved by the vegetable remains deposited in them, we should decide on the latter.

A fibrous structure is not unfrequent in the finer varieties of argillaceous schist, and it is often combined with the laminar or schistose disposition. It may lastly be remarked on this subject of structure, that, in a bed which is principally laminar, there are sometimes found nodules of the same substance, massive and imbedded; the laminæ in the vicinity accommodating themselves to the form of the nodule.

Beds of argillaceous schist are frequently divided by natural joints, which are either at right angles, or oblique, to the plane of stratification. According to these circumstances, they frequently separate into rhomboidal or prismatic 
fragments, more or less regular, and presenting great diversity of form.

They are moreover very frequently intersected by numerous and minute veins of quartz or of calcareous spar ; which, in the case of contortions, frequently follow the flexures of the schist in which they lie; a fact of considerable interest in a geological view.

The essential minerals of the argillaceous schists; are the peculiar indurated clay which by itself forms all the simple varieties, together with quartz and mica, which enter into the coarser or compound kinds. The conglomerated varieties, or the coarse graywackes, contain, in addition to these, fragments of some of the primary rocks. It ought also to be added, that in some rare instances, grains of felspar occur in such a manner as to give the rock a porphyritic appearance.

According to these different circumstances, the texture of the several varieties differ; the finer, presenting one which is perfectly compact and uniform, while the micaceous, the sandy, 
the gravelly, and the conglomerate kinds, are each characterized by textures which these terms will sufficiently explain. A parallel disposition of the mica, is sometimes, in the micaceous varieties, a common cause of fissility, where no such tendency is perceptible in the base. In many of these rocks, it is apparent that the parts are united by something more than a mechanical adhesion. This seems to be the case in many of the compact kinds, or the hone slates, and occasionally, in some of those which contain abundant grains of quartz; but, in the greater number, the indurated clay forms the cement which unites all the fragments, whether great or small, into a solid mass.

The transitions by which the argillaceous schists pass into some of the preceding rocks, have already been mentioned; and it will hereafter be seen, that, under certain circumstances, they also pass into siliceous schist, and into sandstone. Respecting fracture, it is almost unnecessary to say, that it varies according to the direction in which it is made, and according to the nature of the particular variety; but these and 
other matters will find a more appropriate place in the synopsis, where the unessential minerals are also enumerated.

The last circumstance of importance in the general character of the argillaceous schists is, that they sometimes contain organic remains, and even in considerable abundance. These are, however, much more limited in variety than those which occur in the secondary class; but the species have not yet been enumerated or investigated. In a geological view they are highly interesting.

\section{SYNOPSIS "OF ARGILLACEOUS SCHIST.}

\section{FIRST DIVISION.}

Simple: of indurated schistose clay alone.

A. Straight fissile, or continuously laminar.

a. With a straight even fracture on the surface of the lamina.

b. With a rough or undulated fracture. 
The prevailing colour in these varieties, which form roofing slate, is lead blue. It is also of a pale grey, or of an obscure purple, or greenish grey, or mottled with two colours. The greener varieties are not abundant, are coloured by chlorite, and pass into smooth chlorite schist. It occurs, but rarely, of very pale greyish and greenish hues, or nearly white.

B. Imperfectly fissile: inassive slate.

a. Amorphous, but breaking more readily in one direction than in another.

b. Amorphous, considerably harder than the former, and breaking nearly alike in many directions.

c. Fibrous.

d. Massive, but splitting in many directions, with curved surfaces.

e. Black, imperfectly fissile, of a dull earthy aspect.

f. Black, and so soft as to mark paper: black chalk, or drawing slate.-Some varieties of black chalk are fissile.

g. In spheroidal concretions imbedded in the laminar varieties.

C. More compact, with a smooth splintery, or minutely granular and splintery fracture, translucent on the edges. Whet slate, or hone. 
a. Compact, imperfectly fissile, the fragments translucent, and much resembling compact felspar:-common hone.

b. Laminar or scaly; straight or undulated, and the fragments translucent:-also used as hone.

c. Granular, rough: less translucent, particularly when of a dark colour.

These varieties are frequently of a pale yellowish, or greenish grey colour ; sometimes lead blue, or the two colours occupy alternating laminæ. They often weather, like compact felspar, so as to display a white powdery surface, and are at times not easily distinguished from some varieties of that rock.

D. So hard as to strike fire with considerable facility; but the particles of quartz not visible.

This is the flinty slate or siliceous schist of some authors, but it must not be confounded with that which is here enumerated under the head of Siliceous Schist ; which is distinct in its geological position, and also distinguishable, on comparison, by a peculiar aspect of compactness and simplicity which cannot be described. 


\section{SECOND DIVISION.}

Compound: indurated schistose clay, with some other ingredient conspicuously intermixed.

A. Simple argillaceous schist, and mica.

a. The mica extremely thin and broad: passes into micaceous schist. The lustre is sometimes silky, or plumbaginous.

b. With minute scales of mica, either irregularly intermixed or disposed in lamina. Micaceo-argillaceous scbist: the fine graywacke schist of some mineralogists.

B. Simple argillaceous schist and talc: of a greasy feel, and silky lustre: passes into talcose schist.

C. Simple argillaceous schist intermixed with chlorite.

a. The chlorite invisibly minute, as if powdery, the fracture dull and earthy.

b. The chlorite foliated, or scaly, and the fracture glossy.

These varieties pass into chlorite schist.

D. Simple argillaceous schist intermixed with hornblende.

a. The hornblende in minute scaly crystals, or irregular grains, or flat plates.

b. The hornblende fibrous : fascicular; or else straight, or curved, and radiated. 
Some varieties of a. pass into hornblende schist.

E. Argillaceous schist, A. div. first-intermixed with quartz.

a. An uniform arenaceous mixture of sand and blue clay: imperfectly schistose, and somewhat resembling an argillaceous sandstone.

Occurs in Scotland, in Seil and Luing.

b. Quartz sand intermixed with laminar or massive schist. Fine graywacke, and graywacke schist, of mineralogists.

c. Quartz gravel of various sizes similarly intermixed: coarse graywackes.

It is not unusual for the gravel in each different variety to preserve an average general size.

F. Argillaceous schist, C. div. first, intermixed with quartz.

a. With very fine grains or powder of quartz. Not fissile ; fracture sometimes rough splintery, and often resembling the fine and grey varieties of primary sandstone.

b. With visible grains of quartz of various sizes and resembling the coarser varieties of the same rock.

This is also termed graywacke by mineralogists. 
G. Argillaceous schist with imbedded particles of calcareous spar.

Occurs in Galloway, and, as it is said, in some parts of the Alps.

H. Argillaceous schist with imbedded felspar, in crystals or fragments more or less rounded, and having a porphyritic aspect.

This singular variety is found in Isla and Jura.

\section{THIRD DIVISION.}

Of Argillaceous schist, with two or more ingredients.

A. Argillaceous schist with quartz sand, and nica.

a. Schistose.

b. Massive.

These are also ranked under the comprehensive term graywacke. When the quartz predominates, they pass into micaceous sandstone.

B. Argillaceous schist with quartz and felspar.

C. Argillaceous schist with quartz, felspar, and mica.

These form other varieties of graywacke, and are generally thickly fissile. They are found in 
the argillaceous series of the Highland border; as in Bute and Cowal.

\section{FOURTH DIVISION.}

Containing fragments of the same, or of other compound rocks: of a conglomerate structure more or less minute.

A. Fragments of argillaceous schist reunited.

a. Schistose; slaty.

b. Imperfectly schistose; or massive. schist.

B. Fragments of quartz united by argillaceous

a. With simple argillaceous schist.

b. With any of the compound varieties.

C. Fragments of quartz and of schistose slates united by var. C. div. first-massive.

D. Quartz, felspar, and clay slate in minute fragments ; united, with or without an additional argillaceous cement.

E. Fragments of quartz and basalt cemented by a mixture of clay slate and quartz sand.

F. Fragments of jasper and clay slate, with grains and fragments of felspar and quartz, united by a siliceo-argillaceous base : not fissile, very hard.

G. Fragments of micaceous schist and quartz, united by a mixture of schistose clay and sand, or of clay, sand and mica.

H. Fragments of fine or coarse argillaceous schist superadded to the same mixture. 
This catalogue might easily be extended, as the varieties of mixture and aspect are very great; but it has been limited to those which are most conspicuous for their extent and frequency within the limits of my observation, namely, in Scotland, Wales, and Cumberland. It comprises the coarse graywackes and graywacke schists of mineralogists, and these rocks have generally been enumerated in the transition class.

When the fragments become materially increased in size, such rocks would more naturally claim a place among conglomerates; and it is obvious that these varieties bear the same relation to the finer argillaceous schists that the conglomerates do to ordinary sandstone. They might perhaps be conveniently classed under a

\section{FIFTH DIVISION.}

\section{Argillaceous conglomerates.}

The varieties to be ranked under this title, if adopted, need not be specified, as they would merely be repetitions of the preceding catalogue. The only distinction, to the collector of speci- 
mens, would consist in the sizes of the fragments, and the consequent coarse texture of the rocks.

It must be remarked, that many instances occur, in which specimens of these argillaceous schists are undistinguishable from shales, as observed also under that head. The distinction can only be made, in such cases, by reference to the geological connections.

The following minerals occur imbedded in argillaceous schist, and most commonly in the simple and fine varieties.

$\begin{array}{ll}\text { Wavellite. } & \text { Stilbite. } \\ \text { Chiastolite. } & \text { Tremolite. } \\ \text { Staurotide. } & \text { Cyanite. } \\ \text { Andalusite. } & \text { Topaz. } \\ \text { Brown spar. } & \text { Lazulite. } \\ \text { Calcareous spar. } & \text { Opal. } \\ \text { Chlorite. } & \text { Pyrites. } \\ \text { Garnet. } & \text { Oxydulous Iron. } \\ \text { Epidote. } & \end{array}$

In certain argillaceous schists of this division, pyrites occurs in such abundance, and of such a composition, that they form aluminous efflorescences on exposure to air and moisture; producing aluminous slate. The same substance occurs also among the shales. 


\section{3}

\section{PRIMARY LIMESTONE.}

Oun information respecting this rock, from geological writers, is not only scanty, but has been rendered very obscure by the establishment of the transition class. It is impossible to discover which of the limestones, described as belonging to this class, appertain to the primary rocks, and which to the secondary; and hence it is difficult to give any satisfactory information respecting the geological characters of the limestone now under review, except that which is derived from observations made in this country.

No evidence on this subject can be received, short of that which is founded on its alternation with rocks acknowledged to be primary; although cases may be imagined in which, by forming the uppermost of the primary strata, it might be in contact with the lowest secondary sandstone. As the presence of organic remains in some of the argillaceous schists of this class, is 
proved, there is no reason to deny their probable existence in the limestones of the same period; it is even certain, that, in one instance at least, they do so occur. The crystalline texture is equally incapable of proving their nature ; as it is frequent in the secondary limestones, and is not necessarily present in the primary.

Primary limestone is found in strata of the usual variety of forms, alternating with other rocks of the same class, and it occurs in every part of the series. It exists, either in a considerable succession of unmixed beds, or else in rare and slender strata, or laminæ intermixed in small proportion with some other rock; most frequently, with the argillaceous schists. It is also found in irregular masses, or large nodules, which can scarcely be said to possess a stratified shape, and which very much resemble, as already remarked, the masses of serpentine that occur in similar situations. Excepting in the crystalline form, it is never found in veins ; and, in this respect, it is exactly analogous to quartz, the veins of which are very similar, and generally found in the same situations. 
In Scotland, it occurs in contact with granite, in which case it is often indurated, and when very impure, sometimes converted into a cherty substance hereafter described. In gneiss, it is found either in strata or nodules; and these are sometimes penetrated by the same granite veins that pervade the gneiss. Where it occurs interstratified with micaceous schist; as well as with gneiss, it is sometimes so intermixed with mica as to be difficultly distinguishable from these rocks, more particularly in the laminar fracture. In the same manner, where it is associated with argillaceous schist, the limestone is often invisible except in the transverse fracture; the rock yielding in a parallel direction to the stratification, only in those parts where a lamina of schist is interposed.

Beds of limestone are often bent, and even considerably contorted, as are those of the rocks which it accompanies; and these flexures are most visible in the varieties which contain mica. They seem to present no variations of structure, but the laminar, which are deserving of notice.

The texture varies from the highly crystalline, of a larger or finer grain, to the uniformly com- 
pact and the earthy ; and the mineral composition requires no notice, as it is fundamentally, a simple rock. It is often, however, much modified in aspect by the presence of unessential minerals; and the varieties thence resulting are, in many cases, so remarkable, that it has been thought necessary to give them distinct places in the catalogue. The more rarely imbedded minerals, are, as usual, subjoined in a distinct list.

The only instance in which organic remains have occurred to the author in primary limestone, is in Sutherland, and it is described in his work on the Western Islands. As conglomerate beds, or portions of conglomerated rock, are frequently found associated with the simple, it has been judged necessary to enumerate those varieties here; but they will also be found mentioned in the general chapter on that subject.

It is here necessary to add, that although the primary limestones may generally be distinguished from the secondary, by their often containing imbedded minerals which are not found in those, and by the frequent existence of organic remains in the latter, many cases occur where. 
they cannot be thus distinguished in hand specimen; when it becomes unavoidably necessary to have recourse to their geological connections.

In concluding this subject, it must finally be remarked, that, if the limestones supposed to appertain to the transition class, be referred to the secondary, those which are decidedly primary, and which alternate with the several strata already described, will be found to occupy a very small space in nature, when compared to them. Should even many of the transition limestones of geological writers, prove to be strictly primary, this rock will still bear a small proportion to the other substances of this class ; and, in this respect, a strong contrast may be observed between the primary and secondary classes, in the last of which limestone takes so conspicuous a share. The geological considerations arising out of this fact, are of a highly interesting nature. 


\section{SYNOPSIS OF PRIMARY LIMESTONE.}

\section{FIRST DIVISION.}

Simple.

A. Crystalline.

a. Very large grained, with straight lamellæ.

b. The same, with the lamellæ curved.

c. Large grained, and the crystals appearing to have compressed each other, as in coccolite.

d. Of a middle sized grain-marble of Paros, \&c.

e. Finely granular, saccharine, and firm or loose : marble of Carrara.

f. Finely granular and compacted, becoming splintery.

g. The crystals so disposed, in consequence of a common polarity, that the rock has an imperfect schistose structure. In these cases it often appears, on a superficial view, to contain mica.

\section{B. Compact.}

a. Splintery; but with a rough, somewhat granular fracture, passing into the last named variety.

b. Flat splintery; smooth.

c. Splintery and conchoidal. 
The varieties with curved lamellae are generally splendent in the fracture, and contain magnesia. Some of the finely granular, or large granular varieties, also occasionally contain this earth in very large proportion; and the former are, in some cases, known by the name of dolomite. Magnesia occurs also at times in the compact kinds; but these varieties are scarcely distinguishable without analysis.

Under the head of Secondary Limestones, the magnesian limestone occupies a distinct place, on account of its important geological character and connexions. In the case of dolomite this seemed unnecessary.

The colours of primary limestone are various; and, from different modes of intermixture, there results an infinite diversity of marbles, of which a great many are distinguished by technical terms which it would be fruitless to enumerate; as they are rarely descriptive, and will afford the collector of specimens no assistance in arranging his cabinet. The white varieties of a fine grain, are well known as statuary marble: the coloured, derive their tints from inflammable matter, or 
from oxydes of iron, or from the intermixture of other minerals; in which latter case they rank under the following division.

\section{SECOND DIVISION.}

Compound: of two ingredients.

- A. Limestone with mica interspersed.

a. Foliated, irregular, large granular, resembling granitic gneiss. Rannoch.

b. Straight laminar, resembling micaceous schist of various aspects. Blair in Atholl.

B. Interlaminated with argillaceous schist. Isla, \&c.

C. With hornblende interspersed. Loch Laggan, \&c.

D. With sahlite or augit of various colours interspersed. Tirey, \&c.

E. With talc interspersed.

F. With noble serpentine or steatite intermixed or diffused so intimately as to communicate a general colour.

G. With garnets, crystallized imperfectly, or else uniformly diffused.

H. With quartz, either in distinct grains, or so minute as only to be detected on analysis.

I. With felspar.

K. Impregnated with bitumen. Sutherland.

L. With tremolite minutely intermixed.

M. Withactinoliteintermixed in the same tnanner. 


\section{THIRD DIVISION.}

Compound: of three ingredients.

A. Limestone with noble serpentine and mica.

B. With noble serpentine aud sahlite.

C. With hornblende and angit.

\section{FOURTH DIVISION.}

Compound: consisting of any of the preceding varieties with fragments of previous limestones or of other rocks. Conglomerates.

A. With limestone fragments alone, united in various ways.

a. The fragments inbedded in a general continuous calcareous base.

b. The fragments agglutinated with little or no proper base, and of various sizes.

B. Fragments of quartz imbedded in limestone.

C. Fragments of argillaceous schist imbedded in limestone.

D. Fragments of various primary rocks, with or without fragments of limestone also, imbedded in a calcareous base.

Most of the calcareous conglomerates which are found in company with the simple primary limestones, may be referred to one or other of the first three varieties, which are at least the 
most conspicuous and common. For the convenience of the student, they are all noticed again under the head of Conglomerate Rocks:

The colours in these varieties are infinite, and the peculiar disposition of the parts gives rise to many well-known ornamental marbles.

Independently of the general colours before alluded to, and those derived from the intermixture of the minerals just enumerated, the primary limestones present a great diversity of aspect from the passage of veins, as they are frequently fissured in intricate directions, and the fissures are generally filled with a pure white carbonat. In these cases they also occasionally become conglomerates. Further, it may be added that the various shades of grey are among the prevailing colours.

Besides the minerals which are enumerated in the second division, because they sometimes abound so as essentially to modify the character of the rock, others occur imbedded in limestone as their occasional repository. The following catalogue contains those most usual, including the substances which occasionally enter in larger proportion. 
Tremolite. Sahlite.

Augit.

Hornblende; pargasite. Emerald. Hornblende ; common. Spinelle.' Actinolite. Asbestos.

Mica.

Talc.

Chlorite.

Quartz.

Brown Spar.

Schiefer Spar.
Serpentine.

Steatite.

Garnet.

Tabular Spar.

Idocrase.

Stilbite.

Olivin.

Pyrites.

Titanite.

Spheno. 


\section{4}

\section{COMPACT FELSPAR.}

THE present substance offers an example of those difficulties which beset all attempts to make an unexceptionable arrangement of rocks. It is now also, for the first time, admitted to a place among these; a practice justified by the space which it so often occupies among them, and by the peculiar connections in which it is found. To have considered it as a modification of gneiss, would have produced still greater irregularity; and, to have omitted it, would have left a blank not atoned for by finding it enumerated by mineralogical writers in their catalogues of simple minerals.

Compact felspar occurs also in another part of this arrangement, in a very conspicuous manner, both in irregular masses, and in veins, forming a member of the great family of overlying rocks. The student who finds it constituting an integrant part of the series of gneiss, might therefore be misled, were it not here shown to exist also as a primary and stratified rock, of the same age and date as this antient member of the primary strata. The example of limestone would 
have been sufficient to justify the present arrangement, even without the much stronger reasons afforded by these essential differences in the geological characters of this substance as it occurs in the primary and secondary classes.

If there are transient and occasional differences in the specimens of this rock as they are found in these two distinct situations, they are not such as to form a permanent or effectual distinction between the two; while the analysis of both, presents, as far as is yet ascertained, the same remarkable peculiarities.

Compact felspar contains potash and soda united to the other earths that form its principal ingredients; and both these alkalies are found in it, in whatever situation it exists ; proving that it is radically, as well as ostensibly, the same substance in both cases. By this analysis, no less than by its general characters, it differs essentially from common felspar, which contains potash only. Were it either easy or adviseable to change a name long received, this is one, as already hinted, by the reformation of which the - mineralogical nomenclature might acquire an advantage. But, as in many other cases, where 
there is much to reform, and where the various effects which may flow from such changes cannot be foreseen, it is at least prudent to go on as long as possible with the established materials.

The compact felspar in question, is only found, as far as I know, situated in gneiss, in which it commonly forms large flattened masses or imperfect beds. These do not possess the characters of veins, like the compact felspar of the secondary class, but either resemble the masses of limestone which occur in the same situation, or else graduate into the surrounding rock. In this case they are often, but not necessarily, connected with that peculiar variety described in the Synopsis of Gneiss, into which compact felspar enters as an ingredient.

Occasionally, this substance is also found in smaller lumps in the same rock, or else in those forms which are sometimes called by the questionable name of contemporaneous veins ; originating and terminating in the mass in which they lie. It also occasionally forms single laminæe in that gneiss which possesses the granitic or schistose character. More rarely, it occurs in a similarly limited manner in granite. 
The rocks of this character are always easily recognized, even at a distance, by the white, nearly pulverulent, surface which they assume on exposure to the air.

For the general definition of this rock, I may refer to the several treatises on mineralogy in every person's hands, where it is described among the simple minerals, or to the description of its characters given in the thirteenth chapter of this work.

The varieties which it affords are so few, and so slightly different from each other, that they scarcely admit of being distinguished by any description or enumeration of characters. The distinctions of colour are the most conspicuous.

\section{SYNOPSIS OF COMPACT FELSPAR.}

\section{FIRST DIVISION.}

Simple.

a. Massive, compact, with a smooth fracture.

b. Schistose, with a similar fracture.

This variety occurs in Iona.

c. Massive, with a granular or minutely uneven fracture; appearing to be formed, like granite, by a confused crystallization. 


\section{SECOND DIVISION.}

Compound.

a. Cuntaining dispersed particles of hornblende, insufficient in quantity to alter its character.

b. Containing interspersed particles of quartz.

These pass into those varieties of gneiss with which they seem to be invariably associated, and are, of course, not always definite.

The colours of compact felspar are various. I have observed it white, ash-coloured, smoke grey, dark grey, greenish grey, reddish brown, black, olive green, and bright yellowish, or grass, green. Several colours are also often intermixed, and it is not unusual for a mass of one colour to be intersected by filamentary veins, or very thin flat, or laminar, veins of another.

The simple varieties also, pass into the gneiss with which they occur.

I know not that it ever contains any imbedded minerals except those above-mentioned. 


\section{9}

PRELIMINARY REMARKS ON THE NATURE AND CHARACTERS OF THE SECONDARY CIASS.

IN examining the characteristics of the primary class, many of the remarks applicable to the present, were unavoidably anticipated. It was there shown, that it has received this name because the rocks included in it are esteemed of posterior date to those ranked in the primary division. That fact is deduced from multiplied observations, which prove that where the stratified members of both classes occur in the same place, the one is invariably superior to the other ; and that, as no such member of the primary class' is ever found intruding among the secondary strata, so no secondary stratum is ever found included between two strata of the primary class.

But in the secondary class there is also comprehended a great variety of unstratified rocks ; analogous to granite, as well in their leading 
forms, as in their mineralogical characters, and, in a similar manner, intruding in the shape of veins, not only among the stratified members of this class, but extending their ramifications even through the whole of the primary rocks, whether stratified or unstratified.

That interference affords, in itself, ample evidence of the secondary nature of these unstratified substances ; and is a sufficient proof of their posteriority to all the rocks with which they are connected, to supersede the necessity of any further remarks on that subject in this place. The peculiarities of character which render them objects of the greatest interest in the history of the earth, will, with more propriety and utility, be examined, as far as is admissible in a work of this nature, in the preliminary remarks that precede the synoptic catalogue. The observations that here follow, must therefore be considered as extending solely to the secondary strata.

These strata, thus once determined by the characters above mentioned, are discovered to possess, like the primary, other peculiarities, by which they may be recognized when the species of evidence derived from relative position, is in- 
accessible in consequence of the absence of the latter. To repeat these characters, and to mark their insufficiency, singly taken, for the purpose of determining the nature of any member, would be merely to recapitulate that which was already said in the introductory remarks to the primary class, where the nature and extent of these uncertainties were stated. It is sufficient merely to observe, that neither the low inclination of the strata, the mineral characters of the species, nor the presence of organic remains, are, separately, capable of establishing a criterion between the two. The student who is foiled in one quarter, must have recourse to some other: but he can rarely be at a loss in determining their characters from their geological positions ; as the most doubtful rocks will generally be found assuciated in a manner easily investigated, with some other stratum of which the character is unquestionable, and, in particular, very often rendered so by the nature and abundance of the organic bodies which it contains.

In the former remarks on the primary rocks, -no detailed reasons were given for chusing the 
precise line at which the boundary between the primary and secondary classes was drawn: why the red sandstone was considered the first of the secondary series. That enquiry is more particularly connected with the present remarks; as the leading distinction of this rock, namely, the mechanical structure, forms one of the chief characters of the secondary strata.

It has been remarked, that where the primary and the secondary strata are found in contact, the latter do not always follow in parallel order to the former, but rather meet them at some angle. Moreover, in thus meeting, the surfaces of the secondary strata are sometimes found lying on the edges of the primary, as was formerly mentioned in treating of the distinctive general characters of rocks. To this position, as already remarked, the terms unconformable and overlying have been applied, and it has been enumerated among the necessary distinctions between the primary and secondary strata. But, like all the other characters of these latter rocks, this one is by no means universal, and we must beware of erecting from it a general rule, as it is 
by no means unusual for the secondary strata to follow the primary in parallel order. Even among the primary as well as the secondary strata, the reverse or unconformable position sometimes occurs. It is plain also, that, as a practical distinction, this rule is of little value, were it even more constant; because it can only be made use of at the boundary of the two classes, and perhaps not often with great safety even there, unless the very junction also is visible.

As the unconformable position, however, occurs in a sufficient number of instances to be a remarkable circumstance in the history of the secondary strata, it has materially assisted, in conjunction with other characters, to fix the boundary of the class in which they are included, and, consequently, to distinguish the whole of the strata which enter into it. Whatever rock, last in the order of succession downwards, has been found to present this distinction in the predominant cases, especially if that circumstance is united to some other of the characters of the secondary class, it is plain that every rock which follows it in the order upwards, must belong to 
that class also, although the order of succession should in any particular instance be deficient or irregular. It has appeared in the course of geological investigations, that the red sandstone was the last rock in the order of succession downwards which thus holds a position unconformable to the primary strata; and its claims to be considered the lowest or first of the secondary class, have been further confirmed, by finding that it was formed from the fragments of the primary, or of preceding, rocks, and, not unfrequently; even from the ruins of those very strata with which it was in contact, or which occupied the nearest place to it.

Thus the boundary line between the primary and secondary classes seems to have been properly placed between this substance and the nearest primary rock with which it is in contact, or immediately below the red sandstone; it having been already seen, that the inconstant order of succession in the primary class, must render it impossible to determine what that rock may be. As already shown in the table of succession, every rock, from granite through the whole series of 
the primary strata, may be that on which the red sandstone reposes.

But in some instances, as was also shewn in that table, even the red sandstone may be absent; and thus, some other and superior member of the secondary class, may be in contact with the primary rocks. Such deficiencies need excite no surprise, and they can seldom be attended with much practical inconvenience; as the other characters of the strata which are superior to it, are generally so well marked as to leave no ground for doubt respecting their place in the arrangement.

In concluding these remarks on the boundary between the primary and secondary strata, it is necessary to say, that from finding that the first member of the latter is composed of the fragments of the former, geologists have concluded that a marked interval of time had elapsed before the secondary strata were consolidated and deposited on the primary ; a consequence necessarily arising from their composition. The highly interesting conclusions with regard to the whole class, which flow from the presence of coal, and 
from the abundance and nature of the organic remains which they contain, are subjects for the especial consideration of geological treatises, or theories, and can find no place in this work.

As a class, the secondary strata still require a few observations before proceeding to enumerate the individual rocks ranked in it.

In comparing the catalogues of the primary and the secondary strata, it will be seen that many very distinct species are contained in the former, but that the species in the latter are nearly confined to sandstone, limestone, and shale. Notwithstanding this limited number of leading distinctions, they present much variety in the details ; even independently of the organic remains contained in them, by which other differences of a very important nature arealso frequently produced. These distinctions, however, are of such a nature that they can claim but little notice in a catalogue of rocks. They appertain, for the most part, either to that branch of geology which is of a geographical nature, or to that which treats of the order of succession, and of the characters, of those interesting strata which indicate the succes- 
sion of different classes of organized beings, which have occupied the former surfaces of the earth.

That the secondary rocks are much more limited than the primary, in their extent as well as in their depth, is so obvious, as scarcely to need a remark. Were they not indeed often deficient, the primary would not be visible on the surface. While, in fact, the primary rocks constitute, as far as we can discern, the mass of the earth, the secondary are distributed in a very partial and unequal manner. The primary rocks may also be considered universal, since they are found with similar characters over the whole globe ; and if access could be obtained to them, they would doulstless also be found to recur in a continued and similar general succession every where. But the secondary strata can only be.considered as universal in a more limited sense, or inasmuch as similar rocks occur, as far as their leading distinctions, or species, are concerned, in every part of the world. In other respects they are partial, since they are not continuous. There is also reason to suspect that they are partial in a still 
stronger sense of the term ; as the peculiar varieties which occur in one country, or over a certain extent of the surface, appear to have no existence in other remote places.

In the same manner, uncertain as is the recurrence of the different members of the primary class, as far as the order of their relative arrangement is concerned, every one of the members seems to occur in the course of the series, in every country. But, in the secondary, the nature, as well as the order of arrangement of the remarkable varieties, (which, for the purposes of geological history, are distinctions of great moment, ) is very different in different situations; as if the primary rocks had every where been formed and disposed according to a general law for the whole globe, while the secondary were regulated by rules constant only for one limited portion of the surface.

These questions are of great importance in geological science, and open a wide field of investigation to its cultivators. This is not the place to enquire further respecting them. It may only be remarked, that the deficiencies of the secon- 
dary strata may arise from two causes. They may have been destroyed during the lapse of time, in consequence of the ordinary effects of wear, or of other causes respecting which we can only conjecture. There is also reason to suppose that they have often been originally but partial deposits ; limited to certain districts on the surface, probably of a concave form, and technically termed basins. This latter opinion is supported, partly by the peculiar manner in which the different members of a series come successively in contact with the primary strata, the highest stratum covering the widest space, and partly, by the different order of succession of the members in different places, and by the peculiar limited characters of the several deposits. 


\section{0}

\section{LOWEST (RED) SANDSTONE.}

THE rock which forms the subject of the present chapter, has very frequeutly been designated by the name of the old red sandstone, for the purpose of distinguishing it from certain sandstones of the same colour, which are found higher up in the succession of the serondary strata.

These, more recent red sandstones, are frequently separated from the rock in question, by intervening strata of sandstone, limestone, and shale; in which cases the geological distinction is easily made : much more easily indeed than the mineral distinction, which, if certain specimens of both be compared, can scarcely be perceived by the eye; far less be rendered intelligible by description.

Occasionally, however, the more recent red strata, are found in immediate contact with the old red sandstone; an occurrence which often proves a 
source of considerable difficulty to geologists. They have also been found in contact even with the primary strata, as the superior secondary strata of other kinds occasionally are; and, in such cases, it is evident that the difficulty may be materially increased, and that all the sagacity of the geologist may sometimes be required to make the distinction, and to avoid being misled by the consequences that would result, from an error in this case, with regard to the succession of the secondary strata.

Although the mineral distinctions of these two rocks, may be sufficiently determinate to enable an observer to decide on their nature, when a considerable number of specimens from any given tract are examined, or when an average of the characters of the whole deposit is taken, it will not, in most instances, be safe, or even possible, to draw such conclusions from the examination of a small number, much less from that of a single specimen. Similar cases, however, are of such frequent occurrence in examining other rocks, both among the primary and secondary strata, that they offer no novelty in this particular 
instance. They only serve to prove still further, that which has been already fully shown, that the most accurate knowledge of rocks in specimens, or the most attentive examination of their mineral characters, is not sufficient to supersede the necessity of geological investigations, where questions of a geological nature are concerned.

In the case of the lowest red sandstone, therefore, as in many others where the chief interest is of a general or geological nature, the mineral description of the rock must be considered as merely accessory, and as tending to enumerate the varieties in structure and composition, which may occur among the strata that appertain to it. Yet, an accurate knowledge of those varieties may often be of material use to a geologist, by enabling him, sometimes even separately, but, more frequently, in conjunction with other characters, to determine a question of this nature, where the evidence derived from position is obscure, or unsatisfactory, or difficult of access.

The further remarks that might here be offered on this, as on similar subjects, are the busines of 
geological treatises, and do not admit of being detailed in this work. The peculiarities also which distinguish the superior red sandstones, will more properly be examined hereafter, under the head of the upper sandstones, to which these properly belong. It will be merely necessary to remark, that as the term red has been given to both these kinds of sandstone, and as this colour forms a very conspicuous link of resemblance, when there are, moreover, often present but very slight shades of difference in other respects, it is especially requisite for the student, to be on his guard lest he pronounce a judgment from that which must be considered an accidental, and not a necessary, feature. Such terms too often concur in biassing the views of observers, even of great acuteness; more particularly, when derived from characters so striking and so obvious ; and were it possible to change names long received, the abolition of the term red sandstone, would go far towards remedying an evil, of which every geologist must, at some time or other, have been fully sensible.

It must be left to the decision of geologists, 
whether it would not be prudent to adopt for this sandstone some term analogous to the German name of the red dead-lier, by which it has erroneously been described, or to the provincial English name of the red ragstone, more congenial to our own language. In the mean time, the term old red sandstone has not been used in this work; partly, for the purpose of avoiding any confusion between the primary and the secondary sandstones, and partly, because that term, if it must be retained, seems most applicable to the former.

In the observations on the primary sandstone which have preceded, the circumstances, both of mineral structure and composition, and of geological connections, by which that rock is distinguished from the lowest red sandstone of the secondary class, have already been detailed in a great measure. That which remains to be said on the subject, will be found in the following remarks on the position, association, and mineral characters of the latter. The reader will, from those, be enabled to deduce for himself, whatever points of contrast or resemblance the writer has not thought necessary to state in a detailed manner. 
It has often been the practice with geological writers, as has already been remarked, to comprise under the name, not only of this rock, but of many others, several substances of a distinct mineral character, which are, either frequently, or usually, associated with the principal rock. These are generally, if not always, in smaller quantity than the leading substance which gives a name to the whole; and are found, most commonly, in repeated alternation with it.

The term formation has been applied to such groups of alternating strata, and the associated substances are considered as subsidiary, or subordinate to the leading rock of the whole. It is not here the place to enquire respecting the utility or the propriety of this practice, or of that of the terms above mentioned : it is a question that appertains to geology. But in a mineralogical description of rocks, the use of a term so general as that of formation, thus applied, would evidently be improper; as, under the red sandstone for example, in the instance now under examination, there would be found, not only shales of various kinds, but limestone. These are thene- 
fore considered merely in the light of alternating strata, and are separated accordingly, so as to come under examination in their proper place.

When the red sandstone under review is present, it is in contact, at its lower part, with the primary strata ; and, thus, may approximate to any one of the whole series formerly described. It is rarely found so situated with respect to granite; but Kildrummie in Aberdeenshire, and Sutherland, furnish examples of this nature. It is also more frequently found in contact with the argillaceous schists, than with the other members of the primary class; although it does occur in this manner with every one of them. As it is, however, sometimes absent, other members of the secondary strata are found occupying the lowest position.

It was already noticed in the preceding chapter, that the strata of this sandstone are not necessarily placed in a reverse, or unconformable order, to the primary with which they are in contact. In certain cases, they are found to succeed them in a parallel position; and, in these, when argillaceous schist is the preceding rock, it 
sometimes happens that a gradation takes place at the junction. The argillaceous schist becomes coarse and filled with fragments, forming that which is called graywacke; and as a similar character is found in the first beds of the sandstone, the boundary between the two rocks, and, consequently, that between the primary and secondary strata, is indefinite. The peculiar interest attached to this occurrence, is the province of the geologist. The mineral distinction cannot, of course, be made ; and the specimens must necessarily, as in all similar gradations between approximate strata, be considered as of an intermediate nature.

The substances which, as already observed, are found to occur in alternation with the red sandstone, are, generally, varieties of shale. A gradation, in this case also, sometimes takes place at the points of change; so that intermediate rocks of no very definite character, are sometimes found among the sandstone strata. Uuder the same circumstances, small strata of limestone also, are occasionally found; and even there become sometimes indefinite at their sur- 
faces, by a gradual intermixture of fragments of calcareous matter, and of those which appertain more properly to the sandstone. It is as yet uncertain, whether the white sandstones which are sometimes found similarly alternating with the red, are to be considered as colourless portions of the same deposit, or as alternating strata, like the shales; but, in truth, this seems rather to be a doubt respecting the use of a term, than about a geological fact; as there are no means of determining a real difference, under circumstances of this nature, among rocks of mechanical composition deposited in the manner in which all the arenaceous secondary strata appear to have been.

It is almost unnecessary to repeat, that any one of the secondary strata may follow the red sandstone in a continuous series, after it has disappeared, and that these are generally in parallel, or conformable, order.

The strata of red sandstone vary much in thickness, individually, as the whole deposit itself ulso varies in depth. As the latter sometimes ranges from a thousand yards or more, to the thickness of a few feet, so the strata may be found 
reaching to a dimension of many feet, and descending even to that of an inch. They are sometimes separated, merely by planes, without any intermediate substance, or change of structure. In other cases, the separation of the beds is effected by intermediate laminæ of shale, or clay, or by alternating beds of the former substance, or of limestone. Not unfrequently also, the distinction is produced by mere change of structure, or by a difference in the magnitude of the fragments which compose the proximate beds, or the parts immediately in contact. In a few instances, the separation of the beds is caused by a lamina of parallel mica ; and, in this case, it is not unusual for the sandstone to present a laminar structure.

Strata of this sandstone, like those of the primary rocks, are not necessarily of equal thickness throughout; but are, on the contrary, often extenuated till they disappear In the same manner, they are sometimes curved in a greater or less degree; but, in this rock, as in the secondary strata in general, these incurvations never pro- 
ceed to such an extent as in the primary, and call never be said to amount to contortions.

It has been imagined that red sandstone formed veins passing through the adjoining strata, as has also been asserted of the upper sandstones. It were a waste of time to try to prove the erroneous nature of an opinion which could only originate in a total misapprehension of the nature of a vein.

Red sandstone sometimes exhibits peculiarities of internal structure, but they are seldom visible in the entire rock : such as they are, they are detected by the action of the weather, to which the softer parts yield most readily.

Like granite, this rock sometimes splits into cuboidal and prismatic masses, which afterwards become rounder at the angles, so as frequently to emulate, at a distance, the appearance so often exhibited by that substance. As in granite also, it may frequently be concluded, that masses of red sandstone must contain intersecting laminæ of a harder texture than the general body of the rock, as the exposed surfaces present reticu- 
lating and protuberant veins. When the wasting of such masses has proceeded to a considerable length, as often happens where they are exposed to the action of the sea, the intervals between the veins become so deep, that a sort of cancellated or cavernous structure is exhibited; as was formerly noticed in describing the several varieties of concretionary structure found in rocks.

A spheroidal concretionary structure on the small scale, is also occasionally found in the red sandstone; and this, like the former, is principally detected by the action of the sea. Arran exhibits striking examples of this and of the preceding varieties. It is not improbable, that the peculiar disposition of the red and white colours in the mottled varieties of this rock, are the result of a concretionary structure; but, as yet, I have not been able to ascertain this by the examination of such varieties, after an exposure capable of producing the effect in question.

In a general sense, the red sandstone must be considered as formed of fragments, more or less minute, of preceding rocks, or minerals. When these are of the usual size of sand, the 
finer sandstones are produced; when larger, the results are coarser grit-stones, and conglomerates, or breccias. The term sandstone, is however applied equally to the whole; although, rather in a geological, than in a mineralogical sense.

In the finer sandstones, the adhesion of the parts is sometimes slight; and the rock is therefore of a feeble texture, while its mechanical structure is also in this case most evident. In others, the adhesion is very firm, although it is impossible to trace any particular cementing medium by which the union of the parts is effected.

But, in some varieties, it is very apparent, that the harder parts are uniterl by the intervention of a general cementing medium or paste; commonly consisting of that ferruginous clay to which the colour of the rock is, in most cases, owing. In a few instances, this medium appears to be carbonat of lime; or else, by a mixture of the two, there is formed a sort of general basis, in which the harder parts are imbedded.

It was formerly shown, that, in the primary sandstone, the grains of quartz, of which it is principally composed, were often firmly com- 
pacted into an almost uniform mass, by a cementing medium of crystalline quartz; and this, although less frequently, sometimes takes place in the secondary red sandstone. It is in these particular instances, that the distinction between the two rocks, in a mineralogical sense, becomes most difficult. As in all parallel cases, it can then only be made by an examination of the geological characters of the rock in question.

Even in these instances, however, the texture of this sandstone is generally more or less distintly granular, or at least splintery; nor can it be confounded with those rocks, which, like granite, are formed by the mutual interference of parts purely crystalline. If instances of such a difficulty do occur, they are extremely rare, and are limited to the places where such sandstones have been found in contact with granite; a fact to be observed in some parts of Scotland.

Where a stratum of red sandstone is formed of coarser materials, these are almost invariably mixed with the finer sand, and the process of cementation, in these cases also, is subject to the same modifications. 
The sizes of the parts of which this rock is formed, are infinitely various; and, although the largest do not often exceed a few inches in diameter, they sometimes attain to dimensions of more than a foot. In all cases, their aspect varies with respect to the marks of wear which they exhibit; as they are sometimes acutely angular, and, at others, as far rounded as is possible. The proofs which the latter display of distant transportation, or of long continued friction, are highly interesting in a geological view, but are not objects for the present inquiry. It may happen, that angular and rounded fraginents are contained in the same mass, or specimen; but it is more usual for a common character in this respect, if not a very defined one, to pervade one mass or stratum.

It is not necessary that the whole of one stratum should be formed of coarse fraginents, or of fine sand; or that the sandstone and the conglomerate should occupy distinct places. On the contrary, it is not unusual for one part of a bed to be fine, and another coarse; and this variation of structure may occur, either vertically, or at 
right angles to the plane of the bed, or else laterally, or according to its extent. Occasionally also, solitary fragments of a determinate bulk, are found imbedded in the finer rock.

The simple minerals which enter into the composition of the red sandstone, are, quartz, felspar, clay, mica, and carbonat of lime. These are all apparently derived from the disintegration of previous rocks, the larger fragments producing the coarser or conglomerate varieties. Among these, quartz sand is the leading ingredient. Clay is the next, and to the colour of this substance, that of the rock is generally owing. Mica is comparatively a rare ingredient; or, rather, it is not an abundant one. Its presence has been improperly supposed to be always sufficient to distinguish this sandstone from those, superior in position, with which it might otherwise be confounded. Carbonat of lime is also rare; and, of the felspar, it may be remarked, that it is seldom either abundant, or of common occurrence ; having, apparently, been generally decomposed, so as to form the clay already noticed. It is in the frequent presence of this substance, that the dis- 
tinction in the mineral character of the primary sandstone, is most perceptible.

The rocks which, by their fragments, contribute to the formation of the coarser varieties, may consist of any one, or of all, of the members of the primary class. It is very rare, however, that the whole of these are found together. Granite, as among the most durable, is also among the most frequent; and the argillaceous schists, as possessing a more feeble texture, are least common. Large fragments of common quartz, are also of frequent occurrence among the fragments of the compound rocks. It is an interesting point in geology, to note the relation borne by the fragments in any of these sandstones, to the primary rocks in the immediate vicinity; but it does not form part of the present examination.

It is also an important geological fact to remark, that fragments of the trap rocks, here considered as, in a general way, belonging to the secondary class, are sometimes found in the conglomerates; as it proves that some of these, at least, are of an origin prior to the secondary strata; unless indeed such fragments may be 
supposed to have been derived, in some cases, from granite, among the varieties of which, as formerly remarked, such substances are often found.

With respect to the component parts of this rock, it must lastly be observed, that fragments of previous sandstones are sometimes found imbedded in it. Whether these are portions of unknown rocks that have disappeared from the surface, is an object for geological inquiry; but as it has been already shown that there is a red sandstone among the primary strata, it is to this, in all probability, that we must look for their origin.

Few imbedded minerals are found among the secondary rocks. In this, sulphat of barytes sometimes occurs in veins, as does gypsum. Iron stone is not unfrequent, and pyrites also is sometimes present: oxidulous iron is rare. In nocase, however, do any of these interfere with the texture, or modify the general character of the rock.

Few organic substances occur in the red sandstone, nor have the species which do occur, been fully investigated. At any rate, they are - not within the limits of the present inquiry. 
The prevailing colour of this rock is that whence its name has been derived. The red varies from a bright ochre down to the darkest brown, and even to a blackish purple. Many varieties of grey, also occur, from dark blueish to the lightest ash colour, at length passing to an imperfect white.

But the most remarkable modifications of colour, consist of intermixtures of red and white ; and these varieties have been distinguished by the name of the mottled or variegated sandstone, as if they formed a distinct geological mass. That this is not the case, however, is proved by their occurring in alternation and intermixture with all the other varieties. The most remarkable of these, exhibits white circular spots of different sizes, more or less abundantly disseminated in the red ground; and they are proved, by the firacture of the stone, to be spheroidal. In other examples, the white is disposed in veins, or in other ways intermixed with the red colour: and it is remarkable, that where these characters prevail, they generally also pervade the accompanying shales. 


\section{SYNOPSIS OF THE LOWEST (RED) SANDSTONE.}

\section{FIRST DIVISION.}

Simple: of quartz alone.

A. Sand'stone, of various degrees of hardness.
a. Fine, arenaceous.
b. Gravelly.
c. Compact, splintery, scarcely arenaceous.

These varieties are comparatively rare. The colour is sometimes white, but it is also occasionally reddish, yellowish, or grey; the quartz itself being coloured: Var. c. is not to be distinguished from quartz rock, except by its connections.

\section{SECOND DIVISION.}

Compound : of two or more ingredients.

A. Quartz sand mixed with clay. Argillaceous sandstone.
a. Gravelly.
b. Fine, arenaceous.
c. Very fine, the particles of quartz invisible.

These vary materially in aspect and character, - according to the relative proportions of the in- 
gredients ; the last, loses, at times, all appearance of a sandstone and passes into shale and into argillaceous iron stone. They also vary according to the degree of induration. The prevailing colours are reds, and different tints of grey. They are sometimes also of a dull white, or yellowish, or brown, or purplish, or green, or dark lead blue or mottled with two or more colours, as grey and red, or red and white. In this latter case, the colours are often remarkably disposed, as before mentioned.

B. Quartz sand, mixed with sand or particles of felspar.
a. Gravelly.
b. Arenaceous.

These varieties differ in aspect according to the relative proportions of the ingredients. They also vary in colour, that being chiefly determined by the tint of the felspar. The prevailing colour is red, of various tones. White, and grey, are more rare.

C. Quartz sand with carbonat of lime: calcareous sandstone.

a. Gravelly.

b. Arenaceous.

This variety is generally white. 
D. Quartz sand with carbonat of lime and clay: argillo-calcareous sandstone.
a. Gravelly.
b. Arenaceous.

These vary in colour according to the tints of the clay. When the quartz is very fine and in small proportion, they pass into calcareous shale or marle slate.

E. Quartz sand with mica, or with mica and clay: of various degrees of fineness.

a. The mica irregularly interspersed : massive.

b. The mica disposed in a parallel manner, often in separate laminæ: schistose, and splitting more or less perfectly. Schistose sandstone.

F. Quartz sand with indurated or schistose clay.

This may equally be enumerated under the head of argillaceous schist, (graywacke); but it occurs as a transition from sandstones of a decided character, and is associated with them.

G. Quartz sand, with sand from the wearing of trap rocks.

Other varieties occur from the occasional intermixture of other minerals, or from the existence of a greater number of ingredients ; but 
the preceding are the most usual, and it is unnecessary to prolong a catalogue of minute variations.

\section{THIRD DIVISION.}

Containing fragments of previous rocks : of a conglomerated structure. Red sandstone conglomerate, or breccia, of mineralogists.

A. The basis consisting of either of the preceding fine varieties except $F$ and G, Division Second, and containing fragments of quartz only.

B. Similar bases, with fragments of granite, or gneiss, or micaceous schist, or quartz rock, or jasper, or all of these, with quartz.

C. The same bases, including F, Division Second, with fragments of argillaceous schist.

D. The base G, Division Second, containing fragments of trap rocks.

E. The bases A, B, C, D, E, Division Second, containing fragments of sandstone, with or without other fragments of previous rocks.

It is easy to imagine a much greater variety of compounds, and perhaps many others exist. It is unnecessary to refine ou these divisions, and the preceding contain all those which, as far as I have observed, possess distinct characters and occupy important geological positions. 


\section{3}

\section{SUPERIOR SANDSTONES.}

Ir has already been observed, that whatever variety in a mineralogical sense, and whatever important distinctions of a geological nature, may exist among the secondary strata, they are nearly all comprised under the heads of sandstone, limestone, and shale. Among the numerous varieties of the former rock, that which was described in the preceding chapter, is generally very distinguishable from the rest by many important mineral characters, as well as by the steady and peculiar nature of its geological position. But, among those which follow it in order, which alternate with the other members of the same class, it is very difficult to make such mineral distinctions as to render it either necessary or useful, to treat of them separately.

In a geological view however, the distinctions are often of great importance. In many countries, or districts, these strata occur in a certain order, and under certain relations to the accom- 
panying rocks, which, in those tracts at least, are constant; although the same order and the same associations, are not found in remoter tracts and in other countries. Mineralogical differences, in other respects trifling, thus become of great consequence in geological investigations and descriptions; more particularly in the local or geographical department of geology. But the interest of these strata chiefly depend on their geological associations and characters; sometimes on the nature of the organic remains which are contained in them or in the accompanying lime.stones. They rarely, if ever, are founded solely on mineral characters ; nor is it possible, by such characters alone, except in some peculiar instances, to distinguish them from each other, so as to recognize them when separated from their connections. Even in those few cases where they may be distinguishable by an eye practised in their peculiar niceties of aspect, the distinctive characters can seldom be conveyed by words.

If the mineral resemblance of these sandstones, is such, that distinctions can be rarely made among them, sufficient to justify the placing 
of each in a separate division, so, in their geological recurrence, they resemble the analogous primary strata, in which no such distinctions were thought necessary. Among these, argillaceous schist, and quartz rock, occur in as many positions and alternations as do these sandstones in general. The record of these is the business of geology; and, in the case of the secondary sandstone, also, it seemed unavoidable to leave these differences, such as they may be, to those who treat of the geological history of strata, whether local or general. Had a different proceeding been here adopted, it would have been necessary to enter on the details of these local connections; and had each stratum or formation of sandstone which enters into the structure of England, for example, been described under a separate title, the descriptive catalogues of varieties would have been little else than mere repetitions of the same unvarying characters.

It is true, that one, or more, of these, such as the red marle of the English geologists, might have been placed under a separate head: but as nothing was here admissible on the subject of its 
geological relations, and as it presents scarcely any variety of character, that chapter would have been nearly a vacant attempt to preserve an useless appearance of regularity.

For these reasons, it appeared preferable to place the whole of the sandstones which follow the lowest, under one title; referring the reader to geological writers for those distinctions which confer on them their peculiar interest ; and condensing into one catalogue, all the mineral varieties which are the peculiar objects of this work.

Where it has appeared possible to refer any variety to a known position among British strata, it has been done in the Synopsis. But this part of the subject is unavoidably imperfect; as the minute distinctions of many of these local rocks, are scarcely definable in words, and as many of the most important, are derived from œconomical uses, dependent also on properties which cannot be described in an intelligible manner.

There is not much to be said on the general forms and mineral characters of these sandstones, which would not be a repetition of that which has already been stated in the preceding chapter. 
For this reason that enumeration may admit of being brief.

In the forms, dimensions, and divisions of the strata, the upper sandstones resemble the red sandstone already described. The masses, or collections of beds, often also attain to very considerable dimensions, without the intervention of any alternating substances. In the island of Rasay, for example, they reach to a thousand feet and upwards in thickness.

Like the red sandstone also, these strata alternate with smaller intervening beds of shale, and of limestone; and, in a few instances, with beds of clay, and of sand. In some cases, these alternating substances are considered as subordinate to some mass or series of sandstone strata; and thus there is described a formation or particular association, which seems to be sometimes of a very arbitrary, if not of an imaginary nature ; since, in other instances, the same alternations of these calcareous or schistose rocks, under differences of dimension, are held to constitute distinct formations, or to separate one association of sandstone strata bearing some local title, from 
another known by some other name. But this is the peculiar business of geology.

The occurrence of coal, as an alternating substance in the lowest red sandstone, is so rare, that no notice was taken of it in the preceding chapter; although it is known so to exist in the island of Arran. But, in the upper sandstones, it frequently occurs; or rather, the beds of coal are almost necessarily accompanied by alternating strata of these rocks.

Where mica is found in these sandstones, it is often the cause of a laminar tendency, and, as in the red sandstone, flags of considerable value for œconomical purposes are thus generated. This cannot, however, be considered among the modifications of structure; but those forms which may fairly be referred to such a cause, are very conspicuous in some varieties of this rock.

The first of these deserving of notice, is truly laminar, and independent of the intervention of mica, or of any other substance. The sandstone in which it is found, is composed of quartz alone; and the tendency to split, is generally only detected by the action of the weather. The mode 
of division is sometimes extremely singular, but as it cannot be rendered intelligible without a figure, the reader must unavoidably be referred to that work on the Western Islands already quoted, where the most remarkable instance yet described is represented. It is found in the Isle of Sky.

Many singular modifications of a concretionary structure, equally unintelligible without drawings, occur in this rock; and they are, in the same way, detected only by the weathering of the exposed surfaces. The consequences thus produced, are often such as to resemble the artificial ornaments given by architects to rustic basements ; the feebler parts wasting, while the harder remain in a variety of hatched and vermicular forms.

The spheroidal concretionary structure on the large scale, is sometimes found in these secondary sandstones. In this case, the spheroids are independent of each other, and imbedded in the general mass ; being distinguished, after the wasting of the surrounding parts, by their superior hardness and permanence. The surfaces of these spheroids are sometimes cracked into polygonal 
compartments; and it sometimes also happens, as in the accompanying limestones, that two flattened spheroids are connected by a cylindrical stem, so as to resemble a military projectile known by the name of bar, or double-headed shot.

It is not unfrequent, in these sandstones, to find some strata filled with small cylindrical concretions resembling worms, placed parallel to each other, and vertically to the plane of the stratification; but the cause of this, as of the other singular appearances of a similar nature, is as yet unknown.

Indurated laminæ, similar to those already described in the red sandstone, and often intersecting each other, are also found in these rocks ; and they are detected, like all the rest of these peculiarities, only by the action of the weather. In this way, evidence is sometimes afforded, of the decomposition, in situ, of beds of sandstone; as these laminæ, or veins, are sometimes found retaining their original hardness and imbedded in a mass of loose sand. At Kildrummie in Aberdeenshire, a very striking example of this is to be 
seen; and it may serve to prove, that where sand and sandstone are found intermixed, the former is as likely to have originated in the disintegration of the latter, as that the rock has been consolidated from loose sand.

With respect to the supposed veins of white sandstone, it is unnecessary to say more than what was remarked in speaking of similar occurrences in the red. Whatever the nature of such appearances may be, they can only be considered as veins by ignorance or voluntary selfdeception.

The structure of the sandstones under review, is almost invariably fine grained and arenaceous, like the predominant varieties of the red and lowest strata. They rarely afford examples of a conglomerate or coarse grained structure. They vary however materially in point of induration ; being sometimes extremely tender, and, at others, compacted to the hardness of quartz rock. In some rare instances, they are as compact as the most crystalline varieties of that rock; but, in these, it will generally be found that they lie in the immediate vicinity of trap, to the influence 
of which that change of character may be attributed.

Where they are most teuder, the adhesion of the distinct grains is produced without the apparent intervention of another substance. 'The most compact kinds sometimes owe their texture to the cementing property of clay or of carbonat of lime; and where the compactness is still more perfect, it is found that the adhesion is caused, as in quartz rock, by the intermedium of a crystalline continuous cement of quartz. It is in these instances that they are often difficult to distinguish from quartz rock except by their geological position.

Where these sandstones contair much clay or calcareous earth, or both together, and, at the same time, lie in the vicinity of trap rocks, they often pass into jaspers or cherts ; as is mentioned in the places where these rocks are more particularly described.

The minerals which enter into the formation of these sandstones, are very limited; since they consist only of quartz, carbonat of lime, clay, and mica. Quartz is the essential and predominant 
ingredient; the others are comparatively rare, and almost always in very small quantity, but on them chiefly depend the numerous varieties of character which this rock presents.

As these sandstones alternate with shales and with limestones, they sometimes also pass into them by insensible gradations; but the transitions into the former, are -more frequent than those into the latter rock.

No independent minerals, except pyrites, are found imbedded in these sandstones. Cobalt, oxidulous iron, bitumen, and manganese, are too rare to deserve being reckoned among substances capable of modifying the character of the rock.

Many organic substances, both vegetable and animal, are found occasionally included in some of these sandstones, as are fragments of carbonized wood, and of coal. Moreover, there often occur in them, forms which appear to have been produced by the previous existence of vegetable bodies, of which, nearly all but the traces have vanished. There are, generally, cylindrical substances, often of considerable dimensions, with scaly surfaces, or with regular impressions resembling those 
found on the stems of certain palm trees, and supposed to have been derived from some source of that nature. In some of these instances, the originally vegetable nature of the cause is proved by the existence of a portion of coal in tne concretion, occupying the place which the bark must have done in the vegetable. It has even happened in some recent cases, that portions of erect trunks of trees, similarly characterized by the carbonized state of the bark, and by the forms of the roots also, have been found in these strata; the place of the wood being entirely occupied by the sandstone. Remarkable examples of this nature have been lately discovered near Edinburgh, and at Glasgow.

Although the colours of the upper sandstones vary, the predominant hue is white. This is sometimes very pure at others tinged with yellow. Occasionally also, they are grey, or mottled and striped, in various ways, with white and yellow, or white and red, or with more than two of those colours. Those tints are however far less various and remarkable in these than in the red sandstone. In some rare instances, they are 
found of a black colour, from the presence of bitumen or charcoal : the other colours depend on those of the clays which enter into their composition.

The red variety, known by the name of the red marle, and already noticed, requires however to be particularly distinguished on account of its peculiar geological circumstances already alluded to, and because it is the frequent repository of rock salt and of gypsum, as well as of sulphat of strontian.

\section{SYNOPSIS OF THE SUPERIOR SANDSTONES.}

\section{FIRST DIVISION.}

Simple: of quartz alone.

A. An aggregate of grains of quartz, more or less condensed, and varying in hardness.

a. Of a large grain; gravelly.

b. Fine; arenaceous.

These varieties are almost necessarily white; but they vary in brilliancy according to the qua- 
lity of the quartz from which they are formed. When highly indurated, they cannot be distinguished from some of the varieties of quartz rock, except by their position. They are occasionally indurated to the state of common quartz in the vicinity of trap.

\section{SECOND DIVISION.}

Compound : of two or more ingredients.

A. Quartz sand and carbonat of lime.

a. Large grained; gravelly.

b. Fine; arenaceous.

These varieties are generally white.

B. Quartz sand with clay.

a. Large grained; gravelly.

b. Fine; arenaceous.

The colours of these are various. They are either white, or ochre yellow of different hues, or red, or grey of different degrees of intensity, or greenish, or black. They are also occasionally mottled and striped of various colours. The red varieties, more particularly, but many of the grey and white also, are not distinguishable from some of the lowest (or old red) sandstone, except by their geological positions. As sufficient 
access to a whole series is not always to be obtained, it is sometimes impossible to make the requisite distinctions.

C. Quartz sand with schistose clay.

This variety, although akin to the former in name, presents sufficient distinctuess of character to justify a separation. The clay is sometimes more or less distinctly interlaminated, and the rock passes into shale.

D. Quartz sand with clay and carbonat of lime. a. Large grained, gravelly.

b. Fine, arenaceous.

E. Argillaceous or calcareo-argillaceous sandstone mixed with bitumen.

This sometimes passes into bituminous shale.

F. Quartz sand with clay and mica, or with clay, carbonat of lime, mica, and red oxyde of iron.

The red marle of English geologists belongs to this division.

G. Quartz sand, with carbonat of lime, mica, and green earth. Kentish rag.

H. Sandstones of various quality, containing a large proportion of rust of iron: that substance often forming the cement of the other ingredients : ferruginous sandstone.

The sandstones of the Second Division, like those of the former head, when in contact with 
trap, pass into a species of jasper, or into chert. They are sometimes found penetrated by oxyde of cobalt, by oxydulous iron, and by carbonat of copper, and they frequently contain pyrites.

\section{THIRD DIVISION.}

Conglomerates.

A. Sandstone containing fragments of quartz.

B. Sandstone containing nodules of trap.

C. Sandstone containing fragments of previous sandstones.

D. Sandstone containing fragments of schistose clay or shale, or of limestone, or of both.

E. Sandstone containing flints. English pudding stone; of Hertfordshire.

This is sometimes of a loose arenaceous texture ; at others, it is indurated to the hardness of quartz. It is a question whether it does not rather belong to the alluvial rocks.

Organic remains, both vegetable and animal, as already noticed, and fragments of charcoal, are not unfrequent in the sandstones classed under this head. 


\section{9}

\section{SECONDARY LIMESTONE.}

IT was formerly remarked, that the primary limestones bore a very small proportion to the other strata with which they are associated. In the secondary class, on the contrary, the space oucupied by the calcareous strata is very great, whether we consider the thickness of the beds, or the extensive tracts of country in which they are found to be the predominant rocks.

The great importance very properly attached by geologists to many of the secondary limestones, might have appeared to justify a separate description of some of these, instead of thus treating of the whole under one general head. But the present plan, as in that of the sandstones, was not adopted without ample consideration of the subject, and till after a full conviction of the impossibility of forming any other arrangement, -without producing unnecessary repetitions, and 
encroaching on the peculiar department of the geologist.

The same arguments are indeed here applicaible as in the case of the sandstones. The primary limestones exhibit peculiarities of character, much more strongly marked and more various than the secondary; yet no reason thence arose for treating of them under separate heads. On a due examination of those which belong to the latter class, it will immediately appear that the most striking distinctions consist in the nature of the organic substances which they contain; and that their other important differences are of a geological nature; relating, either to their order of succession and association, or to their geographical situations. Neither of these are within the limits of this work.

With respect to many of the limestones described by authors, more particularly in foreign countries, there has been great difficulty in asceltaining their nature from the descriptions, so as to give them places in the catalogue of varieties. It is even uncertain with regard to many, whether they are primary or secondary; and this doubt 
has arisen, as already noticed in treating of the former, from the lax use of the term transition, which seems too often to have been made a convenient evasion for difficulties with which the observer was unable or unwilling to cope. It is not therefore in the case of the white limestone of Greece only, which appears to be secondary, that this difficulty has occurred; and time alone can remedy this and many other defects which unavoidably beset a subject that has hitherto experienced but a very imperfect consideration. There is no one of the sciences in which superficial observations are so easy to make and so. difficult to detect or verify ; and the use of a very few established terms and phrases, enables the most incompetent observer to throw obscurity, for a long period, over the most simple facts, and to convey the semblance of information without the substance.

Secondary limestone is much more decidedly stratified than primary, which, it has already been seen, is often found in the form of large imbedded irregular masses. Yet some cases also occur, where the form of stratification disappears, 
or where this limestone presents the shape of bodies as irregular as granite or serpentine. This loss of the stratified form is sometimes so complete throughout a given mass, that no traces of it are visible ; but, in other instances, it is easy to perceive, that the beds lose their regularity in a gradual manner, and that a shapeless mass is thus continuous with a collection of the most regular strata. It is further important to remark; that, in these cases, the organic bodies which are contained in the shapeless rock, are commonly very obscure and ill defined, and, very generally, rare; while it is also sometimes easy to perceive, that in those instances where a regular series of beds gradually loses its form, the organic remains undergo similar gradual changes, till, at the end, they sometimes entirely disappear.

Under the same circumstances, such limestones undergo an alteration of appearance and texture. The dark varieties change their colour to some lighter tint; and, in this manner, black strata have been observed to become gradually of a pure white. The soft earthy varieties, in the same cases, become compact, or even crystalline ; 
and, in some particular instances, they undergd that more complete change into chert which is noticed under a subsequent head.

These changes will be found sometimes to occur in the vicinity of the trap rocks; in others, they may be observed where no such rocks are present ; but as these highly interesting facts; and their probable causes, are more especially matters for geological discussion, the reader must here be referred, for further information, to the author's account of them in the work already often mentioned, where they are described as occurring in the Isle of Sky and in the Isle of Man.

Strata of limestone vary materially in thickness, and in the parallelism of their opposed planes, as those of sandstone have already been shown to do; and the accumulation of beds, which forms any single series of one variety, differs in the same manner in dimensions, from the thickness of a few feet to masses of mountainous bulk. In a similar way, they often form very extensive tracts of country in some places ; while, in others, they are limited to dimensions of a few miles, or even yards. 
The beds of limestone are associated in a constant system of alternation with the other secondary rocks, and, occasionally, even with clay and with sand. As in the case of the sandstones, when, in such an association, the other substances are subordinate in quantity, they are considered as subordinate in geological phraseology, and the term formation is applied to the whole; the series being named from the limestone. In other instances, the interposition of masses of shale and sandstone, is supposed to distinguish effectually between one set of calcareous strata and another; and thus a series of limestone acquires a different name, which is either provincial, or, if more generally found in nature, derived from some more general source. Thus we have the geographical term Jura limestone, the provincial term Lias, and the more general one, mountain limestone.

If these distinctions are sometimes arbitrary, or limited and local, in others they are sufficiently determinate and indisputable: being accompanied by certain steady and general characters, and, very often, by the peculiar nature of the 
imbedded organic reniains. All these are matters of a highly interesting nature, but the most general notice of them only is admissible in this place.

Some rentarkable varieties of internal structure are found in the secondary limestones. That which has been called the schistose, is improperly so named, as it is, more strictly, laminar. , Almost all the laminar limestones seem to owe their fissility, either to the presence of certain organic remains, or to the interposition of shale or clay, however small in quantity. Although these forms, therefore, may often be very remarkable, they cannot be considered as examples of an internal structure. Even the most thinly laminar limestones, which are often so valuable for oconomical purposes, appear to derive that form from their stratification; and the lamina ought to be considered as thin strata separated from each other without an intervening substance, as the larger frequently are. I am not aware that any example has occurred in the calcareous rocks, of a fissile tendency not conforming to the planes of stratification.m. Should such occur, as 
in the sandstones, it would necessarily be ranked among the modifications of a concretionary structure.

The fibrous structure, already described in the general remarks on the forms of rocks, occurs in this limestone, yet it is not common. As in the case of gypsum, it appears the result of crystallization, and the fibres are always at right angles to the plane of the strata. It is remarkable that the same apparent stratum is sometimes fibrous in one portion of its thickness and amorphous in the remainder; or, if the two are really distinct strata, they are not separable by mechanical force. The fibres are generally both straight and parallel, and they do not lose the latter character even when slightly curved, as they sometimes are. In some rare instances, they present a singular imperfectly ramified appearance, not to be rendered intelligible by words, and very much resembling, on a general view, the effect that would be produced by an aggregate of organic remains.

The small columnar, or large fibrous structure, also occurs in limestones, but still more 
rarely, and it presents several varieties of appearance. In some cases, the prisms are simple and parallel; in others, simply radiated from one center; or else they interfere with each other as they proceed from various centers. These prisms are sometimes, but not necessarily, crystalline; and they are frequently imbedded, in the form of distinct radiating concretions, in continuous masses of an earthy character. In a few rare instances they are not only striated longitudinally, but marked at intervals by protuberant joints ; a structure formerly mentioned as also occurring in some ironstones and jaspers. From the resemblance which some of the above-mentioned appearances present to organic bodies, these varieties have been distinguished by the name of madreporite.

The spheroidal structure occurs in limestones under three very distinct forms.

In the first of these, spherical grains of limestone are agglutinated into a solid mass, the particles varying from the size of poppy seed to that of a pea; and these rocks are known by the name of oolites. The grains are sometimes simple; 
but, in other cases, they are formed of concentric crusts.

In the second variety, the spheroidal structure is on a larger scale, and the spherules, which are simple, interfere with each other so as often to present considerable irregularity. On weathering, as the intermediate soft parts disappear, they become very visible; protruding in the same botryoidal forms which are hereafter mentioned as also occurring in the siliceous schists.

The last variety so exactly resembles that already described as sometimes occurring in the sandstones, that it is only necessary to repeat the remark there made, by observing, that the spheroids are, in this case, imbedded and sparingly dispersed in the general mass of an ordinary stratum; that they extend to the diameter of two, or even three feet, are commonly very much flattened, and are sometimes associated in pairs by a cylindrical stem.

Before quitting the subject of structure, it must be observed, that these limestones are frequently found to have been fractured and re-united by the same materials. In this way they present 
a great variety of appearance, depending on the colours, proportions, intermixture, and size, of the parts; and these, like the primary calcareous rocks which exhilit similar features, are sometimes wrought as ornamental marbles.

Conglomerate limestones are also found among them, consisting of a basis of calcareous matter with imbedded fragments of older rocks; and these are not unfrequently interposed among the strata of the lowest red sandstone. Calcareous conglomerates also occur in the upper limestones of the west of England, which seem to correspond to the magnesian limestone of the north-eastern district. As these are necessarily treated of again under a distinct head, the present brief notice of the fact will in this place suffice:

The texture of secondary limestones, like that of the primary, is very various. They are sometimes earthy, like chalk, or else somewhat more compact, and presenting a dull, but even, fracture, like that of the non-fissile argillaceous schists or claystones. Such earthy limestones are commonly of a very fine texture, but, occasionally, they have a coarser or an arenaceous appearance. 
The dullness of the fracture may diminish, while other circumstances continue the same; and thus they acquire a more compact and a harder aspect, with corresponding varieties of surface on fracture. This appearance of compactness is often so perfect, that the fractured surface is as uniform and smooth as that of pitch or glass ; and, in these cases, it is sometimes even, at others, conchoidal, and, occasionally, splintery.

The secondary limestones, like the primary, are sometimes crystalline; and that crystalline texture presents as many modifications of appearance in the one class, as it does in the other. To detail these varieties could serve no purpose; but it may be added, that it is not uncommon, in certain situations, for crystalline particles to be intermixed in a base of which the prevailing character is compact or earthy.

These resemblances of character between many limestones of the secondary and others of the primary class, are of considerable importance. They serve to prove that which has already appeared in many other cases, namely, that the mineral distinctions between the two, 
are not sufficient to enable us to decide on the class of any such rock from an examination of its mineral characters alone. Where organic remains are not present, that difficulty can only be removed by investigating the geological connections of the rock in question; and it is from a mixture of theoretical opinions on this subject with superficial observations, that so many secondary limestones have been placed in the imaginary transition class.

It ought not to be omitted, that among the peculiar characters of this limestone, that of flexibility has been found to exist, as it is also known occasionally to do in some rare varieties of gneiss and of sandstone. A peculiar magnesian limestone of Sunderland, mentioned in the catalogue of varieties, offers, however, as I believe, the only example which has yet occurred.

The simple minerals which enter into the composition of the secondary limestones, are, principally, carbonat of lime, with occasional, hut far inferior proportions of quartz sand, and of clay. Charcoal, or carbon under some modi- 
fication, and bitumen, also occur, and, in many varieties, in considerable abundance.

Where a notable proportion of quartz, or of sand, is united to carbonat of lime, the texture of the rock is generally very compact; and, although the particles of quartz are rarely visible, such limestones give fire freely with steel. At the same time, they generally effervesce with difficulty, and do not easily burn into friable lime. In the vicinity of trap rocks, such limestones pass into chert, as is hereafter noticed more fully under that head.

Where a large proportion of clay exists, the limestones also effervesce with difficulty ; and, if that substance is in great excess, refuse to burn into lime. As quartz is also an ingredient in these cases, it is not unfrequent for them to fuse into slags in the kiln; but when the proportion of these ingredients is moderate, they produce cements capable of hardening immediately on the application of water, as is in other cases practised, by mixing the burnt clays with pure lime. The lias strata are peculiarly noted for possessing 
this property, by wnich they are often rendered very valuable. It must lastly be remarked on this subject, that these argillaceous liunestones sometimes entirely lose their characters, and pass into the shales by which they are accompanied.

The presence of bitumen, commonly communicates a black colour to limestone, with a fetid smell either on burning or on friction; and these varieties are sometimes, but not necessarily, accompanied by organic remains. Besides simple bitumen, it would however appear that some other inflammable matter is occasionally contained in them; as is proved by the smell of sulphuretted hydrogen, and by other peculiarly fetid and indescribeable odours which they sometimes emit on friction.

It does not appear that the secondary limestones are ever the repository of any simple minerals capable of modifying their characters ; unless pyrites be considered an exception. The metallic substances found in them belong to veins, and are not here subjects for consideration.

The organic remains found in these strata, 
are of great variety, and they form a set of most important geological distinctions. Their value, however, in identifying distant strata, is as yet unsettled, and will probably prove far more limited than was once supposed. The study of these substances is of so important a nature, that it would be injurious to give, in this work, that which must, from its nature, be necessarily superficial and limited. Nor is indeed our knowledge of them as yet so far advanced as to admit of any unexceptionable arrangement of them, even by those to whom this branch of geology has formed a peculiar object of attention. That department of the science is as yet nearly in its infancy; and it must even remain for a future time, to decide in what manner a subject so intimately connected with the study of zoology and anatomy, is to be treated of by geological writers. To attempt to combine that which is imperfectly known, with those departments of which the knowledge is so much further advanced, could serve no useful purpose; and would, by its unavoidable imperfection, throw an air of insufficiency over the whole of this arrangement. 
When our knowledge shall be further extended, it may become possible to combine in one work the proper mineral characters of rocks with the description of those once living bodies which are now imbedded in them; but it is more probable that it will be found necessary to separate into distinct works two subjects which interfere in many important points, more than they coalesce in others.

The last subject relating to the general characters of the secondary limestones, is colour. In those rocks which contain no organic remains, and even in many of those in which they exist, the colour is commonly uniform throughout. In these cases, scarcely any tint is found but the innumerable varieties of grey; at one extremity of which may be placed pure white, as black is sometimes found at the other. Ochry yellow tints are also occasionally to be observed, but varieties of red are far less common,

Where organic remains are imbedded, the colours of these bodies, and those of the base, are sometimes different ; the former being white or light grey, while the latter are dark. In other. 
instances, a much greater variety of hue prevails; different tints of yellow, red, grey, white, and bláck, being sometimes intermixed in various modes. Such secondary limestones are, like the primary, frequently wronght as marbles for purposes of ornament; as are indeed many of those which, with one colour only, present a texture capable of assuming a proper polish. To notice these in greater detail, is beyond the limits of a work which only professes to treat of mineral distinctions. They are often highly interesting in the arts, and ornamental in cabinets of specimens; but are too easily distinguished, and at the same time far too numerous, to find places, even in the catalogues of varieties; among which, the distinctions arising from colour have here been systematically neglected, as of a trifling and unimportant nature.

\section{SYNOPSIS OF SECONDARY LIMESTONE.}

\section{FIRST DIVISION.}

Simple, or nearly so : formed of carbonat of lime with little or no intermixture of other earths. 
Effervesces readily and burns to lime which is easily slacked.

A. Crystalline; more or less perfect.

a. Granular.

b. Granular splintery.

A white variety occurs in Sky, not to be distinguished from primary limestone (marble for sculpture). They are however more frequently grey. In some cases, and not unfrequently near trap, crystalline particles, or portions, more or less extensive and conspicuous, are found imbedded in, or intermixed with, limestone of an earthy texture.

B. Compact, with a smooth fracture more or less glossy.

a. Flat, splintery.

b. Splintery and simall conchoidal.

C. Thin laminar, scarcely schistose.

D. Fibrous, or prismatic.

a. Fibrous, more or less minute : the fibres simple, parallel, and coalescing; sometimes, slightly undulated. The lustre is occasionally silky, and the colour white; forming satin spar.

b. Fibrous, the fibres ramifying; coalescing, and with a pseudo-organic structure. 
This is found in Egg, and elsewhere, with ordinary varieties of the former.

c. Prismatic, parallel or radiating: the prisms more or less easily separable: sometimes striated, and with an obscure appearance of joints:-pseudoorganic; Madreporite of mineralogists.

E. Concretionary spheroidal. Peastone, roestone, and oolite.

a. With large spherules, sometimes compressing each other.

The structure of the spherule is often distinctly laminar and it scales off in concentric crusts : rare ; in some cases, apparently of recent alluvial origin.

b. With spherules of a moderate size: roestone.

c. With minute spherules, varying much in size and sometimes becoming indistinct:-oolites of England.

d. The spherules intermixed with fragments of irregular forms. Purbeck stone.

F. Fragile, or easily sectile.

a. With a smooth somewhat glossy fracture: indurated chalk. Ireland.

b. With an earthy fracture; compact, but soft : common chalk. 
c. Containing clay : grey chalk.

d. Earthy, incompact: chalk marle.

This last might equally have been enumerated, only with marle. The white limestone of Greece is said to resemble var. a. ; but the want of acquaintance with it prevents me from determining its place.

All the varieties of this division become occasionally impure, so as to pass into those of the next. The colours of these limestones are various, as formerly remarked, but the following are among the most common. White, pale grey, dove colour, dark grey, reds of various hue, greyish brown, red brown, dark brown, black. These tints are, as in the primary limestones, sometimes intermixed in various ways; and the varieties of colour are increased by the intersection of veins of a pure carbonat of lime, or by the presence of organic remains. Such varieties are sometimes wrought as marbles for ornamental purposes.

\section{SECOND DIVISION.}

Compound, containing a notable proportion of some other earths or substances. 
The nature of such admixture is only ascertained by chemical analysis; but it is accompanied by certain external characters by which it is afterwards recognized without that assistance.

A. Calcareous carbonat, with magnesia, chiefly. Magnesian limestone.

a. Massive.

b. Laninar, and flexible when moist. Sunderland.

The proportion of magnesia amounts to twenty per cent., or more. The lustre exceeds that of common limestone : the fracture is granular and somewhat arenaceous. That of England (well known) is of a dull ochry yellow colour.

B. Calcareous carbonat, with a conspicuous proportion of clay intermixed: contains also some silica.

Aberthaw limestone. Lias limestone. Occurs in beds among the series of the same name.

a. Massive : sometimes in laminæ divided so minutely by clay or shale as to be nearly schistose.

As the proportion of clay is sometimes very considerable, it often effervesces with difficulty, flies to pieces in the fire, and will not burn so as to slack in water: if the heat is excessive, it forms a slag. The lime produced from some of 
the varieties, hardens suddenly when wetted, like tarras cement. The stone used in lithographic engraving belongs to this place. The colours are generally various tints of grey, from pale to nearly black. It is also occasionally of a dull white. The texture is more or less minutely granular, or uniform and smooth.

b. Concretionary : small spheroidal : botryoidal.

c. Concretionary: large spheroidal: generally oblate, and sometimes attached in pairs by a cylindrical bar.

Occurs imbedded in the massive: in Rasay and Sky.

C. Calcareous carbonat with a considerable proportion of oxyde, or rather rust of iron, as well as of clay and silica. Spheroidal; flattened. Often divided internally into prisms by calcareous spar: septaria.

This is imbedded in the blue clay of England. Produces water cements, like some varieties of the preceding.

D. Calcareous carbonat with notable proportions of clay, silica, and oxydes of iron.

Occurs in the lowest red sandstone. Is frequently red, yellow, or mottled of various colours; or grey, or even white, and scarcely burns to lime. 
a. Imperfectly granular; shining.

b. Earthy.

c. Smooth: the fracture splintery or approaching to the conchoidal.

This variety becomes so overcharged with the other earths, as to pass into calcareous shale, or marle slate.

E. Carbonat of lime, more or less pure, and intermixed with bitumen. Bituminous limestone.

F. Carbonat of lime intermixed with a large proportion of silica chiefly. Effervesces with great difficulty, unless in powder: frrms slags in the fire : passes into calcareous sandstone.

When near trap, it is often highly indurated, even previously to its assuming the character of chert, and it then frequently presents a very anomalous appearance. These varieties effervesce with still greater reluctance, unless reduced to powder.

\section{THIR1) DIVISION.}

Compound: containing some visible ingredient intermixed.

A. Limestone containing mica.

B. Limestone containing mica and sand.

These varieties occur in company with micaceous, or micaceo-arenaceous shale. 


\section{FOURTH DIVISION.}

Containing fragments of limestone, or of quartz, or of different compound rocks. Conglomerated.

A. Containing fragments of previous limestone.

B. Containing fragments or pebbles of quartz.

C. Containing chert or agate, in fragments. Occurs at Clunie in Perthshire.

D. Containing fragments of argillaceous schist ; probably of shales.

Some of these are necessarily noticed again, for the convenience of the student, under the head of Conglomerate Rocks.

There are further, as already noticed, many popular distinctions, often very marked, among the limestones, which do, not admit of being enumerated in a catalogue of this nature. These sometimes depend on actual variations of character, on the presence of certain organic remains, or on the less important distinction of colour. Sometimes they are founded on geolugical position; not unfrequently they are of a local or geographical nature. 
Flint and pyrites are the only minerals which have been observed in the limestones of this class, if we may except crystals of carbonat of lime. The first of these abounds principally in the chalks, but it also occurs, generally under slight modifications of aspect, in the compact limestones. Pyrites is found almost solely in these latter. 


\section{5}

\section{SHALE.}

UNDER this term are included all the argillaceous schists of the secondary class, sometimes also known by the inconvenient and awkward name of slate clay.

These have seldom been found occupying extensive tracts in nature, and it is even rare to. find them in considerable beds. The Orkney Islands are however an exception to this general rule. They are commonly in the form of thin strata, often of mere laminæ, alternating with the other rocks with which they are associated. Hence they are often implied by geologists, where they are not mentioned in any series, or formation; being considered as subordinate substances. They present, in this case, a striking analogy to the argillaceous schists of the primary class, which often occur in a similar manner among the other rocks of that division. 
They are found in the lowest red sandstone, under a great variety of character; and of this, Arran presents a very striking example. Very commonly also, in this case, they resemble the graywacke of the primary class so strongly, that they cannot be distinguished by their mineral characters; a circumstance already mentioned in treating of that rock. In some instances, as in the Orkney Islands and on the north-west coast of Scotland, these beds occupy a space so considerable among the rocks with which they are associated, as to be a source of doubt to the geologist ; since, under peculiar circumstances of exposure, and of limited access to the series, it may thus be impossible to distinguish them from the primary graywacke. In these cases, in fact, there sometimes appears to be an actual transition between the primary and secondary classes; the appearance of such a transition being rendered more perfect by the conformable order of the two.

Shale also forms a member of the various sandstones which lie above the lowest, or red sandstone; occurring through the greater number of those with which we are acquainted, and, 
in some, very conspicuously. In these cases also, it is often very difficult to distinguish it from the finer graywackes of the primary series; while, in some instances, it is even easily confounder with clay slate, as formerly remarked, unless examined in conjunction with its geological connexions.

It occurs in many of the secondary limestones ; either alternating with the calcareous strata in considerable beds, or forming thin laminæ, or else entering as a constituent with other substances, into some of the peculiar groups in which many of these are found

Shale is also found associated with coal. In this case, it either alternates with the coal itself, or forms a component part of the peculiar series of which that substance is the most conspicuous member.

Further, it is found among the clays; somé portions of these important deposits appearing to have been indurated into this form, while others have retained their loose earthy chararter. The enumeration of its associations already given in the two preceding articles, renders it unnecessary - to take further notice of them here. 
Finally, it has been thought necessary to enumerate among the shales, that substance known by the name of adhesive slate, which occurs in that peculiar and supposed fresh-water formation, known by the name of the Paris basin. Hereafter perhaps, when the similar formations discovered in other parts of the world shall be better known, it may become expedient to form a separate geological division for the purpose of containing the rocks that appertain to them. At present, it would be unnecessary, and indeed improper, to attempt such an arrangement; and the substances found in those of France and England, the only two as yet thoroughly known, must therefore be enumerated with those members of the secondary class to which they bear the strongest affinities.

The texture of all the shales is more or less distinctly schistose, and many of them also, break according to certain natural joints, by which they are divided in the beds. In other respects, they present many different aspects, arising from the greater or less fineness of the materials, or the variety of substances which enter into their com- 
position. They sometimes also contain larger fragments or nodules of the rocks, from the decomposition of which they have been formed.

Lastly, they contain organic remains both vegetable and animal. In the limestones, they are often the principal repository of the shells which appertain to these groups of beds. They are also the occasional repositories, like marle and coal, of the remains of vegetables. From analogous causes, they are also often impregnated with bitumen, even in such excess, as to be imperfectly combustible.

A general conception of their distinguishing characters as forming a species of rock, may be deduced from these remarks. More particular notions can only be conveyed by the description of varieties. 


\section{SYNOPSIS OF SHALE.}

Simple.

\section{FIRST DIVISION.}

A. Common shale.

a. Hard, and often not distinguishable from the fine and the coarse and argillaceous schists of the primary class: namely, clay slate, and ordinary graywacke.

This variety occurs chiefly with the lowest or red sandstone

b. Somewhat fragile, and less continuously laminar.

Occurs in alternation with the superior sindstones, or with the secondary limestones, or with common clay.

c. Tender, often scaly rather than laminar.

Occurs in similar situations, where it is frequently the repository of organic remains.

d. Passing into clay.

e. Granular concretionary : occurs, hitherto, only in the Shiant Isles.

f. Spheroidal concretionary: in the same situation: in the vicinity of trap.

The prevailing colours of these shales are various shades of grey, commencing from black 
and terminating in white, but the latter variety is rare. Acquiring red and yellow tints, it passes into the following variety.

B. Ferriferous shale.

a. Laminar, simple, and of various colours, pink, red, purple, brown, obscure blue, yellow, or mottled variously with different tints.

b. Laminar and short columnar : the columnar ironstone of some mineralogists. The surfaces are sometimes remarkably channelled on the margins, as noticed in the chapter on the Forms of Rocks.

c. Containing red oxide of iron in excess, and passing to common ironstone.

C. Adhesive slate. Opaque, adheres to the tongue, pale yellowish, or smoke, grey. The slaty structure is only visible in consequence of the loss of its water by exposure, and is rendered again invisible by wetting it.

This substance is, for convenience, here ranked with the shales, but it belongs to that limited series of rocks occurring in the vicinity of Paris which is supposed to owe its origin to fresh water.

D. Polishing slate. White or yellowish white, opaque, brittle, and lighter than water. 
This substance sometimes contains impressions of wood and of fishes. It is of such limited occurrence that it might perhaps more properly have been ranked, dike Tripoli and other matters, with the minerals of a mineralogical system.

\section{SECOND DIVISION.}

\section{Compound.}

A. Argillo-bituminous.

a. Slightly impregnated with inflammable matter.

b. Highly impregnated with bitumen so as to be combustible: accompanies coal. Black and also brown. The latter is Kimmeridge coal.

B. Argillo-calcareous-containing so much carbonat of lime as to effervesce with acids.

Some of the varieties of this, are the marle slates of certain mineralogists. As these substances are not very distinct, they are again introduced under the head of marle.

C. Argillo-micaceous; containing a conspicuous proportion of mica.

D. Arenaceo-micaceous; containing a large proportion both of sand and mica. With the former, in Sky. 
E. Quartziferous ; and passing into flaggy sandstone.

F. With rounded nodules of trap or other foreign fragments imbedded : occurs in Pabba and Sky.

Pyrites is not unfrequently imbedded in shale. It then sometimes becomes

G. Aluminous schist-or alum slate: forming an aluminous saline efflorescence on exposure to air, particularly if accompanied by heat and moisture, and thus generally falling to pieces.

Shale is also a repository of common iron stone and of the septaria.

It further often contains vegetable and animal remains in great variety; whence arise a set of distinctions which will find their proper place in any arrangement that may be formed of fossil organized bodies, but which do not fall within the plan of this work.

Where it is in contact with trap, it often passes into siliceous schist, as is noticed under that head. 


\section{OVERLYING ROCKS.}

IT was already remarked, in describing the general plan of this work, that it appeared necessary to treat of the whole of the rocks included under this comprehensive title, in one division. Much consideration was besiowerl on various plans for separating them; but none of these could be adopted, without producing inconveniences far greater than those which follow from the present arrangement. If all the masses of these rocks in nature, are not posterior to the secondary strata, no correct and unexceptionable rules can be given for distinguishing those which are of an earlier date; while, in a general sense, they possess the universal common character of being unstratified, and posterior to the rocks with which they are connected.

With respect also to their mineral composition and structure, it must be observed, that every 
modification included under this title, occurs as a recent secondary rock, and that they all, with exceptions that do not affect the present question, pass into each other in an imperceptible manner. There is therefore no distinction, either of a mineral, or of a geological nature, capable of guiding us in any attempt to separate them into distinct families; much less, in dividing them between the two classes of primary and secondary. To illustrate all these circumstances in a manner as ample as the case deserves, would require a geological history of the whole, which it has been found necessary to exclude from this work, and which, in this instance in particular, would lead to a great length of discussion. Hereafter, when additional experience shall have added to our present imperfect knowledge, it may become, comparatively easy to separate them under different heads, and thus to remove an inconvenience of which the writer is fully sensible, but which he confesses himself at present unable to remedy, without producing others still greater.

The several rocks of this family, form tracts of very various extent in different countries; 
and, in that light, they may be considered universal. Yet they cannot be considered universal in the same wide sense as granite, the primary strata, and the principal members of the secondary stratified rocks. They appear, on the contrary, to be in a great measure limited to particular spots, more or less extensive, and to be, if separately considered, partial and independent productions.

Where they do occur, they sometimes rise into high mountains, of which, in this country, Sky and Mull afford examples; at others, they form lower hills, or even summits absolutely independent. These masses are generally irregular, but sometimes bear indistinct marks of stratification; the vertical edges of the successive beds producing that scalar appearance in the outline of the land whence the name Trap has been derived. They also frequently occur in veins; and these are sometimes connected with the larger masses, while, at others, they appear to be absolutely independent of any visible larger portion or tract.

Under the uncertainties already stated, res- 
pecting their possible relation in point of time to the rocks of the primary and secondary classes, it only remains to describe the geological connections in which they actually occur. That they frequently rest on the most antient primary rocks, or that they send veins through them, is no proof, as already shown, of a connection in point of time; as the same effects would take place, although a deposit of this nature were to be formed at the present moment.

They have been found in contact with every rock, from granite, upwards, to some of the most recent of the secondary strata. It is yet however uncertain, whether there are masses of these rocks later than the whole of those strata; and, more particularly, it remains to be proved, whether any such formation has taken place since the deposition of the fresh-water series. As far as relates to their antiquity, when compared to the different members of the secondary class, there is precisely the same difficulty as that stated in the last paragraph: so that we must be content to suppose them posterior to the whole, merely for want of proof to the contrary. This remark, 
however, like the preceding, relates only to individual instances: because the existence of fragments of these rocks in the lowest sandstone conglomerate, proves that there have been formations of this nature, prior to the deposition of the secondary strata; and the intersection and shifting of two or more veins, appear equally to prove, that there has been more than one formation among these.

In granite, they only occur in veins; surmounting it when in masses. But among the stratified rocks of both classes, they are found intruding in masses, as well as in veins; and these sometimes put on a form so far parallel to the stratification, as, when partially viewed, to give them the semblance of beds. The veins, which are also common, are sometimes, in the same manner, partially parallel to the planes of the including strata, so as to have led to similar errors. In either case, the true nature of these may be determined, with proper care, by finding that the parallelism is not long maintained, but that any one such supposed stratum, or vein, quits its place to intersect the adjoining and in- 
cluding stratified rock, or sends ramifications through the whole series.

But there is one case in which these rocks seem to form strata unconnected with veins, and absolutely parallel ; and, of this, the north-western coast of Sky presents examples, as the northeastern does of most of the other circumstances here detailed. These strata alternate with jasper, siliceous schist, and ferruginous clay; probably also, with chert or indurated limestone. It will hereafter be shown, that shale is convertible, in similar circumstances, into siliceous schist, a substance strongly resembling basalt; and it is easy therefore to account for these strata, by supposing that, from the same cause, such substances have been converted into those strata of trap of various kinds, which their several peculiarities of composition enabled them to assume.

In a few cases, where deep sections of cliffs afford opportunity for examination, it is also found that irregular masses lie beneath the stratified rocks in some places, just as they surmount them in others; and that, from these also, veins proceed to the surface, or in other directions. 
A more particular account of such veins is given in the seventh chapter. The other interesting circumstances which attend these veins, must be referred to a geological history of these rocks; and it is only further necessary to add, that the Western Islands of Scotland present, in a very distinct and accessible form, every circumstance requisite for the illustration of that history.

The rocks of this family present many remarkable varieties of structure, of which the general details have already been given in the chapter on that subject. A few more particulars are here necessary, as they form a very important part of the history of these rocks, and are, in a few instances, such, as, when combined with the mineral characters, to lead to dangerous errors in geological investigation.

They often resemble granite in this respect, being disposed in large beds, either straight or curved, and divisible into prismatic and cuboidal masses. When these have been rounded by the weather, the rocks are not distinguishable by the eye from granite; and the deception is often much increased by similarity of mineral charac- 
ter. This modification of structure is not peculiar to those varieties which seem among the more antient, such as hypersthene rock, in which it is very conspicuous; as it occurs in the Corstorphine hills near Edinburgh, in a formation which lies above the coal strata.

The next, and by far the most remarkable variety of structure, is the prismatic. The first tendency to this, is seen in a vertical mode of fracture assumed by the exposed edges of these rocks, which at length becomes more decidedly prismatic, and ultimately columnar. When the mass possesses a parallel disposition, and is at the same time horizontal, while the prisms are at right angles to it, the well-known effect of architectural regularity, so conspicuous in Staffa, is produced.

This columnar structure, however regular it may be in a particular place, sometimes vanishes in the same mass, either laterally, according to the repetition of the prisms, or vertically; any individual column, or group, being found to become imperceptibly amorphous. In other cases, it is found that columns are irregularly dispersed 
in various directions through an amorphous mass, of which the upper part of Staffa also presents a good example. In a similar manner, a solid rock is sometimes merely split at its surface into short prismatic divisions; but this modification is comparatively very rare.

If the mass is mcliued, or not horizontal, the prisms which are at right angles to it, can no longer be vertical, and thus, in vertical veins, they are sometimes horizontal. But columns are not neressarily at right angles to the parallel masses; since, in various places, and conspicuously in staffi, they lie in several irregular positions in the same bed, even where in contact with each other.

Prisms thus irregularly placed, sometimes interfere with earh other so as to lose their regularity. This happens in such a manner in Canna, that they bear a general resemblance to that familiar object, a peat-stack ; while, in other places, they present other modifications of irregularity on which it is unnecessary to dilate. In veins also, they are not necessarily transverse to the walls ; since, in Rum and Cantyre, they occur in 
a parallel position; being vertical in the former case, and horizontal in the latter, in veins that are themselves vertical.

In almost every instance, the adjoining prisms are in contact, without any intervening substance or interval. In one case alone, which occurs in Rum, the prisms which are found on the surface of a large spheroidal mass, are separated by considerable intervals, which contract in the progress downwards till the parts touch.

In many remarkable examples, the prisms, or columns, even for a considerable length, are straight, or nearly so. In others they are slightly incurvated, and, in a few rare cases, as in Staffa, they are much bent, and often, at the same time, in various directions.

The forms of the columns differ; and the number of the sides, where they are most regular, vary from three to twelve; but they are more frequently of four, five, six, and seven; these being intermixed in such a manner, as 10 produce the absolute contact of the whole. Those sides are not always necessarily straight; but are occasionally curved. In size, they have been 
found to differ materially; the breadth varying from an inch to nine feet, and the length, from a foot to three hundred or more.

The columns are sometimes continuous for a considerable space. At others, they are obliquely and irregularly divided by fissures or joints; and, in some remarkable examples, by transverse ones of various character. In all cases, the distances of these vary materially; the divisions being, in some places, so accumulated as to separate the column into numerous parts, and, in others, occurring irregularly only after long intervals. The forms of the proximate surfaces are either irregular, or flat ; or concave and convex ; and, in some rare cases, a process arises from the angle of each inferior portion, so as to cover a corresponding deficiency in the superior.

It only remains to observe, with regard to the columnar structure, that it occurs in many members of this family. It is found in basalt, notedly, but not exclusively; as it exists in syenite and claystone, in Ailsa, Run, and Arran, in augit rock, in Sky, in porphyry in Arran and elsewhere, and in greenstone in various situations. 
The next variety of structure to be noticed, is the laminar. This appears to be sometimes independent of the action of the atmosphere; at others, it is obviously produced by that cause. The laminæ vary in dimensions, being sometimes so thin as to resemble those of argillaceous schist, and having thus given rise to the improper term of porphyry slate. This structure occurs both in masses and veins, and in all the varieties of these rocks. It is also sometimes combined with the columnar form, and, in this case, the laminæ are sometimes parallel to the column, at others transverse. In most of these rocks in which it is found, namely, in the claystones, basalt, and the porphyries, it is independent of the disposition of the integrant parts ; but, in hypersthene rock, it depends on the disposition of the crystals of the characteristic mineral, and the structure thus resembles that of gneiss, being foliated, strictly speaking.

A minute spheroidal structure, sometimes also occurs in these rocks. It is very conspicuous in the rock of the Shiant Isles, but does not appear common. The spherules are not 
separable by weathering, as they are in the siliceous schists of this character.

Besides these obvious modifications, the rocks of this family sometimes give indications of a particular internal structure, by decomposition. Thus they put on a scoriform or a spicular appearance, or are proved to contain veins of a harder material, which are not visible in the fresh rock. They frequently also decompose by a successive exfoliation into spheroidal forms, of which no indications were present ; and it is not uncommon for the portions of jointed columns, to waste in this manner. In this latter case, it may remain a doubt whether, as in the artificial columns of granite formerly mentioned, the effect is not produced merely by the action of the weather; but in some, where this cause cannot have acted in this manner, it must necessarily be the result of an internal concretionary arrangement.

On the subject of decomposition, it is lastly proper to remark, that some of the more solid varieties, such as those which have a base of indurated claystone, or clinkstone, are sometimes changed, without disintegration, to so great a 
depth as to emulate the soft claystones, and thus to mislead an observer respecting their true characters.

The minuter structures are, the small cavernous, the amygdaloidal, and the porphyritic; and, on these two latter, no remarks are necessary, except to observe that they may be combined in the same rock. But the former is worthy of partirular notice, on account of the exact resemblance which it bears to that which occurs in the scoriform lavas; the cells being often elongated, or contorted, and glazed by a vitreous varnish, while they are also sometimes partially filled with the substances that enter into the amygdaloids. Thus the cavernous passes into the amygdaloidal structure, and it is also sometimes found united to the porphyritic.

So many rocks, of different character and composition, are contained in this family, that no general remarks on their texture and composition can be offered; while the confusion which has hitherto reigned among them, renders it necessary to enter into details much more minute 
than have yet been required in treating of any of the precerling. These will be found, either in the following remarks or in the Synopsis, as appears most convenient for elucidating the subject.

It must here however be observer, that the terms already in use for distinguishing the several species, (or varieties,) are neither sufficiently numerous, nor very accurately limited. To have changed the application of these, would have been to depart from the general principles already laid down. Two new terms have however been adopted, those of Hypersthene rock, and Augit rock; these compounds having been hitherto undescribed, and it being absolutely necessary to distinguish them from the greenstones containing hornblende which they so much resemble. The term wacké has also been admitted; but with some hesitation; partly because it did not appear very necessary, and partly because it has been so often misapplied as to be nearly unintelligible. The names adopted therefore, in addition to these three, are claystone, indurated claystone, clinkstone, compact felspar, basalt, greenstone, syenite, porphyry, amygdaloid, and tuff. Trap 
is only used as a general term, and in a geological sense ; having commonly been applied in so vague a manner, to all the rocks of a dark colour which are not porphyry, basalt, or decided greenstone, as to have ceased to form any distinction, and having indeed become a source of confusion. To distinguish two varieties of claystone, is perhaps an unnecessary refinement; but it is not productive of any inconvenience.

Characters derived from colour alone, have been uniformly rejected; and it will be found, that a dependance on this vague criterion, has hitherto formed a principal source of confusion in describing these rocks. It is, in itself, an extremely variable circumstance in every rock, and in none more than these; in which it often differs, in substances in other respects identical. Unquestionably, it depends on differences of chemical composition ; but as it is not considered as a permanent distinction by the best informed mineralogists, it merits no consideration here. The habitual neglect of a mark so variable and so empirical, will teach the student to turn his 
attention to differences of a more constant and essential nature.

Another source of confusion has arisen from dwelling too strongly on peculiarities of structure as essential distinctions ; it being a common practice with collectors of specimens, to reject those of which the characters are not very decided; although these are often the most important, as marking the transitions which occur in nature. Thus the porphyries have been improperly separated from the simple rocks which form their bases, although the transition to the porphyritic structure is imperceptible. An attempt has been made to remedy these defects by adopting an arrangement more consonant to nature; but it is unnecessary to explain it in these preliminary remarks, as the reasons may be deduced from an examination of the Synopsis.

The predominant substance in the members of this family is a simple rock; of which, indurated clay or wacké, may be placed at one extreme, and compact felspar at the other; the interme- 
diate member being claystone, and clinkstone. In some cases, it forms the whole mass; in others, it is mixed with other minerals, in various proportions and in various manners; thus producing great diversities of aspect, without any material variations of the fundamental character. As we are but very imperfectly acquainted with the chemical composition of the simple rocks, it is not at present possible to determine, whether the gradations here supposed, be legitimate; and whether, under varying proportions, and under various states of induration, there is a real transition' between clay and compact felspar. The present arrangement is founded merely on the apparent transitions between the two, as they are found in Nature; all the several substances occurring together in the same geological series, often in the very same mass, and passing into each other without defineable limits.

It was formerly observed, that the term compact felspar, used here, as well as to denote a member of the primary strata, was injudiciously chosen. Chemical analyses have shown, that soda is an ingredient in many greenstones and 
basalts; and as it is not found in hornblende or augit, it is necessarily derived from the other constituents of these, the compact felspar, or the clinkstone, in which latter it has also been shown to exist. In repeating these experiments on some of these rocks which appear to contain compact felspar, they have sometimes been found to yield soda only, at others, both that alkali and potash, like the compact felspar of the primary strata. It is not impossible therefore, that there may be two distinct substances confounded under the term compact felspar; unless the existence of soda alone is, in these cases, held sufficient to prove the presence of clinkstone, and to form the real distinction between this rock and compact felspar. If any alteration in this respect shall be required, it must be reserved till a more extensive analysis of these rocks shall be instituted; and a more complete arrangement may then be made, to supersede that which is here attempted.

These simple rocks, therefore, must be considered as those which are peculiarly essential to the members of the trap family; as it will hereafter be seen that there are not many in which 
one or other of them is not found. It is next requisite to consider those minerals, which, from their less frequent presence, must be regarded as less essential.

Of these, hornblende is perhaps the most common. It appears very constant in its colours and general characters; the only perceptible difference consisting in its proportion and in the magnitude of the crystals. In the syenites it forms but a small proportion of the mass, and is sometimes crystallized in a tolerably distinct manner. In the greenstones, it is commonly more minute and more confused; and when, in these cases, it becomes excessive and very finely divided, it causes them to pass into basalt; a rock concerning which there are frequent differences of opinion, but which is incapable of rigid limitation, since, even under this composition, it is but the last of a regularly graduating series. Where the hornblende is most abundant and most minutely divided, the basalt is most perfectly characterized; but great differences of aspect follow from variations, not only in this ingredient, but in the colour and 
hardness of the clinkstone, or compact felspar, with which it is united. In such cases, where the base is of a very dark colour, and the proportion of the hornblende but small, the character of the rock becomes doubtful, and it may even pass into compact felspar, or rather into clinkstone. In this way, vcry dark clinkstones are frequently known by the name of basalt ; and it will accordingly be found, on examining many of the masses and veins in Scotland usually designated by this term, that they ought rather to be referred to the former substance. Hence the great diversity in the basalts of different authors; if we even exclude those which, like hornblende rock and Lydian stone, have been improperly ranked under this title.

From the presence of hornblende therefore, are derived three of the most leading members of the trap family, basalt, greenstone, and syenite; although it does not seem possible to give any marks by which the two latter substances shall always be effectually distinguished; since, in each, the basis of claystone, clinkstone, or compact felspar, is united to crystals of hornblende, 
while, in both, a similar structure prevails. The present distinctions, as already observed, seem to be regulated chiefly by colour; those rocks in which the three substances above-mentioned are of a pale whitish, yellowish, or reddisn hue, being ranked as syenite; and those where they are grey, greenish, or generally of a dark colour, as greenstone. A better distinction appears to consist in the predominance, or otherwise, of those substances; the rocks in which they exceed, being classed with the former, and those in which the hornblende is equally intermixed, or predominant, with the latter. By duly considering these characters, it will generally be easy to describe an individual rock without much hazard of misapprehension; although cases will often occur, where it will be impossible to determine to which of the two the substance in question ought to be referred. It may be added to this account of hornblende as an ingredient of these rocks, that it is frequently found in the older porphyries; occurring, in these, generally in the shape of imbedded crystals, but sometimes so abundantly 
as to form, with the leading ingredient, a compound or syenitic base.

The next mineral which forms an ingredient in these rocks is augit, which, under different aspects, is of very common occurrence; much more so than has been imagined, since it has, as I have already remarked, been frequently mistaken for hornblende. It presents two varieties of colour, dark green and black; the latter being the most common and the most difficult to recognize : the former can scarcely be mistaken. In many cases, the crystals, though indefinite, are so large, that there is no difficulty in determining the presence of the mineral; when very minute, that difficulty increases; although, with due attention, it is generally possible to make the distinction. Like hornblende, it is found, in the rocks where it enters, combined with different kinds, both of common and of compact felspar ; and it is most obscure whenever it is accompanied with the greenish or dark compact varieties. In Rum, it is united to the glassy variety ; and the distinction is in this case easily made, as 
it is generally of a green colour. At times it predominates so as almost to exclude the other ingredient. In certain cases, it is, like hornblende, sparingly dispersed throughout the rock, the clinkstone or compact felspar predominating; and, in these examples, the mixture resembles the syenites, as already remarked : in others, it becomes so minutely subdivided, and the rock puts on an aspect so nearly homogeneous, that it can scarcely, if at all, be distinguished from basalt. This compound is here only distinguished by the general term of augit rock, but it may be a question whether it would not be convenient to adopt terms applicable to its several varieties, so as to correspond to the three analogous rocks into which hornblende enters. In this case an adjective term might be employed with less inconvenience, and with a slighter change of nomenclature than a new name; and we should then have augitic greenstone, augitic syenite, and augitic basalt. But this is a subject for the consideration of mineralogists.

The next mineral occupying a place analogous to that of hornblende, is hypersthene. The - circumstances under which it is found, are so 
analogous to those just described, that it is unnecessary to repeat them. In certain states of minute admixture, it is, like augit, so easily confounded with hornblende, that we have still to learn whether hypersthene rock is not of more common occurrence than has yet been supposed. Hitherto it has occurred only in my restarches, and has been found in Sky and Airdnamurchan.

Another ingredient in the rocks of the trap family is common felspar; and it is most remarkable in the porphyritic division, on which it confers the distinguishing character. But it occurs also in the syenites, and even in the greenstones, without communicating to them the porphyritic structure. The structure of the rocks is, in these cases, granitic, and the felspar is distinguished from the compact sort, by its confused crystalline texture. In the same way, it occurs with augit and with hypersthene. Thus there are two subdivisions of all these rocks; the one set containing the compact and the other the crystallized or common felspar ; the external characters of each being strongly distinguished. This is 
most remarkable in the case of syenite; since it is only where the latter kind of felspar enters into the composition, that the rock presents the pseudo-granitic aspect : where it is formed of compact felspar and hornblende, as in the rock of Ailsa, it possesses no resemblance to granite.

The glassy variety of felspar is also found, though more rarely, entering into the composition of these rocks; in some cases.it forms the porphyritic imbedded crystal; in others, but more rarely, it occupies the place of common felspar in the compounds of granitic structure. In this latter way it occurs in the augit rock of Rum and in the hypersthene rock of Sky.

It is still necessary to enumerate a few minerals which, though far less frequent ingredients in the rocks of the trap family, and therefore less essential, sometimes enter into their composition as integrant parts; often producing considerable confusion in their characters.

The first of these is mica. This occurs in the greenstones and in the porphyries, but most - rarely in the former. It is a more important cir- 
cumstance when it is found in the syenites, as it is in Sky : on account of the resemblance which they then put on to the granites; a circumstance already noticed under the head of granite. 'To distinguish these two cases, a rigid geological examination is necessary; but the important views which this resemblance involves, is a subject for geological discussion. Mica occasionally occurs in the claystones also, examples of which are found in the schistose isles of the Argy shire coast.

Quartz also, is found in the greenstones, as well as in the syenites; being intimately mixed with the other ingredients, as it is in granite, and, adding much to the difficulty of distinguishing them from some varieties of that rock, without having recourse to their geological connections. Where it is accompanied by mica, as in the rock of Sky above ment oned, the resemblance between the two is $p$ rrfect. Olivin is most frequently found in the situation of an imbedded mineral, like the zeolites; but it also occasionally forms an integrant part of the mixed structure. Very rarely, mesotype, prehnite, stil- 
bite, epidote, and calcareous spar, occur as constituent parts of the trap rocks ; most commonly, they must be considered as accidental and foreign ingredients, occurring in the amygdaloids, or supra-compounded varieties.

The various minerals that appertain to the supra-compounded division of these rocks, and those which occur in other modes imbedded in them, will be enumerated in the Synopsis, and require no particular notice here; they must be considered as accidental substances in their natural repositories, and they produce in the former case, a subdivision of varieties subsidiary to those which arise from the different characters of the the base in which they exist. The bases themselves vary, in these cases, as they do in the simpler ones formerly enumerated; although wacké, and the claystones, under different degrees of induration, are by far the most common.

Such is a general sketch of the nature of the trap rocks as far as my observations have permitted me to delineate it, and on this foundation is constructed the synoptical table that follows. It is confessedly imperfect, but it will have per- 
formed all that is expected if it shall hereafter facilitate a more perfect arrangement of the substances which it includes. That the attempt is new, and that the most indescribeable confusion has hitherto reigned among these rocks, will form an apology, not only for the imperfections of this arrangement, but for the great length of the following catalogue. The minuteness of detail which it was thought necessary to adopt, may possibly be dispensed with whenever these rocks shall become more generally understood.

\section{SYNOPSIS OF THE OVERLYING ROCKS.}

\section{FIRST DIVISION.}

Simple : or apparently simple.

A. Wacke: of the Germans. Resembles indurated clay, with an even and smooth earthy, or an uneven somewhat granular fracture, and a shining streak.

a. Compact.

b. Cellular: but generally, in that case, partly amygdaloidal, and appertaining to another division.

B. Indurated clay: more or less hard: with an earthy and dull fracture. Much more common in Scotland than the preceding.

a. Compact. 
This must not be confounded with the ferruginous clays which are often found among the trap rocks, and which pass into jasper.

b. Cellular.

Like Var. A, b, it is rarely cellular in large masses, without also containing amygdaloidal nodules; when it ranks under another division. The colours of this variety are, either ash colour, or grey of different hues, or modifications of red, or browns, or purplish black.

C. Claystone. The fracture is dull and earthy, and may be smooth and even, or rough and somewhat granular, or imperfectly splintery, or conchoidal. It differs from the preceding substances in hardness ; but, as in many other cases, it is scarcely possible to convey an idea of such distinctions by any mode of definition. Claystone, independently of its geological differences, is distinguishable from argillaceous schist, by the absence of the schistose structure.
a. Massive, irregular.
b. Prismatic, or columnar.
c. Laminar.
d. Cellular.

The laminar structure is scarcely to be detected, except on the surface, and after exposure to weather. It is sometimes combined with the prismatic configuration. It cannot be confounded, 
without great negligence, with the schistose structure of argillaceous slate.

The colours of claystone are various; as, pale greyish, or muddy white, or ochre yellow of various intensity, or flesh colour, or purplish, or various tints of grey, from smoke coloured to dark lead-grey, or nearly black.

This variety occurs in veins, but rarely : it is more common in mountain masses.

D. Indurated claystone. Harder than the former, and distinguished by the superior lustre and acuteness of the fractures, which are also, granular, splintery, or conchoidal. It is here separated, rather on account of its geological importance, than of its mineralogical distinctness. It is among the most common and extensive of the trap rocks in Scotland.

a. Massive, irregular.

b. Prismatic, or columnar.

c. Laminar under the same circumstances as C. $\mathbf{c}$.

The very dark varieties, particularly when found in veins, or in a prismatic form, are sometimes called by the name of basalt, and may be considered as at present forming one of the varieties generally ranked under this indefinite and popular term. It occurs, like the former, 
both in veins and in mountain masses. It is frequent in the former shape, and is even sometimes thus found accompanying the apparently antient porphyries that traverse granite.

The colours are similar to those of the preceding variety. Specimens, of which the colours are brilliant, sometimes pass by the name of jasper, to which they approximate.

E. Clinkstone. This is still harder than the last variety, and is not easily scratched by the knife. The fracture is also more perfectly splintery and conchoidal; occasionally somewhat granular, while the lustre is more considerable, and the fragments are slightly translucent on the edges. It is considerably sonorous when struck, but not so as to be distinguished by this circumstance from many other rocks of the trap family. Its mineral definition was formerly given.

a. Massive.

b. Columnar, or prismatic.

c. Laminar.

The dark varieties of $b$ have also, like the former, been enumerated among the basalts. The same remarks as in the two preceding cases, may be made on var. $c$.

It is also found in similar geological situations, and the colours are equally various. It frequently acquires an arenaceous aspect on the sur- 
face after exposure to the weather ; so as even to have been confounded with sandstone by incautious observers.

As these substances $\mathrm{C}, \mathrm{D}, \mathrm{E}$, pass into each other by insensible gradations, it is not always possible decidedly to refer a specimen to either. This is irremediable, but it does not destroy the utility of the preceding distinctions.

F. Compact felspar; including the hornstone of some mineralogists. This is distinguished from the last substance, to which it is nearly allied, by its superior hardness, compactness, and lustre. The edges of the fragments are also more decidedly translucent. A fuller description was formerly given.

a. Imperfectly laminar.

b. Massive, with a smooth, splintery, and conchoidal fracture.

c. Crystalline-granular.

This substance var. a, b, occurs occasionally in veins in a simple state, but is more frequently slightly porphyritic in some part of its course. I know not that it is found in mountain masses or beds among the trap rocks of secondary origin.

Var. c appears under many different aspects, in consequence of the varying fineness of its texture. It occurs among the secondary traps, 
both in veins and in masses. In some cases, it contains crystals (or grains) of two colours, as white with dark lead blue, or greyish green with blackish green or lead blue, and has then been confounded with the greenstones. This might be called a pseudo-greenstoñe. In other cases it presents various simple tints, like the preceding varieties. It seems doubtful whether this variety does not sometimes consist of an aggregation of common instead of compact felspar.

Fawn and cinnamon colours are found in var. a, b; but they also occur of a brick red hue, of a muddy white, and of every possible tint of grey down to nearly black. There seems to be a gradation from clinkstone to compact felspar, as there is between the varieties $C, D, E$.

The simple compact felspars pass into porphyry so commonly, that it is not easy to find an extensive mass absolutely free from imbedded crystals. Hence a specimen is not a criterion of the nature of an extensive rock.

A similar remark may be made, generally, on the four varieties C, D, E, F ; which, although simple in one place, may be porphyritic or amyg- 
daloidal in another. Where Nature is indefinite, the student must not be disappointed if he cannot frame or find a definite artificial arrangement.

It must be remarked of the preceding rocks, and chiefly of varieties C, D, E, that they often lose their natural characters, even to a great depth from the surface, becoming weathered; if that term can be used to designate a change where the weather can scarcely obtain access. They are not, in these cases, disintegrated, but retain their solidity, together with the appearance of natural rocks. In such circumstances, they acquire an arenaceous aspect, or become carious ; undergoing, at the same time, changes of colour ; and in this way the dark indurated claystones or clinkstones, will put on the appearance of common claystone or even that of the indurated clay, var. B.

G. Hornblende compacted into a solid mass, and apparently consisting of minute crystalline particles. Hence the fracture is more or less coarse grained, and is, further, uneven, splintery, or conchoidal. It varies in lustre, being sometimes considerable glistening. This is one of the varieties of basalt: it is imagined to be the only basalt by some authors. 
The analysis of basalt however, yields soda, even according to those by whom the term is limited to this variety. But hornblende does not contain soda, and the specimens thus analysed must therefore be of a different nature ; probably containing compact felspar. If the term were actually to be thus limited, such specimens do not rank under it.
a. Massive, irregular.
b. Laminar.
c. Columnar, or prismatic.

This basalt occurs both in veins and in masses. It appears to be sometimes laminar in the former, independently of the action of the weather. The columnar and laminar structures are sometimes combined, as they are in the claystones; and the latter is either parallel to the axis of the prisms, or at right angles to it.

The columns of basalt are sometimes jointed, in the various ways already described; but that structure is not limited to this rock, as already shown. Mineralogists have long since rejected the antient distinction of the columnar structure as characterizing basalt. 


\section{SECOND DIVISION.}

Compound: formed of two substances.

FIRST SUBDIVISION.

Granitiform mixtures.

A. Hornblende and compact felspar.

a. In nearly equal proportions, or the hornblende predominant, and the two minerals distinctly visible. Greenstone.

This rock is important from its extent, and it occurs both in veins and in mountain masses. Like some of the preceding, it is also at times columnar, as well as laminar. 'The hornblende is either black or dark green, and is sometimes distinctly crystallized. The felspar is white, or yellowish, or of different hues of red, or pale greenish, or grey of different degrees of intensity down to nearly black. The greenish varieties alone, have been distinguished by some mineralogists by the name of greenstone, the grey by that of greystone; but the former term has been in this country applied to the whole, of whatever colour. It presents a great-variety of aspects, according to the relative proportions of 
the constituent parts and the size of the particles, no less than from their various colours. Rocks not distinguishable from the dark varieties, occur together with granite, as noticed under that head; nor do they, in this case, present any distinction but that of their geological connections.

The felspar is sometimes accumulated in spots in the general mixture; presenting a porphyritic appearance and forming pseudo-porphyries.

When the felspar is red, this rock has often the general aspect of some varieties of granite.

b. The compact felspar predominant. Syenite.

This rock is also important, from its frequency, and the extent which it occupies; occurring principally in mountain masses, much more rarely in veins. It is sometimes found partially laminar, like former varieties of this family, and it is also occasionally columnar; a circumstance, of which Ailsa presents a striking example.

As in other instances in this family, this rock is not always consistent in its composition throughout a large space; so that the determination of the character of a specimen does not 
always determine that of the mass whence it was taken. Thus it passes into many other varieties, as well as into the preceding; occasionally also becoming simple by the exclusion of the hornblende. This forms one of the varieties of the syenite of mineralogists; limiting that term to rocks of the overlying family.

c. The mixture imperceptible, or nearly so, to the naked eye.

In this variety, the hornblende is in equal or greater proportion to the felspar, which latter is generally also of a dark colour. Hence the mixture is dark grey, or blackish green, or nearly black. The substance here called compact felspar is often, possibly, clinkstone, or indurated claystone; but the distinction can scarcely be made in such circumstances. This is also enumerated among the basalts; presenting the same general appearance as some varieties of $\mathbf{D}, \mathbf{E}$, and G, First Division. Like those, it is also sometimes columnar, as well as laminar. It appear's further to pass into other varieties, by a change of the character of the compact felspar, or by omission of one or other of the ingredients. 
B. Hornblende and common felspas

a. In nearly equal proportions.

As already noticed under F, c, Division First, it is sometimes uncertain, from the minuteness of the parts and the state of mixture, whether common felspar is not the mineral present, instead of compact felspar, in some of the preceding varieties.

In other cases, the nature of the felspar is abundantly evident, and it is even confusedly, or more regularly crystallized, and intermixed with the hornblende. The hornblende is also at times crystallized in a manner considerably distinct. The rocks of this variety also, are classed under the very loose term of greenstone; but they generally differ in appearance from most of the varieties of $\mathbf{A}$ in this division, into which they however pass. Some mineralogists are inclined to place them with the syenites. They pass into those in a perfect manner, by the increase of the felspar. When the felspar is red, they have, in a considerable degree, the general aspert of some varieties of granite; and similar rocks are found connected with ordinary granite, un- 
der which head they have already been enumerated.

b. The felspar predominant.

This also forms one of the prevailing varieties of syenite, and occurs under the same circumstances as var. $\mathbf{A}, \mathbf{b}$, of this division. The same remarks respecting variations of structure and connections, are applicable to it. Its aspect is more decidedly granitic than that of the variety which contains compact felspar. When the felspar is of a dark grey, as sometimes happens, it is also included, but improperly, under the general term greenstone. In some cases, compact and common, or common and glassy felspar, occur together, and chiefly in var. a; but these variations do not seem to require separate places.

C. Compact felspar and quartz.

This occurs in conjunction with the syenites and the simple rocks, of which it is an occasional modification ; nor does it appear to form exten- sive distinct masses. Quartz is found, in the same way, united with the simple substances $\mathbf{D}$, E, Division First ; but it is unnecessary to multiply these distinctions. 
D. Common felspar and quartz.

This also occurs among the syenites and analogous rocks, but apparently as an incidental variation only.

E. Hornblende with glassy felspar.

This variety is rare, and appears to occupy but small spaces where it occurs.

F. Augit with compact felspar.

a. The augit in superior or equal proportion to the felspar; distinctly intermixed. Augit rock.

I have distinguished this by the name of augit rock. It is in every respect analogous to the similar compounds of hornblende and compact felspar, with which it has been hitherto confounded. It varies materially in appearance, according to the colours of the augit, which are either black or dark green, and according to the magnitude, relative proportions, and intermixture of the parts. It is occasionally laminar, and also columnar, and is found both in veins and in extensive masses. It abounds in Scotland, chiefly in the Western Islands, as in Rum and Sky. 
b. In a state of minute intermixture, and the parts nearly, or altogether, invisible.

This rock occurs of different colours, namely, pale or dark greenish grey, or greenish black, or black. It has the fracture and general appearance of the basalts, with which the darkest varieties have been confounded. Its nature, as yet, can only be ascertained by tracing its intermixture with, and gradation from the preceding variety; as there appears to be at present no method of distinguishing augit from hornblende when in this minute state of division and mixture.

c. The felspar in excess, and both the minerals distinct.

This rock resembles the analogous variety of syenite into which hornblende enters. It occurs in Rum, and may possibly be found elsewhere, when mineralogists shall turn their attention to these hitherto neglected compounds. Like the common syenites, it presents considerable diversity of aspect.

G. Augit with glassy felspar.

This beautiful rock occurs in Rum.

It is probable that there are also compounds 
of augit with common felspar, but as yet they have not fallen under my observation, and I have therefore forborne to reserve a place for such a variety. It appears further that both augit and hornblende exist together in the same rock; but I also forbear to make a variety of this at present, as the distinction between these two minerals when in a state of mixture is so difficult.

H. Hypersthene with compact felsar.

I. Hypersthene with common felspar.

K. Hypersthene with glassy felspar, and occasionally with common and glassy felspar both. Hypersthene rock.

These form three varieties of a rock hitherto unknown, and to which I have given the name of hypersthene rock. It occurs in large granitiform beds, in mountain masses; and is found, as already noticed, in Sky, and in Airdnamurchan. As yet I have never observed it either in a columnar form or in that of veins.

It occasionally exfoliates like the granites, in a solid form, by the action of the weather. In other cases, it possesses a foliated structure like gneiss, arising from the parallel disposition of the hypersthene. More generally, the structure 
is granitic, and varies exceedingly, according to the magnitude of the parts and their relative proportions. Thus it sometimes resembles large grained granite, at others, ordinary greenstones. It also contains, in some cases, additional imbedded crystals of felspar, resembling thus the porphyritic granite. Occasionally it is so fine as to approach in appearance to basalt. It varies further according to the colours of the felspar, which is greenish grey, or white, or smoke grey, or dark purple grey. It seems, at times, to contain hornblende, as well as hypersthene, but not so conspicuously as to render it necessary to adopt a separate variety.

Pyrites, mispickel, garnets, and octoedral oxidulous iron, occur in hypersthene rock; and the latter in such abundance as to modify its character aud aspect.

SECOND SUBIIVISION.

Compounded of two substances; one of which is more or less distinctly crystallized and imbedded in a simple base of another. Includes some of the porphyries. 
A. Claystone, common, or indurated, with imbedded scales of mica, sometimes regularly crystallized.

This rock occurs both in veins and in masses in the Western Isles of Scotland, but appears to be rare.

B. Grains, or imperfect crystals of quartz imbedded in a simple base.

a. Base of claystone.

b. Base of indurated claystone.

c. Base of clinkstone.

d. Base of compact felspar.

These occur together with the simple rocks that form their bases, and are common in Arran. Varieties. c, d, form rocks of a sufficiently remarkable appearance to attract the notice of a collector. The colours necessarily vary according to that of the bases.

C. Crystals of felspar imbedded in a simple base; or in a base apparently simple. Porphyry.

a. Base of claystone.

b. Base of indurated claystone.

c. Base of clinkstone.

d. Base of compact felspar.

These form the most common of the simple porphyries. The imbedded crystals may consist of common felspar, of glassy felspar, or of both 
together. Occasionally also, the felspar is opake and dull, as if in an incipient state of decomposition; sometimes, it is even in a powdery state; and, in a few instances, it would not be supposed that it had ever existed; the rock having a carious appearance, and the original seats of the crystals being imperfectly filled with an ochry powder.

The colours of the bases are, in all these cases, subject to the same variations as the simple rocks. Hence arise numerous varieties of aspect, still further multiplied by the colours of the imbedded crystals, by their proportion to the base, by their size, and by different modes of disposition which it is unnecessary to specify. Of these latter, the twinning or the crossing of the crystals is the most remarkable.

By the gradual exclusion of the crystals, these porphyries pass into the simple rocks; and as the two frequently exist in one mass, a specimen is not always a criterion of the nature of the rock. Hence the term porphyry, when used in geological description, must not always be taken too strictly in its mineralogical sense.

These rocks are abundant in nature, and occur 
either in the form of mountain masses, or in veins.

The three first varieties, a, b, c, occur chiefly among the latest secondary strata, but are occasionally found traversing even granite, like the simple rocks of which they are varieties, in company with var. d. This latter variety occurs almost exclusively, or at least most commonly, in situations where it may be supposed of far more antient date than the former.

Varieties a, b, and c, are occasionally laminar, like the syenites already enumerated, and also columnar. The var. $d$, is sometimes also of a laminar structure; but I am uncertain if it has yet been found disposed in the columnar form.

e. The base of basalt. Basaltic porphyry.

This rock occurs, like the simple basalts, among the latest strata, and under all the same modifications. The crystals of felspar are very frequently glassy; and, as the base may consist of any of the substances already mentioned as known by the name of basalt, it might be subdivided into varieties, were such refinement necessary. 


\section{THIRD DIVISION.}

Compounds of three or more ingredients.

\section{FIRST SUBDIVISION.}

Granitiform mixtures.

A. Felspar, hornblende, and quartz. Syenite.

This is the substance which alone rigidly accords with the common definition of syenite; although, in practice, mineralogists have not held it necessary to be strict on this subject; feeling, rather than acknowledging, the inconvenience of such refinements in the geological description of rocks. The felspar may be either compact, or common. The former variety occurs among the overlying rocks only ; never, as far as I have observed, very extensively or perfectly, among the granites. The látter compound forms also a well-known and very prevalent variety of granite. Where these rocks occur with the traps, the felspar is often of a grey or greenish hue; and, in this case, they have frequently been called greenstone, the quartz being neglected or overlooked. 
There are many different aspects in this rock, arising from the colours of the felspar, which, besides those just named, may be of a dull white, or ash-coloured, or of an ochry hue, or of reddish tints. The two last, it must however be remarked, are rare among these syenites. It varies also extremely, in the proportions of the ingredients; and those varieties are the most remarkable, which contain a small proportion of hornblende.

B. Felspar, hornblende, and mica.

This variety does not appear to be common. It has been called micaceous greenstone.

C. Felspar, hornblende, and chlorite.

D. Felspar, hornblende, and steatite.

These also are rare, but they are found in Sky.

E. Felspar, quartz, hornblende, and mica.

This variety occurs in Sky, and apparently elsewhere, in connection with some of the preceding, and incumbent on conchiferous limestone. Its geological situation therefore admits of no doubt, notwithstanding its resemblance to granite. Its existence in this situation, and the presence of 
common greenstone and basalt among the granites, present the two strongest examples of the analogy between these rocks, so different in geological connections. In both cases, there is no distinction to the mere mineralogist, or collector of specimens ; but the arrangement here adopted renders it necessary thus to separate substances which are, mineralogically, identical.

No example of a mixture of quartz, felspar, and mica only, has, as far as $I$ know, yet occurred among the overlying rocks.

As in granite, the constituent minerals are sometimes crystallized in these syenites. Crystals of brown quartz, in particular, occur of a considerable size in St. Kilda.

The columnar form of the syenite of Ailsa was mentioned under A, b, Second Div. First Subdiv., and in that rock quartz is sometimes present so as to bring it equally under the var. A just noticed.

Occasionally these varieties, like others, are also laminar.

F. Augit, felspar, and mesotype.

G. Augit, felspar, and prehnite. 
H. Augit, felspar, and chalcedony, or quartz.

I. Augit, felspar, chalcedony and prehnite, or mesotype.

These are varieties of angit rock, and they, occur in different parts of the Western Islands of scotland.

K. Hornblende, felspar, and olivin.

L. Hornblende, felspar, and epidote.

These varieties are accidental, or very limited: they may not possibly deserve a place in a catalogue of rocks formed on this principle; as the last ingredient in each, may be supposed an accidental imbedded mineral.

M. Hornblende, felspar, and prehnite; or hornblende, felspar, prehnite, and mica.

This variety occurs in Dumbartonshire, the prehnite appearing rather to form a constituent part of the rock, than to be an imbedded mineral.

N. Hornblende, common felspar, compact felspar, quartz, and steatite-apparently containing augit also.

Occurs near Edinburgh.

O. Hornblende, and greenish compact felspar forming the chief part of a mixture in which are intermingled glassy felspar, opake white felspar, augit in distinct prisms, and mica, together with pyrites.

\section{12}


I have found this rock, like $\mathrm{N}$, forming a mass of considerable extent, near Glasgow, and havé quoted them both as examples of very complicated varieties of what must be included with the greenstones. Doubtless many other varieties, which have not come under my notice, exist; and these examples will serve to direct the attention of mineralogists to a minute examination of these rocks, should it be thought necessary to add to this catalogue, all the varieties that may be found in a class of rocks which include so many mineral substances.

\section{SECOND SUBDIVISION.}

One species of crystals imbedded in a compound base, or two species of crystals imbedded in a base that is either simple or compound. This includes all the remaining porphyries.

A. Felspar crystals in a base of greenstone.

This is the greenstone porphyry of mineralogists, and it may exist under many different aspects according to the quality of the base. The student may distinguish these by referring to the preceding parts of this catalogue, as the 
enumeration would here serve no purpose but to swell a list already perhaps too long.

B. Felspar crystals imbedded in a base of syenite.

This variety admits of the same remarks; and the porphyries of this character, which are generally connected with the more antient rocks, are often not to be distinguished from porphyritic granites, into which they pass.

C. The crystals consisting of felspar and quartz.

D. The crystals consisting of felspar and mica.

E. The crystals consisting of felspar and talc.

F. The crystals consisting of felspar and epidote.

G. The crystals consisting of felspar and pinite.

H. The crystals consisting of felspar and chlorite.

In the only example of this last variety which $I$ know, the compact felspar that forms the base is of a green colour, and the imbedded felspar has also in most parts the same hue. It occurs near Campbelltown.

I. The crystals consisting of felspar and hornblende.

In all these cases, as in former ones, either variety of felspar may form the imbedded crystals ; namely, the common, or the glassy, or both together. 
In varieties $\mathbf{C}, \mathbf{D}, \mathbf{E}, \mathbf{F}, \mathbf{G}, \mathbf{H}$, the base may be simple; or compound, and analogous to $\mathbf{A}$ and $B$. Hence the varieties of aspect are infinite. Further, the mode of intermixture is often such, that it is difficult to determine whether the crystal, here called imbedded, is not rather a part of the base ; and, in these cases, there is a gradation between porphyritic and granitiform mixtures. This, in particular, frequently happens in var. I. It is among the apparently ancient porphyritic rocks, that this uncertainty of character takes place. The porphyries, like the amygdaloids, sometimes contain empty cavities.

It is probable that this catalogue admits of considerable extension, but I have limited the enumeration to those varieties which have fallen under my own observation, and which occur in considerable masses. A research among cabinet specimens would possibly add many more to the list.

\section{FOURTH DIVISION.}

Supra-compounded rocks. Amygdaloids of mineralogists ; in this country at least, as this 
term appears to have been sometimes used in a different sense by foreign writers.

These comprise many of the rocks, both simple and compound, of the preceding catalogue, as bases, in which are imbedded nodules of various adventitious minerals. The prevailing amygdaloids, however, have bases consisting of the harder varieties of indurated clay B, Division First.

Occasionally the porphyritic and amygdaloidal structures are combined, as already remarked, producing a set of incidental varieties which it has not been thought necessary to describe. The amygdaloids may contain one, or more minerals, and hence also arise numerous varieties.

Their aspects further vary according to the magnitude of the nodules, and the proportion which these bear to the base. These nodules are sometimes solid; at others they do not fill the cavity which contains them.

In some cases, two, or more, minerals are contained in the same cavity, as agate and calcareous spar. At times, considerable portions of an amygdaloid contain cavities, without minerals, as well as others partly filled, together with solid nodules. 
When such cavities are numerous, these rocks bear a considerable resemblance to some of the scoriform or cellular lavas.

The transition from the simple rocks to the amygdaloids, is sometimes imperceptible; as a rock, of which the prevailing character is simple, may contain occasional nodules of the different minerals.

It may easily be conceived, that, under all these circumstances, the variety of amygdaloids is very great; but those which contain the several zeolites and calcareous spar, are apparently the most abundant.

It would produce a long and little useful catalogue were all the varieties of amygdaloid to be enumerated in detail, according to the relative characters of the bases, the nature of the minerals imbedded, and the different combinations in which they exist. It hås therefore been held sufficient to enumerate the minerals in a catalogue; and they are placed, as far as possible, with some regard to the relative frequency of their occurrence. The collector of rocks may form his own arrangement on that basis. 
The amygdaloids generally occur in large masses ; rarely in veins. They are also, in both these cases, occasionally laninar.

The following minerals are found in the nodules of amygdaloids.

A. Siliceous Minerals.

Chalcedony : variously coloured, zoned, and striped; onyx of lapidaries : agates.

Cacholong : and semi opal.

Hyalite.

Heliotrope : a chalcedony coloured by chlorite.

Brown carnelian of lapidaries : a chalcedony coloured by oxyde of iron.

Chert.

Quartz: white, transparent, or opake; and also smoky.

Amethyst : white, transparent, or greenish, or purple.

B. Zeolitic minerals.

Mesotype.

Nadelstein.

Analcime.

Stilbite.

Chabasite.
Prehnite.

Laumonite.

Ichthyopthalmito.

Harmotome.

C. Calcareous minerals.

- Carbonat of lime.

Brown spar.

Schiefer spar.
Fluor spar.

Arragonite. 
D. Miscellaneous minerals.

Sulphat of barytes.

Sulphat of strontian.

Olivin.

- Epidote.

Mica.
Green earth-if different.

Steatite; soft and indurated. Lithomarge.

Chlorophœite: Macculloch W. Isles.

Chlorite: scaly, or crys- Conite: the same authority. tallized. Leucite: Brochant.

E. Metallic minerals.

Specular iron. Pyrites. Copper. Galena.

The following mineral substances are occasionally found in some of the rocks of the preceding catalogue, not occupying amygdaloidal nodules; and the varieties which contain them cannot therefore with propriety be ranked in the preceding or Fourth Division. As in other cases, they must be considered as adventitious occasional minerals.

Apatite.

Tourmalin.

Garnet.

Opal.
Asbestus.

Schiller spar.

Meionite.

Sommite.

These have been observed in the recent greenstones and basalts. It is uncertain whether the two last substances do not rather belong to lava than to the proper traps.

Precious Opal.

Chrysoprase.

These occur, but rarely, in certain porphyries. 


\section{FIFTH DIVISION.}

\section{Conglomerates.}

It has been held necessary to place this title here because of the student's convenience, although the substance included under it is also enumerated under the head of the conglomerate rocks.

A. Fragments of different trap rocks and of various sizes, angular, and re-united into a solid mass. Trap tuff.

a. Fine, tufaceous.

b. Conglomerated, coarse. Trap conglomerates.

These form beds or masses, intermixed with other varieties in different morles. Rarely, and unexpectedly, they are even found in veins.

They occasionally contain fragments of carbonized wood or of foreign rocks, and, in this case, they are ranked with the transported conglomerates. Occasionally they are also found to contain cavities; or, the fragments of which they are composed, adhere in such a manner as to leave interstices. 


\section{4}

\section{PITCHSTONE.}

The information which is to be obtained respecting this rock, is neither very abundant nor very accurate. The causes of this must be sought for, partly in its rarity, and partly, it is probable, in the prevalence of certain hypothetical opinions respecting its origin and connections, similar to those which have been equally the source of confusion in the history of many members of the trap family. The slender sketch of its connections here given, is therefore drawn solely from the writer's observations; and the reasons for mistrusting those which have not been verified by his own experience, will shortly appear.

In its geological connections, as well as in some of its mineral characters, it approaches very nearly to many members of the preceding 
extensive family; although it presents, at the same time, some very remarkable differences. It is also important to remark, that it is only 'found in those districts where the rocks of that family occur.

It has been said to exist in the form of strata, in foreign countries; but no example of that disposition is found in Britain. It will be more fully shown under the head of jasper, that certain varieties of that rock, which are disposed in a stratified form, have been mistaken for pitchstone; and it is more than probable, that all the other instances of a supposed stratification, are examples of veins, like many of those of the trap family, holding a course parallel to the including strata.

In this country, it occurs invariably in the form of veins, traversing all the rucks among which it is found, and, where it is in company with stratified substances, crossing them in angular directions, or insinuating itself in a parallel manner between the strata. The instance of the Scuir of Egg, is an apparent, rather than a real, exception, to this rule; as there is no reason to 
doubt that it is a vein from which the including parts have been removed by the ordinary causes of waste. In one respect, however, the veins of pitchstone differ materially from those of trap; as they have never yet been found connected with large masses, in this country at least; being, on the contrary, of very limited extent, and, at present, independent.

These veins are found situated in granite, in sandstone of recent origin, and in the trap rocks which lie above it ; a variety of connection which affords sufficient evidence of their intruding character, and which is also sufficient to prove, à priori, that no pitchstone is stratified ; as there is no instance in nature, of a stratified rock forming veins, or occurring in connections so distant and discordant as these.

The strong analogy subsisting between pitchstone and basalt, is shown by other circumstances. In two instances, at least, one of which occurs in Lamlash, and the other in Sky, veins of basalt are found, at their outer walls, to pass into this substance by a gradation more or less perfect; and, in the veins found in Egg, an imperfect 
transition of a similar nature may also be seen. In the same island, the remarkable vein called the Scuir, already mentioned, holds a place so intermediate in texture between basalt and pitchstone, as to be but imperfectly referable to either. The same circumstance, on a smaller scale, is visible in many other places; and it is further remarkable, that, in Sky, where veins of basalt sometimes ramify into slender filaments, these gradually become pitchstone.

The last instance of this analogy, is shown by the fact, yet solitary, it is true, which I have elsewhere described, that, in one of the veins in Arran, fragments of the including sandstone strata are imbedded in the vein.

Veins of pitchstone vary much in breadth, as they do in their other dimensions ; attaining one of many yards, and, in some cases, not exceeding the size of a thread. In the same vein, the mineral characters also vary; so that many of the varieties hereafter enumerated, are sometimes found associated, either by transition, or in a laminar manner, in the same vein. Transitions into chert or chalcedony, are also found under 
the same circumstances, as is further pointed out in the Synopsis.

Pitchstone presents many remarkable varieties of structure, both on the great and small scale. In Arran, it is imperfectly prismatic on a very large scale, the prisms being at right angles to the plane of the vein. In Egg, the prisms are smaller, but capable, in many cases, of being easily detached, and often, of very perfect forms : being, at the same time, placed in various intricate directions with regard to the plane of the vein, and, in such a manner, that the ends of the several prisms are extenuated, by being compressed between the middle parts of those adjoining. The laminar disposition of the veins, noticed in a preceding paragraph, is sometimes also on a scale so large as to divide the vein into two or three separate portions, which are most frequently marked by some corresponding change of character in the different laminæ.

The smaller varieties of structure, are numerous, and often very remarkable. Among these, a laminar concretionary structure is not unfrequent; and the lamellæ, which vary very much 
in size, are either straight or curved. In some cases, they are as thin as paper; in others, they are thick, and further, separable-by joints at right angles to the planes of the lamella. Thus they become divisible so as sometimes to present a minute prismatic disposition.

Occasionally, these prisms present also some curved surfaces together with the straight; so as to form columns on a very small scale, which are, further, jointed, in some very rare instances, by surfaces alternately concave and convex; and, when such joints are very near, the parts separate into irregular spheroidal forms. In some rare cases of the jointed columnar structure, a central atom of felspar, or of enamel, is found in each joint.

Analogous to this, is a spheroidal concretionary structure, more or less perfect, and varying in size, but commonly, minute. By a transition from this, it becomes an aggregate of irregular grains, and passes into pearlstone, which can only be considered as a variety of pitchstone, and is accordingly ranked here as a variety. The spherules, or grains of pearlstone, frequently, 
also contain a central atom of felspar or enamel, like the variety mentioned in the preceding paragraph.

The last obvious variety of structure to be noticed in pitchstone, is the porphyritic. This varies much in the magnitude, perfection, or number, of the included crystals ; producing corresponding differences of aspect. Frequently, the larger crystals are rounded, and converted into a white or grey enamel on the exterior; while, in lieu of the smaller, there are only to be found spheroidal grains formed entirely of the same enamel. This variety also passes into pearlstone; each grain of enamel being the centre of an imperfect spheroidal structure, which, acquiring greater distinctness, becomes the substance in question. Thus pearlstone is shown to be merely a variety of pitchstone, and the association here made between the two is justified.

In some rare instances, as in Arran, the crystals, of glassy felspar, are formed of concentric prisms separated by layers of the pitchstone, so that every crystal is a compound body.

Independently of these obvious variations of 
structure, pitchstone sometimes gives indications of an internal arrangement, which, as in the case of the trap rocks, is only detected on weathering. Many of the varieties become of a pure white on the surface after exposure to the air ; scaling off in successive crusts that resemble white enamel, as they still retain the vitreous aspect and fracture. At the same time, the exposed surfaces are covered with undulating lines, resembling certain varieties of marbled paper, and evidently resulting from some corresponding difference of laminar structure; the lamina most sensible to atmospheric action, being thus detected, although invisible in the fresh rock. In a further progress to decomposition, pitchstone is at length converted into a fine clay, forming, in water, a very tenacious paste; and it appears to be very readily acted on by the water, as may be witnessed in Arran.

It does not always weather to a white enamel, becoming occasionally brown, and, more rarely, turning into a black powder. Occasionally, it exhibits the kind of bloom seen on a plum, or on certain kinds of bottle glass. 
It must here also be remarked, that notwithtanding its vitreous aspect, it often contains a great deal of loose water, which is easily separated by drying, as in many other rocks. In these cases it is tender, but becomes brittle after the water has evaporated.

In many cases, pitchstone possesses an uniform structure, showing no tendency to particular forms of any kind. In these, the fracture is flat, or more or less perfectly conchoidal, or sometimes doubly conchoidal, one concave fracture being contained within another. It is, occasionally also, minutely splintery at the same time; and very often the flat, or conchoidal fractures, are on so small a scale, and so various in position, as to produce an irregular angular surface.

The lustre of pitchstone varies exceedingly according to its several states or varieties ; passing from the most perfectly vitreous to one scarcely more glossy than that of the finest basalts.

The colours are various; but a detailed account of them being given in the Synopsis, they need not be noticed here. In Scotland the 
darker hues, and the olive greens in particular, are predominant.

The ordinary transitions of pitchstone are into basalt, chalcëdony, and chert, as already noticed. Orie of the varieties of chalcedonic chert thus found in Arran is of a very singular character; presenting a spheroidal concretionary structure, with an internal radiating or concentric disposition in the spherules, and weathering to a botryoidal surface.

\section{SYNOPSIS OF PITCHSTONE.}

\section{FIRST DIVISION.}

Simple.

A. Amorphous, massive.

a. With a simple conchoidal fracture.

b. With a flat conchoidal fracture.

c. With a splintery couchoidal fracture.

d. With a splintery granular fracture, and of various aspects, according to the size of the parts.

e. With a mixed fracture, the conchoidal being also granular. 
f. With a mixed fracture, the large conchoidal presenting a minute additionally conchoidal surface.

g. The conchoidal fracture covered with minute scales, so as to give, on a superficial view, a porphyritic aspect.

\section{B. Concretionary.}

a. Flat, lamellar: the lamellæ thick or thin; it even becomes schistose, or papery, or fine scaly.

b. Curved, lamellar.

c. Prismatic: the prisms simple, or jointed; with plane, or with curved surfaces.

d. Columnar, or cylindroidal; similarly, either simple or jointed : the concretion is also sometimes partly columnar, and partly prismatic; or has plane and curved sides both.

e. Spheroidal; large. This is generally combined with the columnar. The small spheroidal concretionary, is arranged with the pearistones.

f. Very imperfectly spheroidal concretionary: the transition into pearlstone. It sometimes also passes into the porphyritic.

Sometimes different structures are intermixed in the same rock, as the columnar and prismatic with the lamellar. 
The lamellar pitchstone sometimes contains lamellæ of chert, or of cherty chalcedony, into which it also passes.

\section{SECOND DIVISION.}

Porphyritic.

A. Pitchstone porphyry of mineralogists.

a. With distinct crystals of glassy felspar.

These are sometimes so transparent as to be nearly invisible on a fresh fracture.

b. With distinct crystals of common felspar.

c. With rounded, or shapeless particles of the same.

d. With imbedded spherules, consisting of a grain of felspar surrounded by a grey enamel, or of the grey enamel alone.

This enamel is sometimes blended with the surrounding rock. When the spherules are numerous, this porphyry passes into pearlstone.

e. With imbedded crystals or grains of quartz, or of quartz and felspar both.

f. With grains of quartz surrounded by chert, and blending with the surrounding rock; or with grains of chert alone. This variety is analogous to d. 
g. Porphyritic: but the grains, which are chiefly of quartz and chert, are further condensed in lamells which alternate with a slightly porphyritic pitchstone.

\section{THIRD DIVISION.}

Concretionary spheroidal : Pearlstone.

A. Consisting of simple pitchstone; the grains irregular, and compressing each other in the manner of coccolite.

B. Some, or all of the grains, containing a central substance of another kind : pearlstone porphyry.

a. With grains of felspar, or of felspar and enamel, or of enamel only.

b, With quartz, or quartz and chert.

c. With quartz and felspar both.

d. With a central atom of clay.

\section{THIRD DIVISION.}

Amygdaloidal : containing imbedded nodules of another mineral.

A. Pitchstone containing imbedded zeolites. As yet this variety has occurred only in Baffin's Bay.

The colours of pitchstone are various. They are, principally, dull white, pale ochre, pink, pale green, greenish grey, ochre yellow, ochre red, 
yellow brown, fawn colour, red brown, greenish brown, olives of various hues down to blackish green, dark blue, and black. The colours are sometimes also intermixed, and thus pale and dark green, or pale and dark grey, are interlaminated, producing a striped surface. The colours of pearlstone are much more limited, possibly because the substance is more rare. Those of the porphyritic varieties are numerous, as this rock is more frequently porphyritic than simple.

As the porphyritic varieties may possess any of the modifications of the simple rock as a base, many additional aspects result from this cause.

Besides the passage into chert and cherty chalcedony already noticed, pitchstone passes into basalt, and, as is supposed, into opal and semiopal. In the passage to chert, it is sometimes found to contain minute grains or particles of chalcedony, discernible only by the lens. This variety often possesses a remarkable spheroidal concretionary structure already noticed in the geological part of this subject. 


\section{8}

PRELIMINARY REMARKS ON THE OCCASIONAL ROCKS.

IT was remarked in the third chapter, that this division was adopted for the purpose of comprehending some rocks which occurred both in the primary and secondary classes, together with the stony substances that are found in veins, and which may thus exist indiscriminately in both.

In a geological arrangement, like the present, it is requisite to state more particularly the reasons for adopting this expedient; a proceeding the more necessary, as the views on which it is founded, are in a great degree at variance with the current opinions and usual statements of geological writers.

It is not very easy to discover, in those writings, in what light jasper has been considered, but it has chiefly been treated of as a mineral, not as a rock; while many substances, most obviously appertaining to it, have been 
ranked as pitchstones, so as to have produced great confusion, and to have introduced most important errors into the geological history of this substance. These particulars will be discussed at more length in the preliminary remarks to the catalogue of that rock; and there will then be proved, what need only be mentioned here, that it occurs indiscriminately both in the primary and the secondary classes.

Nearly the same observations may be made on siliceous schist, which also occurs indiscriminately, although generally with some difference. of character, in both classes. Geologists, who have admitted this rock into their syst $\mathrm{ms}$, have, in some measure, felt the necessity of making two divisions of it ; and have accordingly divided it between their primitive and transition classes. But they seem either to have overlooked its frequent situation in the secondary class, or else to have confounded it, when it occurs there in an unquestionable manner, with some varieties of those trap rocks with which it is invariably associated. In this way, much confusion has been introduced into geological descriptions: since 
this rock has, from its mineral characters, been often referred to a primitive or transition class, where it formed a portion of the secondary; thus producing a total misapprehension of the relations of the rocks with which it was connected. It is not the only instance where similar geological errors have been committed by determining the class of a rock from its mineral character; and from thus concluding respecting the place in which it ought to be found: it is one of those which points out most strongly the utility, or rather the necessity, of a geological arrangement of rocks.

That confusion has, in the primary siliceous schists, been much increased by misapprehending even the true mineral characters of the substance in question, and by confounding it with those varieties of argillaceous schist, which, from containing a large proportion of quartz in their composition, present an unusual degree of hardness.

Respecting chert, it is here proper to observe, as formerly noticed, that is is now, for the first time, introduced into a catalogue of rocks. The 
definition of its characters will be found in the proper place; but its introduction would have been indispensible, even if it had not occupied so decidedly the place and presented all the true properties of a rock, on account of its frequent occurrence in company with siliceous schist, and under circumstances in all respects identical.

On these three rocks it may now be remarked, that as they are found both in the primary and secondary classes, and, in each, under slight differences of character, they might have been repeated in each, as is done in the case of limestone, and in that of the red sandstone. But they did not appear sufficiently extensive or important to demand this attention. A further reason for the practice here adopted, appeared to be contained in that peculiarity of position by which, as they occur in either of the classes, they seem to be almost necessarily connected with the unstratified rocks; and to be often, in fact, portions of the ordinary strata with which they are united, more or less altered by the influence of those irregular and intruding masses. The object of this arrangement being to connect, as far as possible, the 
substances described in it, with their geological history, it seemed expedient to adopt such a course as would tend most to illustrate that main end of the study of rocks.

It was with some hesitation that gypsum was admitted into this catalogue. Like salt, it might have been, perhaps with equal propriety, referred to the list of independent minerals; had not the practice of geologists established for it a place, for which the large masses in which it occurs offer some justification. Like many other doubtful points in this arrangement, it must wait the event of future correction : but as it is found both among the primary and secondary strata, and without any differences of character, it seemed more convenient to place it in this part of the classification, than to repeat it in each.

Of the conglomerate rocks, although some have already come under review, there remain others, chiefly of a local nature, which no opportunity was afforded of introducing in a detailed manner. The general and the local rocks of this construction, are moreover distinguished by important differences in their geological rela- 
tions, which it was necessary to point out; nor could the subject be rendered intelligible, without bringing the whole into one division. As they belong both to the primary and the secondary class, they have necessarily found their place in this part of the arrangement.

The veinstones have been introduced into this subsidiary place, solely for the convenience of the reader, and because, had they not been found here, they could not have been noticed in any other part of this work. The geological plan adopted, presents a reason for describing mechanical compounds which might otherwise have passed unnoticed. They are frequent sources of doubt and difficulty to students ; particularly where it is difficult to trace their connections : and if it was necessary to bestow some attention on the local conglomerates, which are so intimately connected with them in character, it was also important, in a geological view, to prevent the two cases from being confounded. 


\section{J ASPER.}

THE reasons for introducing this rock into the arrangement, and for assigning it a place in this division, have been already stated in preceding remarks, and will be more apparent from the following sketch of its geological characters.

Our information respecting jasper is however so imperfect, that this sketch is necessarily very superficial, and, possibly, in some points, incorrect. The causes of this must be sought, partly in the neglect which it has experienced from geologists, partly in its comparative rarity, and, still more, in the confusion which exists respecting the limitation of the name.

The term jasper, being antient, and of a popular nature, has been applied to many rocks, some of which evidently belong to other families. The want of access to specimens, which, from their variety or beauty, have been made objects 
of great interest by mineralogists or lapidaries, however unimportant they may be in a geological view, renders it impossible to know all the substances which have been designated by this term, but the following may be enumerated:

An instance of the extreme laxity in the use of this name, is found in the calcareous stalagmites, sometimes also called onyx-alabaster, which have been thus denominated; but these instances are too striking to be the cause of error to geologists. The striped jasper, however, of many writers, $:$ which might be a suurce of confusion, requires notice; as it is, in all cases, a variety of siliceous schist, or of some analogous substance.

Some of the cherts that are coloured by chlorite, and which are merely varieties of heliotrope, have also been called jasper; as have many other cherty substances which are here treated of in the following chapter; the name being given to them, generally, where they have been remarkable for their colours.

Veinstones, consisting of various fragments entangled in agate, have also acquired this name among collectors; and it has indeed frequently 
been applied in a very vague manner to many agates where their chalcedonic character was imperfect; and indeed, to any hard and uniform rock distinguished by brilliancy or intermixture of tints.

In this work, the name is limited to that substance of which a mineralogical definition is given in the thirteenth chapter, and of which the geological characters are now to be sketched.

It is said to form a range of mountains in Siberia; but the authority for that assertion is not valid. Practical geologists can be at no loss to account for erroneous statements made on this and similar subjects by ordinary travellers, and even by superficial or rapid geologists. That it occurs in large masses in that country, as well as in the Appenines, imbedded among the primary strata, rests however on authority that cannot be questioned, and it is confirmed by similar observations in our own. In Scotland, it occurs in this manner in the micaceous and argillaceous schists. In these cases, it is an undoubted member, like serpentine, of the priniary class.

Where strata of quartz rock, containing much 
felspar or clay, occur in contact with granite, they pass into jasper if the clay abounds ; while, in other places, they are converted into chert if less of that earth is present; or, if pure, are rendered perfectly crystalline. These examples are to be found in Aberdeenshire, and are valuable on account of the light which they throw on the origin of this rock.

In all the following situations, it must be referred to the secondary class, unless, in the following instance, as well as in that just quoted, it is conceived to be a primary rock influenced by the basalt in its vicinity.

In this case, which occurs in France, according to the authority of Soulavie, it occupies a position intermediate between granite and basalt. In the other instances in which it occurs in the secondary class, it is always in some manner connected with the overlying, or trap rocks.

When the iudurated claystones of this family, assume strong and ornamental colours, they are commonly known by this name, not perhaps always very properly. But, in some cases, these rocks, which, in most instances, pass by indura- 


\section{8}

JASPER.

tion into clinkstone or compact felspar, become true jasper, as far as the external characters can be relied on; a change which need excite no surprise, when their various composition is considered. Thus jasper is, rigidly speaking, an occasional member of the trap family; but, on account of its prevailing characters and positions, it was judged proper to treat of the whole in this place. It is only one instance, out of many, of the impossibility of framing any arrangement which shall be in all points unobjectionable.

In many situations where the trap rocks cover or interfere with the secondary strata, jasper is found in contact with the former, and connected with the latter by an imperceptible transition. This transition points to the cause to which such jasper owes its origin; and it will be found that the strata indurated into this new form, are beds of clay, more or less ferruginous, or of argillaceous sandstone. Thus the jasper presents transitions into ordinary yellow clay, into the red ferruginous clay so common among the trap rocks, and into sandstone. In Iceland a green variety is thus found passing into a clay highly coloured by chlorite. 
The varieties which originate in clay, are frequently characterized by a high degree of resinous lustre; and it is important to distinguish them, as they have here been done, because they appear to have given rise to the belief in stratified pitchstone, although essentially different in their mineral characters, as well as in their geological connexions. The greater number of the Hungarian pitchstones, (so called,) existing in the cabinets of mineralogists, will be found to belong to this place.

The forms of jasper vary according to these several circumstances of position. Like limestone or serpentine, it is found in irregular masses, obscurely, or not at all stratified. In other cases, in the primary rocks, it appears to form true strata; a circumstance to be expected. Among the secondary rocks, it is massive and shapeless where it passes into claystone, and is stratified where it forms a portion of the series of strata connected with the trap.

As it is also found in a state of transition into the ordinary stratified rocks, in both classes, it is easy to conceive how it may occur in small por- 
tions, of no determinate form or character, in those parts only of the beds, where the granite or trap to which its origin is referred, are immediately present.

Lastly, it exists in the form of veins, often very minute; and, in these cases, it is probably a mere modification of some venous rock of the trap family, analogous to that case where basalt becomes, in the progress of ramification, converted into pitchstone.

Jasper presents a few modifications of internal structure which require notice. It sometimes gives indications of a spheroidal concretionary disposition, more or less perfect, and resembling that which, under circumstances of a similar nature, occurs in chert and siliceous schist, In the same way, it sometimes possesses a laminar structure, and thus also it approximates to the siliceous schists. It is easy to see how, from similarity of origin, connexions, and composition, it may be thus a matter of doubt to which of those two rocks, any given specimen or bed should be referred. The well-known striped and spotted jaspers, owe their appearance to the two struc- 
tures above mentioned; and, occasionally, the two are combined in the same specimen.

It is much more rare to find jasper possessing a minute columnar structure resembling that of the madreporite limestone, or of ironstone. But this, when it occurs, is easily explained, when it is recollected that it often differs from this latter substance, only in the degree of hardness. The transition into ironstone, is similar to that into the ferruginous clay of the strata which lie under trap. One instance of the columnar structure on the large scale occurs at Dunbar.

The texture, and of course, the fracture, of jasper, differs in the several varieties. The fracture is either flat, or imperfectly conchoidal, or very accurately so; and, in the minute fractures, it is imperfectly granular, or angular and rough, or splintery, or dull and pulverulent, or uniformly smooth. The last variety, where it emulates pitchstone, or common pitch, in lustre, has often . a fracture as perfectly conchoidal as that substance.

From these characters, and from the definition given in the thirteenth chapter, it is pre- 
sumed that the student will rarely be at a loss to recognize this rock, wherever, at least, its characters are perfect: cases of transition must be studied in their geological positions.

The colours of jasper are infinitely various, and are the principal cause of its estimation among mineralogists and lapidaries. They are also, in general, much more brilliant and decided than those of any other rock except limestone; yet the student will, from the preceding description, beware of using them as an empirical character to the neglect of others. Red of various hues, ochre yellow, greens, browns, greys of all tones, and black, are the prevailing tints; and they occur in every mode of intermixture, so as to present almost infinite varieties. From a wish to conform to the popular practice respecting this rock, of which the mere mineral characters are not much varied, these distinctions have therefore been introduced into the Synopsis in a more conspicuous manner than has been adopted with regard to any other substance. 


\section{SYNOPSIS OF JASPER.}

A. With a dull earthy fracture, and passing into claystone, of which it appears to be a modification.

This varies much in colour, but the term is generally limited to those varieties which possess decided or brilliant hues. Reds and yellows are the most remarkable ; but it also occurs of grey, brown, purplish, and greenish tints.

B. More indurated, and resembling the base of certain porphyries.

a. Simple, and of one colour, green, red, brown, yellow, or even black.

As this substance is generally collected for the sake of its colour, the more decided tints are commonly found in cabinets, but it occurs of various hues.

b. Striped with different colours, in consequence of a laminar structure.

The Siberian green and red variety belongs to this; it also occurs of different tints of red alternating, or of greys, or of other colours. The latter are also enumerated among the siliceous schists. 
c. Spotted, or variously mottled, in consequence of a concretionary spheroidal structure.

The Siberian spotted jasper ranks under this variety. The most common colours are, reddish and pale ochre, obscure red and white, and brown and ochre.

C. Highly indurated, with an aspect approaching to that of chert, or even to agate; into which it passes, as it does into chert and quartz.

a. With a somewhat granular fracture.

b. With a granular splintery fracture.

c. With a splintery fracture passing to the conchoidal.

d. With a flat fracture passing to the large conchoidal.

The two latter varieties are among the most esteemed, as assuming the best polish. The colours most prevalent are reds and yellows, single or intermixed in various ways. The varieties under this head occur chiefly among the primary rocks.

D. Intermixed in various ways with chalcedony either white or coloured, and, apparently, at times passing into that substance: jasper-agate of lapidaries.

The ornamental appearance is often produced 
by the veins, and as these become numerous in proportion to the base, it forms brecciated jaspers.

The colours are much varied, but red and yellow with white or colourless veins, are the most conspicuous.

Sicily appears to abound in the most beautiful specimens of this variety.

E. Minutely columnar and resembling, except in hardness, the columnar ironstone. Found in the Isle of Man.

F. With a conchoidal fracture and resinous lustre: pseudo-pitchstone.

These have been generally enumerated among the pitchstones, as already remarked, and as the colours have been considered important, they are here made a ground for distinguishing the subvarieties.
a. Pale yellow.
b. Ochre yellow.
c. Brick red.
d. Brown, and purple brown.
e. Green.
f. Mottled with different colours.

The green variety is coloured by chlorite, and occurs in Iceland. They all pass into clay, and the transition is often found even in hand speci- 
mens. They appear to occur in volcanic, as well as in trap countries. St. Helena and St. Vincent produce examples of this nature.

Some of the jaspers appear to pass into common opal, as they do into agate, but these transitions are scarcely legitimate. 


\section{SILICEOUS SCHIST.}

THE difficulty of procuring accurate information respecting the geological connecrions of this rock, in the works of foreign authors, and the obvious errors that have followed, from confounding it with the quartzose argillaceous schists, compel me to limit the following remarks to my own observations.

The reasons for placing it in this division require no further explanation than that already given in the two preceding chapters.

In the primary class, it occurs in the same situations as the ordinary argillaceous schist to which it is so nearly allied, and it also passes into that rock by imperceptible gradation. Hence its characters vary, not only according to the degree of its induration, or the perfection of its structure, but according to the peculiar quality of the strata with which it is connected. Like jasper, it will 
be found, that, in these situations, it is frequently in the immediate vicinity of granite or of porphyry; or that, at least, the actual existence of the first of these rocks, or the former existence of the last, may be inferred where they are not at present visible.

In the secondary class, siliceous schist occupies situations similar to that which jasper does, and on which it is unnecessary to dwell; particularly, as it would lead to geological disquisitions far too important to be lightly passed over, and in a great measure foreign to the present object. It is here sufficient to say, that, in these cases, it is covered or intersected by trap rocks, and connected with shale, into which it passes by imperceptible transitions. Hence it also presents varieties dependant on the varying character of the original strata, which will be noticed in the Synopsis; and, for the same reason, it is found associated both with the cherts and jaspers that owe their origin to the same cause.

From the circumstances under which the siliceous schists occur, both in the primary and secondary classes, the stratified form is nearly 
always present in both. Yet, in both instances, as the change in the original strata may be produced by the passage of veins of granite or trap, as well as by the contact of exterior masses, it is easy to understand how this substance may occur in a very limited manner, or in portions of strata.

It moreover happens in the siliceous schists of the secondary class, that the stratified form diminishes in regularity till it nearly or altogether disappears; in which case they have sometimes been confounded with the basalts to which they then become intimately allied; giving rise to errors, which it is the business of a geological treatise to examine in a manner not here admissible. The most important of these is the imaginary existence of organic remains in basalt.

The only peculiarity of internal structure deserving of notice which occurs in the siliceous schists, within my observation, is the spheroidal concretionary ; but, as far as I have observed, it is more remarkable in the secondary than in the primary. In the former, it is common in Sky and in the Shiant Isles, the original and connected strata being shale : in the latter, it is found 
in Scalpa, in the schists which alternate with the primary sandstone; and it is more particularly described in that work to which it has been so often found necessary to refer in justification of many of the views here held out.

The texture, and, consequently, the fracture of siliceous schist, is very various. In the primary, it is often similar to that of the analogous primary strata, particularly where it passes into hornblende schist; a transition which sometimes occurs, although on a very limited scale. In the secondary, the texture is always very compact, although the aspect of the fracture varies from that of common flint to the more dull appearance of compact limestone. The form of the fracture, in the primary varieties, presents no peculiarities; but, in the secondary, it is flat, or minutely angular and flat, or conchoidal, or perfectly conchoidal, like that of flint, with an equal degree of lustre.

In the primary varieties, quartz, or mica, may be contained as constituent minerals, just as they are in the unaltered schist, when that has been of a compound or mixed nature; but, in the secondary, no visible mineral has yet been found, 
although carbon is intimately combined with it in those cases where it has originated in bituminous shale.

Organic remains sometimes occur in the secondary varieties, giving rise to the unfounded opinion, already noticed, that these exisetd in basalt, for which this rock has occasionally been mistaken. They are rare, and commonly so far altered in their forms, that their zoological characters cannot be assigned.

The colours of both varieties are, most commonly, tones of grey, varying from an impure white to black; and they are often distinguished, in the same specimen, by a striped disposition, the consequence of laminar alternation.

\section{SYNOPSIS OF SILICEOUS SCHIST.}

\section{FIRST DIVISION.}

\section{Primary.}

A. Simple in appearance, and resembling clay slate, but distinguishable by its extreme hardness. 
B. Containing mica, and distinguishable, in the same way, from the micaceous schists, or micaceo-argillaceous schists (graywacké), which it otherwise resembles.

C. Containing quartz sand, but similarly characterized by its extreme induration.

These varieties present but trifling distinctions of colour, resembling the several schists from which they are derived. As they vary in the degree of induration, so they also pass gradually into the ordinary micaceous and argillaceous schists.

\section{SECOND DIVISION.}

\section{Secondary.}

A. With an earthy dull fracture and the aspect of shale; distinguishable only by its hardness.

B. The fracture somewhat glossy; more indurated.

These two varieties retain the laminar structure of shale.

C. More highly indurated, more brittle and glossy; the laminar structure disappearing, and the fracture splintery and small conchoidal.

The three preceding varieties are either black, or of different shades of grey. The different 
colours are sometimes also interlaminated. They are frequently also interlaminated with chert or with granular limestone, for reasons already described.

D. Extremely brittle, hard, and shining; the fracture large or small conchoidal, and the fragments sharp and cutting.

This is the Lydian stone of mineralogical writers, and is almost always of a pure black.

E. With an internal spheroidal structure, producing a botryoidal surface on weathering.

This variety differs in hardness and in colour; the latter is black or grey.

These five varieties, being derived from the shales which accompany the coal strata, occasionally contain minute shells, sometimes compressed and deformed, as already mentioned.

F. Laminar, with alternate colours, and forming some varieties of the striped jasper of mineralogists. The colours are commonly shades of red, brown, yellow, and purplish black, and these kinds appear to be derived from the coloured shales.

G. Containing imbedded crystals of quartz, and of a porphyritic aspect.

All these substances, as might be expected, and as already noticed, pass into the different rocks from which they are derived. 
564

\section{CHERT.}

THe rock, which, according to the views already held out, I have introduced into the present arrangement by this name, is so like, in most cases, both in external aspect, and in its chemical characters and composition, to the mineral called chert, that it seemed better to adopt that term than to invent a new one.

Its analogy in origin to the two preceding rocks, no less than the convenience of the student, was the inducement to give it a place; as it was impossible to consider it as a variety of those limestones, or sandstones, with which it is particularly connected. The reader will easily discover that it is mentioned in the writings of Saussure, although he has not traced its true atfinities as if he had been fully aware of their nature.

To describe the geological connections of this rock, would be to repeat much of that which 
was stated in the two preceding chapters; and it will abbreviate the account of its history, to say, that it bears the same relations to the argillosiliceous limestones, or the calcareous sandstones, that the siliceous schists do to slate and shale.

It occurs therefore among the primary strata ; yet rarely, as the primary limestones are generally so pure as only to undergo a change to the crystalline texture, by those causes which convert the argillaceous varieties into chert. For the same reasons, nearly, it forms, among the primary rocks, very limited masses; occurring chiefly, if not only, in those cases where granite or porphyry are in contact with limestones of the character just mentioned.

Among the secondary strata, it is often found in extensive portions; passing into the common limestone by intermediate stages of induration, or forming entire strata, varying in character according to the circumstances under which it is associated with the accompanying trap rocks, or according to the previous composition of the -original limestone. In these cases, it is generally associated with siliceous schist; as the unchanged 
calcareous strata are with shale. Where it is the result, merely of the passage, of trap veins, it is limited to a short space from the contact of these, and passes gradually into the ordinary strata whence it is derived.

In those instances where chert originates in the change of beds of calcareous or calcareoargillaceous sandstone, it sometimes forms extensive masses, or involves a considerable series of strata, varying in character, and often approaching in aspect to quartz: and, in some cases, as may easily be understood, where the original limestone is highly argillaceous, it approximates, either to jasper, or to siliceous schist, according to circumstances; so that it might sometimes be as properly referred to either of these. It will illustrate the present views of its origin, to remark, that where a vein or mass of trap is in contact with different strata of limestone varying in character, the purer varieties become crystalline, while the impure are converted into chert.

The only variety of concretionary structure it has hitherto presented, is the spheroidal; and it is a remarkable fact, that this occurs under si- 
CHERT.

milar circumstances in all the associated substances.

The texture, and the corresponding fracture of this rock, vary in different specimens, and chiefly according to the perfection of its character, or to the degree in which it differs from the limestones and sandstones from which it has originated. The texture is, therefore, more or less compact and uniform, and the fracture either dull and earthy, or smooth. The form of the fracture is always plain, or conchoidal, on a large or small scale; and, in those specimens which are highly compacted, the conchoidal fracture is generally very perfect, and the lustre considerable, but resembling that of the most compact limestones. It is further a remarkable part of its character, that, although generally yielding with the greatest difficulty to the hammer in the larger masses, the smaller fragments often fly asunder with great violence, and present cutting edges as sharp as glass. To compare its fragments to those of pottery and porcelain, is to convey the most accurate idea that can be given of this part of the character of these particular varieties. 
As it sometimes originates in secondary limestones, in this latter case it might be expected, like the associated siliceous schists, to contain organic remains; but these have not yet been discovered in it. That fact however need excite no surprise; as, in those cases where the secondary limestones lose the stratified disposition and earthy texture, so as to become massive and crystalline, these bodies invariably disappear.

\section{SYNOPSIS OF CHERT.}

\section{FIRST DIVISION。}

Simple.

A. With an earthy aspect resembling that of the secondary limestones; the fracture rough, scarcely granular.

B. With a similar dry aspect; the fracture splintery, passing to the next variety.

C. With a distinctly conchoidal fracture.

D. With a laminated structure.

E. With an internal spheroidal structure, scarcely discoverable except after weathering. 
F. With a smooth glistening fracture, angular and sharp; extremely sonorous, brittle, and translucent on the edges.

G. With the aspect of chalcedonic quartz, and passing into it.

Some examples of this variety have been called stratified quartz. It originates in calcareous sandstones.

\section{SECOND DIVISION.}

\section{Compound.}

A. Containing interspersed crystals of quartz, or, occasionally, of glassy felspar, and thus somewhat porphyritic.

The colours of this substance are various. It is most commonly pale, or smoke grey, more rarely dark grey, sometimes of a dull white. It is occasionally reddish brown, or purple brown, or nearly black, or mott ed of several colours.

It passes at one extreme into limestone, or into quartz, according to its origin, and occasionally presents an appearance of crystalline plate interspersed. 
I have been under the necessity of introducing into this chapter, as a sort of appendix, a rock for which no other part of the arrangement offers a place; although it differs in many respects from the substances contained in the preceding catalogue. As also it has been called a chert by the authors who have described it, the student will naturally turn to this division for it. It is the cavernous siliceous rock of the fresh-water deposit of Paris, to which the name of Burr-stone is popularly applied. If these deposits shall hereafter call for a separate place in a geological classification, it will be easy to amend this defective part of the present arrangement. 


\section{GYPSUM.}

Although it is mentioned in a former part of this work, that gypsum has been found among. the primary rocks, that occurrence is very rare; nor do the examples quoted seem to have been such as to have satisfied the discoverer, Saussure, respecting its primary nature. On this subject, it is better to wait for further information, than to trust to unsatisfactory statements by the reporters of the opinions of others.

In the secondary class, it occurs chiefly in company with that sandstone called by English geologists the red marle; and, in this manner, it is found, not only in England, but in different parts of the continent of Europe. It also forms a conspicuous member of that peculiar district around Paris, which is supposed to have been deposited under the waters of an inland lake. In this situation, it is accompanied by sand, marle, and other substances, in repeated strata. 
In the inferior strata, it also occurs in independent masses, as well as in the stratified form. As the variations of texture form the only varieties which it presents, they are noticed as such in the Synopsis.

Organic remains of great interest are found in the gypsum of the Paris freshwater deposit. These are the bones of various terrestrial animals, of extinct species and genera ; besides which it also contains shells, and remains of fish and of vege. tables.

\section{SYNOPSIS OF GYPSUM.}

A. Granular.

a. Tender.

b. Compact, the alabaster of artists.

The first of these varieties is white, or grey, or red; the second is either white, or mottled and veined with grey, yellow, and browu.

B. Fibrous, sometimes rather dull, often highly splendent.

C. Platy, either on a somewhat large scale, or approaching to the large granular. 
The minerals that have been found imbedded in gypsum, are quartz, arragonite, boracite, and sulphur.

Anhydrous gypsum appears rather to appertain to a mineral classification, than to claim a place among rocks, and it is therefore omitted. 


\section{CONGI.OMERATE ROCKS.}

Although most of these have already been mentioned in a more or less distinct manner, under the several rocks with which they occur, it appeared expedient, as already remarked, to collect the whole into one general view. The repetition hence produced, will be compensated by the facility of reference thus afforded; while many of the most important varieties, will also be more particularly described, together with others which must otherwise have been omitted altogether.

Some of the conglomerates occupy extensive spaces in nature, while others are exceedingly limited; and they occur, as must already have been perceived, both among the primary and the secondary strata. Those which are found in veins, are described under the title of veinstones.

These rocks may be divided into two kinds, 
the general and the local ; and these are commonly very distinct, both in their geological and mineral characters.

The general conglomerates form portions of those mixed rocks, of which the origin is chiefly mechanical; being constituted from the larger fragments of those substances, which, by a more minute attrition, have furnisher the materials of the finer strata. Thus they necessarily contain various rorks, simple or compound; all of these being olvviously of a more antient date than themselves. The red sandstones, and the argillaceous schists, contain examples of this division. The materials are commonly united without any distinct intervening cement of a crystalline nature, particularly in the secondary class ; and the fragments are almost always more or less rounded by attrition. Though they sometimes form mere portions of the finer rocks which they accompany, they are also frequently found in extensive strata of great depth.

The local conglomerates are comparatively of very limited extent. They generally constitute superficial portions of some simple rock, and are 
most various and remarkable in the limestones. Hence their composition is regulated by that of the rock to which they are united; but, in some cases, where they lie between two rocks of different natures, they contain fragments of both. Such fragments are generally angular, and, in many cases, so little displaced, that the imagination easily restores them to their proper situations. The geological difference of these and the preceding, are therefore chiefly this; that the latter remain in the places where their integrant parts were formed, while the constituents of the former have undergone a transportation more or less considerable. The simple fracture and reunion of strata, account for the formation of the local conglomerates; while the general have originated in geological revolutions of a highly important and extensive nature. They are the consolidated alluvia of a previous state of the globe. The mineral differences consist in the comparatively small number of the substances that enter into the local alluvia. These also are frequently united by a distinct cement, either of fine materials and therefore partly me. 
chanical, or of crystalline matter; this latter case commonly occurring in the calcareous conglomerates.

'The conglomerates of the trap rocks are often distinguished by peculiar geological features, which cannot be discussed in this place as they deserve. Although, in one sense, strictly local, their union is often effected by operations peculiar to the rocks that form this family, and differing from those by which the consolidation of the other local conglomerates is produced. These sometimes contain bituminized wood, and other organic remains. When firmly compacted, they have thus led to an erroneous train of reasoning respecting the origin of the trap rocks in general. In that circumstance they bear no resemblance to these rocks, as they are evidently of more recent date, formed from their ruins, and consolidated under the action of water. 


\section{SYNOPSIS OF THE CONGLOMERATE ROCKS.}

\section{FIRST DIVISION.}

Consisting of fragments of one rock, either imbedded in a continuous base of the same substance, or reunited chiefly by minuter fragments, or united by veins of carbonat of lime or of quartz.

A. Consisting of limestone alone: local.

a. With angular fragments.

This variety is found both among the primary and secondary rocks. It includes the ornamental breccia marbles, and is local, and attached to some simple limestone. The union is chiefly effected by carbonat of lime.

b. With rounded fragments.

This does not often occur in extensive strata or masses, and is not attached like the former: it is formed of transported materials. These may be either primary or secondary. In the latter, the progress of consolidation can sometimes be traced. 
B. Consisting of fragments of quartz alone, or rather of quartz rock, united in various ways.

a. With angular fragments.

This is a local conglomerate connected with quartz rock, and therefore primary. Occurs in Aberdeenshire near granite.

h With rounded, or angular and rounded fragments together.

This forms one of the varieties of quartz rock, under which it is enumerated.

C. Consisting of fragments of jasper united by quartz or chalcedony: fragmented agate.

This is enumerated among the veinstones, but it appears to occur also as a local conglomerate attached to the jaspers.

D. Consisting of fragments of gneiss, of different sizes, united by agglutination.

This is local, attached to gneiss, and often the first bed of the primary sandstone, where that follows gneiss. It is of course primary, and occurs in Scotland in various places on the west coast.

F. Consisting of fragments of argillaceous schist, re-united by minuter particles and by clay, or imbedded in a continuous schist. 
This is primary and local in some cases, as in Kerrera, and is noticed under the head of Argillaceous Schist. It also however occurs as a secondary rock; the parts having been transported, but, from their nature, being incapable of showing decided marks of that transportation. It is thus found in the Isle of Man.

F. Consisting of chlorite schist, and formed in the same manner as the last variety: local.

This rock is primary, and accompanies common chlorite schist. Although it is to be expected that similar conglomerates of micaceous schist will be found, they have not as yet fallen under my observation.

G. Fragments of the different trap rocks reunited by finer particles of the same.

a. With angular fragments.

Trap tuff and noticed under the head of the Overlying Rocks ; local.

b. With rounded and angular fragments together.

This is a conglomerate of transported materials, but is limited to the vicinity of trap rocks, 
and is of partial occurrence. It is found in Canna and elsewhere.

These rocks, as far as can be determined, are secondary, but they may also be primary whenever the rocks to which they are attached can be proved to belong to this class. They pass into the red sandstone at Oban and at Dunkeld, and thus form general conglomerates.

\section{SECOND DIVISION.}

Consisting of two substances or rocks united in modes analogous to the varieties of the First Division.

A. Serpentine and limestone, or calcareous spar: local.

This includes the ornamental substance known by the name of verde antico, already mentioned. It is necessarily primary. The ordinary varieties are connected with serpentine, or lie between that rock and limestone.

The situation of the verde antico is not known. Anglesea affords an accessible example of a corresponding nature.

B. Fragments of argillaceous schist with limestone. 
a. The argillaceous schist imbedded in the limestone.

b. A confused mass of fragments of bothe substances.

c. Fragments of limestone imbedded in argillaceous schist.

These rocks belong to the primary class. Some of them, as that of Sienna, are known among the ornamental marbles. They accompany limestone and schist when these approximate and alternate, and are found, in this country, in Isla, and in the Garveloch Islands. It is unnecessary to form a title to include similar compounds of shale and limestone, as they are in every respect the same. They are, however, rare; and of course appertain to the secondary rocks.

C. Fragments of limestone imbedded in micaceous schist: local.

This variety occurs in cases where limestone accompanies micaceous schist, and is found in Isla.

D. Fragments of granite with micaceous schist or gneiss: local. 
a. The fragments of granite imbedded.

b. An aggregation of fragments of granite and of micaceous schist or gneiss.

These occur in Scotland near granite.

E. Granite uniting fragments of the same rocks, and presenting similar modifications.

Where micaceous schist or gneiss approximate to granite, the latter often contains fragments of those rocks in such abundance as to put on the appearance of a conglomerate. This is common in Rannoch and in Aberdeenshire.

F. Quartz imbedded in limestone: local.

a. In angular fragments.

b. In rounded pebbles.

These occur both among the primary and the secondary rocks; in the latter, in Arran and elsewhere.

G. Trap imbedded in limestone, and in the accompanying shale; local.

The trap is in rounded nodules, generally bearing the marks of weathering on the surface. These occur with the secondary limestones, in Sky and elsewhere.

H. An aggregate of fragments of argillaceous schist and chlorite schist : local. 
This occurs, but in limited quantity, where these two rocks are associated.

I. Sandstone with quartz.

a. The quartz in angular fragments.

b. The quartz in rounded nodules or united with angular fragments.

K. Sandstone and limestone united.

a. Fragments of sandstone imbedded in limestone.

b. Fragments of limestone imbedded in sandstone.

c. A congeries of fragments of these two rocks.

These are general conglomerates, and belong to the secondary sandstones, but chiefly to the lowest. They are enumerated under the heads of the respective rocks to which they belong, and of which they form constituent portions.

L. Sandstone and argillaceous schist, or shale, united : general. The fragments of the schist are commonly imbedded in the sandstone. Belongs like $I$ and $\mathrm{K}$ to the different sandstones, where it is also enumerated.

\section{THIRD DIVISION.}

Consisting of three or more substances or rocks united. 
These are the most common, and they consist of fragments, rounded or angular, or both, united by means of clay, sand, and gravel, derived from the same substances.

A. Fragments of quartz, and of a greater or less number of the primary rocks, united.

This, under various states, forms conglomerates, attached to the sandstones, and is noticed under those heads. It is either primary or secondary, but the former contains a more limited variety of ingredients than the latter.

B. Fragments of a greater or less number of the primary rocks with limestone.

These conglomerates appear to be connected chiefly with the lowest red sandstone.

C. Fragments of a greater or less number of the primary rocks with trap.

This conglomerate is analogous in geological situation to var. A of this division, and is found in those places where trap rocks exist. It forms a large tract near Oban.

D. Fragments of granite, limestone, quartz, and gneiss, imbedded in micaceous schist.

This is, geologically, the same as var. C, D, 
of the second division, and occurs in the same places.

E. Fragments of various primary rocks, or of secondary rocks, or of both, with fragments of trap.

This is a trap conglomerate of recent or gin, analogous to var. G, first division.

Organic remains are found in some of the conglomerates, but only in those of the most recent origin : seldom in those of the lowest sandstone series. Bituminized wood, as already noticed, occurs in those which contain fragments of the trap rocks.

The finer conglomerates of some of the preceding varieties, both primary and secondary, have also been distinguished by the term greywacké, and are noticed under the head of argillaceous schist. 


\section{7}

\section{ON VEINSTONES.}

As these are frequently causes of doubt, or sources of difficulty, to inexperienced geologists; it will not be superfluous to give a slight sketch of them after the conglomerates, to which they are so nearly allied. When they are found in veins, they readily explain their own origin; but they sometimes occur in situations where their real connections cannot be traced, and may thus be confounded, without due attention, with the more general conglomerates, or, occasionally, even with the compound rocks that form extensive beds. In a work that aims to be useful without pretending to be rigidly systematical, the allotment of a place for these accidental substances will be excused.

The larger veins which occur among rocks, are commonly filled with fragments of the including strata, united with various minerals, earthy, 
or metallic, and under every possible modification of form and mixture. The knowledge of these which the student of rocks is presumed to possess, will enable him to determine the nature of such mixtures; while their real nature may generally be decided, by their containing those mineral substances, whether earthy or metallic, which are known not to enter as constituents into beds of rock.

To attempt a complete catalogue of such veinstones, would be to make a tedious enumeration of possibilities; as they are necessarily infinitely varied, and cannot well be connected by any general rules. It will be sufficient to remark, that the fragments which they contain may vary infinitely in size, disposition, and mixture, and that they must necessarily consist, in some place or other, of every rock in which veins are known to exist. The cementing ingredient must also be as various as are the minerals that occur in veins. But it may be remarked, that veinstones are generally to be distinguished from all other mechanical mixtures of rock, by the existence of occasional vacuities among the fragments, or of crystals, or, 
lastly, by a laminar or venous disposition of the mineral substances which they contain.

Besides these venous rocks, of which the origin can commonly be traced, it is not uncommon to find, among masses of bedded or unstratified rocks, other mechanical mixtures of similar character, which cannot decidedly be traced to their original situations. These may generally be recognized to be derived from corresponding sources, by peculiarities of an analogous, though of a less decided nature. They are sometimes the produce of veins also, of a less conspicuous character, and less distinguished by the variety of their ingredients. In many cases, they result from the fracture, and consequent sliding or separation, of a mass of rock. In such iustances, a species of imperfect vein is formed, containing fragments of the separated masses, reunited by minute fragments of the same and by clay, or by the subsequent infiltration of the only two minerals which appear still to exist in a state of occasional solution, namely, quartz, and carbonat of lime.

In some rare instances, of which two have been 
pointed out in the author's work on the Western Islands, veins of an entirely different nature have been observed, consisting of rounded fragments of different substances, compacted into a solid conglomerate, and resembling many of those which were described in the last article. Where one of the including walls of such a vein has fallen away, it presents the unexpected appearance of a bed or stratum of conglomerate, at angles to the strata in which it lies. It is important to point out this variety ; as it might otherwise mislead a geologist, so as to give rise to erroneous conclusions. It is evident that it must have arisen from the consolidation of loose materials which have casually fallen into open fissures.

It is lastly interesting to remark, that the conglomerate veins which are occasionally found among the rocks of the trap family, and which are formed of their fragments, sometimes contain organic substances, namely, portions of bituminized wood, or of lignite. A very remarkable instance of this nature occurs in Mull, where a large portion of a tree is thus situated. Erroneous conclusions respecting the origin of the trap family, have thus 
also been sometimes formed; but into the peculiar circumstances under which this occurrence has taken place, I must not here enter.

It is obviously unnecessary, as already stated, to give a catalogue of all these possible combinations, as there can be no difficulty in distinguishing them, as far as any useful purpose is concerned, by the examination of their constituent parts. They may be arranged however, in a general manner, if that is thought necessary, according to the following division.

\section{SYNOPSIS OF VEINSTONES.}

\section{FIRST DIVISION.}

Angular; or consisting of untransported fragments of the adjoining rocks.

A. Fragments of different kinds, cemented by quartz.

B. Similar fragments, cemented by carbonat of lime.

C. Larger fragments cemented by a mass of simi- 
lar, but finer materials: sometimes with a certain proportion of quartz, or of carbonat of lime, or of both.

\section{SECOND DIVISION.}

Formed of materials more or less altered by friction, and bearing the marks of transportation or motion.

A. Conglomerates, formed of different substances often much rounded.

B. Conglomerates, of a fine or coarse texture, consisting of various fragments of trap rocks.

These resemble many of the tufaceous conglomerates of this family that are not found in veins. 


\section{APPENDIX.}

\section{VOLCANIC ROCKS.}

THE general history of volcanoes is too universally known to require any notice in this place. But, although it might be supposed easy to pronounce on the volcanic nature of any rock, from its connection with such mountains, geologists are by no means agreed respecting the substances to which they attribute this origin. That uncertainty has arisen from various causes. Many observers have differed respecting those rocks which they suppose to have formed parts of the mountain previous to the existence of fire, and those which they chuse to attribute to its action. 
Where volcanoes have been long extinct and some of their most characteristic marks have disappeared, similar doubts have prevailed on this subject, even in a greater degree. But it will be found that the chief confusion has arisen from prejudices respecting the trap rocks, which some of these observers have thought fit to attribute to an aqueous origin. Many of the unquestionably volcanic rocks, so much resemble these in character, that it became necessary to deny them an igneous origin also; since that was supposed to be decided by circumstances which are not always present in the volcanic rocks. Hence, chiefly, that incurable confusion which reigns in the descriptions of writers on this subject, and which the author's want of experience in volcanic countries, does not permit him to elucidate, or remove.

That more correct theory of the trap rocks, which now begins so generally to prevail, will hereafter remove many of these obscurities ; when unprejudiced observers, habituated to the various appearances displayed by these, shall turn their serious attention to the study of volcanoes. It is 
probable, however, that another set of difficulties will always exist: they may even be increased; since, if the trap rocks are of a local or partial nature, and the produce of actions similar to those now present in existing volcanoes, it is by no means improbable that they may occupy the same places, as some of them actually appear to do, and that the produce of the distant and the recent operations of fire, will thus be confounded. But, on this interesting part of geology, it is not here possible to proceed to any further discussion.

From the imperfect and often prejudiced descriptions of writers, it is therefore impossible to know under what different forms the volcanic rocks actually exist. But those are, on all hands, admitted to belong to this division, which, however antient, are connected with existing or extinct volcanoes in the form assumed by currents of modern lava.

The extent of these rocks is extremely variable, as are, necessarily, their forms and disposition; these circumstances depending on the form of the ground over which they have flowed, and no the quantity and the nature of the materials. 
In the same place they are often repeated in simple alternations, having originated in successive eruptions; or else they are found forming alternations of solid rock with various loose matters.

These loose materials, which constitute a principal division of the volcanic substances, consist of various rocks, more or less altered by fire, and often reduced to powder, in which case they have improperly been termed ashes. Besides these, volcanoes are known, in certain cases, to eject water; and the deposits then form mud, which, on drying, is consolidated into a tufaceous or clayey mass.

Respecting the modes of structure in these rocks, it is unnecessary to enter into minute details; as it would be merely to repeat much of what has already been said in treating of the trap family. Of the larger kinds, the prismatic and the lamellar both occur; and, of the smaller, the cavernous, amygdaloidal, and porphyritic, are very predominant. Such details as are more particularly necessary will be found in the Synopsis.

Of the mineral composition, there is equally little to be said. In all the fundamental points, 
it resembles that of the trap rocks, as will shortly appear; and the imbedded minerals which are peculiar to some volcanic productions, will, as on former occasions, be enumerated in the Synoptic catalogue. Respecting these, there have been many doubts; namely, whether they have been ejected in their present forms, whether they are the result of peculiar chemical affinities exerted in the fused mass, and, lastly, whether many are. not the produce of subsequent watery infiltration. Many prejudices, also, appear still to exist on this part of the subject; but the difficulties, such as they are, will not be removed until the substances themselves are better understood.

With respect to the form of the Synopsis, the author has laboured under a difficulty from which, probably, no one is yet exempt, namely, the want of access to a numerous and authentic collection of specimens. It is probable, that, with such a collection, which does not appear to have been yet completed by any one in a satisfactory manner, the whole might have been thrown into the same form as the synopsis of the trap family. 
There is reason at least to suppose that a great many of these rocks have their counterparts in the volcanic productions. But as no positive demonstration on this subject could be procured, it was thought advisable to model the catalogue by the writings of those who have had the greatest experience, and who seem to have laboured under the fewest prejudices. Some alterations, which were suggested by the examination of specimens, by comparing the reports of others, and by general analogies, have been made; but the whole must remain for a correction which, it is hoped, is not far distant.

It may only be remarked, in concluding this obscure subject, that if a general modification of the whole Synopsis should be required, it will probably consist in a different manner of treating those substances which are here enumerated only as imbedded minerals. The quantity of Leucite, for example, which occurs in many of the lavas, is such that it forms a principal part of the rock, and must perhaps therefore be considered essential, not accidental. Whenever a complete collec- 
tion of these rocks shall have been formed, it will probably not be difficult to construct a new catalogue, by adopting a different division with respect to the essential and unessential minerals.

\section{SYNOPSIS OF THE VOLCANIC ROCKS.}

\section{FIRST DIVISION.}

More or less perfectly vitreous.

\section{FIRST SUBDIVISION.}

Solid.

A. Obsidian: volcanic glass.

a. Massive.

b. With an imperfect laminar structure, indicated by a striped appearance, and by the action of the weather.

c. Concretionary, imperfectly spheroidal or granular.

d. Fibrous, loose, resembling spun glass, rare.

e. Porphyritic; enclosing felspar. Obsidian porphyry.

The most common colours are black, dark 
green, pale muddy green, grey, and brown. It is sometimes striped, of two colours. The lustre varies, as does the degree of opacity. In some cases it possesses an internal texture which causes it to give reflections resembling those of the cat's eye. It has been found in one instance to contain mica.

\section{SECOND SUBDIVISION.}

Cavernous.

A. Cavernous obsidian : passes to pumice.

B. Pumice.

a. Simply cellular.

b. Cellular protracted, becoming nearly fibrous.

C. Scoria. Formed of a less perfect glass and passing to porous lava,

\section{SECOND DIVISION.}

With a base of compact felspar, or, at least, supposed to consist of this substance.

A. Simple: solid, or imperfectly granular.

B. Porphyritic: pale volcanic porphyries.

The pale lavas appertain chiefly to this division. Other imbedded minerals, besides felspar, may occur in this variety. 


\section{THIRD DIVISION.}

With a base of basalt, or some analogous substance, simple to the eye.

A. Simple: dark lava, and scoriform lava.

a. Compact : compact lava.

b. Porous : cavernous lava; or scoria of some authors. The caverns are sometimes partially filled with some of the minerals which constitute the volcanic amygdaloids, into which this variety passes.

c. Prismatic, or columnar: volcanic basalt of authors.

d. Concretionary on a smaller scale: spheroidal or otherwise.

B. Compound: containing felspar: porphyries.

This variety may also contain many minerals besides felspar.

C. Compound: containing amygdaloidal nodules: volcanic anygdaloid.

The most remarkable of the imbedded nodules are, calcareous spar, fluor, the zeolitic minerals, and chalcedony. These appear to be the produce of infiltration, as they are sometimes accompanied by water. The imbedded minerals not properly amygdaloidal, and which may exist 
together with these, are enumerated, as in other cases, at the end of the catalogue. The colours of these rocks are various, namely, black, grey, brown, \&c.; and they depend much on the number and nature of the imbedded minerals, where these exist.

\section{FOURTH DIVISION.}

With a base of greenstone, or of some analogous compound. The compact felspar in these rocks, seems to be united to augit, not to hornblende.
A. Simple.
B. Porphyritic.
C. Amygdaloidal.

This division appears to contain many of the additional modifications found in the last, but it is unnecessary to repeat them.

\section{FIFTH DIVISION.}

With a base of common felspar.

These are granitic compounds, but they must not be confounded with ejected granites. As they have not received much attention, I am unable to describe the varieties that may exist in 
this division. They are highly interesting in a geological view, and deserve a careful examination. It must be remarked of the whole of these lavas, that they present many modifications of external form, arising from the manner in which they have flowed, and resembling those found in the slags of furnaces.

\section{SIXTH DIVISION.}

Ejected substances, more or less altered by the fire.

\section{FIRST SUBDIVISION.}

Solid ; conglomerates.

A. Conglomerates of various fragments of different rocks, with mica, augit, and other minerals.

B. Conglomerates consisting chiefly of clay, and having apparently been ejected in the state of mud. Tufo.

a. Coarse tufaceous conglomerates.

b. Fine and powdery tufa.

The local varieties of these latter, such as those of Herculaneum and Rome, are very interesting; but they do not admit of enumeration in this place. They often contain augit, mica, or other imbedded minerals, as well as the solid lavas. 


\section{SECOND SUBDIVISION.}

\section{Loose.}

A. Fragments of various rocks, both primary and secondary, more or less altered by the fire.

B. Powdery matters : puzzolana, ashes, dust.

The following catalogue contains the principal imbedded minerals which have been observed in volcanic rocks. It is unnecessary to add the names of the amygdaloidal minerals already mentioned.

Felspar.

Pyroxene.

Hornblende.

Garnet.

Peridot.

Mica.

Hauyne.

Meionite.

Melilite.

Tabular spar.

Sommite.

Leucite.
Melanite.

Idocrase.

Tourmalin.

Apatite.

Jargon.

Pseudo-sommite.

Ice spar.

Pleonaste.

Arragonite.

Oxidulous iron.

Sphene.

Copper.

Other minerals have recently been introduced into the catalogue as found in similar situations ; but as these new species are not yet thoroughly ' established, I forbear to quote them. 
It is barely sufficient here to notice, that certain burnt clays, known by the name of porcelainjasper, have been considered as pseudo-volcanic substances. They are, in every sense of the word, artificial, and no more deserving of a place than other products of common fire. They occur in the vicinity of coal beds which have been casually ignited. 


\section{6}

\section{CLAY, MARLE, AND SAND.}

Some of these substances are of an alluvial origin, and are therefore treated of in the chapter appropriated to that subject. As others, however, are found interstratified with various rocks, in several parts of the secondary series, they are more properly introduced in a separate place. This is the more necessary, as the two latter, in many cases, are partially solidified so as to form rocks; offering an exact analogy to that which happens in similar transitions between the clays and shales. They might perhaps with greater propriety have been placed in the secondary class, but, not having universally the general characters of rocks, it seemed at least equally convenient to include them in this Appendix.

The clays are found in beds of greater or less dimensions, partially independent, or minutely interstratified with limestone, sandstone, and 
shale. Their geological and local importance; no less than their oconomical uses, render them objects of considerable interest to a geologist, but an examination of these subjects is not here admissible. The elays of the coal fields, which contain ironstone, the blue clay of London, and Fuller's earth, are among the most interesting.

The marles occur in similar situations, and are, most particularly, interstratified with limestone; being often solid, and thus forming marle slates. Those of Gloucestershire and Lincolnshire are among the most interesting in the English strata. In the foreign, it yet remains to be ascertained what the true nature of many of these rocks are; as, in some, which are said to occur with primary limestone, organic remains are found.

The positions of the sands are similar, and they are frequently also intermixed with extensive consolidated portions forming sandstones, which it has been necessary to notice already under that head. Among the English strata, the ferruginous and the green sand, are the most conspicuous 
and extensive; the former lying above the Purbeck limestone, and the latter immediately beneath the chalk.

\section{SYNOPSIS OF CLAY, MARLE, AND SAND.}

\section{CLAY.}

A. Ferruginous clay: scarcely ever plastic, red, or yellow. Occurs in beds under trap rocks, and passes into jasper; where it is also noticed.

B. Fuller's earth : dull green or grey: semitransparent, and crumbling, when in water. Occurs in the upper sandstones, in the limestones, and in the red marle sandstone.

C. Schistose clay: white or grey: scarcely plastic till after exposure to air, when it crumbles. Pipe clay. Above the chalk in Dorsetshire.

D. Indurated, generally in irregular nodules ; very refractory in the fire. In the coal series. Stourbridge clay.

E. Plastic clay, potter's clay, of various colours and properties. Occurs in different parts of the secondary series. It is perhaps not essentially distinct from $\mathrm{C}$.

F. Blue clay: London clay: plastic in various degrees. Contains peculiar imbedded fossils, whence 
arises a geological interest not here admitting of discussion.

It is unnecessary to enumerate more varieties of a substance of which the composition and characters are so unsteady. The clays pass into shale, sand, and marle, and contain ironstone, pyrites, gypsum, and various organic remains. Menilite is found near Paris, in some cases, in a clay marle. Lithomarge, bole, tripoli, and other partial substances, cannot claim places in this enumeration.

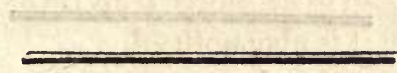

\section{MARLE.}

A. Simple, or earthy.

a. Massive, more or less compact.

b. Schistose, marle-slate.

Some of the specimens of both these, fall into pieces by exposure to air, and then become plastic. They occur, principally, with the secondary limestones, and vary much in their appearance, colours, and composition. They -pass into shale by the diminution or loss of the calcareous ingredient. 
B. Bituminous marle : more or less distinctly schistose.

There is considerable obscurity in the history of this substance; as it contains fish, and is yet said to accompany primary limestone, as above remarked. It is found in various parts of the continent of Europe.

The other substances known to agriculturists by the name of marle, belong to the alluvia, where they are fully described.

\section{SAND.}

A. Quartz alone.

B. Quartz and clay.

C. Quartz and limestone, or quartz, limestone, and clay.

D. Quartz and mica

These occur in different parts of the series of the secondary strata: some of them, conspicuously, under the English chalk. They are sometimes partially indurated into sandstones, as already mentioned.

E. Quartz and highly ferruginous clay, or ochre, 
with other ingredients of less importance. The ferruginous sand of the English strata.

F. Quartz, limestone, mica, and green earth. The green sand of the same series.

These also are sometimes indurated into sandstones which have been already enumerated under that title for the convenience of the reader. 


\section{COAL.}

'THIs valu the rocks, for the reasons formerly assigned, is found in various parts of the world, but most conspicuously in Britain. It occurs both in the primary and secondary strata; but so rarely and in such small quantity in the former, as scarcely to deserve notice here, were it not for the sake of the connection in mineral characters between the two.

In the prinary rocks, it has been found in gneiss, in micaceous schist, and in argillaceous schist; forming small laminæ, or scattered portions; and thus it occurs in several parts of the continent of Europe. It has also been found in detached lumps in limestone, in Norway, and in an antient conglomerate rock, in France.

In the secondary class, it forms beds of considerable extent, alternating with rocky or earthy 
strata, and associated with different members of that series. The whole of its connections of this nature, have not been ascertained; but to detail even that which is known, would here be out of place; while it is not of a nature to admit of an useful or intelligible abridgment within the prescribed limits. It forms, in its application to the uses of life, one of the most important branches of geological science.

The lateral extent of these deposits, commonly known by the name of coal fields, is often very considerable, and it is observed, that, in many cases, they occupy basin-like cavities, often incurvated upwards on all sides. In others, they are inclined at various angles, in such a manner that their probable extent cannot be conjectured. It is usual for more than one bed of coal to be found in a deposit, and sometimes they reach to ten, twenty, or more. At Liege, it is said that there are sixty beds. The alternating substances are sandstone, limestone, shale, clay, and sand. The thickness of the coal strata varies from less than an inch to many feet. Where they are traversed by trap veins, or in contact with masses 
of that rock, they are often converted into cinder, or coke.

The strata of coal are generally divided by natural joints, more or less perfect and extensive, by which they are formed into cuboidal and prismatic masses. The most frequent variety of structure which they present is the laminar; and, in some rare instances, where in contact with trap, they also assume prismatic forms.

The mineral composition of coal is scarcely a subject for consideration in this work, of which it is not the object to record the chemical nature of the simple minerals. Yet, as it has been generally misapprehended, it will be useful to sketch it in the briefest possible manner.

All the bitumens, from naphtha to asphaltum, consist of compounds, apparently indefinite, of carbon and hydrogen principally ; the small quantities of oxygen and azote which they contain, appearing to have little or no effect in modifying their mineral characters. In the most fluid, the hydrogen predominates, diminishing progressively according to the order of their relative tenacity or solidity. Where asphaltum ends this 
series, cannel coal, with some interruption in composition, and a considerable one in texture, commences that of the coals. From this variety, down to the most perfect anthracite, there is a similarly indefinite range of composition; the hydrogen gradually diminishing as the coal becomes less inflammable, as it is less capable of being separated into bitumen and charcoal by distillation, and as it yields a smaller comparative proportion of the former. Thus the composition of the bitumens illustrates that of the several varieties of coal. This gradation is, however, only noticed in a general manner in the Synopsis, where the several popular and received varieties, are distinguished as if they were all definite. The most perfect anthracite appears to yield no bitumen, yet it still contains hydrogen, perhaps in every case; as that element is present even in common charcoal, which is itself a compound substance. Where anthracite passes to plumbago, which may in fact be considered as the true end of this series, the hydrogen seems to have disappeared; and, if this substance be not mere carbon, as it probably is not, from the 
apparent combustion which it undergoes on exposure to air, when its base has been extricated from iron under water, it undoubtedly approaches nearer to that element than any of the preceding substances.

It is impossible to enter here at greater length into this interesting subject: the fuller details of these views must be reserved for some more appropriate place. But this sketch is sufficient to show the incorrectness of those opinions in which coal is considered as a compound of charcoal and bitumen; these being themselves varying compounds of simpler chemical elements.

The organic remains found in coal, are limited to the secondary varieties, as might be expected, and they consist of unknown vegetables of different kinds, which, from their general characters, appear to be chiefly of aquatic origin. Pyrites also occurs in this substance.

\section{SYNOPSIS OF COAL.}

A. Burning with difficulty and without flame: anthracite, when this character is perfect. 
This is a modification of carbon which contains so little hydrogen as to yield no naphtha or petroleum on distillation; whence it gives neither flame nor smoke.

a. Massive; with a conchoidal shining fracture of an aspect sometimes nearly metallic.

This occurs in Germany and other countries among the primary rocks; in Staffordshire, among the secondary coals. It passes into plumbago.

b. Friable, pulverulent, or scaly.

This variety is rare and in small quantity: it occurs in Switzerland.

c. Laminar : known by the name of blind coal, stone coal, culm, and Kilkenny coal.

This occurs, like the preceding, in the primary strata, in micaceous schist, argillaceous schist, and gneiss. But it is far more abundant in the secondary, as in many parts of Britain and Ireland. It passes into common coal.

d. Columnar, or rather prismatic.

Occurs in the vicinity of trap rocks, and is therefore partial and rare. It passes into 
plumbago, forming the anthracolite of Baron Born.

B. Flaming, and burning easily; with smoke. Common coal.

It occurs either massive or slaty; but the two are so generally united, that it is unneressary to distinguish them as separate varieties. It differs much in quantity in different situations; chiefly in consequence of the degree in which it recedes from the preceding, or the quantity of bitumen which it yields on distillation. The best kinds unite, or cake, in the fire, by a partial fusion. It presents other varieties of much inferior value, in consequence of mixtures of clay, forming coarse coal. These pass into bituminous shale, formerly noticed. They are always secondary.

C. Very inflammable: leaving little coak after inflammation; massive or imperfectly laminar: with a large conchoidal fracture more or less bright, but sometimes quite dull. Cannel coal and Parrot coal.

Occurs in the secondary coal of other qualities, and is sometimes wrought, like jet, for ornaments.

D. Coak, ashes, and smut. These rare and partial modifications occur in the vicinity of trap, as already noticed. 


\section{9}

\section{ALLUVIA.}

Tне history of the greater number of these deposits is of the most interesting kind, but is so purely matter of geological inquiry as to be inadmissible in this work. There are two distinct divisions of substances comprised under this head, the loose and the solid; both of them posterior to the latest indurated strata, and the latter, evidently more recent than the former. A few words must suffice respenting both.

Alluvial, unconsolidated deposits, occur in various situations, bespeaking, in many, important differences of origin.

Where they are found in vallies through which rivers flow, they generally arise from the abrasion of the channels in which these run; and more particularly, from the wear of the higher rocky hills that form their sources and contain their springs. They originate in the 
same causes, in most instances, where they form those extensive plains that accompany the estuaries of rivers, whether these terminate in the sea or in an inland lake. In the former case, they constitute submarine banks and low islands; in the latter, in the course of their progress, they obliterate the lakes, and thus form solid and extensive deposits in vallies, which have sometimes been imagined to originate in causes of a more general nature.

The action of the sea on its shores, is sometimes such as to reject on them the loose materials which it contains, and which it may have derived, either from more distant and similar sources, or from the perpetual reproduction and leath of the tribes of shell-fish by which it is inhabited. In some cases of this nature, the sea is thus caused to retire before the increasing shore, and that increase is often accelerated or consolidated by the growth of various plants which take root in the new-formed soil. In others, the winds disperse the lighter materials, consisting of sand; which thus frequently overwhelms the interior land, for a certain space, 
with deposits of this substance, often of great depth.

In consequence of the daily waste of mountains, and without the assistance of streams, but urged solely by the force of gravity and the ordinary drainage of the surface, beds of alluvial matter are in many situations deposited on the sides of hills, and in some cases to a considerable depth.

Lastly, in some places, rocks are found to have been disintegrated in situ in consequence of the action of water or other causes, and sometimes to a considerable depth. In favourable circumstances of position, these remain in their places, forming beds or masses of loose materials, consisting of larger fragments of the more solid parts, mixed with the clay and sand resulting from the more complete decomposition of others. This occurrence takes place, chiefly, in granite, in gneiss, in some of the trap rocks, and in the red sandstone. Of the latter, Arran and Cantyre present some remarkable examples.

Thus there seem to occur in nature four distinct classes of partial alluvia, namely, those of 
rivers and estuaries, marine alluvia, alluvia of descent, and untransported alluvia.

A separate division must be formed to contain the general alluvia, which occur in situations where none of these causes can have acted, and which appear to owe their origin, in many cases, to deluges, apparently, of a temporary and partial nature, in others, to that great event of the same description recorded in sacred history. It is extremely important to distinguish these from the former, with which they have often been confounded; but to attempt even the slightest sketch of this, would be to enter on a subject foreign to the nature of this work. In all these cases, the distinctions are chiefly, in many, purely, of a geological nature.

The extent, the depth, the forms, and the connections of all these deposits, are so various, that no description admissible in these prefatory observations could convey an idea of them, and they must consequently be reserved for their more appropriate place in a System of Geology. It is only necessary to observe in the briefest manner, that their forms are under the daily influence of 
the causes which produced a great portion of them; and that in consequence of these daily actions, the alluvia of a general nature are often in danger of being confounded with those of more recent and partial origin.

Many of the alluvial deposits present an alternating stratification, more or less frequent and regular, of the different modifications of which they are formed, often emulating, in every thing but consolidation, the finer and coarser beds of the red sandstone. They also, in some places, alternate with beds of peat, or of those substances called lignite or brown coal, which are hereafter noticed.

Respecting their structure, if this term be admissible, it is only necessary to remark that they consist of materials varying from the fineness of mud and of sand to the bulk of many cubic feet: and that in their mineral composition they contain fragments of every rock in the system of nature. Whether the larger fragments are rounded or angular, depends partly on the distance whence they have been transported, on the time and degree during which they have been 
exposed to the several causes of waste, and on the nature of the materials.

Organic remains, both vegetable and animal, are found in the alluvial deposits, and these are frequently interesting, as consisting of the bones of many species of terrestrial animals now extinct. It is scarcely perhaps necessary to remark, that minerals sufficiently permanent in their nature to resist the effects of waste, also occur in them; among which the diamond and gold are the most remarkable.

In treating of the consolidated alluvia, or of alluvial rocks, strictly speaking, no notice is here necessary of those very partial deposits, formed by infiltration or otherwise, which are found in many situations, and which are more properly described in works of mineralogy. If a line indeed has not been strictly drawn between those which seem to claim a place here, and those which belong to mineralogical arrangements, it 
is only a defect which, on other occasions, it has been found impossible to avoid.

The substances here considered as alluvial rocks, are, either extensive calcareous deposits from existing waters, or loose alluvia which have been consolidated by one or other of the following causes; namely, the deposition of carbonat of lime from water, or the agglutinating power of that compound of water and carbonat of iron, called rust, to which no chemical term has yet been applied. It is not improbable that, in some more rare instances, there may be added to these, the recent solution of silica, and an adhesion of certain mixed earths which, although it appears to be merely the result of pressure and repose, is probably owing to the same circumstance in a degree less perceptible.

The power of carbonat of lime, it must also be added, may be called into action without the actual infiltration of foreign solutions; and thus, fragments of shells, or mixtures of these, or of other calcareous matters, with sand, are sometimes consolidated; the very substances them- 
selves affording, by their partial solution, that cement by which they are united.

The alluvial rocks which are formed by depositions from water, necessarily vary in dimension and disposition, as well as in situation, according to circumstances which do not admit of being here described. Those which originate in the other causes just mentioned, also present many variations, depending on circumstances which may easily be apprehended. Thus they are found in inland situations, or on sea shores, or occupying portions, more or less extensive, of the looser materials in which they are found. A certain class of them form some of the varieties of the veinstones mentioned in a preceding chapter.

In a geological view, they are in some other respects very interesting; as indicating those actions of a corresponding nature, though much more distant in point of time, which have led to the consolidation of many of the looser strata of sand and similar matters, and which, as they are portions of the consolidated series of strata, have 
been considered in another place. Most of the secondary rocks indeed, and, perhaps, not a few of the primary, may be supposed to have had a similar origin ; but these are questions appertaining to geology.

Respecting the texture and composition of these rocks, it is scarcely possible to say any thing which would not be a repetition of what has been said in treating of the loose alluvia, or which may not be as easily deduced from the preceding observations. The more minute peculiarities will find a more proper place in the Synopsis.

Like the loose alluvia, they may also contain imbedded minerals; and the diamond has thus been found forming part of a conglomerate alluvial rock. Organic remains also occur in them; and some of the instances, such as that of the West Indies so well known as containing human skeletons, are particularly interesting; as, from confounding them with earlier rocks of similar character, the most serious geological errors might arise. 


\section{SYNOPSIS OF ALLUVIA.}

\section{FIRST DIVISION.}

Loose.

A. Single stones, more or less accumulated in particular places, generally bearing marks of waste in a greater or less degree, and commonly consisting of the older rocks.

a. Granite boulders.

b. Boulders of other rocks, which it is unnecessary to distinguish, as the former, from their greater conspicuity and frequency, have here been. Single in inland situations, and forming heaps on sea shores.

B. Stones of various sizes mixed with sand or clay or both.

a. The produce of one rock: alluvia formed in situ.

b. Pebbles of flint with sand and clay. London gravel bed. It is uncertain whether these pebbles have been rounded by the action of water, or are in their original forms.

c. Rounded fragments of various rocks, intermixed with clay or sand. Diluvian alluvia, and the alluvia of rivers.

d. Fragments slightly rounded, or angular, with clay and sand. Alluvia of descent. 
C. Of fine materials, consisting of sand and clay more or less compacted.

a. Clay.

Many varieties, both in a mineralogical and in an œeconomical view, are comprised under this head. It contains variable proportions of alumina and of silica, and in some places, it also contains magnesia and lime. Among the most remarkable varieties which 1 have observed in this country, are the white clay of north Uist and Harris, and the porcelain clay found in some parts of Cornwall in superficial beds; the former produced from gneiss, the latter from granite. Although many of the clays described at page 608, may resemble others belonging to the alluvial deposits, their geological differences are important. The colours are various, blueish black, grey, yellow, or white.

b. Clay with a large proportion of sand : loam of agriculturists.

c. Compact sand, always with a mixture of fine clay sufficient to consolidate it: found in the alluvia of rivers and lakes, and on the sea shore.

d. Clay containing inflammable or carbonaceous matter arising from the de- 
composition of animals and vegetables : mud. In many estuaries, and in the deposits of slow moving rivers.

D. Consisting principally of calcareous matter. Marle.

a. Powdery, or imperfectly plastic, with few or no distinct fragments of shells : often much mixed with sand and clay.

b. A congeries of shells and fragments of shells, more or less pure. Shell marle of agriculturists.

Those which contain organic remains, are found on sea shores, or on lands that have been deserted by the sea, as well as in lakes, where they often accompany peat. Where found in dry places inland, they generally maik the situations of antient lakes. But, in several parts of Perthshire, they also occur on declivities, having been formed by terrestrial shells. In other cases, they are formed by the alluvia of calcareous rocks.

E. Of fine materials, and loose, or incompact.

a. Quartz sand.

On sea shores, and also removed by the winds, so as to form sand hills and other similar inland deposits, which are consolidated by the growth of vegetables, and sometimes by the for- 
mation of peat; in which latter case they are mixed with powdery peat earth.

b. Of calcareous sand; commonly from the decomposition of sea shells, and found under similar circumstances.

F. Sands of various constitution, found in partial deposits in different places, and commonly, if not always, arising from the decomposition of rocks.

a. Quartz and argillaceous schist.

b. Quartz and felspar.

c. Quartz and the sand of trap rocks.

d. Mica: or mica with clay, or felspar, or quartz, or hornblende, or all of these. From gneiss and granite.

G. Mixtures of various kinds, forming the soil of agriculturists.

Some of these are transported materials, others are the produce of rocks decomposed in situ. Those produced, in the latter case, by the decomposition of many trap rocks, of the argillaceous limestones, and of the argillaceous schists, are the most fertile and valuable.

H. Vegetable soil, or mould, consisting of a mixture of any of the preceding with a hydrocarbonaceous compound, analogous to peat, which results from the decomposition of vegetables.

Other circumstances being equal, the fertility 
of these depends on the proportion of this substance in the compound.

\section{SECOND DIVISION.}

Solid.

\section{FIRST SUBDIVISION.}

Simple.

A. Compacted sand of quartz, or recent sandstones: sometimes found in river alluvia; tender.

B. Compacted shell sand : recent oolite.

This occurs abundantly on the shores of the Bahama Islands; also in similar situations elsewhere. The grains are often perfectly rounded, and it serves to explain the origin of the older limestones of this nature.

C. Compact limestone, deposited from the waters of existing rivers or lakes in large masses.

The well-known travertino of Rome belongs to this variety. The stalagmitic rocks, such as that of Gibraltar, may also be arranged under this head. 


\section{SECOND SUBDIVISION.}

\section{Compound.}

A. Substances of various kinds and sizes cemented by carbonat of lime.

a. Quartz sand cemented in this manner.

On sea shores and in river alluvia. Abounds on the shores of the Messina, where it is wrought for œconomical purposes. Occurs under singular modifications near Delvin in Perthshire.

b. Fragments of many kinds cemented in the same way into a solid mass.

On the north coast of Cornwall, near Dunbar, in Rasay, and on other sea shores.

B. Various substances cemented by rust of iron.

a. Quartz, sand, and gravel: recent ferruginous sandstone. Resembles the hard portions of the ferruginous sand deposits of the English strata.

b. Flint gravel, clay, and sand, united by the same means.

Occurs near Croydon, and elsewhere, in the gravel bed.

Some of the trap rocks seem to undergo a similar process after disintegration; forming a . recent tufa.

The English puddingstones, so well known, 
and found in Hertfordshire, ought probably to be referred to the second subdivision, under which they would form a variety $\mathbf{C}$, cemented by quartz. But as the real origin of this substance does not appear to have been ascertained, I have preferred leaving it in doubt for future enquiry, although enumerated in the mean time, under the head of the superior sandstones. 


\section{LIGNITE.}

Is giving a place to peat in this arrangement, it seemed also indispensibly necessary to introduce those analogous matters, very conveniently designated by Brongniart's term lignite, which are even more intimately connected with coal by their origin and position.

The superior antiquity of lignite to peat, is proved by its position under considerable depths of alluvial matter, and by the greater degree in which it has undergone the process of bituminization. They differ also in another essential circumstance, namely, that the production of lignite has long since ceased, whereas that of peat is in daily and visible progress.

In its chemical properties, lignite holds a station intermediate between peat and coal ; while, among the varieties also, a gradation in this respect may be traced ; the brown and more 
organized kinds, approaching very near to peat, while the more compact, such as jet, approximate to coal.

Chemical analysis proves that the most imperfect peat differs little from wood, and that jet, the most perfect lignite, differs in the same manner but slightly from coal. The intermediate varieties between these extremes, present corresponding differences which show that the whole of these substances are in the progress of bituminization, and which render it probable that, by the completion of that process, and by certain changes in their texture, they are ultimately destined to form that substance. It is not within the limits of this work to enter further into this interesting subject, which will find a more appropriate place in a system of geological science.

Lignite is found in strata varying in thickness, from a few inches even to fifty feet, and, sometimes occupying extensive tracts in alluvial valleys. It is always covered with the alluvial deposits, and, although it sometimes forms only one stratum, it occasionally exists in repeated alternations with clay, sand, and marle, and 
occurs even in alluvial or recent sandstones. At Bovey, there are seventeen strata. It is sometimes also found dispersed in small masses; a circumstance which happens more particularly in the case of jet.

Organic vegetable remains are found in lignite, and it also sometimes contains mellite, amber, and sulphur.

\section{SYNOPSIS OF LIGNITE.}

A. Jet. Hard and compact; has a pitchy lustre and takes a good polish : sometimes retains marks of the wood whence it has been derived.

In France, Spain, Germany, \&c. In the former it sometimes occurs in recent sandstone.

B. Surturbrand. Less compact and more brittle than jet.

Found in Iceland, in Sussex, and elsewhere.

C. Friable : moor coal of some writers.

Is found in the south of France: contains marks of vegetables, and it occurs in sand and marle. 
D. Fibrous : brown coal, bituminized wood, Bovey coal. The vegetable texture very apparent, the colours brown or brownish black.

Some of the surturbrand of Iceland belongs to this variety.

E. Earthy or pulverulent, sometimes a little compact and retaining the texture of wood: contains also remains of vegetables. .

Is found under a deep alluvial soil near Cologne, and is known by the name of Cologne earth in the arts. The thickness of the beds reaches even to fifty feet.

The lignite, or bituminous wood, found under trap rocks, is of a more distant origin, and in some cases appertains rather to the family of coal.

F. Retaining more or less of the texture of wood and passing into true coal. Basaltic wood; and basaltic coal of some. 
Although peat does not in every instance lie above all the alluvial soils which may be present, that is at least its predominant position. It is invariably found above those of an extensive and general nature which may be referred to a diluvian cause ; and, where it lies beneath deposits of clay or sand, these will be found of modern origin, and produced by the very recent action of rivers.

These alternations are not frequent where they do occur ; and they consist either of marle or sand, deposited in lakes, or of clay and sand formed at the estuaries of rivers. The beds of peat, in these instances, are generally of inconsiderable thickness. Where it is found, as is most frequently: the case, at the surface, it lies above the ordinary alluvial soil ; forming strata, or tracts, more or less extensive, according to the 
nature of the country and the form of the ground which it occupies. These deposits have often the form of basin-like cavities, from circumstances that will be immediately apparent. Their thickness is exceedingly variable, and has been known to reach to fifty feet and upwards.

In some instances, the formation of peat in particular places has ceased; in others, it is still in progress, being maintained by the continuance of those actions from which all the deposits of this nature have originated. This is the successive growth and decay of vegetable substances of various kinds. It is not possible to enter on this part of the subject here; but it is necessary to enumerate the different circumstances under which this substance is formed, as it tends to illustrate the different varieties which it presents.

It is found on declivities which are easily drained; generally in very thin beds, and of a loose texture, forming the mountain peat, or heath soil, of agriculturists. On the margins of lakes, it occurs in a solid form; tending, by its annual increase, ultimately to obliterate their cavities, and thus to produce many of those ex- 
tensive basin-like deposits, now found in mountainous countries, and which so often include beds of marle formed from the shell-fish that once iuhabited their waters. In a similar manner it occurs in low undrained or marshy situations. Where antient forests have fallen, it is also found, sometimes forming very extensive tracts, and generally distinguishable by the peculiar structure of the mass, and by the remains of trees imbedded. It also occurs on flat sea shores, being generally, in these cases, much intermixed with sand, and having been generated by the growth and decay of zostera marina and various semimaritime and marine plants. Lastly it is found, often in very considerable tracts, deposited at some distance from the places where it was formed, and at first in a semifluid state; being afterwards consolidated into a very compact mass, by the drainage of the water.

Recent animal remains and works of art, are occasionally contained in peat. 


\section{SYNOPSIS OF PEAT.}

A. Loose or powdery, and often intermixed with clay or sand: mountain and beath peat.

B. Spongy, imperfect, and containing a large proportion of the roots and fragments of undecomposed vegretables.

C. Compact, but still retaining numerous fragments of vegretables and passing into the former. This is the most ordinary variety of that used for fuel.

D. Highly compacted, with a total loss of the vegetable texture. The specific gravity of this is greater than that of the last, and it burns, nearly like coal, with a considerable flame. It is much more rare than the former varieties, but is found in North Uist and the adjoining islands.

The varieties $B, C, D$, are commonly found in the same deposit; $\mathbf{B}, \mathbf{C}$, always ; the spongy kinds being at the top, and the compact below. The progress of vegetable decomposition, or of the perfection of the peat, is thus indicated. When wet, and in their native places, all the varieties of peat are soft, but they become hard by drying.

E. Compact, generally flaky when dry, and containing fragments, roots, and trunks of trees. Forest peat.

F. When wet, a mixture of water and fine pow- 
der of peat : on drying, very compact. Transported peat; forming fluid bogs.

G. Containing bitumen. Bituminous peat.

As long as the growth of the vegetables proceeds, the peat is perpetually renewed after removal; but the process, except in the case of transported peat, ceases when the vegetating surface is removed, unless it is renewed by nature or by artificial means. 
644

\section{ADDITIONS AND CORRECTIONS.}

\section{$-\infty 000000$ \\ DIALLAGE ROCK.}

W HEN the preceding pages were written, and indeed until the greater part had been printed, I had no practical knowledge of the geological connections of diallage rock, and was unable to procure any accurate information respecting it. I was therefore compelled to leave it as a subject for future correction; but it was enumerated at the end of the article on Granite, as I had been informed by an observer that it was an unstratified rock, and that it belonged to the primary class. The nature of its composition seemed to claim that as its most probable place.

Having, since that period, had an opportunity of examining it in Shetland, where it forms an extensive tract, the following description, drawn from its characters in that country, is subjoined. 
It ought; of course, to be introduced into the tabular arrangement among the stratified rocks of the primary class; and, as it occurs, indifferently, in company with gneiss, micaceous schist, chlorite schist, and argillaceous schist, while it is at the same time rare, it may conveniently be placed in the table immediately before limestone.

It abounds in the islands of Unst, Balta, and Fetlar; and occurs also, but in very small quantity, at the northern extremity of the Mainland of Shetland. It appears further to exist, in a very limited manner, in Ayrshire and in Cornwall; and I formerly remarked that it was said to be abundant in Piedmont and in Corsica.

In Shetland, the largest mass of this rock, which is that of Unst, succeeds, in some places, to gneiss ; in others, to micaceous schist, chlorite schist, and argillaceous schist; and it is also foumd, both in this island and in Fetlar, in contact with serpentine.

Although the stratification is often very obscure, it may be determined without much difficulty ; partly by the conformable direction of the masses to the prevailing bearing of the ac- 
companying strata, and partly by its alteruation with these; while, in a few instances, it is perfectly distinct; the strata, at the same time, being prolonged in a parallel direction to the general bearing, and dipping in the same manner as those of the neighbouring rocks.

The strata of diallage rock are intersected in all directions by innumerable joints, from which their frequent obscurity arises. From this cause, the protruding surfaces present an aspect resembling that which is exhibited in similar circumstances by granite; an appearance which has probably given rise to the opinion that it was an unstratified substance. This feature is very remarkable in the abrupt cliffs; which are broken in an irregular angular manner, by fissures so numerous and extensive, as to confound all appearance of stratification.

As this rock alternates, on the large scale, with the primary schistose strata before mentioned, so it frequently contains minute beds of micaceous schist, chlorite schist, and talcose schist; more rarely, of hornblende and actinolite schists. In the same manner it is found to in- 
clude small masses of serpentine, as well as to alternate with large bodies of the same rock. It must also be remarked that, in one or two instances, it occurs in very thin beds among the rocks now described, and very widely separated from any other masses of the saine substance.

The internal structure, or rather the texture, of diallage rock, is sometimes merely granular crystalline; and it therefore breaks, like granite, indifferently, in any direction; although, from its toughness, with great difficulty. But it is often fissile, or breaks with more ease in one direction than another. The texture then resembles that of gneiss; this effect being the result of a predominant parallelism in the crystals of the diallage. It is very frequently also intersected by extremely thin veins, or laminæ, of talc, chlorite, or mica; these being only discovered by the yielding of the rock in those parts : and hence it is with great difficulty that a true fracture is procured. Lastly, it is often traversed by veins, resembling those which occur in granite and in hypersthene rock, in which the constituent minerals are crystallized in larger forms, 
and in which, either the diallage, or else the felspar, are at times altogether absent, the one or other mineral alone remaining.

Diallage rock is either simple, or, essentially, compounded of felspar and diallage; the aspect varying exceedingly according to the magnitude of the parts. When these are very minute, it is often difficult to recognize; the peculiar characters of the diallage nearly disappearing. The colours of the diallage vary from very pale greyish green to a brighter green, to light and dark grey, purplish brown, and black. The aspect. of the felspar is very various. It is either platy and distinct, or else confusedly compacted, or very finely granular, or, lastly, uniformly compact. The colours are white, or greenish grey, or grey, or purplish grey; but, in Shetland, the paler varieties predominate. From these several causes, the general colour of this rock varies from light grey or greenish grey, to dark grey, and brown.

This rock passes into talcose and chlorite schists by the intervention of mixtures of talc or chlorite with the felspar; there appearing to be transitions from diallage to both of these minerals. I 
seems also to pass in a gradual manner into serpentine; or, at least, the boundaries of the two are not always to be defined. For this reason a mixture of diallage and serpentine has been included among the varieties in the Synopsis. It will probably be found to present many other modifications when it shall become better known; but, in the mean time, I have introduced into the catalogue, among the more legitimate varieties, all those mixtures in which diallage occupies $a$ conspicuous place; trusting to future observations for the correction of this still imperfect account.

\section{$\overline{0}$ \\ SYNOPSIS OF DIALLAGE ROCK.}

\section{FIRST DIVISION.}

Simple : of diallage alone.

A. A confused mixture of crystals of diallage.

The aspect of this simple rock varies thaterially according to the magnitude of the crystals; and it appears rather to form veins or concretions 
in the mixed rock than to occur in distinct masses or strata.

\section{SECOND DIVISION.}

Compound: of two ingredients.

A. A mixture of diallage and felspar.

a. With platy felspar.

b. With fine granular felspar.

c. With compact felspar.

The aspects of these mixtures vary much, both according to the proportions of the constituent minerals and to the magnitude of the parts. These are sometimes so minute that the peculiar character of the diallage disappears.

B. Diallage and actinolite.

C. Diallage and talc, or chlorite.

D. Diallage and serpentine.

The varieties $\mathbf{B}, \mathbf{C}$, are rare. $\mathrm{D}$ is also, for convenience, enumerated under the head of Serpentine; since it is often difficult to determine whether this variety, occurring at the common boundary of diallage rock and serpentine, belongs to the former or the latter. In general, in some parts of this transition, the diallage abounds so as nearly to exclude the serpentine. 


\section{THIRD DIVISION.}

Compound: of three ingredients.

A. Diallage, felspar, and mica.

B. Diallage, felspar, and quartz.

These are rare. It is not unlikely that there is a quaternary compound of these ingredients, but it has not fallen under my notice.

Diallage rock contains imbedded portions, or rather laminar veins, some of which were already mentioned, of talc, chlorite, actinolite, asbestos, and steatite; but I am not aware that it is ever so minutely intermixed with any independent minerals as to suffer any changes of its character. 
652

\section{SERPENTINE.}

The examination of a considerable tract of this rock in Shetland, has, like the investigation of the diallage rock of the same country, given rise to an important correction of its history as it was described in the body of the work ; and for the same reasons it is introduced into the present Appendix.

There can be no doubt respecting its stratification in the island of Unst. Although less regularly disposed in Fetlar, it seems there also subject to the same law. It will be necessary therefore to remove it from the division of the unstratified rocks, and to place it with the primary strata, among which it may conveniently follow limestone.

In general, in the tracts above mentioned, the great mass of serpentine seems rather to hold a parallel course to the stratified rocks which it 
accompanies, namely, diallage rock, gneiss, micaceous schist, argillaceous schist, and chlorite schist, than to be itself disposed in strata. Yet, in different places, the courses of the individual strata can be distinctly traced, parallel to the general direction of the whole, and dipping in a similar manner; although the seams or divisions between them are not strongly marked. In this respect, however, it is no more obscure than gneiss and micaceous schist often are; since, in these also, the stratified disposition is, in individual instances, rather inferred from analogy than deducible from observation. It still more strongly resembles limestone in this respect; the primary rocks of this nature being often very obscurely or imperfectly stratified; while, occasionally, they show no marks of that disposition, but rather seem to form, like serpentine, large imbedded shapeless masses or huge irregular nodules.

It will not be difficult now to see, that, by attending to the analogous disposition of these limestones, all the masses of serpentine yet described will be found to be disposed in similar 
modes ; forming large irregular masses, or smaller nodules; or else stratified in a manner more decided and géneral, or in the shape of small evanescent beds included in other strata.

In some instances indeed, as in Aberdeenshire, they form nodules in granite; a position in which I believe limestone has not been found.

It ought also to be added, as a correction to the article on serpentine, that this rock is occasionally schistose; splitting, as it would appear, always in the direction of the stratum.

In Shetland, serpentine contains chromat of iron; often in great abundance, and so interspersed in grains throughout the rock as materially to alter its appearance and characters.

In consequence of these two alterations, I have thought it necessary to reprint the tabular view of rocks given at p. 78 ; which will therefore now stand under the following form : 


\section{5}

\section{PRIMARY CLASS.}

\section{UNSTR ATIFIED.}

Granite.

STRATIFIED.

Gueiss.

Red sandstone.

Micaceous schist. Argillaceous schist.

Chlorite schist. Diallage rock.

Talcose schist.

Limestone.

Hornblende schist. Serpentine. Actinolite schist. Compact felspar. Quartz rock.

\section{SECONDARY CLASS.}

STRATIFIED.

Lowest (red) sandstone.

Limestone.

Superior sandstones.

Shale.

UNSTR ATIFIED.
Overlying (and venous)
Pitchstone. rocks.

\section{OCCASIONAL ROCKS.}

Jasper.

Siliceous schist.

Chert.
Gypsum.

Conglomerate rocks. Veinstones.

\section{APPENDIX.}

Volcanic rocks.

Clay, marle, sand. Coal.
Alluvia.

Lignite.

Peat.

END. 




\section{RETURN EARTH SCIENCES LIBRARY}

\begin{tabular}{l|l|lr}
$\begin{array}{l}\text { TO } \rightarrow \\
\begin{array}{l}1 \text { MON PERIOD 1 } \\
\text { MONTH }\end{array}\end{array}$ & 2 & 3 \\
\hline 4 & 5 & 6 \\
\hline
\end{tabular}

ALL BOOKS MAY BE RECALLED AFTER 7 DAYS

Books needed for class reserve are subject to immediate recall

\section{DUE AS STAMPED BELOW}

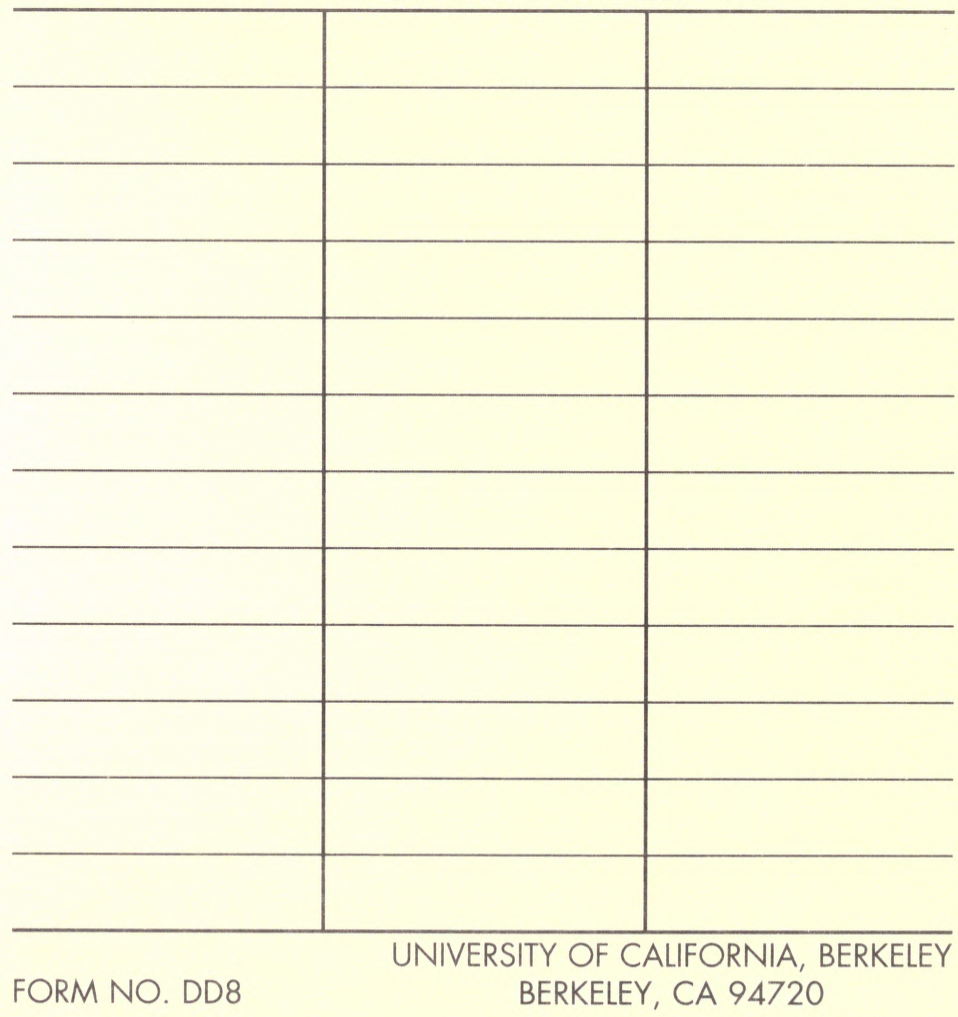


storaae

$-104$

C03463395 
